\title{
Ivy Jungerman
}

Validação para o português - Brasil do inventário de preocupações de pacientes com câncer de cabeça e pescoço, avaliação de suas preocupações e expectativas e relação com a qualidade de vida

Tese apresentada à Faculdade de Medicina da Universidade de São Paulo para a obtenção de título de Doutor em Ciências

Programa de Oncologia

Orientador: Prof. Dr. Luiz Paulo Kowalski

São Paulo 


\section{Dados Internacionais de Catalogação na Publicação (CIP)}

Preparada pela Biblioteca da

Faculdade de Medicina da Universidade de São Paulo

Creprodução autorizada pelo autor

\section{Jungerman, Ivy}

Validação para o português - Brasil do inventário de preocupações de pacientes com câncer de cabeça e pescoço, avaliação de suas preocupações e expectativas e relação com a qualidade de vida / Ivy Jungerman. -- São Paulo, 2016.

Tese(doutorado)--Faculdade de Medicina da Universidade de São Paulo. Programa de Oncologia.

Orientador: Luiz Paulo Kowalski.

Descritores: 1.Neoplasias de cabeça e pescoço 2.Qualidade de vida 3.Estudos de validação 4.Perfil de impacto da doença 5.Questionários 6.Avaliação de resultados (cuidados de saúde)

USP/FM/DBD-314/16 


\section{DEDICATÓRIA}

Para àqueles a quem mais amo, meus pais Davide Beatriz, meu esposo Sergio, meus filthos Alan e Isabela, aos quais dou o methor de mim...!

Para minhas avós Esther e Marien, "in memorian" 


\section{AGRADECIMENTOS}

Minha profunda gratidão

A Deus, por me abençoar com uma família maravilhosa e amorosa, por guiar meus passos e me mostrar os caminhos certos, mesmo quando achei que não os encontraria e por me dar forças para lutar, mesmo quando achei que não as teria.

Ao meu orientador Prof. Dr. Luiz Paulo Kowalski, por confiar em meu trabalho, acreditar em minha capacidade, pelo imenso respeito e consideração aos meus esforços como aluna, estando sempre aberto a discussões e sugestões e, especialmente, por me honrar com sua competentíssima orientação.

Ao Dr. Simon N. Rogers, Professor na Faculdade de Saúde - Edge Hill University, Cirurgião maxilofacial consultor da University Hospital Aintree, University of Liverpool (UK), por me permitir validar o PCI para o português, possibilitando aos pacientes brasileiros com câncer de cabeça e pescoço a chance de expressar suas preocupações e dividir seu pesado fardo.

A Julia Toyota, enfermeira pesquisadora do A.C.Camargo Cancer Center, pelo imenso apoio que me deu durante todas as etapas deste estudo, ajudando incansavelmente na identificação e recrutamento dos pacientes, na aplicação dos questionários e, acima de tudo, pela sua inestimável e valiosa amizade.

A Aline Damascena, pela cuidadosa e competente análise estatística, pela constante disponibilidade em me ajudar e esclarecer minhas dúvidas sempre que precisei, pelo apoio e amizade.

A Ricardo Tussolini, assistente administrativo no ambulatório do Serviço de Cabeça e Pescoço do A.C.Camargo Cancer Center - torre Brentani, pela valiosa ajuda na localização dos pacientes.

A toda a equipe, da biblioteca da Fundação Antônio Prudente pela inestimável ajuda e boa vontade em providenciar os inúmeros artigos científicos consultados. 
A minha querida amiga Suely Francisco, bibliotecária da Fundação Antônio Prudente, que me apoiou incansavelmente, sempre com carinho, dedicação e boa vontade extremas, desde o início da minha formação acadêmica até este momento. Meu muito obrigada pelo impecável trabalho na formatação da tese e correção das referências.

A amiga Rubia Simplício, o meu carinho e reconhecimento pela ajuda nas questões burocráticas relacionadas a aprovação do projeto.

Aos membros de minha banca de qualificação Dra. Lica Arakawa-Sugueno, Dr. Mauro Ikeda e Dr. Fábio L. M. Montenegro, pelas correções, críticas construtivas e pelas valiosas sugestões feitas ao meu trabalho.

A todos os funcionários do Departamento de Pós-graduação da FMUSP, especialmente à Sra. Yara Corradini, Chefe do Serviço de Pós-graduação / FMUSP.

As minhas amadas amigas, "irmãs" de coração por mim escolhidas, Elma Heitmann M. Azevedo, Neyller Patriota Montoni, Keyla Moraes e Renata L. V. Guedes, pela valiosíssima amizade, carinho, apoio e preocupação.

Às queridas amigas Ana Lucia Francisco e Margareth Souza Andrade, pela amizade e disponibilidade em me ajudar em todos os momentos em que necessitei.

À Coordenação de Aperfeiçoamento de Pessoal de Nível Superior (CAPES), pela bolsa de estudo concedida para a realização deste estudo.

A todos os pacientes que participaram desta pesquisa, por sua incomensurável e impagável generosidade, por me doarem sem ressalvas seu tempo, atenção e confiança, e muitas vezes seu sorriso, mesmo nas piores circunstâncias de suas vidas. Levo todos vocês no meu coração... 
"O papel de um médicoé, certamente, $\sigma$ de aliviar o sofrimento. $\dot{E}$ também $\sigma$ de ajudar a construir um novo entendimento, permitindo que a pessoa reinterprete sua vida no contexto de novas condiçōes. A doença não é uma entidade patológica. $\dot{E}$ uma experiência vivida. Doença só pode ser compreendida pela apreciação de sew efeito sobre uma vida".

RichardForton, 2016 


\section{NORMALIZAÇÃO ADOTADA}

Esta tese está de acordo com as seguintes normas, em vigor no momento desta publicação:

Referências: adaptado de International Committee of Medical Journals Editors (Vancouver).

Universidade de São Paulo. Faculdade de Medicina. Divisão de Biblioteca e Documentação. Guia de apresentação de dissertações, teses e monografias. Elaborado por Anneliese Carneiro da Cunha, Maria Julia de A. L. Freddi, Maria F. Crestana, Marinalva de Souza Aragão, Suely Campos Cardoso, Valéria Vilhena. 3a ed. São Paulo: Divisão de Biblioteca e Documentação; 2011.

Abreviaturas dos títulos dos periódicos de acordo com List of Journals Indexed in Index Medicus. 


\section{SUMÁRIO}

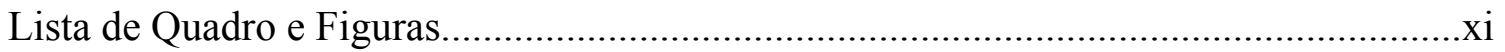

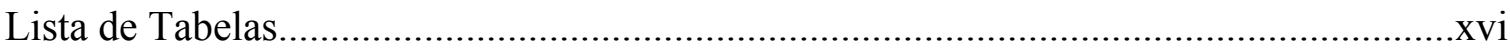

Lista de Abreviaturas e Siglas......................................................................................

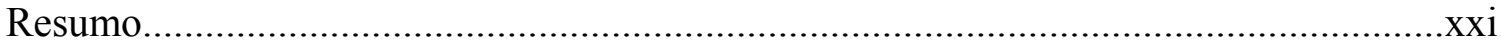

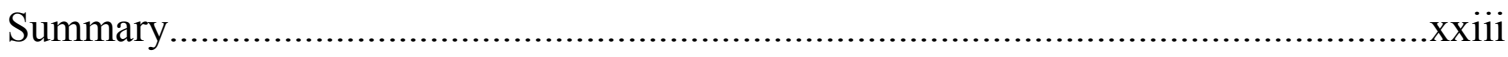

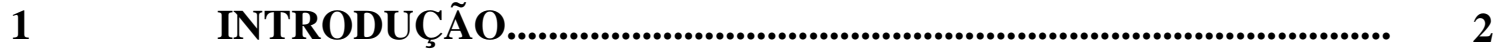

2 OBJETIVOS........................................................................................ 9

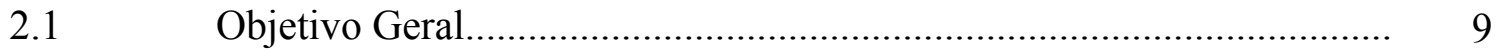

$2.2 \quad$ Objetivos Específicos................................................................... 9

$3 \quad$ REVISÃO DA LITERATURA.................................................... 12

$4 \quad$ CASUÍSTICA E MÉTODOS.......................................................... 22

4.1 PARTE I - Tradução e Adaptação Transcultural.................................... 23

4.1.1 Critérios de Inclusão........................................................................ 23

4.1.2 Critérios de Exclusão.......................................................................... 23

4.1.3 Processo de Tradução e Adaptação Transcultural................................... 24

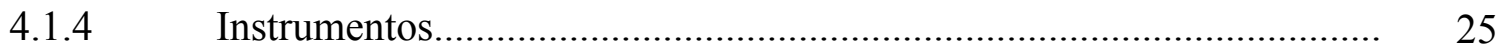

4.1.5 Processo de Validação......................................................................... 26

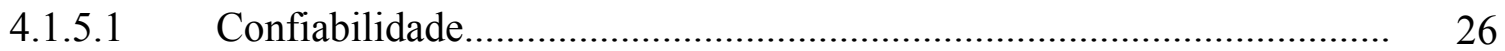

4.1.5.2 Validade de Conteúdo......................................................................... 27

4.1.5.3 Validade de Critério............................................................................. 27

4.1.5.4 Validade de Construto................................................................... 27

4.1.5.5 Reprodutibilidade.......................................................................... 27

4.2 PARTE II - Avaliação Pré-tratamento e aos 6 e 12 meses após o diagnóstico................................................................................... 28

4.2.1 Critérios de Inclusão...................................................................... 28 
4.2.2 Critérios de Exclusão............................................................................. 29

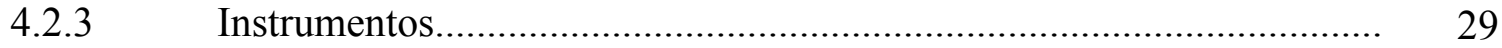

4.3 Análise Estatística......................................................................... 36

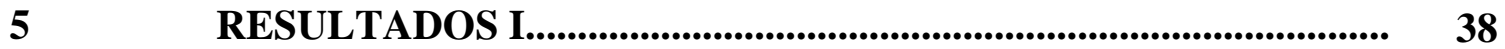

5.1 Tradução e Adaptação Transcultural e Validação.................................. 38

5.2 Características da Amostra.................................................................. 41

5.3 Resultados do UW-QOL ............................................................... 46

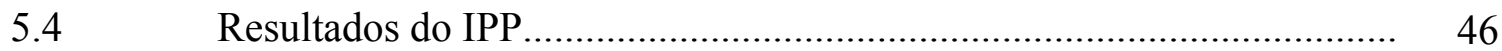

5.5 Correlações entre os Resultados do UW-QOL e do IPP......................... 49

RESULTADOS II.......................................................................... 55

6.1 Características das Amostras Avaliadas................................................ $\quad 55$

6.2 Grau de Ansiedade e Depressão (HADS) .............................................. 62

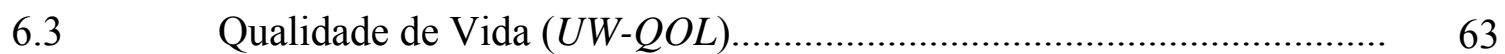

6.4 Intensidade Dos Sintomas (MDASI- H\&N) …................................... 71

6.5 Necessidades, Preferências e Atitudes Frente às Informações (QIP)..... 84

6.6 Preocupações dos Pacientes (IPP)....................................................... 87

6.7 Avaliação das Expectativas No Momento Pré-Tratamento (PAE)........ 97

$6.8 \quad$ Preenchimento da Expectativas (PPE)................................................ 100

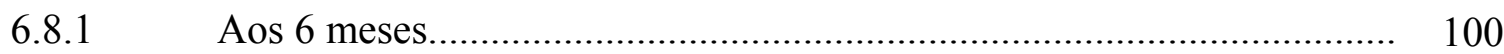

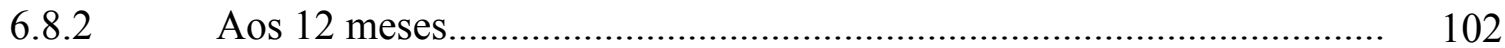

6.9 Associações entre o Grau de Preenchimento das Expectativas com a Qualidade de Vida....................................................................... 110

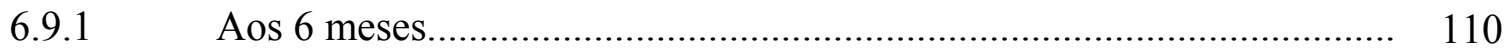

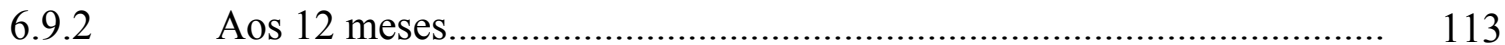

$7 \quad$ DISCUSSÃO

7.1 Parte I - Tradução, Adaptação Transcultural e Validação...................... 117

7.2 Parte II - Avaliação Pré-tratamento e aos 6 e 12 meses após o diagnóstico.................................................................................... 129

7.2.1 Características Demográficas e Clínicas das Amostras Avaliadas.......... 129

7.2.2 Ansiedade e Depressão........................................................................ 130

7.2.3 Qualidade de Vida......................................................................... 137 
7.2.4 Prevalência dos Sintomas.

7.2.5 Necessidades, Preferências e Atitudes dos Pacientes Frente às Informações.

7.2.6 Preocupações dos Pacientes

7.2.7 Avaliação das Expectativas.......................................................... 170

7.2.8 Preenchimento das Expectativas......................................................... 176

7.2.9 Associações entre o Grau de Preenchimento das Expectativas e a Qualidade de Vida......

7.2.10 Considerações Finais.

ANEXOS

Anexo A - Carta de aprovação do Comitê de Ética em Pesquisa FMUSP.

Anexo B - Carta de aprovação do Comitê de Ética em Pesquisa A.C.Camargo Cancer Center.

Anexo C - Ficha de Registro do Prontuário.

Anexo D - Ficha de Registro do Paciente.

Anexo E - Termo de Consentimento Livre e Esclarecido I - PCI Validação do Patients Concerns Inventory - PCI.

Anexo F - Termo de Consentimento Livre e Esclarecido II..

Anexo G - The Head \& Neck Cancer Patients' Concerns Inventory (PCI)..

Anexo H - Termo de Autorização - University Hospital Aintree

Foundation

Anexo I - Questionário de qualidade de vida da Universidade de Washington- (UW-QOL v4).

Anexo J - Versão final do Inventário de Preocupações dos Pacientes IPP.

Anexo K- Escala de Ansiedade e Depressão - HADS.

Anexo L - Inventário de Sintomas do M.D. Anderson (MDASI) - Head \& Neck-Parte I.

Anexo M- Questionário de Informação do Paciente (QIP)...

Anexo N- Protocolo de Avaliação das Expectativas (PAE)... 
Anexo O- Protocolo de Preenchimento das Expectativas (PPE).

Anexo P - Medidas de tendência central e de variabilidade dos domínios do $U W-Q O L$, nos momentos pré-tratamento $(\mathrm{N}=104), 6$ meses $(\mathrm{N}=80)$ e 12 meses $(\mathrm{N}=62)$ após o diagnóstico

Anexo Q - Frequência e porcentagem de pacientes, de acordo com a intensidade de sintomas, no momento pré-tratamento $(\mathrm{N}=104)$.

Anexo R- Frequência e porcentagem de pacientes, de acordo com a intensidade de sintomas, aos 6 meses após o diagnóstico $(\mathrm{N}=80)$.

Anexo S - Frequência e porcentagem de pacientes, de acordo com a intensidade de sintomas, aos 12 meses após o diagnóstico $(\mathrm{N}=62)$.

Anexo T - Frequência e porcentagem de pacientes, de acordo com a intensidade de sintomas, nos momentos pré-tratamento $(\mathrm{N}=104), 6$ meses $(\mathrm{N}=80)$ e 12 meses $(\mathrm{N}=62)$ após o diagnóstico.

Anexo U - Frequência relativa das preocupações selecionadas pelos pacientes no Inventário de Preocupações dos Pacientes - IPP, no momento pré - tratamento $(\mathrm{N}=104)$...

Anexo V - Frequência relativa dos profissionais selecionados pelos pacientes no Inventário de Preocupações dos Pacientes - IPP, no momento pré- tratamento $(\mathrm{N}=104)$.

Anexo W - Frequência relativa das preocupações selecionadas pelos pacientes no Inventário de Preocupações dos Pacientes - IPP, aos 6 meses após o diagnóstico $(\mathrm{N}=80)$.

Anexo X - Frequência relativa dos profissionais selecionados pelos pacientes no Inventário de Preocupações dos Pacientes - IPP, aos 6 meses após o diagnóstico $(\mathrm{N}=80)$.

Anexo Y - Frequência relativa das preocupações selecionadas pelos pacientes no Inventário de Preocupações dos Pacientes - IPP, aos 12 meses após o diagnóstico $(\mathrm{N}=62)$.

Anexo $\mathrm{Z}$ - Frequência relativa dos profissionais selecionados pelos pacientes no Inventário de Preocupações dos Pacientes - IPP, aos 12 meses após o diagnóstico $(\mathrm{N}=62)$. 


\section{APÊNDICES}

Apêndice 1 - Associações não significantes entre o grau de preenchimento das expectativas e qualidade de vida global aos 6 meses após o tratamento (Itens/ Profissionais)

Apêndice 2 - Associações não significantes entre o grau de preenchimento das expectativas e qualidade de vida global aos 12 meses após o tratamento (Itens/ Profissionais)

Apêndice 3 - Carta - comentário de paciente sobre itens do IPP

Apêndice 4 - Comentários dos pacientes ao longo do estudo 


\section{LISTA DE QUADRO E FIGURAS}

Quadro 1 Descrição do número de pacientes participantes e instrumentos utilizados nas partes I e II do estudo.

Figura 1- Descrição das alterações realizadas nos itens descritos na parte 1 do $P C I$, durante o processo de tradução e adaptação transcultural para o português- Brasil

Figura 2- Descrição das alterações realizadas na lista de especialistas descrita na parte 2 do $P C I$, durante o processo de tradução e adaptação transcultural para o Português- Brasil

Figura 3- Frequência relativa das preocupações selecionadas pelos pacientes no Inventário de Preocupações dos Pacientes - IPP ( $n=84)$.

Figura 4- Frequência relativa dos profissionais selecionados pelos pacientes no Inventário de Preocupações dos Pacientes - IPP $(n=84)$.

Figura 5- Valores médios e respectivos intervalos de confiança para o escore do domínio Dor (UW-QOL) ao longo das avaliações.

Figura 6- Valores médios e respectivos intervalos de confiança para o escore do domínio Atividade (UW-QOL) ao longo das avaliações.

Figura 7- Valores médios e respectivos intervalos de confiança para o escore do domínio Recreação (UW-QOL) ao longo das avaliações

Figura 8- Valores médios e respectivos intervalos de confiança para o escore do domínio Ombros (UW-QOL) ao longo das avaliações. 
Figura 9- Valores médios e respectivos intervalos de confiança para o escore do domínio Humor (UW-QOL) ao longo das avaliações.

Figura 10- Valores médios e respectivos intervalos de confiança para o escore do domínio Ansiedade (UW-QOL) ao longo das avaliações

Figura 11- Valores médios e respectivos intervalos de confiança para o escore do domínio Aparência (UW-QOL) ao longo das avaliações

Figura 12- Valores médios e respectivos intervalos de confiança para o escore do domínio Deglutição (UW-QOL) ao longo das avaliações.

Figura 13- Valores médios e respectivos intervalos de confiança para o escore do domínio Mastigação (UW-QOL) ao longo das avaliações

Figura 14- Valores médios e respectivos intervalos de confiança para o escore do domínio Fala (UW-QOL) ao longo das avaliações.

Figura 15- Valores médios e respectivos intervalos de confiança para o escore do domínio Paladar (UW-QOL) ao longo das avaliações

Figura 16- Valores médios e respectivos intervalos de confiança para o escore do domínio Saliva (UW-QOL) ao longo das avaliações.

Figura 17- Valores médios e respectivos intervalos de confiança para o escore global (UW-QOL) ao longo das avaliações

Figura 18- Valores médios e respectivos intervalos de confiança para o escore do sintoma Dor (MDASI) ao longo das avaliações.

Figura 19- Valores médios e respectivos intervalos de confiança para o escore do sintoma Cansaço (fadiga) (MDASI) ao longo das avaliações. 
Figura 20- Valores médios e respectivos intervalos de confiança para o escore do sintoma Enjôo (náusea) (MDASI) ao longo das avaliações

Figura 21- Valores médios e respectivos intervalos de confiança para o escore do sintoma Problemas de sono (MDASI) ao longo das avaliações

Figura 22- Valores médios e respectivos intervalos de confiança para o escore do sintoma Preocupações (aborrecimentos) (MDASI) ao longo das avaliações.

Figura 23- Valores médios e respectivos intervalos de confiança para o escore do sintoma Falta de ar (MDASI) ao longo das avaliações.

Figura 24- Valores médios e respectivos intervalos de confiança para o escore do sintoma Dificuldade para lembrar das coisas (MDASI) ao longo das avaliações.

Figura 25- Valores médios e respectivos intervalos de confiança para o escore do sintoma Falta de apetite (MDASI) ao longo das avaliações.

Figura 26- Valores médios e respectivos intervalos de confiança para o escore do sintoma Sonolência (MDASI) ao longo das avaliações.

Figura 27- Valores médios e respectivos intervalos de confiança para o escore do sintoma Sensação de boca seca (MDASI) ao longo das avaliações.........

Figura 28- Valores médios e respectivos intervalos de confiança para o escore do sintoma Sentimento de tristeza (MDASI) ao longo das avaliações.

Figura 29- Valores médios e respectivos intervalos de confiança para o escore do sintoma Vômitos (MDASI) ao longo das avaliações 
Figura 30- Valores médios e respectivos intervalos de confiança para o escore do sintoma Sensação de dormência/formigamento (MDASI) ao longo das avaliações

Figura 31- Valores médios e respectivos intervalos de confiança para o escore do sintoma Catarro na boca ou na garganta (MDASI) ao longo das avaliações

Figura 32- Valores médios e respectivos intervalos de confiança para o escore do sintoma Dificuldade para engolir/mastigar (MDASI) ao longo das avaliações.

Figura 33- Valores médios e respectivos intervalos de confiança para o escore do sintoma Engasgamento (MDASI) ao longo das avaliações

Figura 34- Valores médios e respectivos intervalos de confiança para o escore do sintoma Problemas com a voz/ para falar (MDASI) ao longo das avaliações.

Figura 35- Valores médios e respectivos intervalos de confiança para o escore do sintoma Dor/queimação ou irritação na pele (MDASI) ao longo das avaliações.

Figura 36- Valores médios e respectivos intervalos de confiança para o escore do sintoma Constipação (MDASI) ao longo das avaliações

Figura 37- Valores médios e respectivos intervalos de confiança para o escore do sintoma Dificuldade para sentir o gosto da comida (MDASI) ao longo das avaliações.

Figura 38- Valores médios e respectivos intervalos de confiança para o escore do sintoma Feridas na boca/garganta (MDASI) ao longo das avaliações.... 
Figura 39- Valores médios e respectivos intervalos de confiança para o escore do sintoma Problemas com dentes/gengivas (MDASI) ao longo das avaliações.

Figura 40- Frequência relativa das preocupações relacionadas aos itens de Bemestar Físico e Funcional do Inventário de Preocupações dos PacientesIPP, selecionadas pelos pacientes, de acordo com a época do tratamento.

Figura 41- Frequência relativa das preocupações relacionadas aos itens de Tratamento do Inventário de Preocupações dos Pacientes-IPP, selecionadas pelos pacientes, de acordo com a época do tratamento....

Figura 42- Frequência relativa das preocupações relacionadas aos itens de Assistência Bem-estar Social do Inventário de Preocupações dos Pacientes-IPP, selecionadas pelos pacientes, de acordo com a época do tratamento

Figura 43- Frequência relativa das preocupações relacionadas aos itens de Bemestar Psicológico, Emocional e Espiritual do Inventário de Preocupações dos Pacientes-IPP, selecionadas pelos pacientes, de acordo com a época do tratamento.

Figura 44- Frequência relativa dos profissionais selecionadas pelos pacientes no Inventário de Preocupações dos Pacientes-IPP, de acordo com a época do tratamento 


\section{LISTA DE TABELAS}

Tabela 1- Número e porcentagem de pacientes participantes do processo de validação do IPP, segundo dados demográficos e estilo de vida $(\mathrm{N}=84)$.

Tabela 2- Número e porcentagem de pacientes participantes do processo de validação do IPP, de acordo com classificação TNM (UICC), local da lesão e tipo histológico $(\mathrm{N}=84)$.

Tabela 3- Número e porcentagem de pacientes participantes do processo de validação do IPP, de acordo com o tipo de tratamento e situação clínica $(\mathrm{N}=84)$.

Tabela 4- Número de preocupações e profissionais selecionados no teste com IPP, de acordo com as características dos pacientes e escores compostos do UW-QOL $(\mathrm{N}=84)$

Tabela 5- Associações entre as características dos pacientes e domínios do UW-QOL com as preocupações e profissionais específicos selecionados no teste com IPP $(\mathrm{N}=84)$

Tabela 6- Número e porcentagem de pacientes excluídos do estudo aos 6 meses (N=24) e 12 meses $(\mathrm{N}=18)$ após o diagnóstico, de acordo com o motivo da exclusão

Tabela 7- Número e porcentagem de pacientes avaliados nos momentos pré-tratamento $(\mathrm{N}=104), 6$ meses $(\mathrm{N}=80)$ e 12 meses $(\mathrm{N}=62)$ após o diagnóstico, segundo dados demográficos e estilo de vida

Tabela 8- Número e porcentagem de pacientes coletados nos momentos pré-tratamento $(\mathrm{N}=104), 6$ meses $(\mathrm{N}=80)$ e 12 meses $(\mathrm{N}=62)$ após o diagnóstico, de acordo com classificação TNM (UICC), local da lesão e tipo histológico. 
Tabela 9- Número e porcentagem de pacientes coletados aos 6 meses $(\mathrm{N}=80)$ e 12 meses $(\mathrm{N}=62)$ após o diagnóstico, de acordo com o tipo de tratamento realizado e situação clínica.

Tabela 10 Número e porcentagem de pacientes, de acordo com os graus de ansiedade e depressão apresentados nos momentos pré-tratamento $(\mathrm{N}=104), 6$ meses $(\mathrm{N}=80)$ e 12 meses após o diagnóstico

Tabela 11 Número e porcentagem de pacientes, nos momentos pré-tratamento ( $N=104), 6$ meses $(\mathrm{N}=80)$ e 12 meses $(\mathrm{N}=62)$ após o diagnóstico, conforme a atitude preferencial no que diz respeito às informações gerais sobre a doença

Tabela 12 Número e porcentagem de pacientes, nos momentos pré-tratamento ( $N=104), 6$ meses $(\mathrm{N}=80)$ e 12 meses $(\mathrm{N}=62)$ após o diagnóstico, conforme as necessidades de informações específicas sobre a doença e o tratamento

Tabela 13 Número e porcentagem de pacientes, nos momentos pré-tratamento $(\mathrm{N}=104), 6$ meses $(\mathrm{N}=80)$ e 12 meses $(\mathrm{N}=62)$ após o diagnóstico, conforme a preferência quanto à pessoa que o informou sobre a sua doença na primeira vez que esta lhe foi explicada.

Tabela 14 Frequência das preocupações relacionadas aos itens de Bem-estar Físico e Funcional do Inventário de Preocupações dos Pacientes - IPP, selecionadas pelos pacientes, de acordo com a época do tratamento

Tabela 15 Frequência das preocupações relacionadas aos itens de Tratamento, Assistência e Bem-estar Social e Bem-estar Psicológico, Emocional e Espiritual do Inventário de Preocupações dos Pacientes - IPP, selecionadas pelos pacientes, de acordo com a época do tratamento.

Tabela 16 Frequência dos profissionais selecionados pelos pacientes no Inventário de Preocupações dos Pacientes - IPP, de acordo com a época do tratamento 
Tabela 17- Tipo e frequência das expectativas dos pacientes em relação aos itens de Bemestar Físico e Funcional do Protocolo de Preenchimento das Expectativas PAE, no momento pré-tratamento $(\mathrm{N}=104)$

Tabela 18- Tipo e frequência das expectativas dos pacientes em relação aos itens de Tratamento, Assistência e Bem-estar Social e Bem-estar Psicológico, Emocional e Espiritual do Protocolo de Preenchimento das Expectativas - PAE, no momento pré-tratamento $(\mathrm{N}=104)$

Tabela 19- Grau de preenchimento das expectativas dos pacientes, em relação aos itens de Bem-estar Físico e Funcional do Protocolo de Preenchimento das Expectativas - PPE, de acordo com as diferentes épocas do tratamento

Tabela 20- Grau de preenchimento das expectativas dos pacientes, em relação ao Tratamento, Assistência e Bem-estar Social e Bem-estar Psicológico, Emocional e Espiritual do Protocolo de Preenchimento das Expectativas - PPE, de acordo com as diferentes épocas do tratamento

Tabela 21- Grau de preenchimento das expectativas dos pacientes, em relação à qualidade, quantidade e clareza das informações fornecidas pelos profissionais, de acordo com as diferentes épocas do tratamento

Tabela 22- Associações significantes entre o grau de preenchimento das expectativas e qualidade de vida global aos 6 meses após o tratamento $(\mathrm{p}<0,001)$

Tabela 23- Associações significantes entre o grau de preenchimento das expectativas e qualidade de vida global aos 6 meses após o tratamento $(0,001<\mathrm{p}<0,01)$.

Tabela 24- Associações significantes entre o grau de preenchimento das expectativas e qualidade de vida global aos 12 meses após o tratamento $(\mathrm{p}<0,001)$

Tabela 25- Associações significantes entre o grau de preenchimento das expectativas e qualidade de vida global aos 12 meses após o tratamento $(0,001<\mathrm{p}<0,01)$ 


\section{LISTA DE ABREVIATURAS E SIGLAS}

ASA

CA

CEC

CO

CP

CX

dp

EORTC-QLQ-C30

FACT-G

FACT - H\&N

FMUSP

HADS

$H \& N$

HRQOL

IPP

IPQ-R

ISQ

máx

MADSI

MDASI-H\&N

mín

$\mathbf{N} / \mathbf{n}$

OMS

PAE

PCI

PEG
American Society of Anesthesiologists

Câncer

Carcinoma espinocelular

Cavidade oral

Cabeça e pescoço

Cirurgia

Desvio padrão

European Organisation for Research and Treatment of

Cancer Quality of Life Questionnaire-Core Questionnaire

The Functional Assessment of Cancer Therapy-

General

The Functional Assessment of Cancer Therapy- Headand

Neck Module

Faculdade de Medicina da Universidade de São Paulo

Hospital Anxiety and Depression Scale

Head and Neck

Health-related quality of life

Inventário de Preocupações dos Pacientes

Revised Illness Perception Questionnaire

Information styles questionnaire

Máximo

M.D.Anderson Symptom Inventory

Head \& Neck MD.Anderson Symptom Inventory

Mínimo

Número de pacientes

Organização Mundial de Saúde

Protocolo de Avaliação das Expectativas

Patients Concerns Inventory

Gastrostomia percutânea 
PPE

Q1-Q3

QIP

QT

QV

QVRS

RDT

SCNS-SF34

SNE

$S R M$

TQT

TU

UICC

UK

UW-QOL
Protocolo de Preenchimento das Expectativas

Primeiro e terceiro quartis

Questionário de Informação dos Pacientes

Quimioterapia

Qualidade de Vida

Qualidade de vida relacionada à saúde

Radioterapia

Supportive Care Needs Survey- Short Form

Sonda nasoenteral

Self Regulation Model

Traqueostomia

tumor

União Internacional Contra o Câncer

United Kingdom - Reino Unido

Questionário de qualidade de vida da Universidade de

Washington 


\section{RESUMO}

Jungerman I. Validação para o português - Brasil do inventário de preocupações de pacientes com câncer de cabeça e pescoço, avaliação de suas preocupações $e$ expectativas e relação com a qualidade de vida [tese]. São Paulo: Faculdade de Medicina, Universidade de São Paulo; 2016.

INTRODUÇÃO: O impacto do diagnóstico do câncer de cabeça e pescoço e as consequências de seu tratamento podem alterar profundamente a qualidade de vida de um indivíduo. OBJETIVOS: Realizar a validação psicométrica do Patients Concerns Inventory - PCI-H\&N para o Português-Brasil, caracterizar nos momentos pré-tratamento e após o diagnóstico, os graus de ansiedade e depressão, a qualidade de vida, a intensidade dos sintomas, suas necessidades, preferências e atitudes em relação às informações, suas preocupações, expectativas, o grau de preenchimento de suas expectativas (pós-tratamento). MÉTODOS - Parte I: Estudo transversal. Após as etapas de tradução e adaptação transcultural, a validade de construto foi realizada pela comparação do $P C I$ com o Questionário de Qualidade de Vida da Universidade de Washington (UW-QOL). Parte II: Estudo prospectivo longitudinal. Os participantes completaram a Escala de Ansiedade e Depressão (HADS), o Questionário de Qualidade de Vida da Universidade de Washington (UW-QOL), o Inventário de Sintomas do M.D. Anderson (MDASI- H\&N), o Questionário de Informação dos Pacientes (QIP), a versão em Português validada do Inventário de Preocupações dos Pacientes (IPP), o Protocolo de Avaliação das Expectativas (PAE) e o Protocolo de Preenchimento das Expectativas (PPE). Na primeira etapa, os testes não paramétricos de Mann-Whitney ou Kruskal-Wallis foram utilizados para avaliar a associação do número de itens/profissionais selecionados com as características dos pacientes. O teste de Mann-Whitney também foi utilizado para associar os escores dos domínios do $U W-Q O L$ com os itens/profissionais específicos selecionados pelos pacientes. Associações entre os itens/profissionais específicos selecionados com as características dos pacientes foram avaliadas por meio do teste Qui-Quadrado ou o teste Exato de Fisher. RESULTADOS - Parte I: Oitenta e quatro pacientes participaram do processo de validação. Os itens mais selecionados pelos pacientes no IPP foram: medo do câncer voltar, boca seca, mastigar/comer, e fala/voz/ser entendido. Os profissionais mais assinalados pelos pacientes foram o fonoaudiólogo, 
dentista e psicólogo. Os domínios físico e sócio-emocional do UW-QOL apresentaram correlações significantes com o número de preocupações e de profissionais selecionados. Resultados - Parte II: As amostras foram constituídas respectivamente por 104 pacientes (pré-tratamento), 80 pacientes (aos 6 meses) e 62 pacientes (aos 12 meses). Em todos os momentos do estudo, a maioria dos pacientes apresentou escores de ansiedade e de depressão dentro dos limites de normalidade. A qualidade de vida apresentou um declínio nos primeiros meses, seguida por uma melhora geral ao longo do primeiro ano. Os sintomas mais assinalados no MDASI$H \& N$ foram dor, preocupações, problemas de sono e dificuldade para engolir/mastigar (pré-tratamento), dificuldades para engolir/mastigar, boca seca e catarro (aos 6 meses) e boca seca, dificuldades para engolir/mastigar e preocupações (aos 12 meses). Em todas as épocas, a maioria dos pacientes desejava receber toda a informação possível. As principais preocupações dos pacientes e os principais profissionais por eles assinalados, foram: mastigar/comer, tratamento do câncer, fala/voz/ser entendido e engolir; fonoaudiólogo, nutricionista e oncologista/radioterapeuta. Em geral, as expectativas dos pacientes no momento prétratamento, eram boas. As expectativas dos pacientes em relação aos itens ligados à alimentação: mastigar/comer, boca seca, engolir, paladar e perda de peso foram as menos preenchidas após o tratamento. Foram encontradas diversas associações significativas entre a qualidade de vida global dos pacientes e o grau de preenchimento de várias expectativas após o tratamento. CONCLUSÕES: $O$ Inventário de Preocupações dos Pacientes-IPP pode ser considerado apropriado e psicométricamente válido para uso em pacientes brasileiros portadores de câncer de cabeça e pescoço. Ao longo de um ano após o diagnóstico os pacientes com neoplasias de cabeça e pescoço tendem a apresentar diminuição de comorbidades (ansiedade e depressão), boa qualidade de vida (com declínio aos 6 meses), predomínio de sintomatologia física/funcional associada à preocupações, desejam todas as informações possíveis, têm preocupações eminentemente físicas/funcionais, associadas ao medo de recidiva da doença e priorizam o contato com os clínicos responsáveis pelo tratamento e reabilitação, têm suas expectativas gerais preenchidas e o nível de satisfação de suas expectativas impacta a qualidade de vida global.

Descritores: neoplasias de cabeça e pescoço; qualidade de vida; estudos de validação; perfil de impacto da doença; questionários; avaliação de resultados (cuidados de saúde). 


\section{SUMMARY}

Jungerman I. Validation into Portuguese - Brazil of the head and neck cancer patients concerns inventory, assessment of their concerns and expectations and relationship with quality of life [thesis]. São Paulo. "Faculdade de Medicina, Universidade de São Paulo"; 2016.

INTRODUCTION: The impact of cancer diagnosis and consequence of its treatment have a major effect on quality of life on these patients. OBJECTIVES: To perform a psychometric validation of the Patients Concerns Inventory - PCI-H\&N in Portuguese-Brazil and characterize, at pre-treatment, and after diagnosis, the degree of anxiety and depression of patients, their quality of life, severity of symptoms, their preferences regarding information, their concerns, expectations, extent to which expectations were met (post-treatment). METHODS - Part I: Cross-sectional study. After the translation and transcultural adaptation stages, construct validity was determined by comparing the PCI against the University of Washington Quality of Life Questionnaire (UW-QOL). Part II: Prospective, longitudinal study. Participants completed the Anxiety and Depression Scale (HADS), the University of Washington Quality of Life Questionnaire (UW-QOL), the MD Anderson Symptom Inventory (MDASI-H\&N), the Information Styles Questionnaire (ISQ), the validated Portuguese version of the Patient Concerns Inventory (PCI), the Expectations Assessment Protocol (EAP), and the Meeting Expectations Protocol (MEP). In stage one, non-parametric Mann-Whitney or Kruskal-Wallis tests were employed to assess the association of number of items/professionals selected with patient characteristics. The Mann-Whitney test was also used to associate scores on the UW-QOL domains with specific items/professionals selected by patients Associations of specific items/professionals selected with patient characteristics were assessed using the Chisquare or Fisher Exact tests. RESULTS - Part I: Eighty-four patients took part in the validation process. The items most frequently selected by patients on the PCI were: fear of cancer coming back, dry mouth, chewing/eating and speech/voice/being understood. The professionals most indicated by patients were speech/language 
therapist, dentist and psychologist. The physical and social-emotional domains of the UW-QOL were significantly correlated with number of concerns and of professionals selected. Results - Part II: The samples comprised 104 patients (pretreatment), 80 patients (at 6 months) and 62 patients (at 12 months), respectively. At all study timepoints, anxiety and depression scores of most patients were within normal limits. A decline in quality of life was evident in the first few months, followed by a general improvement during the course of the first year. The most frequently reported symptoms on the MDASI-H\&N were pain, concerns, disturbed sleep and difficulty swallowing/chewing (pre-treatment), difficulties swallowing/chewing, dry mouth and catarrh (at 6 months), and dry mouth, difficulties swallowing/chewing and concerns (at 12 months). At all timepoints, most patients wished to receive all possible information. The main patient concerns and professionals selected were: chewing/eating, cancer treatment, speech/voice/being understood, swallowing; speech-therapist, nutritionist and oncologist/radiotherapist. In general, patient expectations at pre-treatment were good. Patient expectations for food-related items: chewing/eating, dry mouth, swallowing, taste and weight loss were the least met after treatment. A number of significant associations were found between global quality of life of patients and extent to which various expectations were met after treatment. CONCLUSIONS: The Patient Concerns Inventory-PCI was shown to be appropriate and psychometrically valid for use in Brazilian head and neck cancer patients. During the course of one year after diagnosis, the head and neck cancer patients tended to exhibit a decrease in comorbidities (anxiety and depression), good quality of life (with decline at 6 months), predominance of physical/functional symptoms associated with concerns, desire for all possible information, predominantly physical/functional concerns, associated with fear of disease recurrence and prioritized contact with the physicians responsible for treatment and rehabilitation, had general expectations met and the extent to which expectations were met impacted global quality of life.

Descriptors: head and neck neoplasms; quality of life; validation studies; sickness impact profile; surveys and questionnaires; outcome assessment (health care). 


\section{INTRODUÇÃO}

Mundialmente, cerca de 650.000 pessoas por ano são diagnosticadas com câncer de cabeça e pescoço (Crozier; Sumer, 2010), sendo este o $6^{\circ}$ tipo mais comum de neoplasia (Parkin, 2001) e com maior proporção dos casos reportados em países em desenvolvimento (Pelucchi et al., 2008).

Ferlay et al. (2012) estimaram para o Brasil a incidência de 10.439 novos casos de câncer de cavidade oral / lábios, 804 casos de câncer de nasofaringe, 5.504 casos de câncer de orofaringe / hipofaringe e 7.131 casos de câncer de laringe, em ambos os sexos. As estimativas do Ministério da Saúde-Instituto Nacional do Câncer (INCA), apontam para o ano de 2016 a ocorrência de 6.360 novos casos de câncer de laringe em homens e 990 em mulheres e 11.140 novos casos de câncer de cavidade oral/lábios em homens e 4.350 em mulheres.

A cidade de São Paulo possui uma das mais altas taxas de incidência de câncer de laringe e de boca em todo o mundo e o Brasil apresenta um índice de ocorrência notável, comparado a outros países da América Latina (Wünsch Filho, 2004).

O tipo histológico, em mais de $90 \%$ dos casos de câncer de cabeça e pescoço (CA/CP), é o carcinoma espinocelular (CEC), que ocorre em órgãos recobertos por epitélio escamoso, tais como lábios e cavidade oral, cavidades nasais, seios paranasais, nasofaringe, orofaringe, hipofaringe e laringe (Yan et al., 2011).

O sexo masculino é o mais acometido, entre a $5^{\mathrm{a}}$ e $7^{\mathrm{a}}$ décadas de vida, sua incidência nos órgãos que compõem as vias aerodigestivas superiores demostra 
variações e sua etiologia está fortemente relacionada ao tabagismo e etilismo, a higiene oral, fatores nutricionais, exposições ambientais (irradiação e poluição), exposições ocupacionais (metais, indústria têxtil), exposição a vírus oncogênicos (exemplos: Papilomavírus Humano, vírus Epstein-Barr), fatores hereditários, refluxo gastro-esofágico e defeitos genéticos no DNA que comprometem o metabolismo de carcinógenos e os mecanismos de reparo da mucosa (Schlecht et al., 1999; Kowalski 2000a; Llewellyn et al., 2004; Crozier; Sumer, 2010, Jiang et al., 2015).

A cirurgia, a radioterapia e a quimioterapia, isoladas ou combinadas, são as principais formas de tratamento do câncer de cabeça e pescoço e a decisão terapêutica depende de fatores como sítio do tumor primário, estadiamento/histopatologia do tumor e resultados esperados (Kowalski, 2000b).

A taxa de sobrevida global de pacientes precocemente diagnosticados e tratados por câncer de CA/CP em 5 anos é de cerca de 75\% (Silveira et al., 2008). Entretanto, a maioria dos pacientes com doença metastática no momento do diagnóstico tem esta taxa reduzida para $35 \%$ ou menos (Chin et al., 2005).

Apesar dos avanços diagnósticos e terapêuticos alcançados nas últimas décadas, a taxa de mortalidade por $\mathrm{CA} / \mathrm{CP}$ se manteve relativamente constante e os resultados, em termos de controle de recorrência loco-regional da doença, metástases e desenvolvimento de segundos tumores primários ainda são pobres (Carvalho et al. 2005, Sahu; Grandis, 2010; Crozier; Sumer, 2010).

Em função da centralidade da cabeça e da face para diversos aspectos da vida, além de sua importância para a expressão social, emocional e na comunicação (Vickery et al., 2003), alterações na sua anatomia ou no seu funcionamento podem ter consequências assoladoras (Jones et al., 1992). 
Apesar dos avanços alcançados, o câncer e seu tratamento continuam a causar um sofrimento devastador, não só para os pacientes que podem morrer devido a esta doença, como também para aqueles que são bem-sucedidos em seu tratamento (Sayed et al., 2009).

A partir da década de 80 os pacientes passaram a ser avaliados de maneira cada vez mais holística, por meio do uso de questionários de Qualidade de Vida (QV), gerais e/ou doença-específicos (Rosen et al., 2004). Segundo alguns autores, QV é um conceito multidimensional e subjetivo, pois engloba as percepções individuais do paciente e uma ampla gama de aspectos de sua vida. Ainda, para estes, os resultados alcançados com a reabilitação podem ser considerados um equivalente da QV (de Boer et al., 1999). Outros autores consideram que QV é um construto dinâmico, pois muda frequentemente ao longo do tempo e em diferentes situações (Kreitler et al., 1993, D’Antonio et al., 1996). De acordo com Morton (1995), Cella (1992) e Calman (1984) a QV pode ser representativa da lacuna entre a realidade percebida do que um indivíduo tem e o que ele quer ou espera ter.

No campo da pesquisa científica, alguns autores utilizam a expressão "Health-related quality of life" (HRQOL) - Qualidade de vida relacionada à saúde (QVRS), que é um conceito afim, também subjetivo, mas necessariamente ligado ao impacto do estado de saúde sobre a capacidade de um indivíduo de viver plenamente (Fleck et al., 1999). A avaliação da QVRS inclui tipicamente os domínios físico, psicológico e social, sendo geralmente feita por meio de questionários que refletem esta estrutura conceitual complexa (Llewellyn et al., 2005a). Os instrumentos de avaliação da QVRS devem exibir características psicometricamente comprovadas, tais como consistência, confiabilidade, reprodutibilidade, validade e sensibilidade para mudanças (Silveira et al., 2010). 
Sayed et al. (2009) acrescentam que estes instrumentos devem, entre outras coisas, ser multidimensionais, auto-administráveis, fáceis de pontuar e ter uma abordagem minimalista, consumindo pouco tempo do paciente e evitando sua fadiga.

Os indivíduos portadores e/ou tratados de CA/CP geralmente têm sua QVRS mensuradas por instrumentos específicos, que pretendem avaliar o impacto da doença e seu tratamento nos aspectos de comunicação, deglutição, mastigação e nutrição. Os principais parâmetros (domínios) abrangidos pelas ferramentas específicas para o $\mathrm{CA} / \mathrm{CP}$ são: funcionamento físico e seus sintomas, dor, funcionamento psicossocial, auto-imagem, imagem corporal, fatores relacionados ao tratamento, informações e suporte recebidos, outros fatores que influenciam os resultados de reabilitação e classificações globais de QV (de Boer et al., 1999).

A avaliação da qualidade de vida dos pacientes oncológicos é necessária para que se alcance uma clara compreensão dos graus de melhoria e/ou estabilização, ou mesmo de piora destes pacientes, obtidos com os procedimentos terapêuticos (Vartanian et al., 2004, Thomas et al., 2008).

Num estudo sobre os resultados e prováveis diretrizes da pesquisa sobre QV no campo do CA/CP, Sayed et al. (2009) comentam que, atualmente, a avaliação da QV constitui uma disciplina científica organizada e que, apesar das dificuldades em transformar as percepções dos pacientes em medidas quantitativas, o número de questionários de avaliação de QV aumentou rapidamente. Atualmente, a tendência nas pesquisas sobre QV é verificar quais as possíveis relações concorrentes entre as inúmeras variáveis que a determinam, a fim de possibilitar a predição de resultados (Llewellyn et al., 2007).

A Organização Mundial de Saúde-OMS (1998) define QV como "a percepção do indivíduo de sua posição na vida, no contexto da cultura e sistema de 
valores nos quais ele vive, e em relação aos seus objetivos, expectativas, padrões e preocupações". O uso do termo expectativa não está claramente definido na literatura científica (Williams et al.; 1995), apesar do crescente reconhecimento na área de cuidados à saúde sobre a importância de se conhecer as preocupações, expectativas e o grau de satisfação dos pacientes com o suporte recebido. Uma comunicação efetiva entre o médico e seus pacientes é parte essencial do processo de cuidados médicos. O reconhecimento das principais necessidades, preocupações, expectativas dos pacientes e o preenchimento destas, estão atrelados à eficácia deste processo.

Conforme preconizado por Calman (1984), modificar as expectativas dos pacientes a fim de torná-las mais realistas ou melhorar sua experiência do tratamento corrente contribui para o estreitamento das disparidades entre suas expectativas e o que eles realmente vivenciam, otimizando sua QV. Não se encontrou na língua portuguesa ferramenta clínica direcionada à avaliação das preocupações e expectativas dos pacientes com $\mathrm{CA} / \mathrm{CP}$. Tampouco se encontrou na literatura nacional algum estudo que avaliasse, simultaneamente, o estado emocional dos pacientes, sua QV, suas posturas preferenciais frente às informações, as mudanças em suas preocupações ao longo do tempo, suas expectativas gerais ao diagnóstico e o grau de preenchimento destas expectativas em diferentes momentos no curso da doença. A literatura encontrada avalia, em geral, as expectativas de pacientes em amostras heterogêneas, tratados de diversos tipos de CA (mama, pulmão, ginecológico, próstata, linfoma, reto, outros). Poucos estudos se limitam exclusivamente à avaliação de pacientes tratados do CA/CP. Dada à importância deste tema e o aumento da sobrevida dos pacientes com $\mathrm{CA} / \mathrm{CP}$, torna-se necessária a disponibilização de uma ferramenta clínica específica e de fácil utilização, na língua portuguesa, que possibilite a identificação das preocupações dos pacientes com 
$\mathrm{CA} / \mathrm{CP}$, em qualquer fase do tratamento ou após o seu término. Ainda, a obtenção de dados sobre suas preocupações, expectativas ao diagnóstico e sobre suas percepções durante e após o tratamento, podem subsidiar a adoção de estratégias adequadas, o que poderá, por sua vez, minimizar o impacto da doença e de seu tratamento nas diferentes áreas da vida dos pacientes. 


\section{OBJETIVOS}

\subsection{OBJETIVO GERAL}

Realizar a validação psicométrica do Patients Concerns Inventory - PCI$H \& N$ (Inventário de Preocupações dos Pacientes - IPP) para o Português-Brasil.

\subsection{OBJETIVOS ESPECÍFICOS}

- Caracterizar o grau de ansiedade e de depressão dos pacientes com neoplasias de cabeça e pescoço nos momentos pré-tratamento e aos 6 e 12 meses póstratamento.

- Caracterizar a qualidade de vida dos pacientes com neoplasias de cabeça e pescoço nos momentos pré-tratamento e aos 6 e 12 meses pós-tratamento.

- Caracterizar a prevalência dos sintomas apresentados por pacientes com neoplasias de cabeça e pescoço nos momentos pré-tratamento e aos 6 e 12 meses pós-tratamento.

- Caracterizar as necessidades, preferências e atitudes dos pacientes com neoplasias de cabeça e pescoço em relação às informações sobre o câncer, seu tratamento e prognóstico, nos momentos pré-tratamento e aos 6 e 12 meses pós- tratamento.

- Caracterizar as preocupações dos pacientes com neoplasias de cabeça e pescoço, nos momentos pré-tratamento e aos 6 e 12 meses pós- tratamento. 
- Caracterizar as expectativas dos pacientes recém diagnosticados no momento pré-tratamento.

- Caracterizar o grau de preenchimento das expectativas dos pacientes com neoplasias de cabeça e pescoço aos 6 e 12 meses pós-tratamento.

- Associar o grau de preenchimento das expectativas com a qualidade de vida de pacientes com neoplasias de cabeça e pescoço aos 6 e 12 meses póstratamento. 


\section{REVISÃO DA LITERATURA}

A partir da década de setenta, os pacientes passaram de uma posição passiva a uma posição de ativos e prestativos participantes do processo de cuidados à saúde e as mudanças neste cenário foram de grande significância no campo das pesquisas sobre as percepções da doença pelo paciente (Weinman; Petrie, 1997).

Já a partir da década de oitenta do Século XX, a QV emergiu nas pesquisas em oncologia como um elemento central, face ao crescimento acentuado da tecnologia médica usada na terapêutica do CA e ao crescimento da complexidade das decisões médicas (Macguire; Selby, 1989). Desde então, os aspectos psicossociais da doença oncológica, seu impacto na QV dos pacientes e a influência das expectativas dos pacientes no processo de recuperação têm sido abordados na literatura. Pruyn et al. (1986), conduziram a revisão de 117 estudos, realizados entre 1966 e 1984, sobre aspectos psicossociais do $\mathrm{CA} / \mathrm{CP}$ relacionados aos fatores que influenciavam os processos de reabilitação dos pacientes. Os autores observaram que a maioria dos estudos estava focada na reabilitação de pacientes submetidos à laringectomia e que poucos descreviam as consequências físicas e psicossociais do tratamento cirúrgico do câncer de cavidade oral e/ou orofaringe. Concluíram que havia escassez de informações sobre os fatores que influenciavam a reabilitação, sobre a natureza dos problemas experimentados pelos pacientes e sobre os fatores que influenciavam estes problemas durante o curso da doença. Para Flood et al. (1993), as expectativas dos pacientes afetam os resultados por eles alcançados, disparando nos mesmos uma resposta psicológica, motivando-os a alcançar melhores respostas, condicionando-os 
a observar certos tipos de sintomas e a ignorar outros, modificando o entendimento da doença, ou agindo em consonância com a ansiedade para aumentar ou reduzir os sintomas. Em 1999, de Boer et al comentaram que o CA/CP era descrito como o tipo de câncer mais traumático do ponto de vista psicológico, induzindo o paciente a problemas psicossociais. Os autores realizaram uma revisão de 50 estudos, desenvolvidos entre 1984 e 1995, constatando que muitos deles descreviam integradamente aspectos médicos e psicossociais e que havia ocorrido um crescimento considerável no desenvolvimento de instrumentos de avaliação específicos para o CA/CP. White (2004), considerou que o CA e seu diagnóstico estão associados a perdas, afetam todas as dimensões da vida de um indivíduo, alteram sua percepção sobre o ambiente que o rodeia, resultando num desequilíbrio espiritual, trazendo consequências psicológicas e importantes repercussões na QV. Kazi (2007a) afirmou que o impacto do diagnóstico do câncer e as consequências de seu tratamento em múltiplos domínios funcionais podem alterar profundamente a QV de um indivíduo. Para Paredes et al. (2008), o diagnóstico do CA e todo o processo da doença são vividos pelo paciente e também por sua família, como momentos de grande sofrimento, ansiedade, tristeza e angústia, durante os quais o paciente vivencia perdas e sintomas adversos, que comprometem as suas habilidades funcionais, vocacionais e conduzem a uma incerteza quanto ao futuro. Segundo os autores, de um modo geral, a deterioração progressiva sofrida pelo paciente, sua dependência de cuidados específicos, o impacto físico, psicológico, social e espiritual da doença e a necessidade de gerir a doença ao longo de meses, anos ou até mesmo durante toda a vida, conduzem a uma redução significativa em sua $\mathrm{QV}$, podendo afetar seu tratamento e reabilitação. 
Atualmente, as perspectivas de um melhor gerenciamento do CA e da obtenção de melhores resultados são bastante promissoras, tendo em vista os avanços tecnológicos significativos em cirurgia e em radioterapia, assim como a melhor compreensão da genômica envolvida no $\mathrm{CA} / \mathrm{CP}$ e dos novos agentes imunoterapêuticos (Rischin et al., 2015). Porém, conforme assinalado por Ringash (2015), o inquestionável aumento das taxas de sobrevida implica, também, em um aumento crescente no número de sobreviventes do $\mathrm{CA} / \mathrm{CP}$, especialmente devido à proporção cada vez maior de casos de CA de orofaringe associados ao Papiloma vírus humano (HPV) ao longo das últimas décadas. O autor ainda ressalta que, neste caso, os pacientes acometidos pelo $\mathrm{CA} / \mathrm{CP}$ encontram-se em idade mais ativa, são responsáveis por famílias mais jovens e, potencialmente, enfrentarão um grande impacto financeiro e nos seus papéis funcionais, decorrentes de sua doença, tratamento e sequelas. Portanto, conforme já afirmado por Pimentel (2003), o sucesso da terapêutica oncológica, se mensurado apenas em termos de sobrevivência, complicações e taxas de recidiva, não abrange toda a complexidade da doença oncológica. De acordo com o autor, a percepção que o doente tem de todos os eventos ligados à sua doença, é mais globalizante, assumindo um papel central da sua vivência. Fisher et al. (2003) também sugeriram que para os pacientes com $\mathrm{CA} / \mathrm{CP}$, a QV tem assumido uma importância tão grande quanto a extensão de sua sobrevida. Neste contexto, a avaliação da QV assume também um papel auxiliar na decisão do tratamento, no controle das sequelas e efeitos adversos do tratamento, servindo também como um fator de prognóstico (Amar et al., 2002, Seidl; Zannon, 2004).

Apesar de frequentemente utilizado na literatura com objetivos semelhantes à conceituação geral de QV, o termo QVRS envolve mais diretamente os aspectos associados às enfermidades ou intervenções em saúde e sua influência direta na 
saúde física e mental de um indivíduo (Seidl; Zannon, 2004; McHorney, 1999).

Llewellyn et al. (2005a) mencionaram que a QVRS para pacientes com CA/CP varia ao longo do tempo e de acordo com a modalidade de tratamento, porém o entendimento sobre as razões pelas quais pacientes com o mesmo estadiamento da doença e que receberam tratamentos similares experimentam diferentes níveis de QV era escasso. Os autores comentaram, ainda, que os pacientes se ajustam à doença de diferentes maneiras e a natureza destes ajustamentos é crucial para determinar os resultados de saúde física e psicológica. Em 2005, Scharloo et al. buscaram identificar potenciais alvos de intervenção para a melhora da QV de 68 pacientes (média de idade 60 anos) recém diagnosticados com $\mathrm{CA} / \mathrm{CP}$ avançado e investigaram quais as percepções da doença explicavam a variância em sua QV. Para controle de variáveis, eventuais comorbidades foram classificadas de acordo com a American Society of Anesthesiologists classification system of physical status - ASA (Reid et al., 2001). Os pacientes completaram o IPQ-R (Moss-Morris et al., 2002) e o EORTC QLQ - C30 (Aaronson et al., 1993) nos intervalos entre os diversos procedimentos diagnósticos. Os resultados encontrados demonstraram que as percepções da doença estavam significantemente relacionadas à QV, ou seja, as correlações demonstraram que menos sintomas percebidos, menor crença de que a doença e/ou seus sintomas são cíclicos por natureza, resposta emocional menos intensa à doença e menor crença no próprio comportamento como causador da doença estavam significantemente relacionadas com as sub-escalas física, emocional, cognitiva, social e saúde global do EORTC QLQ - C30. Os autores concluíram que a reestruturação de percepções negativas dos pacientes sobre sua doença no momento denominado linha de base (início do tratamento), por meio do fornecimento de informações 
acuradas/apropriadas pode ajudá-los a lidar mais adequadamente com a doença durante e após o tratamento.

Em 2005a, Llewellyn et al realizaram a revisão de dezesseis estudos sobre os fatores psicossociais ou comportamentais que influenciavam a QVRS de pacientes com $\mathrm{CA} / \mathrm{CP}$ e identificaram cinco fatores principais: personalidade (neuroticismo, extroversão, propensão ao otimismo), suporte social, satisfação com a consulta / informações recebidas e fatores comportamentais (tais como, tabagismo, etilismo e sintomas depressivos). Em 2005b, Llewellyn et al. avaliaram a satisfação do paciente com a consulta e com as informações recebidas sobre sua doença e tratamento e concluíram que as expectativas dos pacientes pré e pós tratamento derivam parcialmente das informações recebidas. Esta conclusão foi obtida após um estudo conduzido por este grupo, com os objetivos de examinar os tipos de expectativas que os pacientes tinham antes do tratamento, o quanto os mesmos consideravam que estas expectativas tinham sido atingidas após o tratamento e o papel da informação no desenvolvimento destas expectativas. A metodologia do estudo incluiu a entrevista de 15 pacientes tratados de $\mathrm{CA} / \mathrm{CP}$, com idades entre 38-75 anos (média $=$ 54 anos, dp $=10.5$ ), entre 1,5 a 18 meses (média 9,7 meses, dp $=4,8$ ) após o diagnóstico, submetidos à cirurgia e/ou radioterapia. As entrevistas eram gravadas (média de 30 minutos), transcritas literalmente e em seguida analisadas segundo uma estrutura de análise de dados qualitativos proposta por Ritchie e Spencer (1994). A entrevista, inicialmente interativa, era seguida por uma pergunta aberta: "Você poderia descrever algumas das experiências pelas quais passou desde o seu diagnóstico?". Os pacientes eram encorajados pelo entrevistador a elaborar histórias e situações que ilustravam os aspectos mais importantes para eles. As expectativas foram sub-categorizadas em "específicas" (efeitos colaterais do tratamento, estética 
pós-tratamento e processo de recuperação) e "globais" (experiência com o câncer como um todo). O papel da informação foi sub-categorizado em muita informação, muito pouca informação e a época de informação. Os resultados, quanto às expectativas específicas, demonstraram que os pacientes eram capazes de descrever suas experiências sobre efeitos colaterais específicos que tinham excedido suas expectativas, que o desfiguramento após a cirurgia era particularmente uma questão delicada em função da incerteza relativa à extensão da cirurgia e que as expectativas quanto ao processo de recuperação variavam entre mais ou menos realistas para os pacientes. As expectativas tinham mudado ao longo do tempo, indicando que muitos pacientes eram otimistas nos estágios iniciais da recuperação, mas que com o passar do tempo suas expectativas tinham se tornado mais realistas, o que sugere um processo de adaptação. Quanto às expectativas globais, um grande número de pacientes reportou que a experiência com o CA, como um todo, havia sido muito pior do que suas expectativas iniciais. Muitos pacientes demonstraram um conflito entre não querer receber muitas informações e a sensação de estar "perdendo" informações importantes sobre assuntos específicos (eventuais complicações e efeitos colaterais). A quantidade de informações sobre o tratamento sugerido e riscos associados pareceu claramente relacionada às expectativas dos pacientes, que reportaram comumente a falta de clareza sobre os efeitos colaterais da radioterapia. Já a carência de informações específicas ou falta de informação pareceu relacionada à época do recebimento da mesma. Os achados indicaram que as necessidades de informação dos pacientes variam individualmente, que muitos pacientes não estão preparados para saber sobre alguns aspectos de seu tratamento e recuperação e, principalmente, que após o tratamento, alguns pacientes reportam que suas 
experiências não corresponderam às suas expectativas em função da carência de informação.

A opinião de 74 pacientes com $\mathrm{CA} / \mathrm{CP}$ sobre a utilidade de questionários de QV para comunicar seus problemas de saúde aos clínicos foi avaliada por Mehanna e Morton (2006). Os resultados indicaram que cerca de $60 \%$ dos pacientes foi favorável ao uso de questionários como forma de comunicação com os médicos; a maioria considerou os questionários fáceis de entender, relevantes para seus problemas de saúde e o tamanho dos mesmos pareceu não afetar sua utilidade, apesar de a maioria preferir um questionário mais curto (com menos de 20 itens).

As relações longitudinais entre as cognições de 117 pacientes com $\mathrm{CA} / \mathrm{CP}$ no momento do início do tratamento e a predição da QV dois anos após o diagnóstico foram estudadas por Scharloo et al. (2010). Os pacientes completaram o IPQ-R (Moss-Morris et al., 2002) e o EORTC QLQ - C30 (Aaronson et al., 1993) no início do tratamento e um e dois anos após o término do tratamento. Os resultados indicaram que menor crença do paciente em seu próprio comportamento como agente causador da doença foi preditiva para melhor funcionamento e melhor QV global, identidade forte com a doença foi preditiva para pior funcionamento e pior QV global e que percepções negativas e crônicas sobre a duração da doença e de suas consequências também foram preditivas de pior QV. O estudo conclui que avaliar o processo de mudança nas cognições da doença é mais apropriado do que estudar as crenças pré-tratamento como fatores preditivos de resultados longitudinais; que a identificação de fatores cognitivos específicos no momento pré-tratamento pode propiciar a adoção de estratégias de aconselhamento e intervenção que promovam a melhora dos resultados funcionais e do ajustamento ao $\mathrm{CA} / \mathrm{CP}$ a longo prazo e, por fim, que entender a experiência da doença sob a perspectiva do paciente pode prover 
informações clínicas relevantes que direcionem o tratamento. Com o intuito de entender e explorar a experiência dos pacientes sobre o recebimento do tratamento para o $\mathrm{CA} / \mathrm{CP}$, focando-se em particular em suas experiências sobre os sintomas, Molassiotis e Rogers (2012) realizaram um estudo qualitativo prospectivo, por meio de entrevistas realizadas com uma amostra heterogênea de 16 pacientes com $\mathrm{CA} / \mathrm{CP}$ ao longo de um ano (T1 - após diagnóstico, T2 - aos 3 meses, T3 - aos 6 meses, T4 aos 12 meses). Os pacientes foram entrevistados sempre pelos mesmos avaliadores, a fim de construir um relacionamento entre si, propiciando respostas mais honestas dos pacientes. Os quatro temas principais que emergiram das entrevistas foram preocupações de caráter nutricional (comer, ingestão de alimentos e suplementos, preocupações com o peso, apetite, paladar, xerostomia, disfagia), cansaço ou falta de energia (e assuntos relacionados), o uso da máscara de radioterapia (causando pânico) e, por fim, a reobtenção da normalidade em suas vidas. Os resultados demonstraram que, no momento $\mathrm{T} 1$, os pacientes estavam mais centrados nos efeitos do tratamento, no T2 os mesmo estavam focados nos seus esforços para normalizar suas vidas e retornar ao seu estilo de vida anterior à doença (este momento aparentou ser o de balanço feito pelos pacientes sobre as experiências positivas e negativas de ter o CA), no $\mathrm{T} 3$ os pacientes sentiam-se ansiosos para retornar ao trabalho e frustrados por continuarem a experimentar alguns sintomas e, finalmente, no T4, os pacientes continuavam a expressar sentimentos de ansiedade, especialmente em relação ao futuro e preocupações relativas à mobilidade restrita secundária à fadiga, reportando que estes problemas interferiam na qualidade de sua sobrevivência. Os autores concluíram que os pacientes com $\mathrm{CA} / \mathrm{CP}$ experimentam um processo complexo de tratamento, pós-tratamento, sintomas significantes e dificuldades que, conjuntamente, dificultam sua transição à sobrevivência, impactando sua QV. 
Conforme mencionado por Ojo et al. (2012), a avaliação da QV de pacientes com $\mathrm{CA} / \mathrm{CP}$ é fundamental, não somente para avaliação das opções de tratamento, mas também para o desenvolvimento de serviços de reabilitação e de materiais de educação do paciente. Todavia, segundo os autores, ainda há falta de compreensão do verdadeiro significado clínico de $\mathrm{QV}$ no $\mathrm{CA} / \mathrm{CP}$, assim como o desconhecimento sobre a melhor maneira de interpretar os resultados dos estudos realizados e os colocar na prática clínica.

Após conduzir uma meta-síntese de 29 estudos qualitativos (produzidos entre 1993 e 2011), que se focavam em qualquer aspecto da experiência do paciente sobre viver com o CA/CP, Lang et al. (2013) encontraram seis conceitos centrais que caracterizavam esta experiência: 1 - incerteza e espera (representando que o paciente vive num limbo, convivendo com a incerteza de viver com a doença e a incerteza sobre o futuro, a espera pelo diagnóstico, pelo tratamento, pela cura), 2 - ruptura da vida diária (na funções físicas, nas emoções e na vida social), 3 - auto-diminuição (perdas temporárias ou duradouras da auto-imagem, da auto-estima, do senso existencial, esforços contínuos para dar sentido à experiência e ao CA, e desenvolvimento de expectativas sobre prováveis resultados), 4 - partilhar o fardo (importância de uma relação de apoio com os profissionais de saúde, cujo papel é crucial para incutir esperança, manter a auto-estima e neutralizar a vulnerabilidade do paciente) e, por fim, 6 - encontrar um caminho (viver além do CA, percepção de um futuro diminuído ou modificado). Os autores concluíram que é necessário que se tenha um entendimento mais amplo sobre esta experiência, para que possam ser desenvolvidas intervenções significativas, efetivas e multidimensionais. 


\section{CASUÍSTICA E MÉTODOS}

Este é um estudo de caráter transversal, quando da realização do processo de validação (Parte I) e de caráter prospectivo longitudinal, quando da realização dos objetivos específicos (Parte II).

A coleta de dados foi realizada no Departamento de Cirurgia de Cabeça e Pescoço e Otorrinolaringologia do A.C.Camargo Cancer Center, entre fevereiro e agosto de 2013 (Parte I) e entre abril e dezembro de 2014 (Parte II).

O presente estudo foi aprovado pelo Comitê de Ética e Pesquisa da Faculdade de Medicina da Universidade de São Paulo-FMUSP (instituição proponente - Anexo A) e, em seguida, aprovado pelo Comitê de Ética e Pesquisa (CEP) do A.C.Camargo Cancer Center (instituição co-participante - Anexo B).

Os dados relativos às variáveis clínicas e terapêuticas dos pacientes que participaram de todos os objetivos propostos neste estudo foram coletados por meio da revisão dos prontuários e registrados em uma ficha de coleta de dados padronizada (Anexo C). Os dados relativos às variáveis sócio-demográficas foram coletados pessoalmente com os pacientes no momento prévio à aplicação dos questionários e registrados na Ficha de Registro do Paciente (Anexo D). Todos os pacientes participantes deste estudo assinaram o Termo de Consentimento Livre e Esclarecido I - PCI (Anexo E ).

A versão original em inglês, que vem sendo atualmente utilizada pelos autores do PCI, está descrita no Anexo G. Sua livre utilização, adaptação para situação clínica e mudanças no processo de aplicação estão autorizadas pelo autor, 
conforme descrito na página da Instituição que concebeu o instrumento (Merseyside Regional Head \& Neck Cancer Centre).

O processo de adaptação e validação desta ferramenta para o Português Brasil foi formalmente autorizado pelo autor, conforme descrito no Anexo $\mathrm{H}$.

Todos os questionários utilizados neste estudo foram aplicados pela pesquisadora e/ou por uma enfermeira treinada. A aplicação dos questionários para indivíduos não alfabetizados foi feita sob forma de entrevista, apenas por meio da leitura dos mesmos para o paciente e subsequente anotação da resposta, sem qualquer tipo de interferência do entrevistador.

Nenhum dos participantes deste estudo realizou fonoterapia com a pesquisadora principal.

\subsection{PARTE I - Tradução e Adaptação Transcultural}

\subsubsection{Critérios de Inclusão}

Para a realização do objetivo geral foram incluídos pacientes com 18 anos ou mais que já estiveram ou estavam em tratamento do $\mathrm{CA} / \mathrm{CP}$, independentemente do tipo histológico, do estadiamento tumoral e do tratamento adotado.

\subsubsection{Critérios de Exclusão}

Para o objetivo geral foram excluídos pacientes com diagnóstico de neoplasia de tireóide, diagnóstico médico de alterações neurológicas e/ou déficits na compreensão e/ou expressão da comunicação; indivíduos que reportaram não ter condições físicas e/ou psicológicas para responder aos questionários; indivíduos que 
optaram por interromper a coleta de dados e pacientes que se recusaram a participar do estudo.

A exclusão de pacientes portadores de neoplasias de tireóide deveu-se ao fato de que estes tumores diferem dos demais tumores de cabeça e pescoço quanto à etiologia, histologia e terapia padrão.

\subsubsection{Processo de Tradução e Adaptação Transcultural}

A tradução e adaptação transcultural do PCI seguiram as diretrizes internacionalmente aceitas (Guillemin et al., 1993, Beaton et al., 2000).

Inicialmente, dois tradutores bilíngues, especialistas na área de saúde e atuantes na área de $\mathrm{CA} / \mathrm{CP}$, realizaram a tradução da versão original em Inglês do PCI para o Português-Brasil. Os mesmos foram orientados a evitar a tradução literal e a realizar a tradução conceitual dos termos. Um terceiro tradutor bilíngue realizou a comparação entre as duas versões e um consenso foi alcançado. A versão consensual da tradução em Português-Brasileiro foi submetida à retrotradução para o inglês (“back-translation“), realizada por outros dois tradutores bilíngues de língua nativa inglesa, em conjunto com o autor do instrumento original (Dr. Simon Rogers Regional Head and Neck Unit- University Hospital Aintree Foundation Trust Liverpool - UK). Para verificar a equivalência transcultural da versão original e da traduzida, nos diferentes aspectos - semântico, idiomático, experimental e conceitual, um comitê formado por três profissionais da área de saúde com experiência em $\mathrm{CA} / \mathrm{CP}$ revisou a versão final, em comparação à original.

Eventuais discrepâncias entre as versões original e a retrotraduzida foram resolvidas repetindo-se o processo conforme necessário. 
A etapa seguinte compreendeu a aplicação de dois testes piloto para checar a equivalência entre as duas versões em português. A seleção dos pacientes foi feita a partir do levantamento da agenda diária do Departamento de Cirurgia de Cabeça e Pescoço e Otorrinolaringologia do A.C.Camargo Cancer Center. Os mesmos foram convidados a participar da pesquisa conforme sua chegada ao ambulatório

O Inventário foi aplicado em 20 pacientes (piloto 1) com $\mathrm{CA} / \mathrm{CP}$ que já estavam em tratamento, independentemente do estadiamento tumoral, do tipo histológico e do tratamento adotado. Foi solicitado ao paciente que ele circulasse os termos não compreendidos (preocupações / profissionais) a fim de identificar itens não compreendidos ou inapropriados para o público-alvo. As respostas foram analisadas pelo comitê, realizando-se as adaptações necessárias para a população e cultura brasileiras. As modificações foram consideradas sempre que algum item fosse circulado pelos pacientes. A versão pré-final, com as alterações realizadas, foi novamente aplicada em outros 25 pacientes (piloto 2), chegando-se à versão final do instrumento.

Realizou-se, então, nova seleção de pacientes para a aplicação da versão definitiva e finalização do processo de validação.

\subsubsection{Instrumentos}

Os instrumentos utilizados durante o processo de validação foram $o$ Questionário de Qualidade de Vida da Universidade de Washington - The University of Washington QOL questionnaire - UW-QOLv4 (Hassan; Weymuller, 1993; Vartanian et al., 2006a) (Anexo I) e o Inventário de Preocupações dos Pacientes IPP (versão final). (Anexo J). Ambos os questionários serão descritos a seguir. 


\subsubsection{Processo de Validação}

Os pacientes participantes da etapa de validação completaram a versão final traduzida e impressa do PCI, o Inventário de Preocupações dos Pacientes - IPP, e o Questionário de Qualidade de Vida da Universidade de Washington - UW-QOLv4 (Hassan; Weymuller, 1993; Vartanian et al., 2006a).

Não foi utilizada a tecnologia digital para a aplicação do IPP (utilizada no Reino Unido), porque a mesma ainda não está disponível na rotina clínica dos pacientes recrutados.

Conforme metodologia utilizada por Rogers et al. (2009) quando do desenvolvimento do PCI, neste estudo os resultados do UW-QOL também foram analisados considerando-se dois escores compostos: "função física" (média simples dos escores dos domínios deglutição, mastigação, fala, saliva, paladar e aparência) e “função sócio-emocional” (média simples dos escores dos domínios atividade, recreação, dor, humor, ansiedade e ombros).

\subsubsection{Confiabilidade}

Neste estudo não coube verificar a confiabilidade teste-reteste ou consistência interna, pois o instrumento estudado tem como um dos principais objetivos ser capaz de mapear as mudanças nas preocupações dos pacientes e, também, porque estas podem variar em maior ou menor número e grau, em quaisquer intervalos de tempo, de acordo com as características individuais do paciente e do momento de seu tratamento. 


\subsubsection{Validade de Conteúdo}

A validade de conteúdo foi garantida na concepção inicial do PCI por seus autores (Rogers et al., 2009; Ghazali et al., 2011) e assegurada pelo rigoroso método de tradução e adaptação transcultural.

\subsubsection{Validade de Critério}

A validade de critério é determinada por meio da comparação dos dados do instrumento estudado com outro questionário considerado padrão ouro, que avalie as preocupações dos pacientes com $\mathrm{CA} / \mathrm{CP}$. Como não há, no Brasil, nenhum questionário desta natureza já validado, não foi possível realizar a validade de critério.

\subsubsection{Validade de Construto}

Para a validação psicométrica de construto, os resultados do IPP foram correlacionados com o $U W-Q O L$, porque este instrumento avalia a qualidade de vida em diferentes aspectos e apresenta alguns domínios que podem ser relacionados e/ou comparados com os itens presentes no instrumento em estudo.

\subsubsection{Reprodutibilidade}

De acordo com os autores do PCI, a aplicação do teste-reteste é inviável, tendo em vista que, na prática, o seu objetivo é o de mensurar se o paciente quer ou não discutir alguma preocupação e, desta forma, não pode ser psicometricamente testado da mesma forma que outros questionários de QVRS. 


\subsection{PARTE II - Avaliação Pré-tratamento e aos 6 e 12 meses após o diagnóstico}

Para a seleção dos pacientes, a pesquisadora responsável e uma enfermeira treinada realizavam uma verificação diária na agenda ambulatorial do Departamento de Cirurgia de Cabeça e Pescoço e Otorrinolaringologia do A.C.Camargo Cancer Center, a fim de identificar os pacientes elegíveis, ou seja, pacientes com $\mathrm{CA} / \mathrm{CP}$ recém diagnosticado e confirmado por biópsia e pacientes com biópsias em andamento (incluindo revisão de lâminas de casos externos).

Os pacientes com o diagnóstico confirmado eram abordados na sala de espera do referido ambulatório e convidados a participar do estudo antes do início de sua consulta. Pacientes com biópsia em andamento eram convidados a participar somente após a consulta devolutiva de diagnóstico positivo, a fim de evitar a abordagem do paciente sem que o mesmo já tivesse ciência da confirmação de sua doença. Para garantir que o paciente abordado já estava ciente de seu diagnóstico eram realizadas as seguintes perguntas antes do início da coleta de dados: 1- O Sr. (a) sabe onde é o seu problema? 2- Já fez o exame de biópsia? 3- Já sabe o resultado da mesma?

\subsubsection{Critérios de Inclusão}

Para a coleta de dados referente aos objetivos específicos foram incluídos todos os pacientes com 18 anos ou mais, que obedeceram aos seguintes critérios: diagnóstico recente (já biopsiado) de neoplasia cabeça e pescoço: cavidade oral, orofaringe, nasofaringe, fossas nasais, seios paranasais, hipofaringe, laringe, glândulas salivares, independentemente do tipo histológico e nunca antes sido submetidos a nenhum tipo de tratamento oncológico. 


\subsubsection{Critérios de Exclusão}

Para os objetivos específicos foram excluídos pacientes submetidos à biópsia excisional, pacientes com diagnóstico de neoplasia de tireóide ou de doenças linfoproliferativas, diagnóstico médico de alterações neurológicas e/ou déficits na compreensão e/ou expressão da comunicação; indivíduos que reportaram não ter condições físicas e/ou psicológicas para responder aos questionários; indivíduos que optaram por interromper a coleta de dados no momento da aplicação dos questionário e pacientes que se recusaram a participar do estudo.

Assim, como já descrito na Parte I deste estudo, a exclusão de pacientes portadores de neoplasias de tireóide deveu-se ao fato de que estes tumores diferem dos demais tumores de cabeça e pescoço quanto à etiologia, histologia e terapia padrão.

Ainda que este também seja o caso para os tumores de glândulas salivares, optou-se pela não exclusão destes casos, pois os mesmos foram incluídos no estudo original, quando da concepção do PCI (Rogers et al., 2009).

Os pacientes elegíveis que aceitaram participar voluntariamente do estudo assinaram o Termo de Consentimento Livre e Esclarecido II (Anexo F).

\subsubsection{Instrumentos}

Os questionários utilizados nos momentos pré-tratamento e aos 6 e 12 meses após o início do tratamento foram: 
A. Escala de Ansiedade e Depressão - Hospital Anxiety and Depression Scale HADS (Zigmond; Snaith, 1983; Botega et al., 1995) (Anexo K)

Aplicado nos momentos pré-tratamento, aos 6 meses e 12 meses após o diagnóstico.

Esta escala, já validada no Brasil, foi desenvolvida para ser aplicada em pacientes com doenças físicas e em ambientes não psiquiátricos, sendo largamente utilizada para mensurar os sintomas de ansiedade e depressão em pacientes oncológicos. É constituída por 14 questões do tipo múltipla escolha, subdivididas em duas sub-escalas: sete questões avaliam os sintomas de depressão (HAD-D) e sete questões avaliam os sintomas de ansiedade $(H A D-A)$. O escore de cada questão pode variar de 0 a 3 e a pontuação global em cada subescala varia de 0 a 21. Os pontos de corte considerados foram os recomendados por Zigmond e Snaith (1983) para ambas as sub-escalas, respectivamente: $0-7=$ normal, $8-10=$ leve, $11-14=$ moderada, $15-21=$ severa

\section{B. Questionário de Qualidade de Vida da Universidade de Washington -}

The University of Washington QOL questionnaire - UW-QOL (Hassan; Weymuller, 1993; Vartanian et al., 2006a) - (já descrito no Anexo I)

Aplicado nos momentos pré-tratamento, aos 6 meses e 12 meses após o diagnóstico.

Este protocolo teve sua primeira versão desenvolvida por Hassan e Weymuller (1993). Sua versão 4 foi validada e adaptada para o português (Brasil) por Vartanian et al. (2006a). Este questionário doença-específico para pacientes tratados do câncer de cabeça e pescoço abrange doze domínios: dor, aparência, atividades diárias, recreação, deglutição, mastigação, fala, paladar, incapacidade de 
ombros, saliva, humor e ansiedade. Os escores variam de 0 a 100 e o menor escore implica em maior incapacidade ou pior qualidade de vida. O escore composto final corresponde à média dos doze domínios avaliados.

C. Inventário de Sintomas do M.D. Anderson (MDASI- H\&N) - Head \& Neck MD.Anderson Symptom Inventory (Cleeland et al., 2000; Rosenthal et al., 2007; Ferreira et al., 2008) - Parte I (Anexo L).

Aplicado nos momentos pré-tratamento, aos 6 meses e 12 meses após o diagnóstico.

O M.D. Anderson Symptom Inventory (MDASI) foi originalmente elaborado e validado por Cleeland et al. (2000). Sua versão específica para pacientes com CA/CP - Head \& Neck M.D. Anderson Symptom Inventory (MDASI-H\&N) foi desenvolvida e validada por Rosenthal et al. (2007), e traduzida para o português (Brasil) por Ferreira et al. (2008). A versão brasileira deste inventário, ainda não validada para o Português, é composta por 28 itens, divididos em 2 sub-escalas: sintomas gerais e específicos - Parte I (22 itens) e interferência dos sintomas na vida do paciente Parte II (6 itens). A intensidade dos sintomas e sua interferência na vida são avaliadas numa escala Likert, que varia de 0 a 10 (11 pontos) e se referem às últimas 24 horas vivenciadas pelo paciente. Neste estudo aplicou-se apenas a Parte I do questionário. Maiores valores pontuados pelo paciente correspondem a uma maior intensidade do sintoma ou maior interferência em sua vida. O MDASI-H\&N não possibilita o cálculo de um escore geral, porém possibilita o cálculo de um escore para as 2 sub-escalas. O escore final é determinado pela somatória dos escores assinalados em cada item e dividida pelo número de respostas. 


\section{Questionário de Informação dos Pacientes (QIP) - Information Styles}

Questionnaire - ISQ (Cassileth et al., 1986) - (Anexo M)

Aplicado nos momentos pré-tratamento, aos 6 meses e 12 meses após o diagnóstico.

Este instrumento, desenvolvido na Pensilvânia, possui questões que objetivam conhecer as necessidades, preferências e atitudes dos pacientes em relação às informações sobre o câncer, seu tratamento e prognóstico. Sua segunda versão, adaptada por Meredith et al. (1996) foi utilizada no Brasil apenas de forma traduzida por Pinto (2001) e por Gimenes (2008) e procura saber qual o tipo de informação os pacientes com câncer desejam e necessitam saber. O instrumento divide-se em três seções A, B e C.

A sessão A tem por objetivo descrever a atitude do paciente em relação à informação a ser recebida: não se interessar pela informação, desejar a informação apenas quando são boas notícias ou querer toda informação possível. A sessão B consta de uma lista de sete tipos de informações específicas relativas aos aspectos da doença e do tratamento e a atitude do paciente frente à sua necessidade e desejo destas informações: informação é necessária de qualquer maneira, informação desnecessária e informação necessária, mas que não deseja ter. A seção C é constituída por uma questão que verifica qual pessoa o paciente preferia que tivesse lhe informado sobre seu diagnóstico. 


\section{E. Inventário de Preocupações dos Pacientes - IPP - Patients Concerns} Inventory - PCI (Rogers et al., 2009, Ghazali et al., 2011) - (versão final, já descrita no Anexo J).

Aplicado nos momentos pré-tratamento, aos 6 meses e 12 meses após o diagnóstico.

Este instrumento, desenvolvido conjuntamente com o Merseyside Regional Head \& Neck Cancer Centre Support Group, consiste de um inventário baseado em uma síntese de ítens de vários questionários de QVRS. O questionário é uma ferramenta de uso ambulatorial, holística, auto-aplicável para pacientes alfabetizados e pode ser utilizado nos diferentes momentos após o diagnóstico do $\mathrm{CA} / \mathrm{CP}$.

$\mathrm{O}$ instrumento tem como objetivos ajudar os pacientes com $\mathrm{CA} / \mathrm{CP}$ a identificar e a sinalizar suas preocupações, necessidades, prioridades individuais e problemas, encorajá-los a discuti-los durante sua consulta clínica e indicar outros profissionais (clínicos multidisciplinares ou não) com os quais gostariam de conversar durante seu retorno ambulatorial ou para os quais gostariam de ser encaminhados. A primeira parte da ferramenta original em Inglês (PCI) possui 57 itens, agrupados em 5 domínios: bem-estar físico e funcional (29 itens), relacionados ao tratamento (4 itens), assistência e bem-estar social (9 itens), bem-estar psicológico, emocional e espiritual (14 itens) e outros (texto livre). A segunda parte consta de uma lista de 17 especialistas, também agrupados em 5 domínios: bem-estar físico e funcional (9 profissionais), relacionados ao tratamento (3 profissionais), assistência e bem-estar social (3 profissionais), bem-estar psicológico, emocional e espiritual (3 profissionais) e outros (texto livre). Em ambas as partes do inventário os pacientes podem sinalizar tantos itens e profissionais quantos desejarem.

Não há pontuação ou escore composto. 
F. Protocolo de Avaliação das Expectativas (PAE) - baseado no Patients Concerns Inventory - PCI (Rogers et al., 2009; Ghazali et al., 2011) (Anexo N)

Aplicado apenas no momento pré-tratamento.

Este protocolo foi utilizado neste estudo como um piloto. Nele encontram-se descritos os mesmos itens da primeira parte do IPP. Seu objetivo é avaliar o tipo de expectativa dos pacientes em relação aos itens citados. As respostas podem ser classificadas como: 0 - não se aplica, 1- não tenho expectativas; 2 - tenho expectativas ruins; 3 - tenho boas expectativas. O PAE não possui lista de especialistas.

G. Protocolo de Preenchimento das Expectativas (PPE) - baseado no Patients Concerns Inventory - PCI (Rogers et al., 2009; Ghazali et al., 2011) (Anexo O)

Aplicado aos 6 e 12 meses após o início do tratamento.

Este protocolo foi utilizado neste estudo como um piloto. Nele encontram-se descritos os mesmos itens do IPP, sendo constituído por duas partes. A parte 1 busca mensurar o grau de preenchimento das expectativas dos pacientes em relação aos itens citados. Os escores para o grau de preenchimento das expectativas são respectivamente: 0- não se aplica, 1- pior do que eu esperava, 2- igual ao que eu esperava, 3- melhor do que eu esperava.

A parte 2 tem por objetivo avaliar se os profissionais com os quais o paciente eventualmente conversou durante o tratamento preencheram de forma positiva ou negativa as expectativas do mesmo, em termos de qualidade, quantidade e clareza das informações recebidas. As respostas podem ser classificadas como: 0- não conversei com este profissional, 1- preencheu pouco minhas expectativas, 2- 
preencheu razoavelmente minhas expectativas, 3- preencheu muito minhas expectativas.

Todos os instrumentos utilizados nas Partes I e II do estudo estão descritos no Quadro 1.

Quadro 1 Descrição do número de pacientes participantes e instrumentos utilizados nas partes I e II do estudo

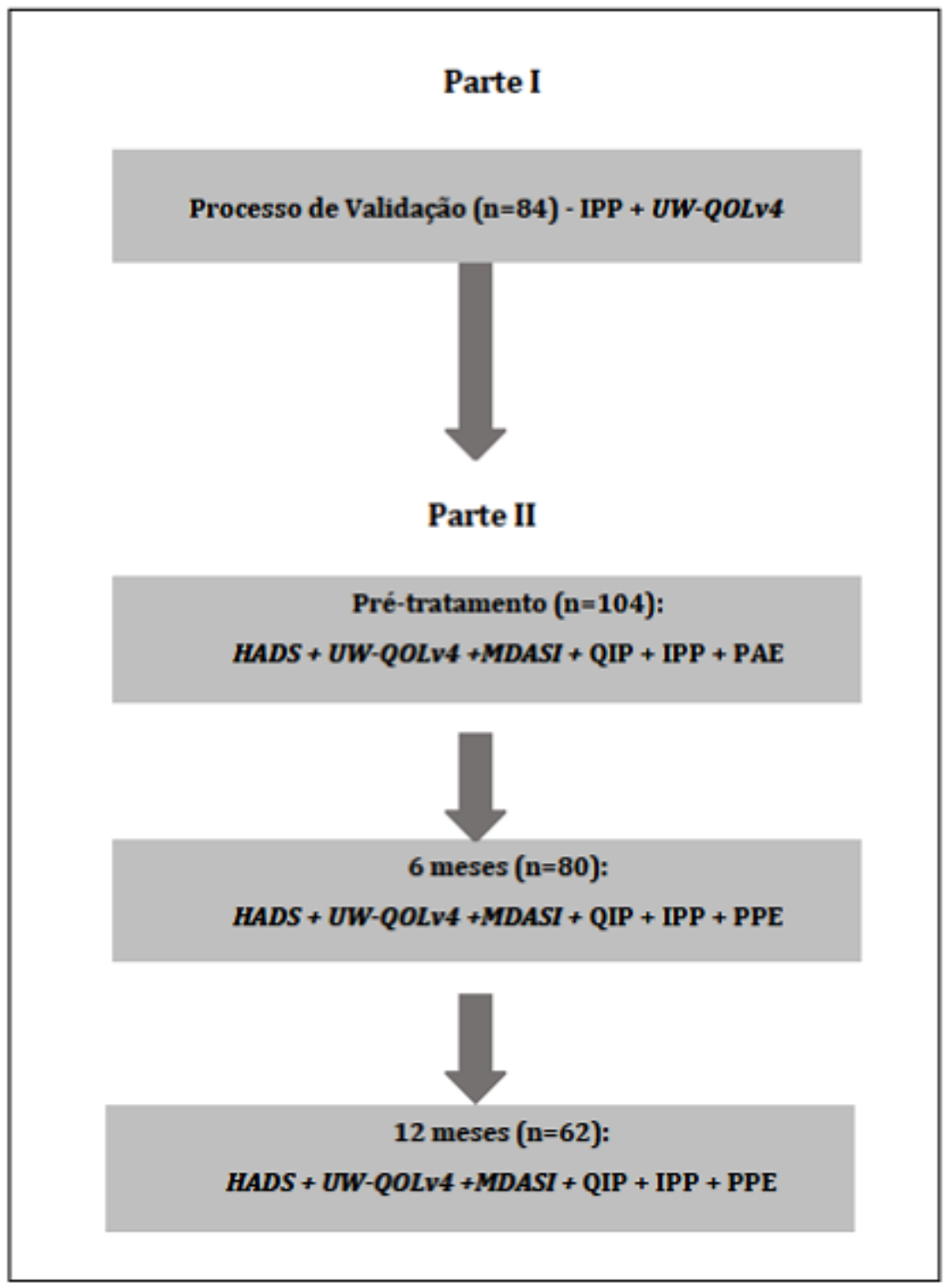




\subsection{ANÁLISE ESTATÍSTICA}

Para a descrição das características clínicas e demográficas dos pacientes foram apresentadas as frequências absoluta e relativa (características qualitativas) ou as principais medidas resumo como média, desvio padrão, mediana, valor mínimo e valor máximo (características quantitativas). Para o número de itens/profissionais selecionados apresentou-se a mediana e a amplitude interquatil (Q1-Q3). Os testes não paramétricos de Mann-Whitney e de Kruskal-Wallis foram utilizados para avaliar a associação do número de itens/profissionais selecionados com as características dos pacientes, quando essas possuíam duas ou três categorias, respectivamente. O teste de Mann-Whitney também foi utilizado para associar os escores categorizados dos domínios do UW-QOL (físico, sócio-emocional e global) com os itens/profissionais específicos selecionados pelos pacientes. As associações entre os domínios do $U W-Q O L$ com idade e tempo de diagnóstico e com o número de itens/profissionais selecionados, foram verificadas por meio do coeficiente de correlação de Spearman. Associações entre os itens/profissionais específicos selecionados com as características dos pacientes foram avaliadas por meio do teste Qui-Quadrado ou o teste Exato de Fisher. As associações entre os itens do PPE e o escore global do $U W-Q O L$ foram avaliadas por meio do teste não paramétrico de Mann-Whitney. O nível de significância adotado foi o de 1\% e o software utilizado foi o R versão 3.0.1 (www.R-project.org.br). 


\section{RESULTADOS I}

\subsection{TRADUÇÃO, ADAPTAÇÃO TRANSCULTURAL E VALIDAÇÃO}

Esta etapa do estudo foi realizada no período compreendido entre fevereiro e agosto de 2013.

Não houve divergências significativas entre a primeira tradução e a retrotradução, apesar das diferenças gramaticais e culturais entre as populações brasileira e inglesa. A primeira tradução do PCI para o Português-Brasil foi aplicada em 20 pacientes portadores de $\mathrm{CA} / \mathrm{CP}$ (piloto 1), evidenciando que o significado dos termos muco, deglutição, olfato, paladar, gastrostomia percutânea (PEG), medo de eventos adversos e estratégias de enfrentamento não foram compreendidos por alguns dos pacientes. Os termos assistência em casa/programa de saúde da família, originalmente descritos como "home care/ district nurse" foram erroneamente interpretados como qualquer familiar ou pessoa para ajudar/convênio médico. Já o termo atividade foi interpretado de diferentes maneiras pelos pacientes, ora sendo entendido como exercícios físicos ora como atividades da vida diária. Ainda, os pacientes se confundiram com os termos salivação e boca seca, não conseguindo diferenciá-los.

Dentre os profissionais listados na versão original, as profissões de higienista dental e capelão não foram aqui identificadas pelos pacientes, assim como o terapeuta de suporte emocional (especialidade clínica com grau inferior ao de psicólogo existente no Reino Unido - UK). 
Após a adequação das equivalência e adaptações para a população brasileira, realizou-se então uma nova versão em português, substituindo-se ou completando-se os termos não compreendidos, mal interpretados ou indiferenciados, respectivamente, por catarro/secreção, engolir, olfato (sentir cheiro), paladar (sentir sabor), sonda para alimentação, medo de acontecimentos desfavoráveis, estratégias para enfrentar a doença e o tratamento, atendimento de profissionais em domicílio, atividade física e muita salivação. Optou-se por substituir a expressão gastrostomia percutânea $(P E G)$ por sonda para alimentação (termo mais generalista), tendo em vista que a grande maioria dos pacientes oncológicos no Brasil faz uso de sonda nasoenteral (SNE).

A especialidade de higienista dental foi retirada e as outras profissões foram substituídas por autoridade religiosa/líder de sua religião, psicólogo e se acrescentando a especialidade de psiquiatra.

A versão pré-final, com as alterações realizadas, foi novamente aplicada em outros 25 pacientes (piloto 2), chegando-se à versão final do instrumento.

Oitenta e quatro pacientes foram, então, recrutados para responder à versão definitiva do IPP.

As Figuras 1 e 2 descrevem, respectivamente, as modificações realizadas durante o processo de tradução e adaptação transcultural do IPP. 


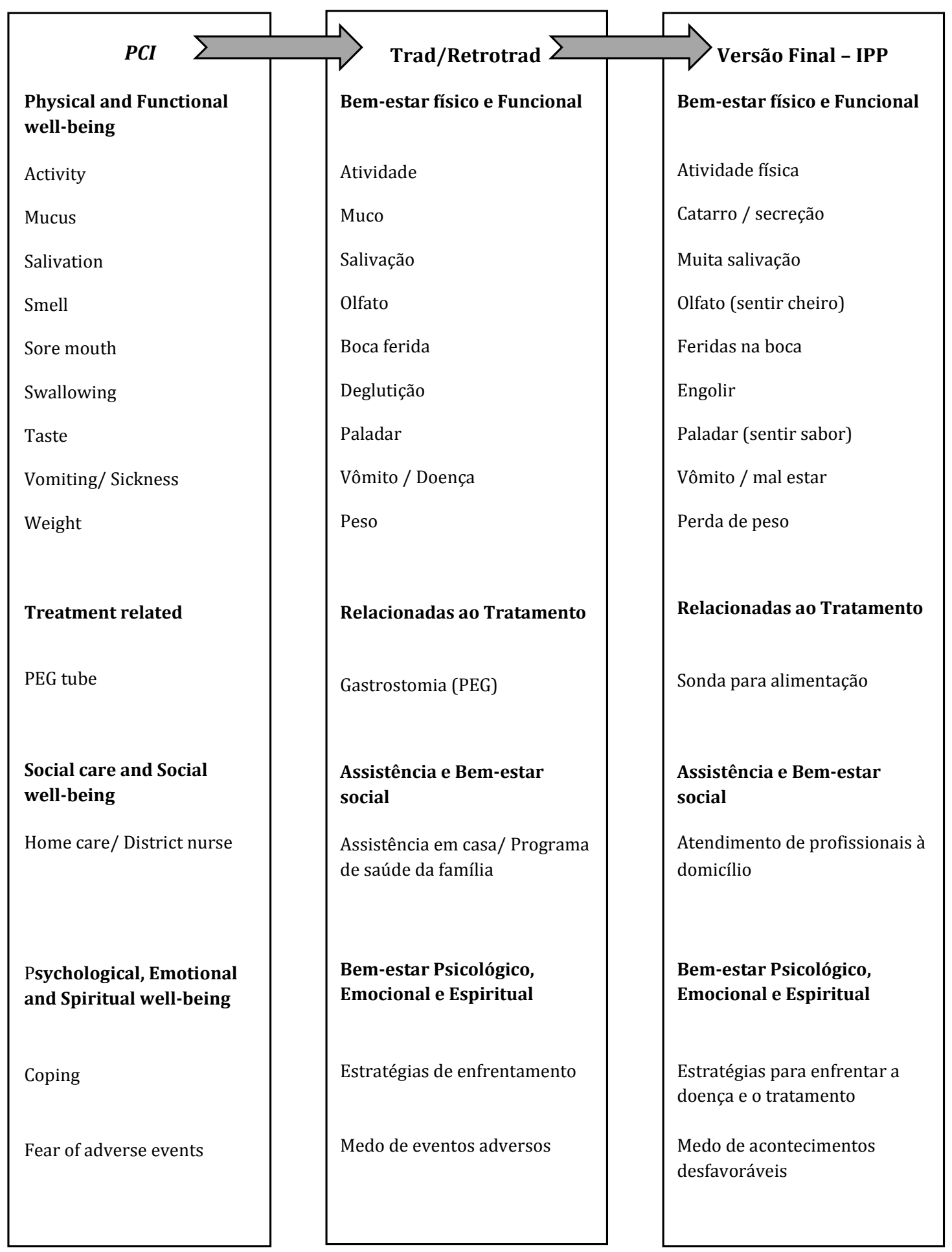

PCI: Patients Concerns Inventory; Trad /Retrotrad: Tradução - Retrotradução; IPP- Inventário de Preocupações dos Pacientes

Figura 1 Descrição das alterações realizadas nos itens descritos na parte 1 do PCI, durante o processo de tradução e adaptação transcultural para o Português-Brasil 


\begin{tabular}{|c|c|c|}
\hline PCI & Trad/Retrotrad $/$ & Versão Final - IPP \\
\hline $\begin{array}{l}\text { Physical and Functional } \\
\text { well-being }\end{array}$ & Bem-estar físico e Funcional & $\begin{array}{l}\text { Bem-estar físico e } \\
\text { Funcional }\end{array}$ \\
\hline Dental Hygienist ${ }^{1}$ & Higienista dental & \\
\hline $\begin{array}{l}\text { Psychological, } \\
\text { Emotional and Spiritual } \\
\text { well-being }\end{array}$ & $\begin{array}{l}\text { Bem-estar Psicológico, } \\
\text { Emocional e Espiritual }\end{array}$ & $\begin{array}{l}\text { Bem-estar Psicológico, } \\
\text { Emocional e Espiritual }\end{array}$ \\
\hline Chaplain & Líder religioso & $\begin{array}{l}\text { Autoridade religiosa / Líder } \\
\text { da sua religião }\end{array}$ \\
\hline $\begin{array}{l}\text { Emotional support } \\
\text { therapist }^{2}\end{array}$ & $\begin{array}{l}\text { Terapeuta de suporte } \\
\text { emocional }\end{array}$ & Psicólogo \\
\hline Clinical Psychologist ${ }^{3}$ & Psicólogo & Psiquiatra \\
\hline
\end{tabular}

PCI: Patients Concerns Inventory; Trad/Retrotrad: Tradução - Retrotradução; IPP: Inventário de Preocupações dos Pacientes

${ }^{1}$ Especialidade não identificadas pelos pacientes

${ }^{2}$ Especialidade clínica existente na Reino Unido (UK), com grau inferior ao de psicólogo

${ }^{3}$ Substituído por psiquistra

Figura 2 Descrição das alterações realizadas na lista de especialistas descrita na Parte 2 do $P C I$ durante o processo de tradução e adaptação transcultural para o Português- Brasil

\subsection{CARACTERÍSTICAS DA AMOSTRA}

Dentre os oitenta e quatro pacientes que participaram da etapa de validação do IPP, a maioria era do sexo masculino $(73,8 \%, \mathrm{n}=62)$ e idades variando entre 36 a 89 anos (média de 62 anos). As características sócio-demográficas da amostra estão descritas na Tabela 1. 
Tabela 1 Número e porcentagem de pacientes participantes do processo de validação do IPP, segundo dados demográficos e estilo de vida $(\mathrm{N}=84)$

\begin{tabular}{|c|c|c|c|}
\hline Variável & Categoria & $\mathbf{n}$ & $(\%)$ \\
\hline \multirow{2}{*}{ Sexo } & masculino & 62 & $(73,8)$ \\
\hline & feminino & 22 & $(26,2)$ \\
\hline \multirow{3}{*}{ Idade } & mín-máx & $36-89$ & \\
\hline & mediana & 61 & \\
\hline & média $\pm \mathrm{dp}$ & $62 \pm 11$ & \\
\hline \multirow{4}{*}{ Estado Civil } & solteiro & 6 & $(7,1)$ \\
\hline & casado & 60 & $(71,4)$ \\
\hline & viúvo & 8 & $(9,5)$ \\
\hline & divorciado & 10 & $(12,0)$ \\
\hline \multirow{7}{*}{ Escolaridade } & analfabeto & 3 & $(3,6)$ \\
\hline & ensino fundamental I incompleto & 48 & $(57,1)$ \\
\hline & ensino fundamental I completo & 8 & $(9,5)$ \\
\hline & ensino fundamental II incompleto & 3 & $(3,6)$ \\
\hline & ensino fundamental II completo & 13 & $(15,5)$ \\
\hline & superior incompleto & 1 & $(1,2)$ \\
\hline & superior completo & 8 & $(9,5)$ \\
\hline \multirow{2}{*}{ Trabalha atualmente } & $\operatorname{sim}$ & 62 & $(73,8)$ \\
\hline & não & 22 & $(26,2)$ \\
\hline \multirow{3}{*}{ Tabagismo } & nunca & 23 & $(27,4)$ \\
\hline & parou & 56 & $(66,7)$ \\
\hline & mantém o vício & 5 & $(5,9)$ \\
\hline \multirow{3}{*}{ Etilismo } & nunca & 26 & $(31,0)$ \\
\hline & parou & 48 & $(57,1)$ \\
\hline & mantém o vício & 10 & $(11,9)$ \\
\hline \multirow{6}{*}{ Religião } & ateu & 3 & $(3,6)$ \\
\hline & católico & 64 & $(76,1)$ \\
\hline & evangélica & 8 & $(9,5)$ \\
\hline & protestante & 4 & $(4,8)$ \\
\hline & budista & 2 & $(2,4)$ \\
\hline & outros & 3 & $(3,6)$ \\
\hline
\end{tabular}

mín-máx: mínimo-máximo; dp: desvio padrão 
No momento do preenchimento dos questionários propostos $33,0 \%(\mathrm{n}=25)$ dos pacientes tinham sido diagnosticados há menos de 12 meses, 25,0\% ( $n=22)$ estavam entre 12 e 36 meses pós-diagnóstico e 41,0\% (n=37) tinham sido diagnosticados há 36 meses ou mais. O sítio tumoral e estadiamento prevalentes foram, respectivamente, cavidade oral $(41.6 \%, n=35)$ e $\mathrm{T} 4(29.7 \%, \mathrm{n}=25)$. Metade da amostra era clinicamente negativa para comprometimento linfonodal $(50,0 \%, n=42)$ e a maioria era clinicamente negativa para metástase à distância $(96.4 \%, n=81) .0$ tipo histológico prevalente foi o CEC $(90,4 \%, n=76)$.

A Tabela 2 descreve as características dos pacientes, de acordo com a classificação TNM, proposta pela UICC (2010), local da lesão e tipo histológico. 
Tabela 2 Número e porcentagem de pacientes participantes do processo de validação do IPP, de acordo com classificação TNM (UICC), local da lesão e tipo histológico $(\mathrm{N}=84)$

\begin{tabular}{|c|c|c|c|}
\hline Variável & Categoria & $\mathbf{n}$ & $(\%)$ \\
\hline \multirow{5}{*}{$\mathbf{T}$} & T1 & 15 & $(17,9)$ \\
\hline & $\mathrm{T} 2$ & 23 & $(27,4)$ \\
\hline & $\mathrm{T} 3$ & 19 & $(22,6)$ \\
\hline & $\mathrm{T} 4$ & 25 & $(29,7)$ \\
\hline & $\mathrm{Tx}$ & 2 & $(2,4)$ \\
\hline \multirow{5}{*}{$\mathbf{N}$} & No & 42 & $(50,0)$ \\
\hline & N1 & 17 & $(20,2)$ \\
\hline & $\mathrm{N} 2$ & 22 & $(26,2)$ \\
\hline & N3 & 2 & $(2,4)$ \\
\hline & Nx & 1 & $(1,2)$ \\
\hline \multirow[b]{2}{*}{$\mathbf{M}$} & M0 & 81 & $(96,4)$ \\
\hline & M1 & 3 & $(3,6)$ \\
\hline \multirow{10}{*}{ Sítio da Lesão } & cavidade oral & 35 & $(41,6)$ \\
\hline & orofaringe & 19 & $(22,6)$ \\
\hline & hipofaringe & 1 & $(1,2)$ \\
\hline & laringe & 22 & $(26,2)$ \\
\hline & nasofaringe & 5 & $(6,0)$ \\
\hline & fossas nasais / seios maxilares & 2 & $(2,4)$ \\
\hline & $\mathrm{CEC}$ & 76 & $(90,4)$ \\
\hline & $\mathrm{CA}$ indiferenciado & 2 & $(2,4)$ \\
\hline & adenocarcinoma & 3 & $(3,6)$ \\
\hline & outros & 3 & $(3,6)$ \\
\hline
\end{tabular}

IPP: Inventário de Preocupações dos Pacientes; UICC: União Internacional Contra o Câncer; T: extensão da neoplasia no sítio primário e envolvimento de estruturas adjacentes; N: linfonodos regionais: M: metástases à distância; CA: carcinoma: câncer; $\mathrm{CEC}$ : Carcinoma espinocelular. 
À época do preenchimento dos questionários, $56(66,7 \%), 9(10,7 \%)$ e 47 $(56,0 \%)$ pacientes haviam utilizado, respectivamente, sonda nasoenteral (SNE), gastrostomia percutânea $(P E G)$ e traqueostomia (TQT) em algum momento do tratamento. As características do tratamento e a situação clínica dos pacientes no momento da avaliação estão descritas na Tabela 3.

Tabela 3 Número e porcentagem de pacientes participantes do processo de validação do IPP, de acordo com o tipo de tratamento e situação clínica $(\mathrm{N}=84)$

\begin{tabular}{|c|c|c|c|}
\hline Variável & Categoria & $\mathbf{n}$ & (\%) \\
\hline \multirow{2}{*}{ Cirurgia } & não & 21 & $(25,0)$ \\
\hline & $\operatorname{sim}$ & 63 & $(75,0)$ \\
\hline \multirow{3}{*}{ Esvaziamento Cervical } & não & 33 & $(39,3)$ \\
\hline & ipsilateral & 30 & $(35,7)$ \\
\hline & bilateral & 21 & $(25,0)$ \\
\hline \multirow{2}{*}{ Radioterapia } & não & 16 & $(19,0)$ \\
\hline & $\operatorname{sim}$ & 68 & $(81,0)$ \\
\hline \multirow{2}{*}{ Quimioterapia } & não & 49 & $(58,0)$ \\
\hline & $\operatorname{sim}$ & 35 & $(42,0)$ \\
\hline \multirow{4}{*}{ Alimentação Atual } & VO exclusiva & 67 & $(79,8)$ \\
\hline & VO mista & 5 & $(5,9)$ \\
\hline & SNE & 8 & $(9,5)$ \\
\hline & $P E G$ & 4 & $(4,8)$ \\
\hline \multirow{5}{*}{ Comunicação } & voz laríngea & 72 & $(85,7)$ \\
\hline & $\mathrm{VE}$ & 3 & $(3,6)$ \\
\hline & VTE & 6 & $(7,1)$ \\
\hline & vibrador & 1 & $(1,2)$ \\
\hline & outros (gráfica/gestual) & 2 & $(2,4)$ \\
\hline \multirow[t]{2}{*}{ Doença em atividade } & não & 72 & $(85,7)$ \\
\hline & $\operatorname{sim}$ & 12 & $(14,3)$ \\
\hline
\end{tabular}

IPP: Inventário de Preocupações dos Pacientes; VO: via oral; SNE: sonda nasoenteral: PEG: gastrostomia percutânea; VE: voz esofágica; VTE: voz traqueoesofágica. 


\subsection{RESULTADOS DO UW-QOL}

A média (desvio padrão) do escore global dos doze domínios do UW-QOL foi $73(\mathrm{dp}=20)$. Levando-se em conta o domínio físico, a média do escore foi $78(\mathrm{dp}=$ 21) e para o domínio sócio-emocional $67(\mathrm{dp}=24)$. Houve correlação significante entre o escore global do UW-QOL e os domínios físico e sócio-emocional, respectivamente 0.85 e $0.92($ ambos $\mathrm{p}<0.001)$.

\subsection{RESULTADOS DO IPP}

O tempo para o preenchimento do IPP variou entre 6 e 20 minutos (média 13 minutos). A maioria dos participantes considerou que o IPP é fácil de ser preenchido, extremamente importante e eficiente para a sinalização de suas preocupações, conforme comentário informal feito pela maioria dos pacientes. A frequência das preocupações e dos profissionais assinalados no IPP estão descritos, respectivamente, nas Figuras 3 e 4.

Dentre os 56 itens presentes na Parte 1 do IPP, as preocupações assinaladas com maior frequência pelos pacientes foram: medo do câncer voltar $(57,5 \%, n=48)$, boca seca $(45,4 \%, n=38)$, mastigar/comer $(44,4 \%, n=37)$, fala/voz/ser entendido (43,4\%, $n=36)$, engolir $(40,3 \%, n=34)$, saúde dental/dentes $(36,3 \%, n=30)$, ansiedade $(31,3 \%, \mathrm{n}=26)$, fadiga/cansaço, paladar (sentir sabor) e medo de acontecimentos desfavoráveis (todos $30,3 \%, \mathrm{n}=25$ ). 
Figura 3 Frequência relativa das preocupações selecionadas pelos pacientes no Inventário de Preocupações dos Pacientes - IPP durante o processo de validação $(\mathrm{N}=84)$ 
Os três profissionais mais assinalados pelos pacientes foram o fonoaudiólogo $(26,1 \%, n=22)$, dentista $(23,8 \%, n=20)$ e psicólogo $(18,0 \%, n=15)$.

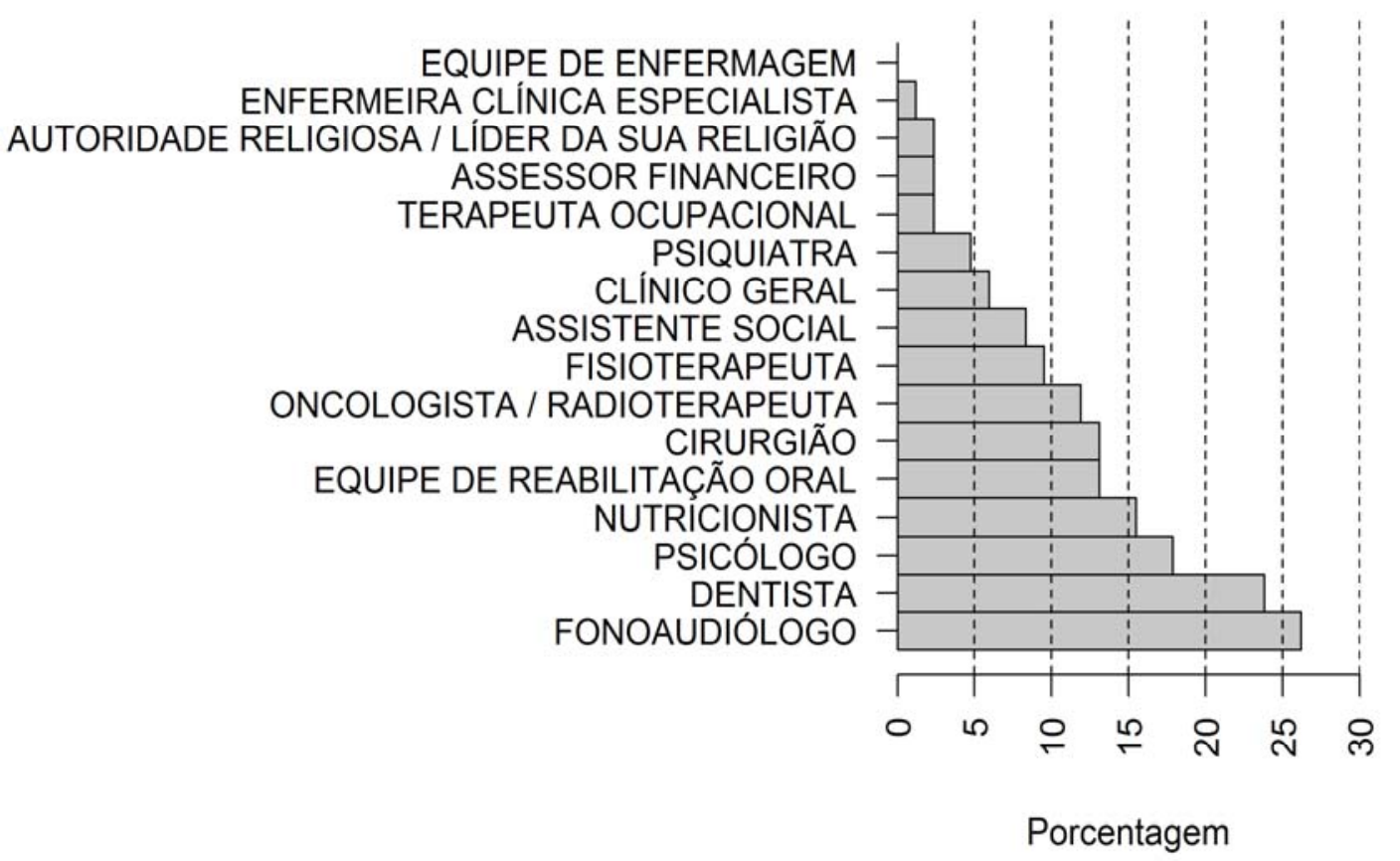

Figura 4 Frequência relativa dos profissionais selecionados pelos pacientes no Inventário de Preocupações dos Pacientes - IPP durante o processo de validação $(\mathrm{N}=84)$

A mediana (Q1-Q3) do número de preocupações selecionadas foi 8 (5-13), variando entre 0 e 42 assuntos, com 75 pacientes (63,0\%) selecionando pelo menos 1 assunto. A mediana (Q1-Q3) do número de profissionais assinalados foi $1(0-2)$, variando entre 0 e 8 profissionais, com 30 pacientes $(36,0 \%)$ assinalando pelo menos 1 profissional. 


\subsection{CORRELAÇÕES ENTRE OS RESULTADOS DO UW-QOL E DO IPP}

Foram encontradas correlações estatísticas negativas fracas entre o número de preocupações e o número de profissionais selecionados pelos pacientes com o tempo de diagnóstico $(-0.29, \mathrm{p}=0.007 \mathrm{e}-0.28, \mathrm{p}=0.01)$, sendo que indivíduos com menor tempo de diagnóstico selecionaram mais itens.

A idade dos pacientes apresentou correlação estatística negativa fraca com o número de profissionais selecionados $(-0.28, \mathrm{p}=0.009)$, sendo que indivíduos mais jovens selecionaram um maior número de especialistas.

Os domínios físico e sócio-emocional do $U W-Q O L$ apresentaram correlações estatísticas negativas moderadas com o número de preocupações selecionadas $(-0.46$ e -0.45 , ambos $\mathrm{p}<0.001)$ e com o número de profissionais selecionados $(-0.46$, $\mathrm{p}<0.001$ e $0.33, \mathrm{p}=0.002$ ). Quanto piores foram os escores compostos do $U W-Q O L$, mais itens foram selecionados no IPP.

As correlações estatísticas significantes entre as características dos pacientes, os domínios físico e sócio-emocional do $U W$-QOL e o número de preocupações e de profissionais selecionados estão descritas na Tabela 4 . 
Tabela 4 Número de preocupações e profissionais selecionados no teste com IPP, de acordo com as características dos pacientes e escores compostos do $U W-Q O L(\mathrm{~N}=84)$

\begin{tabular}{|c|c|c|c|c|c|c|c|c|c|c|}
\hline \multirow{3}{*}{ Variável } & \multirow{3}{*}{ Categoria } & \multirow{3}{*}{$\mathbf{n}$} & \multicolumn{4}{|c|}{ Número de itens marcados } & \multicolumn{4}{|c|}{ Número de profissionais marcados } \\
\hline & & & \multirow[b]{2}{*}{ Mediana } & \multirow[b]{2}{*}{ Q1-Q3 } & \multicolumn{2}{|c|}{$5+$ itens } & \multirow[b]{2}{*}{ Mediana } & \multirow[b]{2}{*}{ Q1-Q3 } & \multicolumn{2}{|c|}{$2+$ profissionais } \\
\hline & & & & & $\%$ & $\mathbf{n}$ & & & $\%$ & $\mathbf{n}$ \\
\hline \multirow{3}{*}{ Idade $^{*}$} & $<55$ & 20 & 9 & $5-12$ & 80,0 & 16 & 2 & $0-4$ & 60,0 & 12 \\
\hline & $55-64$ & 27 & 7 & $4-12$ & 67,0 & 18 & 1 & $0-3$ & 37,0 & 10 \\
\hline & $>=65$ & 37 & 9 & $5-14$ & 78,0 & 29 & 0 & $0-1$ & 22,0 & 8 \\
\hline \multirow{3}{*}{ Sexo } & masculino & 62 & 8 & $5-13$ & 76,0 & 47 & 0 & $0-2$ & 31,0 & 19 \\
\hline & feminino & 22 & 10 & $4-15$ & 73,0 & 16 & 1,5 & $1-4$ & 50,0 & 11 \\
\hline & cavidade oral & 35 & 8 & $4-13$ & 71,0 & 25 & 1 & $0-3$ & 31,0 & 11 \\
\hline \multirow{4}{*}{ Sítio } & orofaringe & 19 & 9 & $5-15$ & 79,0 & 15 & 1 & $0-3$ & 47,0 & 9 \\
\hline & laringe & 20 & 8 & $5-10$ & 75,0 & 15 & 0 & $0-2$ & 30,0 & 6 \\
\hline & outros & 10 & 10 & $7-13$ & 80,0 & 8 & 1 & $0-2$ & 40,0 & 4 \\
\hline & $<12$ & 25 & 13 & $7-15$ & 84,0 & 21 & 2 & $0-4$ & 60,0 & 15 \\
\hline \multirow[t]{2}{*}{ Tempo de diagnóstico ${ }^{+}$} & $12-36$ & 22 & 9 & $4-12$ & 73,0 & 16 & 0,5 & $0-2$ & 36,0 & 8 \\
\hline & $>=36$ & 37 & 7 & $4-11$ & 70,0 & 26 & 0 & $0-1$ & 19,0 & 7 \\
\hline \multirow{2}{*}{$\mathbf{T}$} & 1_2 & 38 & 7,5 & $4-12$ & 66,0 & 25 & 1 & $0-2$ & 37,0 & 14 \\
\hline & $3 \_4$ & 44 & 8,5 & $6-14$ & 82,0 & 36 & 0,5 & $0-3$ & 34,0 & 15 \\
\hline \multirow{2}{*}{$\mathbf{N}$} & $0 \_1$ & 59 & 7 & $4-12$ & 69,0 & 41 & 0 & $0-2$ & 27,0 & 16 \\
\hline & $2 \_3$ & 24 & 11 & $8-15$ & 88,0 & 21 & 2 & $0-3$ & 54,0 & 13 \\
\hline \multirow{2}{*}{ Reconstrução } & nã̃o & 38 & 8,5 & $4-12$ & 68,0 & 26 & 1 & $0-2$ & 34,0 & 13 \\
\hline & $\operatorname{sim}$ & 46 & 8 & $5-14$ & 80,0 & 37 & 1 & $0-3$ & 37,0 & 17 \\
\hline \multirow{3}{*}{ RDT } & não & 16 & 8,5 & $4-16$ & 63,0 & 10 & 1 & $0-2$ & 38,0 & 6 \\
\hline & $\operatorname{sim}$ & 68 & 8 & $5-13$ & 78,0 & 53 & 1 & $0-2$ & 35,0 & 24 \\
\hline & cirurgia sem RDT & 21 & 10 & $4-17$ & 67,0 & 14 & 1 & $0-3$ & 48,0 & 10 \\
\hline \multirow[t]{3}{*}{ Tratamento } & cirurgia com RDT & 34 & 7 & $5-11$ & 76,0 & 26 & 0 & $0-1$ & 21,0 & 7 \\
\hline & RDT primária & 29 & 9 & $6-13$ & 79,0 & 23 & 1 & $0-3$ & 45,0 & 13 \\
\hline & $<50$ & 9 & 9 & $8-16$ & 100,0 & 9 & 3 & $2-4$ & 89,0 & 8 \\
\hline \multirow{3}{*}{ UW-QOL Físico ${ }^{++* *}$} & $50-74$ & 19 & 12 & $9-16$ & 84,0 & 16 & 1 & $0-5$ & 47,0 & 9 \\
\hline & $75-89$ & 26 & 9 & $4-13$ & 73,0 & 19 & 1 & $0-2$ & 38,0 & 10 \\
\hline & $90+$ & 30 & 6 & $3-9$ & 63,0 & 19 & 0 & $0-1$ & 10,0 & 3 \\
\hline \multirow{4}{*}{$U W-Q O L$ Emocional $^{++*}$} & $<50$ & 20 & 12 & $8-15$ & 90,0 & 18 & 1,5 & $0-4$ & 50,0 & 10 \\
\hline & $50-74$ & 27 & 9 & $6-14$ & 85,0 & 23 & 1 & $0-3$ & 48,0 & 13 \\
\hline & $75-89$ & 20 & 6 & $4-10$ & 70,0 & 14 & 0 & $0-1$ & 20,0 & 4 \\
\hline & $90+$ & 17 & 4 & $2-8$ & 47,0 & 8 & 0 & $0-1$ & 18,0 & 3 \\
\hline
\end{tabular}

Q1-Q3: Primeiro e terceiro quartis; T: extensão da neoplasia no sítio primário e envolvimento de estruturas adjacentes; $\mathrm{N}$ : linfonodos regionais; RDT: radioterapia. NOTA: ${ }^{+} 0.001<=$ p $<0.01$ - significância da correlação de Spearman com número de preocupações; *0.001<=p $<0.01$ - significância da correlação de Spearman com número de profissionais; .001 - significância da correlação de Spearman com número de preocupações; ** $<0.001$ - significância da correlação de Spearman com número de profissionais. Nenhuma outra característica dos pacientes associou-se, ao nível de significância de 0.01 , com o número de preocupações ou com o número de profissionais. Teste não paramétrico de Mann-Whitney (Sexo, T, N, Reconstrução, RT, Cirurgia) ou teste não paramétrico de Kruskal-Wallis (Sítio, Tratamento) 
Os pacientes com menos de 55 anos selecionaram mais frequentemente os ítens saúde dental $(50,0 \%, n=10 / 20)$ e medo do câncer voltar $(75,0 \%, n=15 / 20)$. Sono e ansiedade foram mais assinalados, respectivamente, por $36,0 \%(\mathrm{n}=8 / 22)$ e $55,0 \%$ $(n=12 / 22)$ dos pacientes do sexo feminino, ou seja, mais do que o dobro da porcentagem de pacientes do sexo masculino. Pacientes tratados há doze meses ou menos assinalaram consideravelmente mais itens do que os pacientes com maior tempo após o diagnóstico, assinalando como assuntos mais preocupantes o apetite $(40,0 \%, n=10 / 25)$, tratamento do câncer $(48,0 \%, n=12 / 25)$, uso de sonda para alimentação $(32,0 \%, n=8 / 25)$, cicatrização de feridas e suporte para a família $(16,0 \%$, $\mathrm{n}=4 / 25)$ e indicando o nutricionista $(28,0 \%, \mathrm{n}=7 / 25)$ e o fonoaudiólogo $(52,0 \%$, $n=13 / 25$ ) como os profissionais com os quais mais gostariam de conversar. As preocupações com o apetite $(42,0 \%, n=10 / 24)$ e a aparência $(46,0 \%, n=11 / 24)$ foram quase três vezes mais selecionadas por pacientes clinicamente positivos para comprometimento linfonodal N2-N3 do que pelos pacientes N0-N1. Indivíduos submetidos à reconstrução $(22,0 \%, \mathrm{n}=10 / 46)$ indicaram muita salivação, ao contrário dos que não realizaram a mesma. $\mathrm{O}$ item boca seca foi indicado por $34,0 \%(n=16 / 46)$ dos pacientes que realizaram radioterapia e por $81,0 \%(n=17 / 21)$ dos que não realizaram cirurgia. Ainda, 66,0\% $(\mathrm{n}=19 / 29)$ dos pacientes que realizaram radioterapia (RT) primária assinalaram mais boca seca e aqueles que foram submetidos à cirurgia sem RT selecionaram mais os itens muita salivação e depressão (ambos 33,0\%, $\mathrm{n}=7 / 21$ ), estratégias para enfrentar a doença e o tratamento $(24,0 \%, \mathrm{n}=5 / 21)$ e humor $(29,0 \%, \mathrm{n}=6 / 21)$.

O escore do domínio físico teve associação significante com a seleção dos itens apetite, abertura de boca, dor na cabeça e pescoço, engolir, inchaço, recreação, relacionamentos, fala/voz/ser entendido e medo de acontecimentos desfavoráveis e, 
na indicação do dentista, fonoaudiólogo e oncologista/radioterapeuta. O escore do domínio sócio-emocional associou-se significantemente com os itens apetite, mastigar/comer, abertura de boca, engolir, paladar, sonda para alimentação, fala/voz/ser entendido, memória e com a indicação do fonoaudiólogo e do oncologista/radioterapeuta, especialmente para pacientes com escores compostos do $U W-Q O L$ mais baixos $(<50)$. Estes resultados demostram que ambos os domínios foram preditivos de diversas preocupações relacionadas à função oral.

Novas preocupações que não estão presentes no instrumento original foram sugeridas nos textos livres presentes no IPP: cônjuge (duas vezes), refluxo gastroesofágico, seguimento durante e após o tratamento, queda de cabelo, engasgos, demência, qualidade de vida, transporte para o hospital (deslocamento/custo), encaminhamento do médico para realização de fonoterapia em outra cidade, convênio médico, depender de outros para agilizar a vida em geral, diabetes, tratamentos alternativos, ardor na língua e sensação de sufocamento.

Os novos profissionais sugeridos foram geriatra, professor de educação física especialista em oncologia, otorrinolaringologista, neurologista, acupunturista, hematologista, médico vascular, dermatologista (quatro vezes), gastroenterologista, nefrologista, oftalmologista e ortopedista.

As associações significantes entre as características dos pacientes com as preocupações e profissionais específicos selecionados no IPP e com os domínios físico e sócio-emocional do $U W-Q O L$ estão descritas na Tabela 5. 
Tabela 5 Associações entre as características dos pacientes, domínios do UW-QOL com as preocupações e profissionais selecionados no teste com IPP $(\mathrm{N}=84)$

\begin{tabular}{|c|c|c|c|c|c|}
\hline & Categoria & \multirow[t]{2}{*}{ Item ou profissional selecionado } & \multicolumn{3}{|c|}{$\begin{array}{c}\text { Resultados para ilustrar a associação entre as características } \\
\text { com um item específico ou profissional selecionado }\end{array}$} \\
\hline \multirow{2}{*}{ Idade* } & anos & & $<55: 50,0 \%, 10 / 20$ & $55-64: 48,0 \%, 13 / 27$ & $>=65: 19,0 \%, 7 / 37$ \\
\hline & & Medo do câncer voltar & $<55: 75,0 \%, 15 / 20$ & $55-64: 67,0 \%, 18 / 27$ & $>=65: 41,0 \%, 15 / 37$ \\
\hline \multirow{2}{*}{ Sexo } & masculino, feminino & Sono & M: $11,0 \%, 7 / 62$ & $\mathrm{~F}: 36,0 \%, 8 / 22$ & \\
\hline & & Ansiedade & M: $23,0 \%, 14 / 62$ & F: $55,0 \%, 12 / 22$ & \\
\hline \multirow[t]{3}{*}{ Sítio Tumoral** } & cavidade oral, orofaringe, faringe, outros & - & & & \\
\hline & meses & Apetite & $<12 \mathrm{~m}: 40,0 \%, 10 / 25$ & $12-36 \mathrm{~m}: 23,0 \%, 5 / 22$ & $36+\mathrm{m}: 11,0 \%, 4 / 37$ \\
\hline & & Tratamento do câncer & $<12 \mathrm{~m}: 48,0 \%, 12 / 25$ & $12-36 \mathrm{~m}: 32,0 \%, 7 / 22$ & $36+\mathrm{m}: 14,0 \%, 5 / 37$ \\
\hline \multirow{5}{*}{$\begin{array}{l}\text { Tempo de } \\
\text { Diagnóstico* }\end{array}$} & & Sonda para alimentação & $<12 \mathrm{~m}: 32,0 \%, 8 / 25$ & $12-35 \mathrm{~m}: 9,0 \%, 2 / 22$ & $36+\mathrm{m}: 3,0 \%, 1 / 37$ \\
\hline & & Cicatrização de feridas & $<12 \mathrm{~m}: 16,0 \%, 4 / 25$ & $12-35 \mathrm{~m}: 0,0 \%, 0 / 22$ & $36+\mathrm{m}: 0,0 \%, 0 / 37$ \\
\hline & & Suporte para minha família & $<12 \mathrm{~m}: 16,0 \%, 4 / 25$ & $12-35 \mathrm{~m}: 0,0 \%, 0 / 22$ & $36+\mathrm{m}: 0,0 \%, 0 / 37$ \\
\hline & & Nutricionista & $<12 \mathrm{~m}: 28,0 \%, 7 / 25$ & $12-35 \mathrm{~m}: 18,0 \%, 4 / 22$ & $36+\mathrm{m}: 5,0 \%, 2 / 37$ \\
\hline & & Fonoaudiólogo $^{++}$ & $<12 \mathrm{~m}: 52,0 \%, 13 / 25$ & $12-35 \mathrm{~m}: 23,0 \%, 5 / 22$ & $36+\mathrm{m}: 11,0 \%, 4 / 37$ \\
\hline $\mathbf{T}$ & $\mathrm{T} 1-2, \mathrm{~T} 3-4$ & - & & & \\
\hline \multirow{2}{*}{$\mathbf{N}$} & N0-1, N2-3 & Apetite & N0-1: $15,0 \%, 9 / 59$ & $\mathrm{~N} 1-2: 42,0 \%, 10 / 24$ & \\
\hline & & Aparência & N0-1: $14,0 \%, 8 / 59$ & N1-2: $46,0 \%, 11 / 24$ & \\
\hline Reconstrução & sim, não & Muita salivação & não: $3,0 \%, 1 / 38$ & sim: $22,0 \%, 10 / 46$ & \\
\hline RDT & sim, não & Boca seca $^{++}$ & não: $58,0 \%, 22 / 38$ & sim: $34,0 \%, 16 / 46$ & \\
\hline \multirow[t]{3}{*}{ Cirurgia } & sim, não & Boca seca $^{++}$ & não: $81,0 \%, 17 / 21$ & sim: $33,0 \%, 21 / 63$ & \\
\hline & RDT primária, $\mathrm{CX}+\mathrm{RDT}$, $\mathrm{CX}$ sem $\mathrm{RDT}$ & Boca seca & RDT primária: $66,0 \%$, & CX+RDT: $44,0 \%$ & CX sem RDT: 19,0\%, \\
\hline & & Muita salivação & RDT primária: $10,0 \%, 3 / 29$ & CX +RDT: $3,0 \%, 1 / 34$ & CX sem RDT: $33,0 \%$, \\
\hline \multirow[t]{3}{*}{ Tratamento** } & & Estratégias para enfrentar a doença e o tto. & RDT primária: 7,0\%, $2 / 29$ & CX+RDT: $0,0 \%, 0 / 34$ & CX sem RDT: $24,0 \%$, \\
\hline & & Depressão & RDT primária: $3,0 \%, 1 / 29$ & CX +RDT: $6,0 \%, 2 / 34$ & CX sem RDT: $33,0 \%$, \\
\hline & & Humor & RDT primária: 7,0\%, 2/29 & $\mathrm{CX}+\mathrm{RDT}: 3,0 \%, 1 / 34$ & $\begin{array}{r}\text { CX sem RDT: } 29,0 \%, \\
\text { Continua }\end{array}$ \\
\hline
\end{tabular}




\section{Continuação}

Tabela 5 Associações entre as características dos pacientes, domínios do UW-QOL com as preocupações e profissionais selecionados no teste com IPP $(\mathrm{N}=84)$

\begin{tabular}{|c|c|c|c|c|c|c|}
\hline & \multirow[t]{2}{*}{ Categoria } & \multirow{2}{*}{$\begin{array}{l}\text { Item ou profissional selecionado } \\
\text { Apetite }\end{array}$} & \multicolumn{4}{|c|}{$\begin{array}{c}\text { Resultados para ilustrar a associação entre as características } \\
\text { com um item ou profissional selecionado }\end{array}$} \\
\hline \multirow{11}{*}{ UW-QOL Físico* } & & & $<50: 56,0 \%, 5 / 9$ & $50-74: 26,0 \%, 5 / 19$ & $75-89: 27,0 \%, 7 / 26$ & $90+: 7,0 \%, 2 / 30$ \\
\hline & \multirow{9}{*}{ escala $0-100$} & Abertura de Boca & $<50: 44,0 \%, 4 / 9$ & $50-74: 21,0 \%, 4 / 19$ & $75-89: 35,0 \%, 9 / 26$ & $90+: 7,0 \%, 2 / 30$ \\
\hline & & Dor em cabeça e pescoço & $<50: 33,0 \%, 3 / 9$ & $50-74: 16,0 \%, 3 / 19$ & $75-89: 35,0 \%, 9 / 26$ & $90+: 0 / 30$ \\
\hline & & Engolir & $<50: 56,0 \%, 5 / 9$ & 50-74: $58,0 \%, 11 / 19$ & $75-89: 42,0 \%, 11 / 26$ & $90+: 23,0 \%, 7 / 30$ \\
\hline & & Inchaço & $<50: 33,0 \%, 3 / 9$ & 50-74: $16,0 \%, 3 / 19$ & $75-89: 8,0 \%, 2 / 26$ & $90+: 3,0 \%, 1 / 30$ \\
\hline & & Recreação & $<50: 44,0 \%, 4 / 9$ & 50-74: 5,0\%, 1/19 & $75-89: 8,0 \%, 2 / 26$ & $90+: 0 / 30$ \\
\hline & & Fala/voz/ser entendido ${ }^{++}$ & $<50: 67,0 \%, 6 / 9$ & 50-74: $58,0 \%, 11 / 19$ & $75-89: 46,0 \%, 12 / 26$ & $90+: 23,0 \%, 7 / 30$ \\
\hline & & Medo de acontecimentos desfavoráveis & $<50: 67,0 \%, 6 / 9$ & 50-74: $42,0 \%, 8 / 19$ & $75-89: 19,0 \%, 5 / 26$ & $90+: 20,0 \%, 6 / 30$ \\
\hline & & Dentista & $<50: 67,0 \%, 6 / 9$ & $50-74: 26,0 \%, 5 / 19$ & $75-89: 23,0 \%, 6 / 26$ & $90+: 10,0 \%, 3 / 30$ \\
\hline & & Fonoaudiólogo $^{++}$ & $<50: 78,0 \%, 7 / 9$ & $50-74: 26,0 \%, 5 / 19$ & $75-89: 27,0 \%, 7 / 26$ & $90+: 10,0 \%, 3 / 30$ \\
\hline & \multirow{10}{*}{ escala $0-100$} & 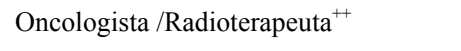 & $<50: 44,0 \%, 4 / 9$ & $50-74: 32,0 \%, 6 / 19$ & 75-89: 0/26 & $90+: 0 / 30$ \\
\hline \multirow{9}{*}{ UW-QOL Emocional* } & & Apetite & $<50: 45,0 \%, 9 / 20$ & $50: 74: 26,0 \%, 7 / 27$ & $75-89: 10,0 \%, 2 / 20$ & $90+: 6,0 \%, 1 / 17$ \\
\hline & & Mastigar/Comer ${ }^{++}$ & $<50: 75,0 \%, 15 / 20$ & $50-74: 56,0 \%, 15 / 27$ & $75-89: 20,0 \%, 4 / 20$ & $90+: 18,0 \%, 3 / 17$ \\
\hline & & Engolir $^{++}$ & $<50: 70,0 \%, 14 / 20$ & $50-74: 48,0 \%, 13 / 27$ & $75-89: 30,0 \%, 6 / 20$ & $90+: 6,0 \%, 1 / 17$ \\
\hline & & Paladar & $<50: 45,0 \%, 9 / 20$ & $50-74: 44,0 \%, 12 / 27$ & $75-89: 20,0 \%, 4 / 20$ & $90+: 0 / 17$ \\
\hline & & Sonda & $<50: 30,0 \%, 6 / 20$ & $50-74: 15,0 \%, 4 / 27$ & $75-89: 5,0 \%, 1 / 20$ & $90+: 0 / 17$ \\
\hline & & Fala/voz/ser entendido ${ }^{++}$ & $<50: 65,0 \%, 13 / 20$ & 50-74: $52,0 \%, 14 / 27$ & $75-89: 40,0 \%, 8 / 20$ & $90+: 6,0 \%, 1 / 17$ \\
\hline & & Mémória & $<50: 0 / 20$ & $50-74: 22,0 \%, 6 / 27$ & $75-89: 20,0 \%, 4 / 20$ & $90+: 6,0 \%, 1 / 17$ \\
\hline & & Fonoaudiólogo ${ }^{++}$ & $<50: 40,0 \%, 8 / 20$ & 50-74: 41,0\%, 11/27 & $75-89: 10,0 \%, 2 / 20$ & $90+: 6,0 \%, 1 / 17$ \\
\hline & & Oncologista/Radioterapeuta $^{++}$ & $<50: 30,0 \%, 6 / 20$ & 50-74: $41,0 \%, 11 / 27$ & $75-89: 5,0 \%, 1 / 20$ & $90+: 0 / 17$ \\
\hline
\end{tabular}

M: masculino; F: feminino; T: extensão da neoplasia no sítio primário e envolvimento de estruturas adjacentes; N: linfonodos regionais; RDT: radioterapia; CX: cirurgia; tto: tratamento

NOTA: *teste não paramétrico de Mann-Whitney; ${ }^{* *}$ teste Qui-Quadrado, caso contrário, teste exato de Fisher; ${ }^{++} \mathrm{p}<0.001$, caso contrário $0.001<\mathrm{p}<0.01$. A tabela mostra apenas as associações significantes $(\mathrm{p}<0,01)$ 


\section{RESULTADOS II}

Os resultados referentes aos 3 momentos do estudo serão apresentados de forma comparativa (quando possível).

\subsection{CARACTERÍSTICAS DAS AMOSTRAS AVALIADAS}

De acordo com a metodologia proposta, foram excluídos 24 pacientes aos 6 meses e 18 pacientes aos 12 meses, conforme descrito na Tabela 6 .

Tabela 6 Número e porcentagem de pacientes excluídos do estudo aos 6 meses $(\mathrm{N}=24)$ e 12 meses $(\mathrm{N}=18)$ após o diagnóstico, de acordo com o motivo da exclusão

\begin{tabular}{lcc}
\hline \multicolumn{1}{c}{ Motivo da Exclusão } & $\mathbf{6}$ meses (N=24) & $\mathbf{1 2}$ meses (N=18) \\
\hline & $\mathbf{n ~ ( \% )}$ & $\mathbf{n}(\mathbf{\%})$ \\
Óbito & $8(33,3)$ & $5(27,7)$ \\
Acidente Vascular Cerebral & $1(4.2)$ & 0 \\
Sem condições físicas & $4(16,6)$ & $3(16,7)$ \\
Sem condições cognitivas & $1(4,2)$ & 0 \\
Realizando tratamento em outra Instituição & $4(16,7)$ & $3(16,7)$ \\
Perdido de vista & $2(8,3)$ & 0 \\
Não quis responder & $3(12,5)$ & $5(27,7)$ \\
Abandono de tratamento & $1(4,2)$ & $1(5,6)$ \\
Sem condições emocionais & 0 & $1(5,6)$ \\
\hline Total & $\mathbf{2 4}(\mathbf{1 0 0})$ & $\mathbf{1 8 ~ ( 1 0 0 )}$ \\
\hline
\end{tabular}


Entre abril e dezembro de 2014 foram recrutados 104 pacientes, recém diagnosticados com $\mathrm{CA} / \mathrm{CP}$. No momento pré-tratamento, a maioria dos pacientes que participaram do estudo era do sexo masculino $(76,0 \%, n=79)$, com média de idade de 61 anos.

Aos 6 e aos 12 meses após o diagnóstico, as amostras foram constituídas, respectivamente, por 80 pacientes, a maioria do sexo masculino $(73,8 \%, n=59)$, média de idade de 60 anos e por 62 pacientes, a maioria do sexo masculino $(75,8 \%$, $\mathrm{n}=47$ ) e com média de idade de 59 anos.

As características sócio-demográficas destes pacientes, nos três momentos do estudo, estão descritas na Tabela 7. 
Tabela 7 Número e porcentagem de pacientes avaliados nos momentos prétratamento $(\mathrm{N}=104), 6$ meses $(\mathrm{N}=80)$ e 12 meses $(\mathrm{N}=62)$ após o diagnóstico, segundo dados demográficos e estilo de vida

\begin{tabular}{|c|c|c|c|c|c|c|c|}
\hline \multirow{2}{*}{ Variável } & \multirow{2}{*}{ Categoria } & \multicolumn{2}{|c|}{ pré $(\mathrm{N}=104)$} & \multicolumn{2}{|c|}{6 meses $(N=80)$} & \multicolumn{2}{|c|}{12 meses $(\mathrm{N}=62)$} \\
\hline & & $\mathbf{n}$ & $(\%)$ & $\mathbf{n}$ & (\%) & $\mathbf{n}$ & (\%) \\
\hline \multirow{2}{*}{ Idade } & média (dp) & \multicolumn{2}{|c|}{$61(13)$} & \multicolumn{2}{|c|}{$60(13)$} & \multicolumn{2}{|c|}{$59(13)$} \\
\hline & mediana (mín-máx) & \multicolumn{2}{|c|}{$62(21-72)$} & \multicolumn{2}{|c|}{$62(21-71)$} & \multicolumn{2}{|c|}{$61(21-68)$} \\
\hline \multirow{2}{*}{ Sexo } & masculino & 79 & 76,0 & 59 & 73,8 & 47 & 75,8 \\
\hline & feminino & 25 & 24,0 & 21 & 26,3 & 15 & 24,2 \\
\hline \multirow{4}{*}{ Estado Cívil } & solteiro & 16 & 15,4 & 11 & 13,8 & 10 & 16,1 \\
\hline & casado & 69 & 66,4 & 55 & 68,8 & 45 & 72,6 \\
\hline & viúvo & 11 & 10,6 & 8 & 10,0 & 3 & 4,8 \\
\hline & divorciado & 8 & 7,7 & 6 & 7,5 & 4 & 6,5 \\
\hline \multirow{8}{*}{ Escolaridade } & analfabeto & 6 & 5,8 & 5 & 6,3 & 2 & 3,2 \\
\hline & ens. fund. I inc. & 32 & 30,8 & 21 & 26,3 & 15 & 24,2 \\
\hline & ens. fund. I compl. & 13 & 12,5 & 11 & 13,8 & 8 & 12,9 \\
\hline & ens. fund. II inc. & 10 & 9,6 & 6 & 7,5 & 5 & 8,1 \\
\hline & ens. fund. II compl. & 11 & 10,6 & 8 & 10,0 & 8 & 12,9 \\
\hline & sup. inc. & 8 & 7,7 & 6 & 7,5 & 6 & 9,7 \\
\hline & sup. compl. & 19 & 18,3 & 18 & 22,5 & 13 & 21,0 \\
\hline & pós-graduação & 5 & 4,8 & 5 & 6,3 & 5 & 8,1 \\
\hline \multirow{6}{*}{ Religião } & ateu & 4 & 3,9 & 3 & 3,8 & 1 & 1,6 \\
\hline & católico & 75 & 72,1 & 54 & 67,5 & 41 & 66,1 \\
\hline & evangélico & 11 & 10,6 & 9 & 11,3 & 8 & 12,9 \\
\hline & espírita & 5 & 4,8 & 5 & 6,3 & 4 & 6,5 \\
\hline & budista & 2 & 1,9 & 2 & 2,5 & 2 & 3,2 \\
\hline & outros & 7 & 6,7 & 7 & 8,8 & 6 & 9,7 \\
\hline \multirow{3}{*}{$\begin{array}{l}\text { Trabalha } \\
\text { atualmente }\end{array}$} & não & 65 & 62,5 & 45 & 56,3 & 31 & 50,0 \\
\hline & $\operatorname{sim}$ & 39 & 37,5 & 35 & 43,8 & 31 & 50,0 \\
\hline & nunca & 30 & 28,9 & 25 & 31,3 & 22 & 35,5 \\
\hline \multirow[t]{3}{*}{ Fumo } & parou & 51 & 49,0 & 41 & 51,3 & 30 & 48,4 \\
\hline & mantém o vício & 23 & 22,1 & 14 & 17,5 & 10 & 16,1 \\
\hline & nunca & 31 & 29,8 & 26 & 32,5 & 21 & 33,9 \\
\hline \multirow[t]{2}{*}{ Álcool } & parou & 54 & 51,9 & 39 & 48,8 & 28 & 45,2 \\
\hline & mantém o vício & 19 & 18,3 & 15 & 18,8 & 13 & 21,0 \\
\hline
\end{tabular}

(dp): desvio padrão; (mín- máx): mínimo - máximo; ens. fund.: ensino fundamental; inc.: incompleto; compl.: completo; sup: superior 
No momento pré-tratamento, assim como aos 6 e aos 12 meses após o diagnóstico, os sítios tumorais prevalentes foram cavidade oral $(41,4 \%, n=43 ; 41,2 \%$, $\mathrm{n}=33 ; 38,7 \%, \mathrm{n}=24)$, orofaringe $(25,0 \%, \mathrm{n}=26 ; 27,5 \%, \mathrm{n}=22 ; 25,8 \%, \mathrm{n}=16)$ e laringe $(17,3 \%, n=18 ; 13,8 \%, n=11 ; 17,7 \%, n=11)$.

$\mathrm{O}$ estadiamento prevalente no momento pré-tratamento e aos 6 meses foi o T4, respectivamente $36,6 \%, n=38$ e $31,3 \%, n=25$. Já aos 12 meses, a distribuição dos casos quanto à extensão da neoplasia foi praticamente equivalente $(\mathrm{T} 1-\mathrm{T} 2=51,6 \%$, $\mathrm{n}=32 ; \mathrm{T} 3-\mathrm{T} 4=48,4 \%, \mathrm{n}=30)$

Ao longo de todos os momentos do estudo, mais do que a metade da amostra era clinicamente negativa para comprometimento linfonodal, a grande maioria era clinicamente negativa para metástase à distância e o tipo histológico predominante foi o CEC.

A Tabela 8 descreve as características clínicas dos pacientes nos três momentos do estudo, de acordo com a classificação TNM (UICC), local da lesão e tipo histológico. 
Tabela 8 Número e porcentagem de pacientes coletados nos momentos prétratamento $(\mathrm{N}=104), 6$ meses $(\mathrm{N}=80)$ e 12 meses $(\mathrm{N}=62)$ após o diagnóstico, de acordo com classificação TNM (UICC), local da lesão e tipo histológico

\begin{tabular}{|c|c|c|c|c|c|c|c|}
\hline \multirow{2}{*}{ Variável } & \multirow{2}{*}{ Categoria } & \multicolumn{2}{|c|}{ PRÉ } & \multicolumn{2}{|c|}{6 meses } & \multicolumn{2}{|c|}{12 meses } \\
\hline & & $\mathbf{n}$ & $(\%)$ & $\mathbf{n}$ & $(\%)$ & $\mathbf{n}$ & $(\%)$ \\
\hline \multirow{4}{*}{$\mathbf{T}$} & 1 & 23 & 22,1 & 18 & 22,5 & 16 & 25,8 \\
\hline & 2 & 20 & 19,2 & 17 & 21,2 & 16 & 25,8 \\
\hline & 3 & 23 & 22,1 & 20 & 25,0 & 15 & 24,2 \\
\hline & 4 & 38 & 36,6 & 25 & 31,3 & 15 & 24,2 \\
\hline \multirow{4}{*}{$\mathbf{N}$} & 0 & 58 & 55,8 & 46 & 57,5 & 37 & 59,7 \\
\hline & 1 & 18 & 17,3 & 13 & 16,2 & 10 & 16,1 \\
\hline & 2 & 20 & 19,2 & 16 & 20,0 & 11 & 17,7 \\
\hline & 3 & 8 & 7,7 & 5 & 6,3 & 4 & 6,5 \\
\hline \multirow{2}{*}{$\mathbf{M}$} & 0 & 101 & 97,1 & 78 & 97,5 & 61 & 98,4 \\
\hline & 1 & 3 & 2,9 & 2 & 2,5 & 1 & 1,6 \\
\hline \multirow{4}{*}{ Sítio da Lesão } & cavidade oral & 43 & 41,4 & 33 & 41,2 & 24 & 38,7 \\
\hline & orofaringe & 26 & 25,0 & 22 & 27,5 & 16 & 25,8 \\
\hline & laringe & 18 & 17,3 & 11 & 13,8 & 11 & 17,7 \\
\hline & hipofaringe & 3 & 2,8 & 1 & 1,2 & 1 & 1,6 \\
\hline \multirow[t]{3}{*}{ Primária } & nasofaringe & 6 & 5,8 & 5 & 6,3 & 5 & 8,1 \\
\hline & fossas nasais/seios maxilares & 5 & 4,8 & 5 & 6,3 & 2 & 3,3 \\
\hline & glândula salivar & 3 & 2,9 & 3 & 3,7 & 3 & 4,8 \\
\hline \multirow{4}{*}{ Histologia } & CEC & 96 & 92,3 & 73 & 91,2 & 55 & 88,7 \\
\hline & CA indiferenciado & 3 & 2,9 & 2 & 2,5 & 2 & 3,2 \\
\hline & adenocarcinoma & 3 & 2,9 & 3 & 3,8 & 3 & 4,9 \\
\hline & outro & 2 & 1,9 & 2 & 2,5 & 2 & 3,2 \\
\hline
\end{tabular}

UICC: União Internacional Contra o Câncer; $\mathrm{T}$ : extensão da neoplasia no sítio primário e envolvimento de estruturas adjacentes; N: linfonodos regionais; M: metástases à distância; CA: carcinoma; CEC: Carcinoma espinocelular. 
Aos 6 meses após o diagnóstico, a maioria dos pacientes havia sido submetida à cirurgia como forma de tratamento inicial $(60,0 \%, n=48 / 80)$, dentre os quais 73,0\% (n=35/48) realizaram reconstrução e 75,0\% $(n=36 / 48)$ realizaram esvaziamento cervical (ipsilateral ou bilateral). A radioquimioterapia foi a segunda forma de tratamento inicial prevalente $(26,3 \%, n=21 / 80)$.

A maioria dos pacientes irradiados, no tratamento inicial ou durante o tratamento adjuvante, recebeu dose total de radiação $\geq 60 \mathrm{~Gy}$.

Aos 12 meses após o diagnóstico, 95,2\% $(\mathrm{n}=59)$ dos pacientes participantes estavam em seguimento clínico ambulatorial e três dos pacientes que responderam aos questionários estavam com a doença em atividade $(4,8 \%)$.

As variáveis de tratamento dos pacientes aos 6 e aos 12 meses após o diagnóstico e a situação clínica dos pacientes aos 12 meses estão descritas na Tabela 9. 
Tabela 9 Número e porcentagem de pacientes coletados aos 6 meses $(\mathrm{N}=80)$ e 12 meses $(\mathrm{N}=62)$ após o diagnóstico, de acordo com o tipo de tratamento realizado e situação clínica

\begin{tabular}{|c|c|c|c|c|c|}
\hline \multirow[b]{2}{*}{ Variável } & \multirow[b]{2}{*}{ Categoria } & \multicolumn{2}{|c|}{6 meses $(\mathrm{N}=80)$} & \multicolumn{2}{|c|}{12 meses $(N=62)$} \\
\hline & & $\mathbf{n}$ & $(\%)$ & $\mathbf{n}$ & $(\%)$ \\
\hline \multirow{5}{*}{ Tratamento } & $\mathrm{CX}$ & $48 / 80$ & 60,0 & $39 / 62$ & 62,9 \\
\hline & RDT & $3 / 80$ & 3,7 & $3 / 62$ & 4,8 \\
\hline & QT neoadj. & $7 / 80$ & 8,7 & $3 / 62$ & 4,8 \\
\hline & $\mathrm{RDT}+\mathrm{QT}$ & $21 / 80$ & 26,3 & $16 / 62$ & 25,8 \\
\hline & QT paliativa & $1 / 80$ & 1,3 & $1 / 62$ & 1,7 \\
\hline \multirow{3}{*}{ Reconstrução } & não & $13 / 48$ & 27,0 & $12 / 39$ & 30,8 \\
\hline & $\operatorname{sim}$ & $35 / 48$ & 73,0 & $27 / 39$ & 69,2 \\
\hline & não & $12 / 48$ & 25,0 & $10 / 39$ & 25,6 \\
\hline Esvaziamento cervical & $\operatorname{sim}$ & $36 / 48$ & 75,0 & $29 / 39$ & 74,4 \\
\hline \multirow{3}{*}{ Tratamento adjuvante } & nenhum & 44 & 55,0 & 36 & 58,1 \\
\hline & RDT adjuv. & 17 & 21,3 & 14 & 22,6 \\
\hline & RDT + QT adjuv. & 19 & 23,7 & 12 & 19,3 \\
\hline \multirow{3}{*}{ Dose RDT (Gy) } & $<60$ & $6 / 60$ & 10,0 & $5 / 45$ & 11,1 \\
\hline & $\geq 60$ & $54 / 60$ & 90,0 & $40 / 45$ & 88,9 \\
\hline & não & 49 & 61,3 & 37 & 59,7 \\
\hline \multirow[t]{2}{*}{ SNE / PEG } & $\operatorname{sim}$ & 31 & 38,7 & 25 & 40,3 \\
\hline & não & 52 & 65,0 & 40 & 64,5 \\
\hline TQT & $\operatorname{sim}$ & 28 & 35,0 & 22 & 35,5 \\
\hline Situação aos 12 meses $(\mathrm{N}=62)$ & & & & $\mathbf{n}$ & $(\%)$ \\
\hline Seguimento & & & & 59 & 95,2 \\
\hline $2^{\circ} \mathrm{TU}$ primário - $\mathrm{CX}+\mathrm{RDT}$ adjuv. & & & & 1 & 1,6 \\
\hline $\begin{array}{l}\text { Cuidados paliativos (doença } \\
\text { metastática) }\end{array}$ & & & & 1 & 1,6 \\
\hline QT adjuvante (recidiva local) & & & & 1 & 1,6 \\
\hline
\end{tabular}

CX: cirurgia; RDT: radioterapia; QT neoadj.: quimioterapia neoadjuvante; RDT + QT: radioquimioterapia concomitantes; QT paliativa: quimioterapia paliativa; RDT adjuv.: radioterapia adjuvante; RDT + QT adjuv.: radioquimioterapia adjuvantes; RDT (Gy): radioterapia (Grays); SNE/PEG: sonda nasoenteral/gastrostomia percutânea; TQT: traqueostomia; TU: tumor; CX + RDT adjuv.: cirurgia e radioterapia adjuvantes; QT adjuv.: quimioterapia adjuvante 


\subsection{GRAU DE ANSIEDADE E DEPRESSÃO (HADS)}

Em todos os momentos do estudo, a maioria dos pacientes apresentou escores de ansiedade e de depressão dentro dos limites de normalidade, de acordo com os pontos de corte determinados na literatura adotada para ambas as sub-escalas. Os graus de ansiedade e de depressão apresentados pelos pacientes ao longo do estudo estão descritos na Tabela 10.

Tabela 10 Número e porcentagem de pacientes, de acordo com os graus de ansiedade e depressão apresentados nos momentos pré-tratamento $(\mathrm{N}=104), 6$ meses $(\mathrm{N}=80)$ e 12 meses após o diagnóstico

\begin{tabular}{|c|c|c|c|c|c|c|c|}
\hline \multirow{2}{*}{ Escala } & \multirow{2}{*}{ Escore } & \multicolumn{2}{|c|}{ pré $(\mathrm{N}=104)$} & \multicolumn{2}{|c|}{6 meses $(N=80)$} & \multicolumn{2}{|c|}{12 meses $(N=62)$} \\
\hline & & $\mathbf{n}$ & $(\%)$ & $\mathbf{n}$ & (\%) & $\mathbf{n}$ & $(\%)$ \\
\hline \multirow{4}{*}{ Ansiedade } & normal (0-7) & 72 & 69,2 & 67 & 83,7 & 53 & 85,5 \\
\hline & leve $(8-10)$ & 18 & 17,3 & 5 & 6,2 & 8 & 12,9 \\
\hline & moderada (11-14) & 9 & 8,7 & 7 & 8,8 & 1 & 1,6 \\
\hline & severa $(15-21)$ & 5 & 4,8 & 1 & 1,3 & 0 & 0,0 \\
\hline \multirow{4}{*}{ Depressão } & normal (0-7) & 82 & 78,8 & 67 & 83,7 & 57 & 91,9 \\
\hline & leve $(8-10)$ & 15 & 14,4 & 8 & 10,0 & 1 & 1,6 \\
\hline & moderada (11-14) & 6 & 5,8 & 5 & 6,3 & 3 & 4,9 \\
\hline & severa $(15-21)$ & 1 & 1,0 & 0 & 0,0 & 1 & 1,6 \\
\hline
\end{tabular}




\subsection{QUALIDADE DE VIDA (UW-QOL)}

No momento pré-tratamento os resultados do $U W-Q O L$ demontraram que os pacientes apresentavam boa QV, com escores médios $>90$ para os domínios ombro e saliva, escores entre 75 e 90 para os domínios atividade, recreação, humor, aparência, deglutição, fala e paladar e escores entre 50 e 74 para os domínios dor, ansiedade e mastigação.

Aos 6 meses após o diagnóstico, os resultados indicaram escore médio $>90$ apenas para o domínio ombro, escore entre 75 e 90 para os domínios dor, recreação, humor, aparência e fala e escores médios pontuados entre 50 e 74 para os domínios atividade, ansiedade, deglutição, mastigação, paladar e saliva.

Aos 12 meses após o diagnóstico, as médias dos escores encontradas foram > 90 para o domínio ombro, entre 75 e 90 para os domínios dor, atividade, recreação, humor, ansiedade, aparência, deglutição, fala e paladar e entre 50 e 74 para os domínios mastigação e saliva.

A média do escore global do $U W-Q O L$ manteve-se entre 75 e 90 em todos os momentos do estudo.

De forma geral, observou-se que os escores dos domínios dor, humor e ansiedade apresentam discreta melhora com o passar do tempo, indicando melhora na QV associada a estes domínios.

Para os domínios atividade, recreação, mastigação e para o global, observouse uma discreta piora aos 6 meses após o diagnóstico, seguida de uma melhora aos 12 meses após o diagnóstico, com médias que ultrapassam os valores observados no momento pré-tratamento. 
Para os domínios ombro, fala, saliva, deglutição e paladar, observou-se comportamento similar aos domínios anteriormente citados, porém a QV aos 12 meses após o diagnóstico não supera a QV observada no momento pré-tratamento.

A QV relacionada ao domínio aparência apresentou piora aos 6 meses, com pouca melhora aos 12 meses após o diagnóstico.

Em relação às questoes gerais do $U W-Q O L$, os problemas mais importantes para os pacientes nos sete dias que antecederam a avaliação no momento após o diagnóstico foram dor (46,15\%), aparência (21,15\%) e ansiedade (16,35\%). Aos 6 meses, os problemas mais importantes para os pacientes eram a aparência $(26,25 \%)$, atividade $(15,0 \%)$ e mastigação $(12,5 \%)$. Já aos 12 meses, os principais problemas referidos foram a aparência (20,97\%), a deglutição (14,52\%) e a mastigação $(14,52 \%)$

Os pacientes consideraram sua QV geral como média $(46,15 \%, n=48)$, ruim $(20,19 \%, n=21)$ ou muito ruim $(18,27 \%, n=19)$ no momento pré-tratamento. Aos 6 meses, a QV geral foi considerada média para 37,5\% $(\mathrm{n}=30)$ dos pacientes, como ruim ou muito ruim por $18,75 \% \quad(n=15)$ e $26,25 \% \quad(n=21)$ dos pacientes, respectivamente. Aos 12 meses, 40,32\% $(n=25)$ dos pacientes avaliados consideraram sua QV geral como média, 22,58\% $(\mathrm{n}=14)$ como ruim ou muito ruim $(27,42 \%, n=17)$.

As Figuras 5 a 16 e a figura 17 descrevem, respectivamente, os valores médios e respectivos intervalos de confiança para os escores dos 12 domínios específicos e para escore global do UW-QOL, ao longo das avaliações. A Tabela com as principais medidas resumo para os escores dos domínios específicos e global do UW-QOL em cada época do estudo estão descritas no Anexo P. 


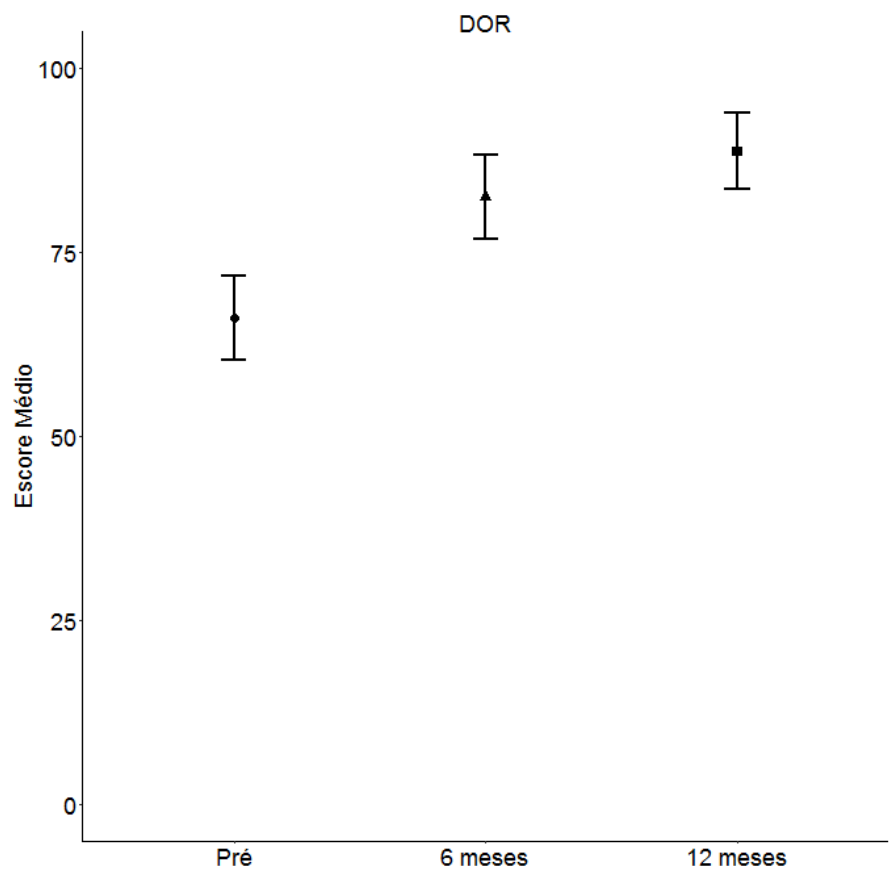

Figura 5 Valores médios e respectivos intervalos de confiança para o escore do domínio Dor (UW-QOL) ao longo das avaliações

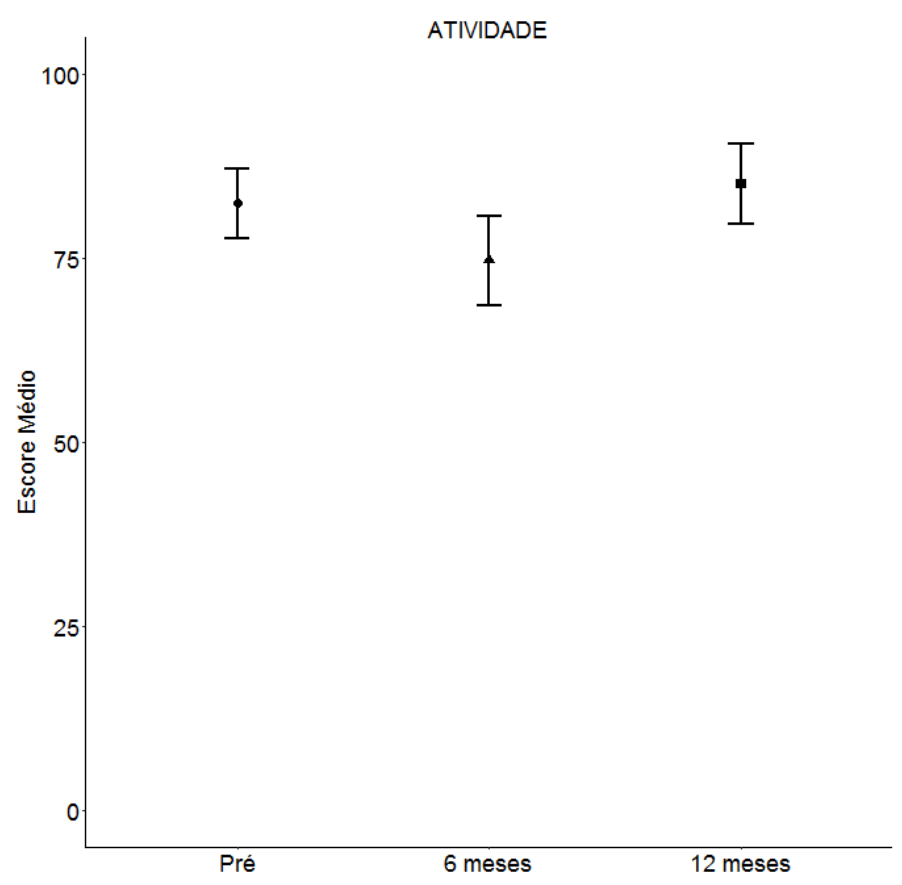

Figura 6 Valores médios e respectivos intervalos de confiança para o escore do domínio Atividade (UW-QOL) ao longo das avaliações 


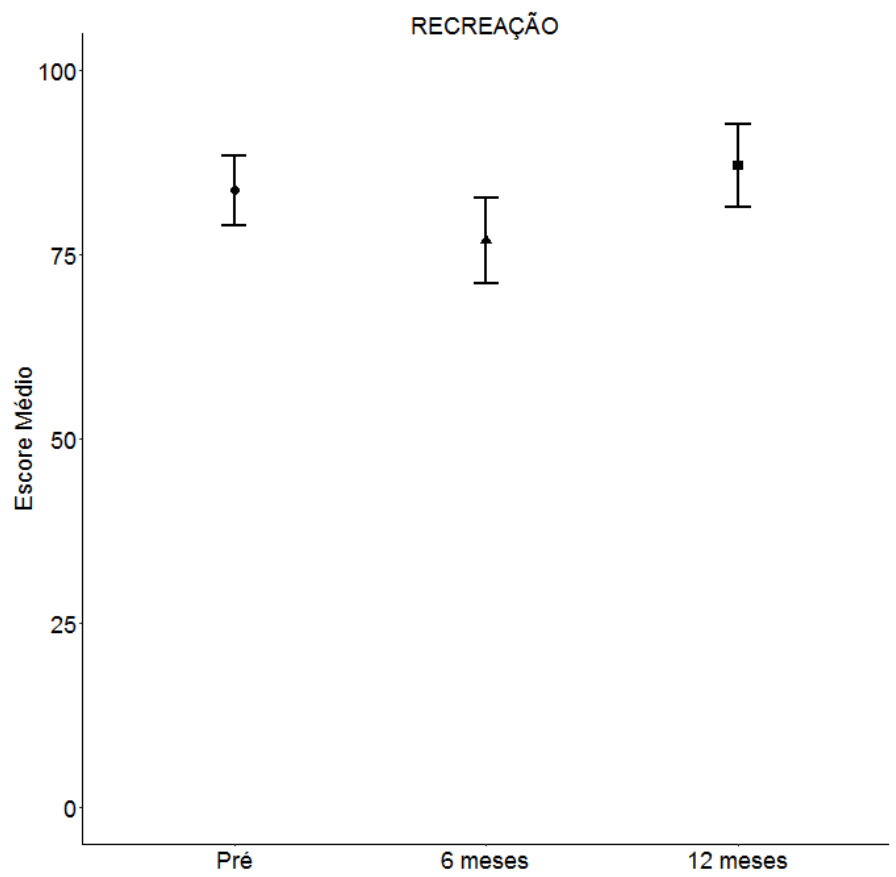

Figura 7 Valores médios e respectivos intervalos de confiança para o escore do domínio Recreação (UW-QOL) ao longo das avaliações

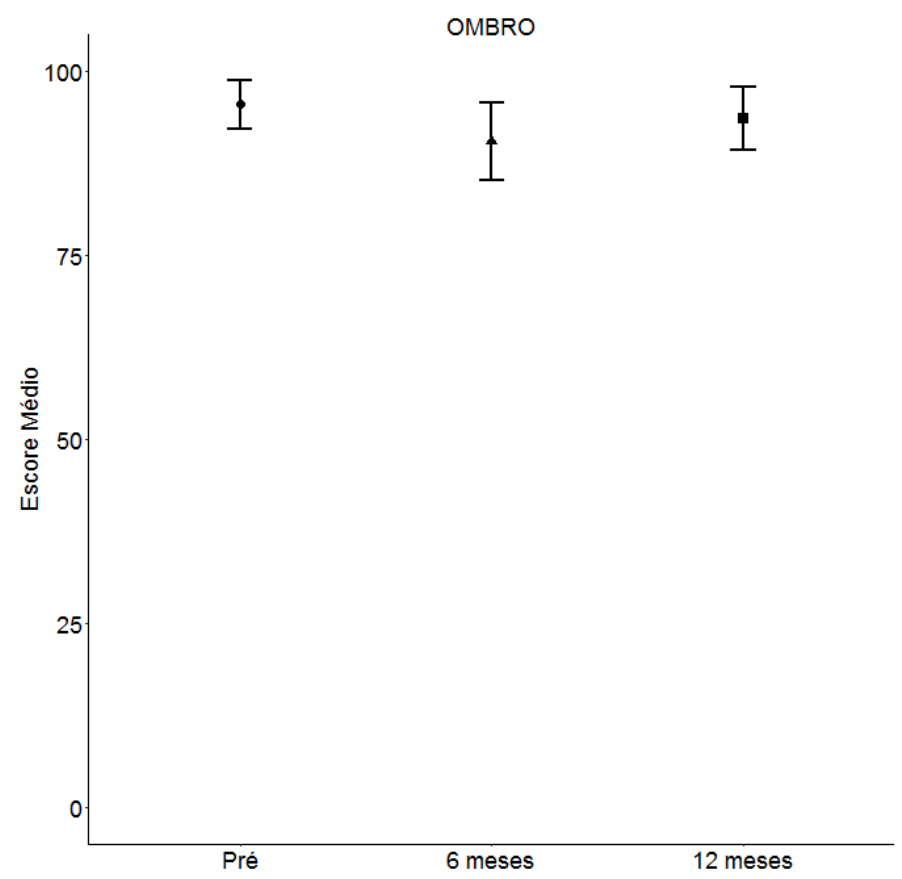

Figura 8 Valores médios e respectivos intervalos de confiança para o escore do domínio Ombros (UW-QOL) ao longo das avaliações 


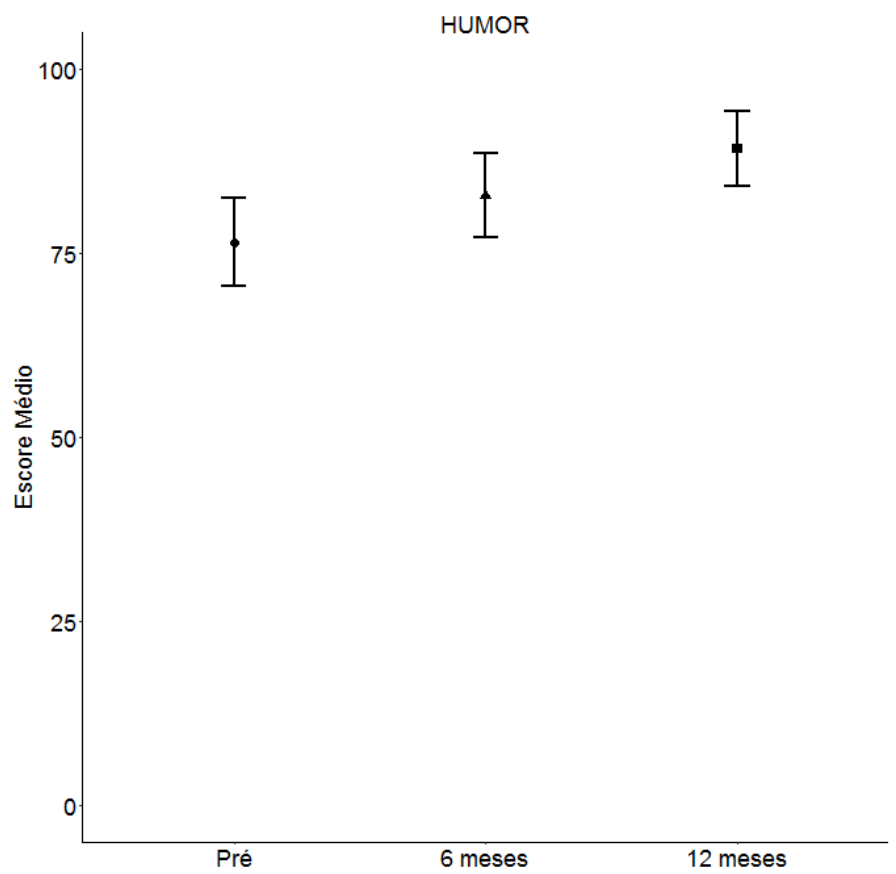

Figura 9 Valores médios e respectivos intervalos de confiança para o escore do domínio Humor ( $U W-Q O L)$ ao longo das avaliações

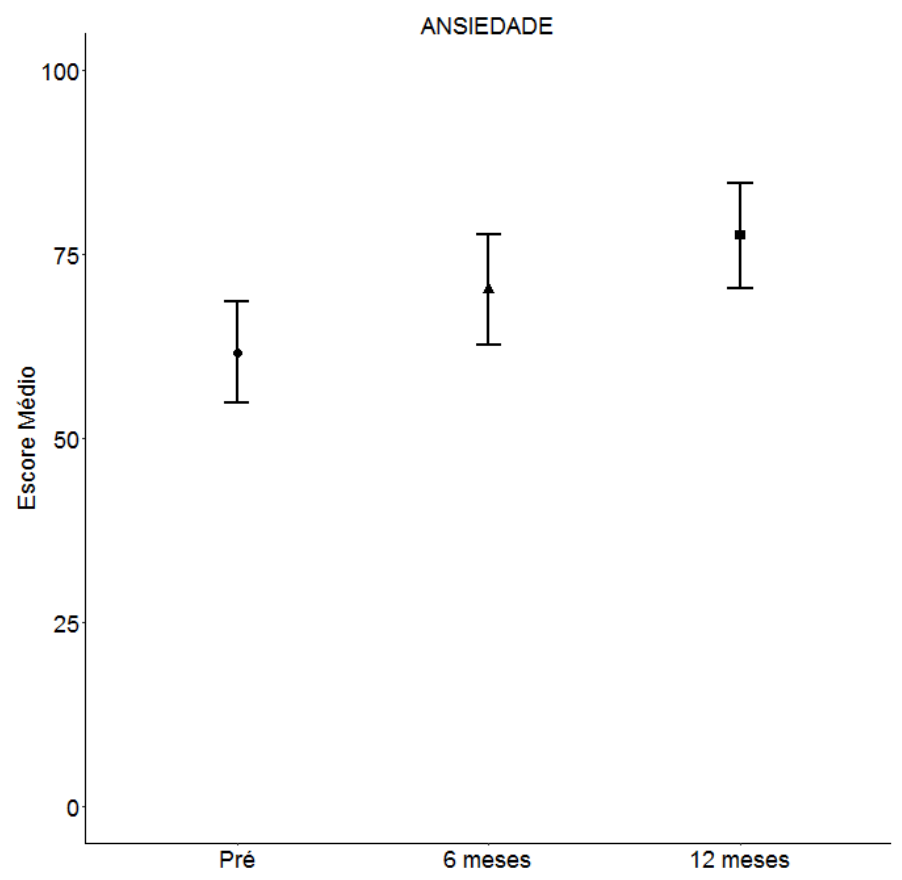

Figura 10 Valores médios e respectivos intervalos de confiança para o escore do domínio Ansiedade (UW-QOL) ao longo das avaliações 


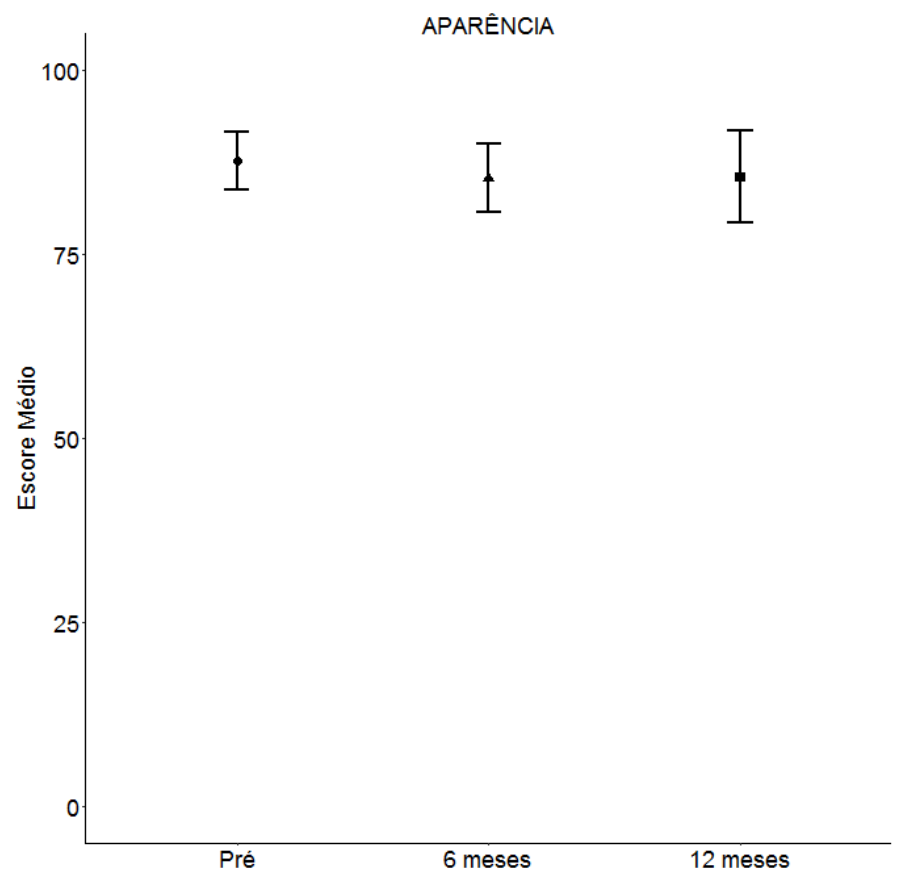

Figura 11 Valores médios e respectivos intervalos de confiança para o escore do domínio Aparência (UW-QOL) ao longo das avaliações

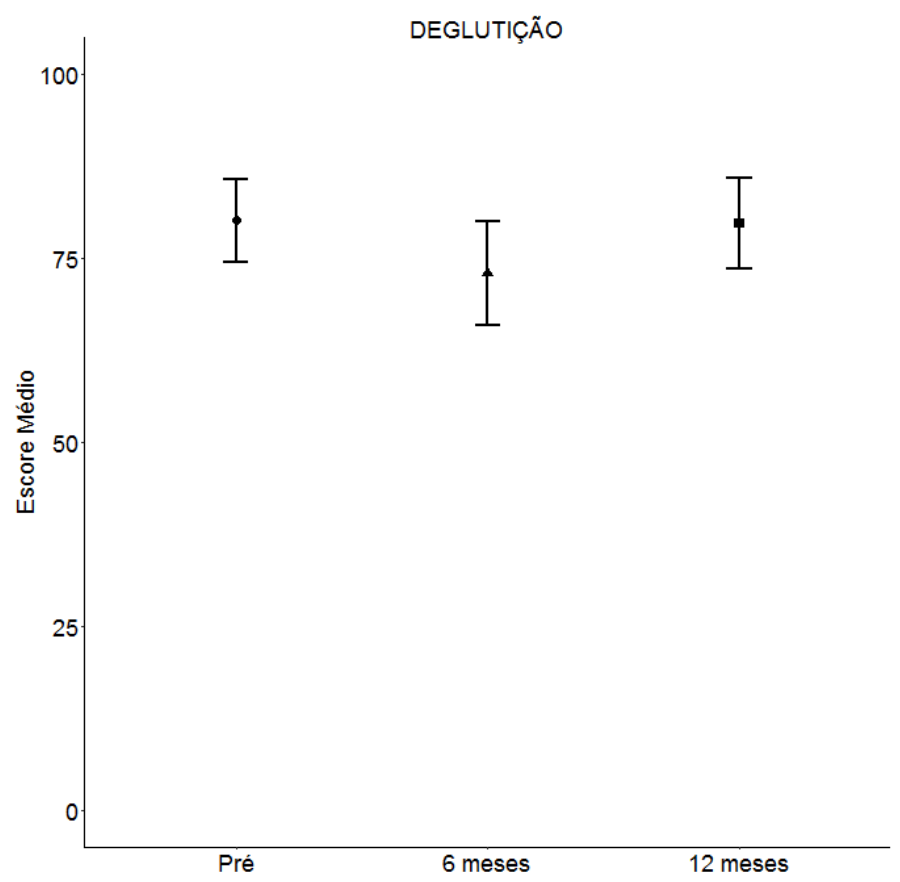

Figura 12 Valores médios e respectivos intervalos de confiança para o escore do domínio Deglutição (UW-QOL) ao longo das avaliações 


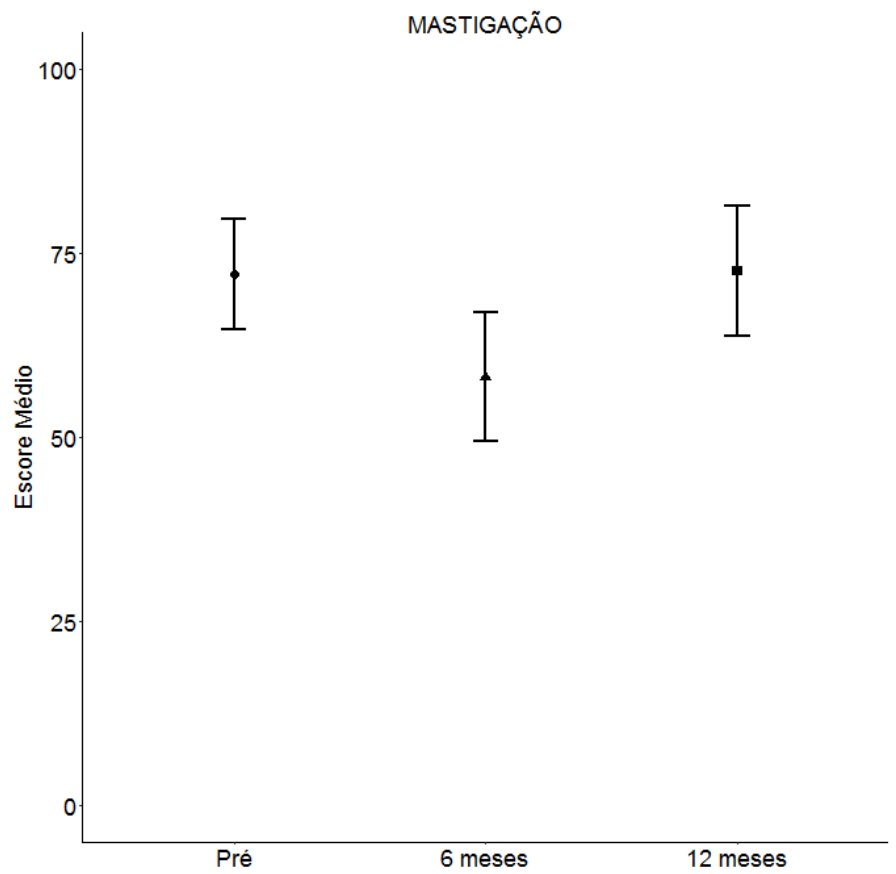

Figura 13 Valores médios e respectivos intervalos de confiança para o escore do domínio Mastigação (UW-QOL) ao longo das avaliações

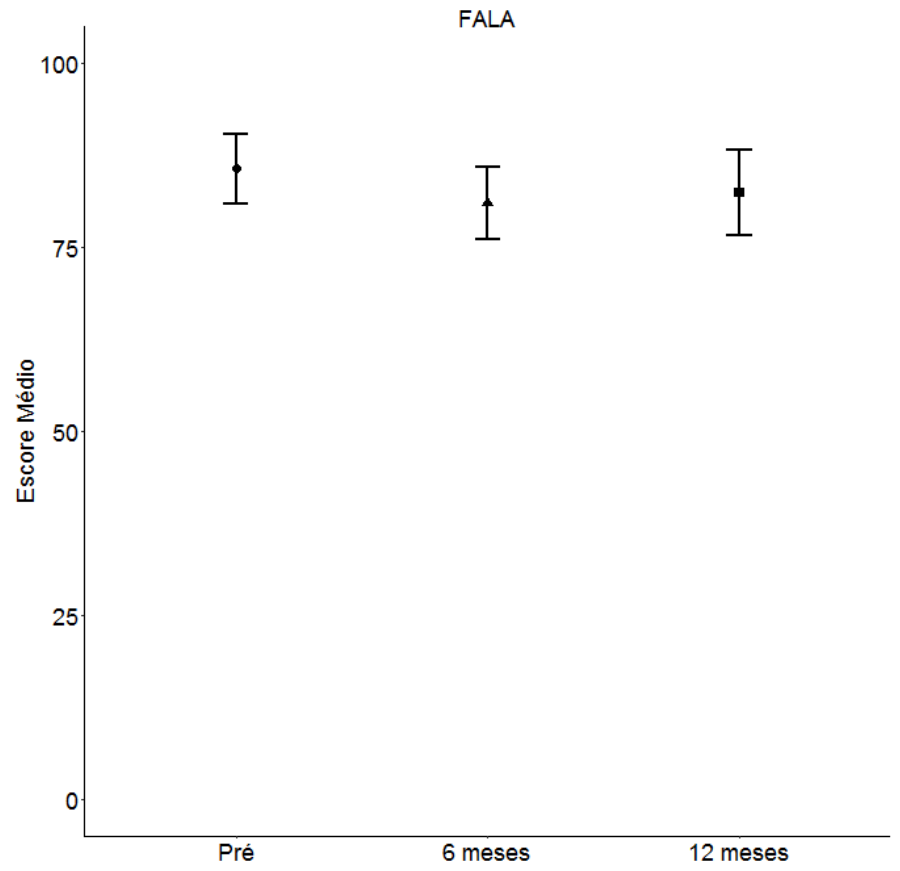

Figura 14 Valores médios e respectivos intervalos de confiança para o escore do domínio Fala (UW-QOL) ao longo das avaliações 


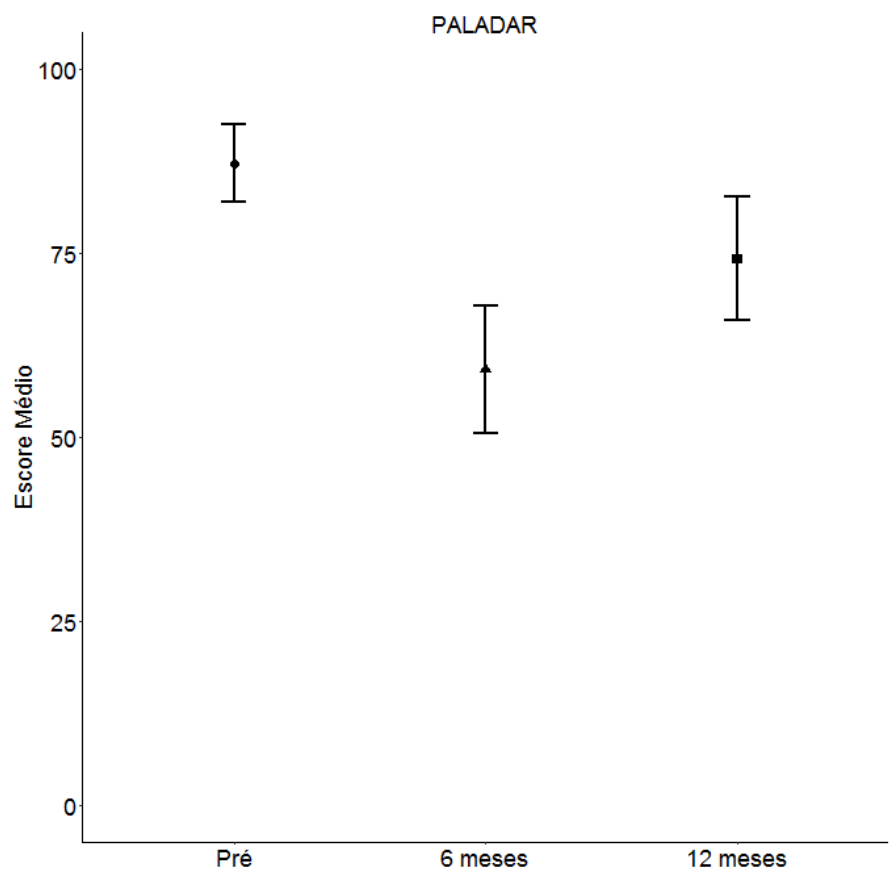

Figura 15 Valores médios e respectivos intervalos de confiança para o escore do domínio Paladar ( $U W-Q O L)$ ao longo das avaliações

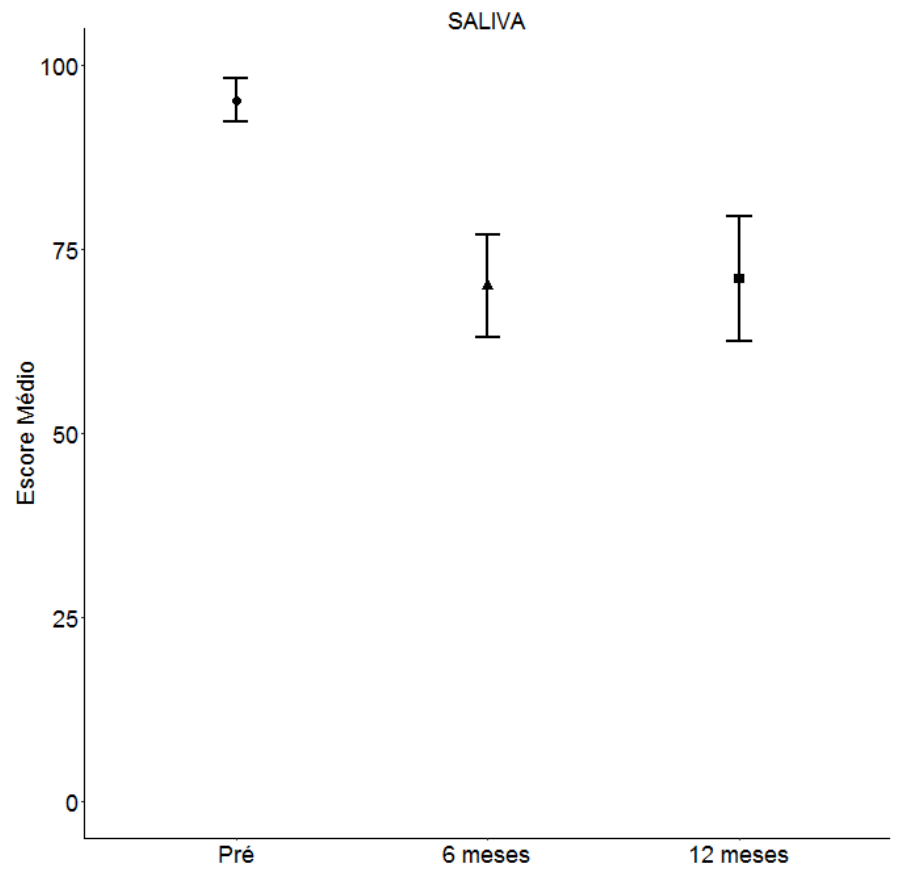

Figura 16 Valores médios e respectivos intervalos de confiança para o escore do domínio Saliva (UW-QOL) ao longo das avaliações 


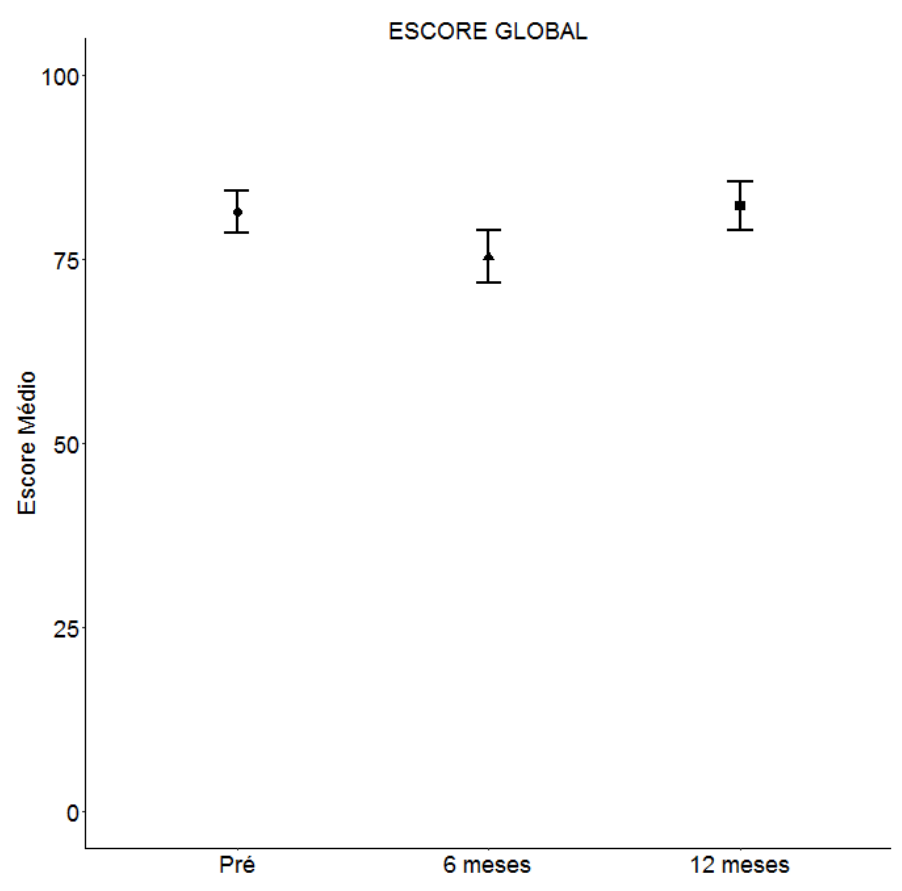

Figura 17 Valores médios e respectivos intervalos de confiança para o escore global (UW-QOL) ao longo das avaliações

\subsection{INTENSIDADE DOS SINTOMAS (MDASI- H\&N)}

A análise da presença e intensidade dos sintomas, de acordo com cada época do estudo, indicou que, no momento pré-tratamento, os pacientes assinalaram com maior frequência e em diferentes intensidades os sintomas dor, preocupações (aborrecimentos), problemas de sono e dificuldade para engolir/mastigar, seguidos por cansaço (fadiga), catarro na boca ou garganta, problemas com a voz/para falar e sentimento de tristeza.

Aos 6 meses após o diagnóstico, observou-se a prevalência de sintomas mais intensos relacionados à dificuldade para engolir/mastigar, sensação de boca seca, catarro na boca ou garganta, dificuldade para sentir o gosto da comida, preocupações 
(aborrecimentos), problemas com a voz/para falar, cansaço (fadiga) e problemas com dentes (gengivas).

Aos 12 meses após o diagnóstico, a sensação de boca seca e a dificuldade para engolir/mastigar foram os sintomas mais assinalados (porém em menor intensidade do que aos 6 meses), seguidos por preocupações (aborrecimentos), catarro na boca ou garganta, problemas com a voz/para falar, dificuldade para sentir o gosto da comida e cansaço.

As Figuras 18 a 39 descrevem os valores médios e respectivos intervalos de confiança para os escores dos sintomas elencados no MDASI, ao longo do estudo.

A frequência e porcentagem de pacientes, de acordo com a presença e intensidade dos sintomas em cada momento do estudo e na análise comparativa dos resultados longitudinais do MDASI que originaram as figuras apresentadas, estão descritas nos anexos Q, R, S e T.

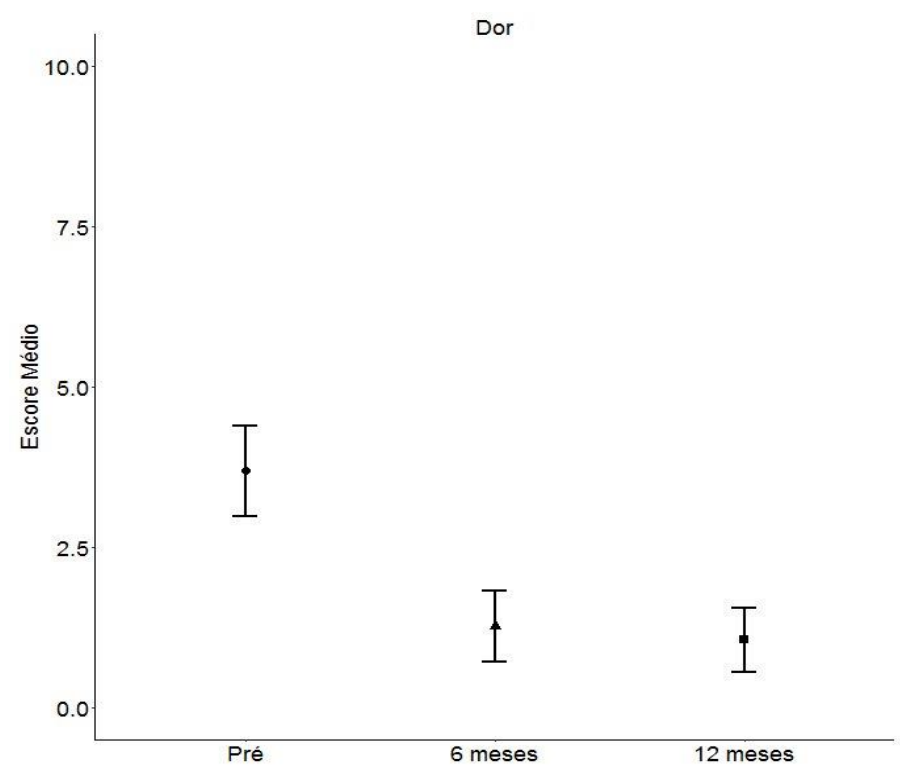

Figura 18 Valores médios e respectivos intervalos de confiança para o escore do sintoma Dor (MDASI) ao longo das avaliações 


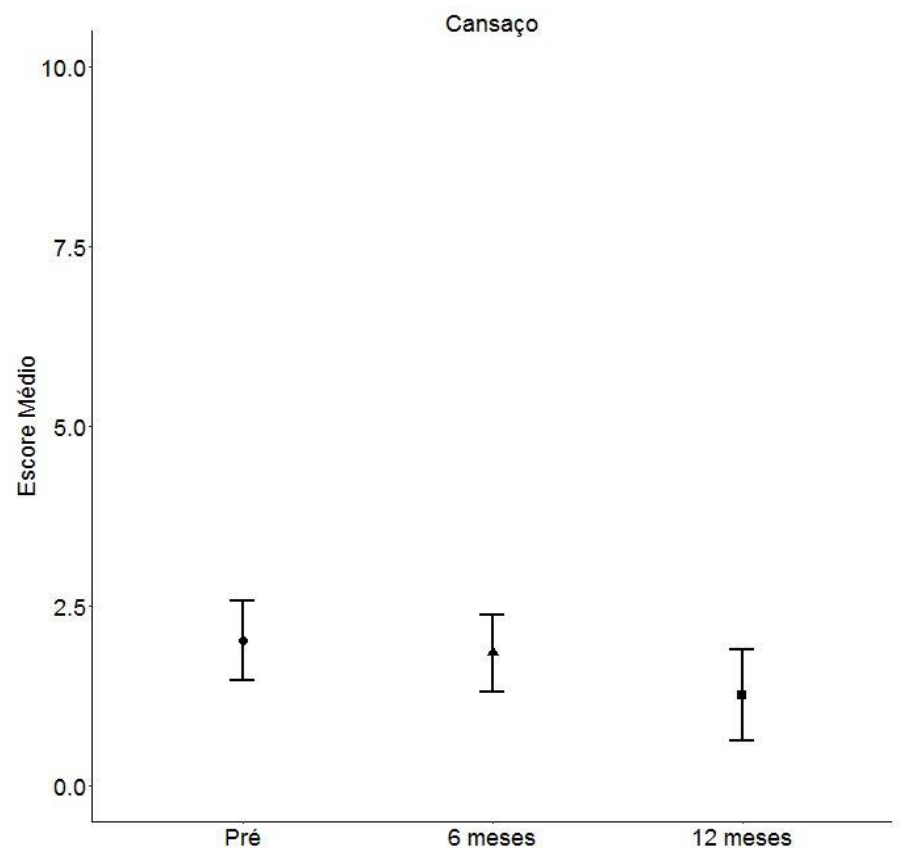

Figura 19 Valores médios e respectivos intervalos de confiança para o escore do sintoma Cansaço (fadiga) (MDASI) ao longo das avaliações

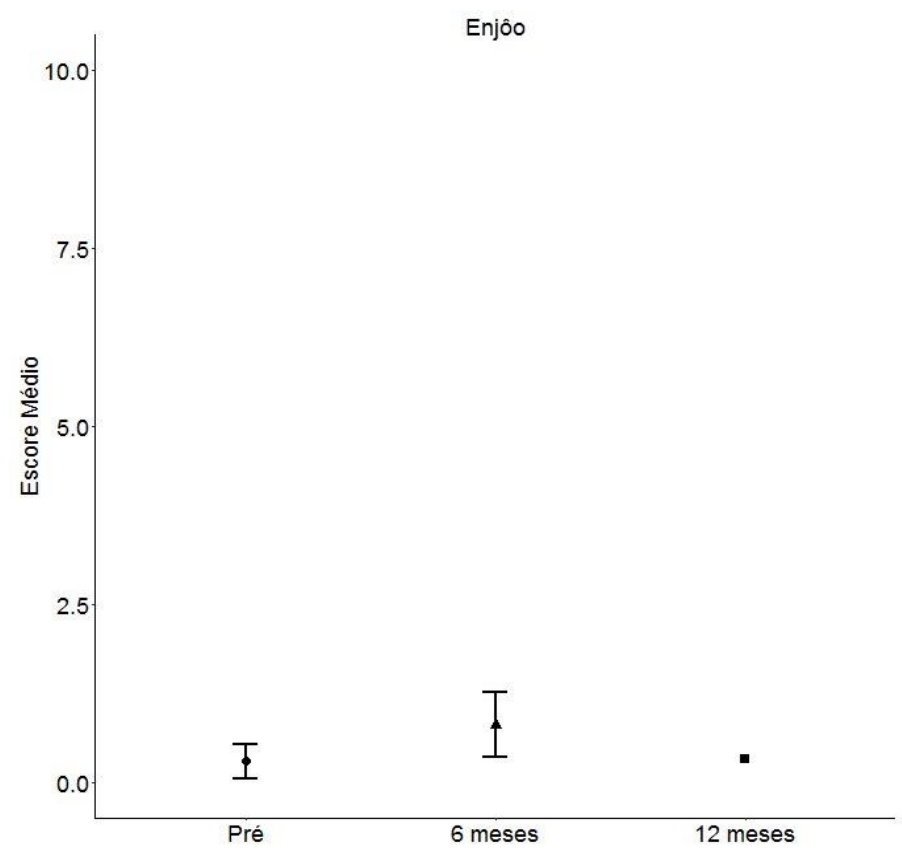

Figura 20 Valores médios e respectivos intervalos de confiança para o escore do sintoma Enjoo (náusea) (MDASI) ao longo das avaliações 


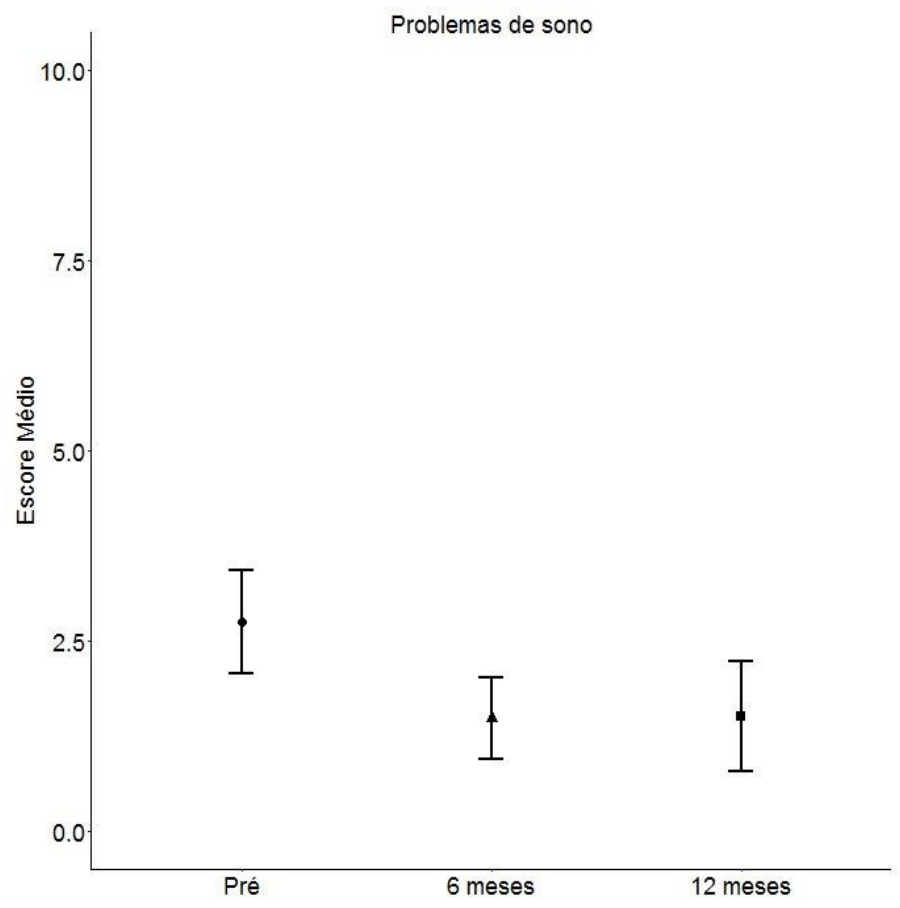

Figura 21 Valores médios e respectivos intervalos de confiança para o escore do sintoma Problemas de sono (MDASI) ao longo das avaliações

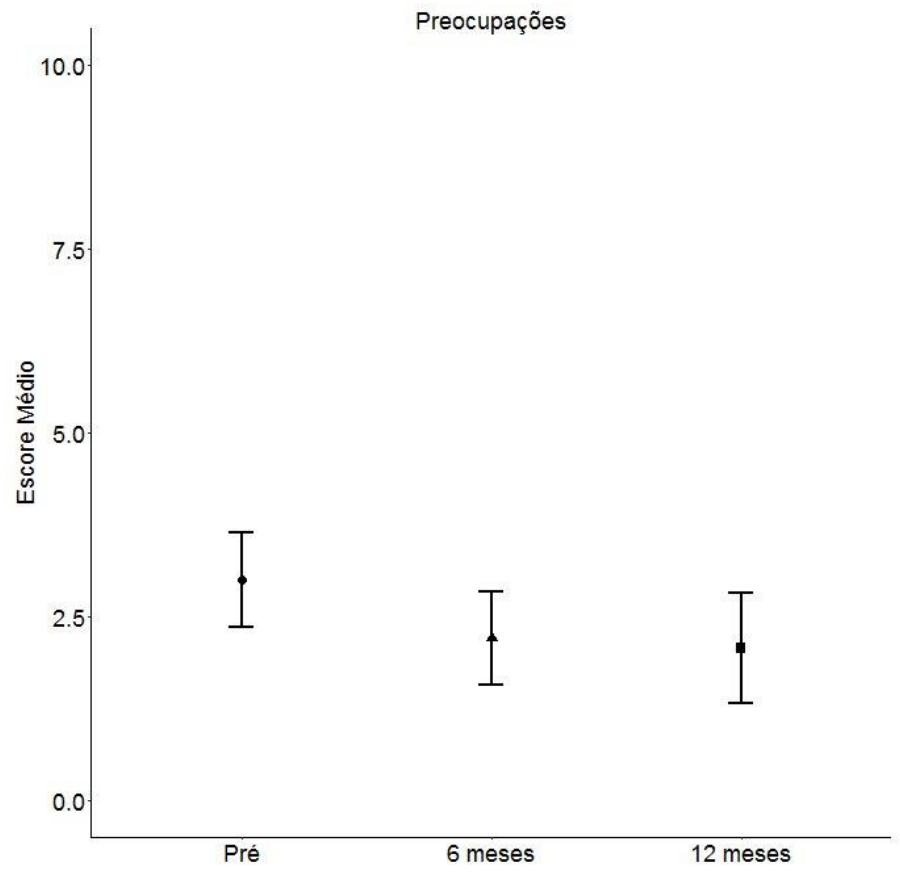

Figura 22 Valores médios e respectivos intervalos de confiança para o escore do sintoma Preocupações (aborrecimentos) (MDASI) ao longo das avaliações 


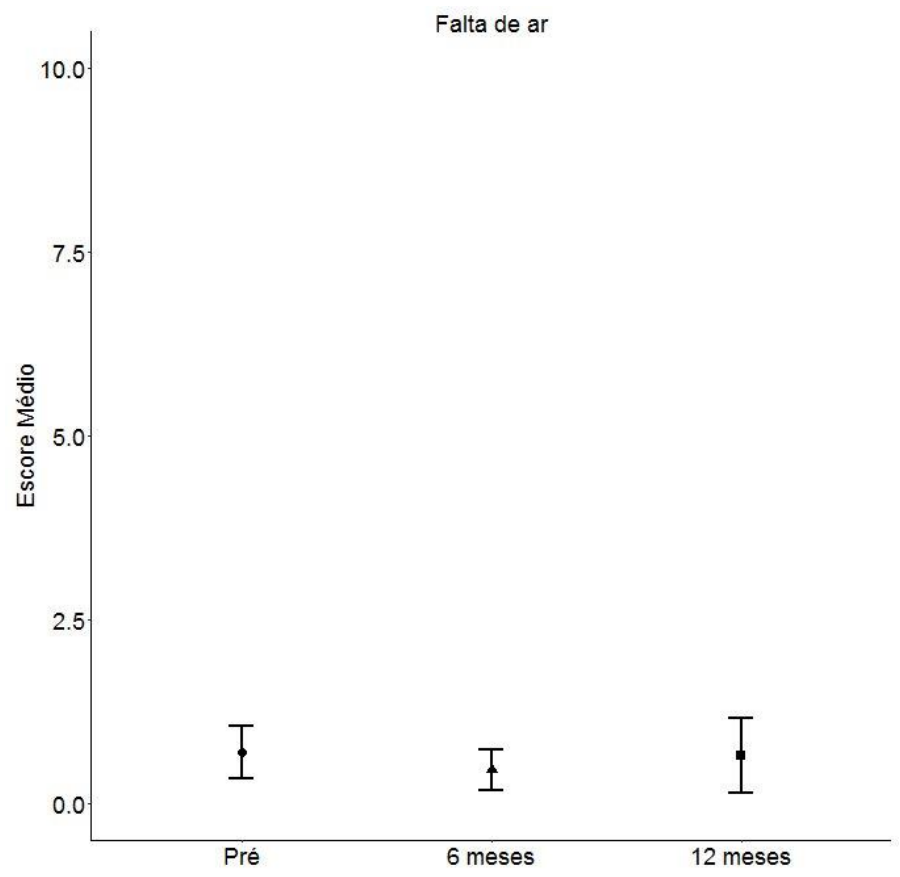

Figura 23 Valores médios e respectivos intervalos de confiança para o escore do sintoma Falta de ar (MDASI) ao longo das avaliações

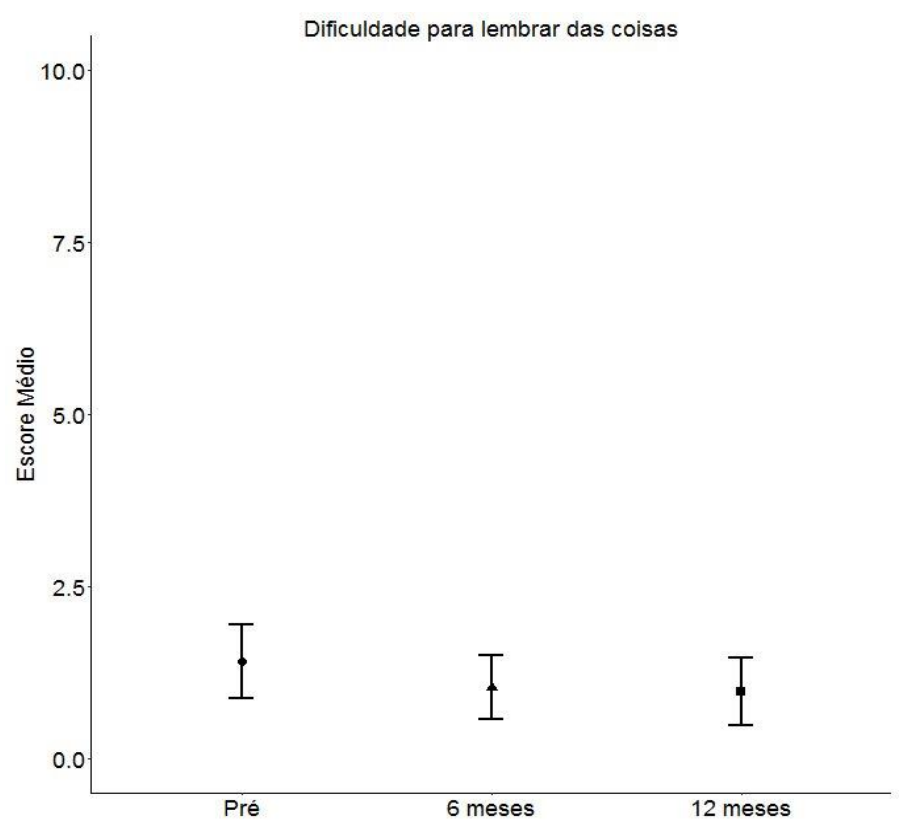

Figura 24 Valores médios e respectivos intervalos de confiança para o escore do sintoma Dificuldade para lembrar das coisas (MDASI) ao longo das avaliações 


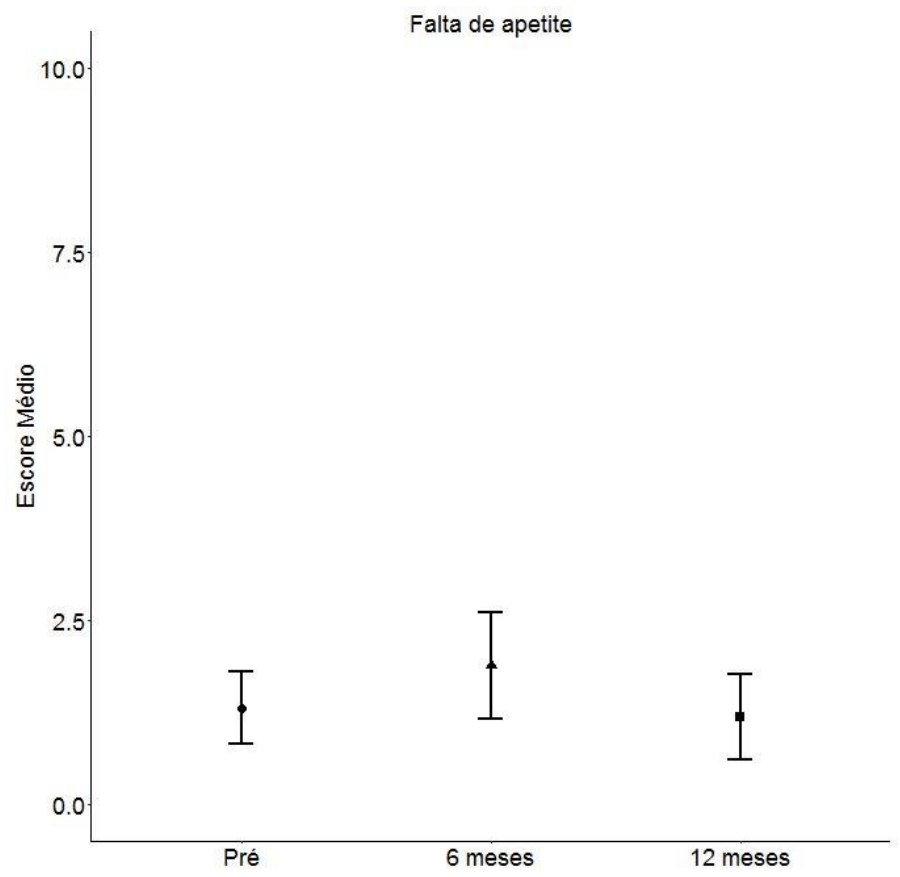

Figura 25 Valores médios e respectivos intervalos de confiança para o escore do sintoma Falta de apetite (MDASI) ao longo das avaliações

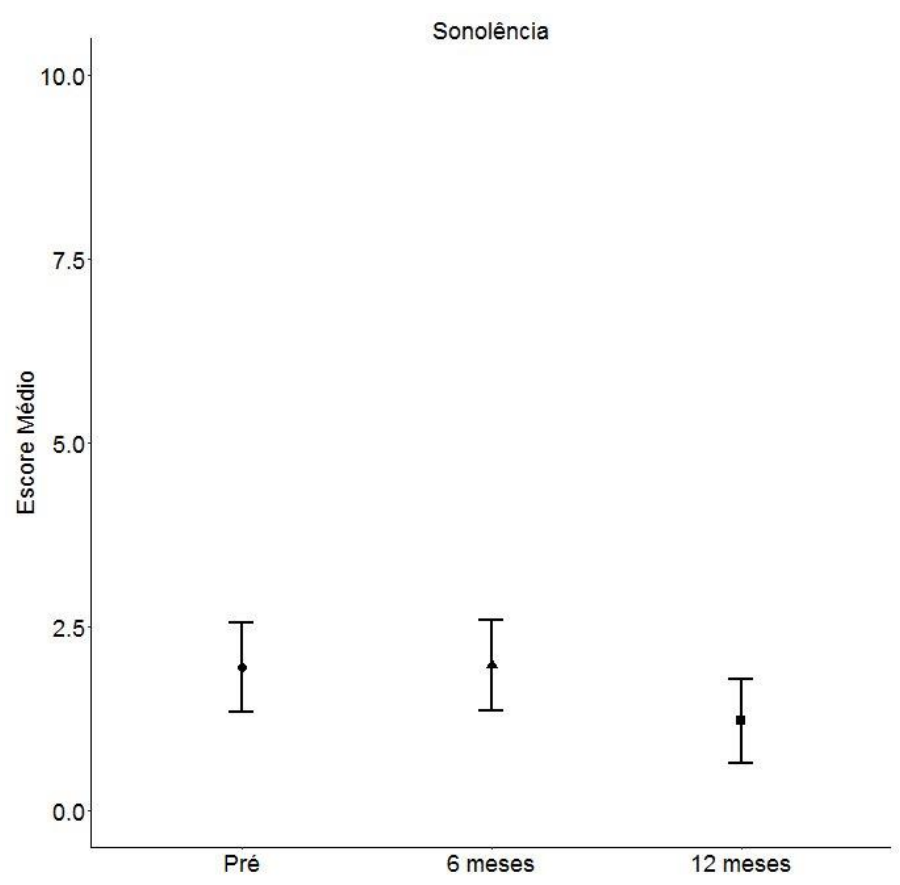

Figura 26 Valores médios e respectivos intervalos de confiança para o escore do sintoma Sonolência (MDASI) ao longo das avaliações 


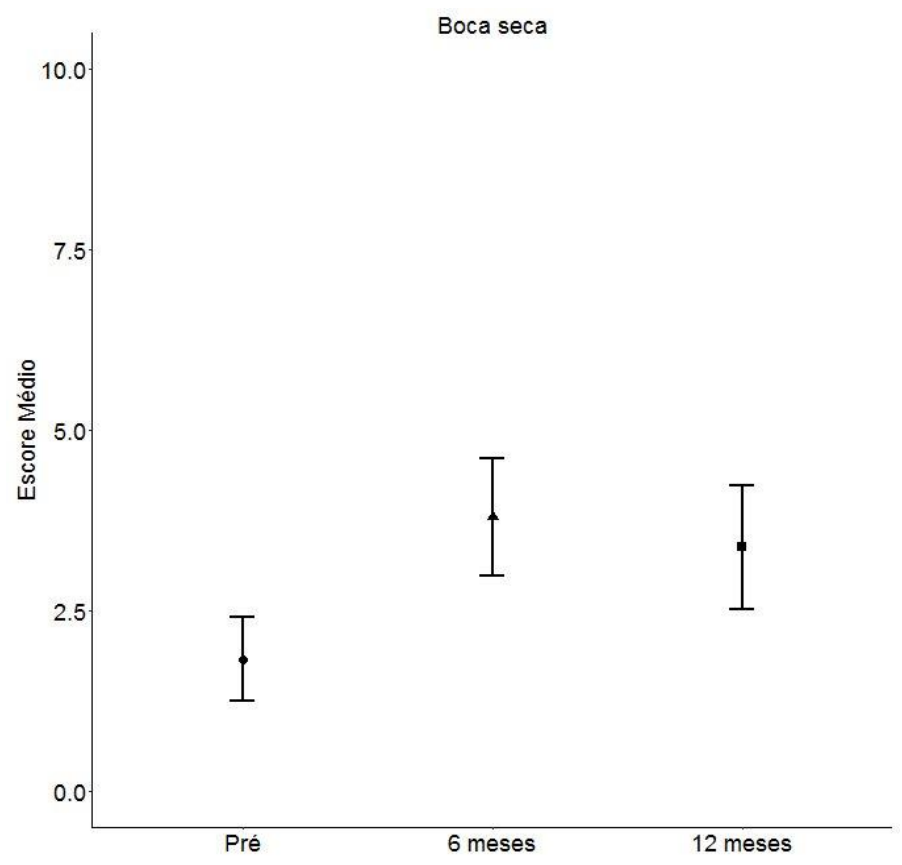

Figura 27 Valores médios e respectivos intervalos de confiança para o escore do sintoma Sensação de boca seca (MDASI) ao longo das avaliações

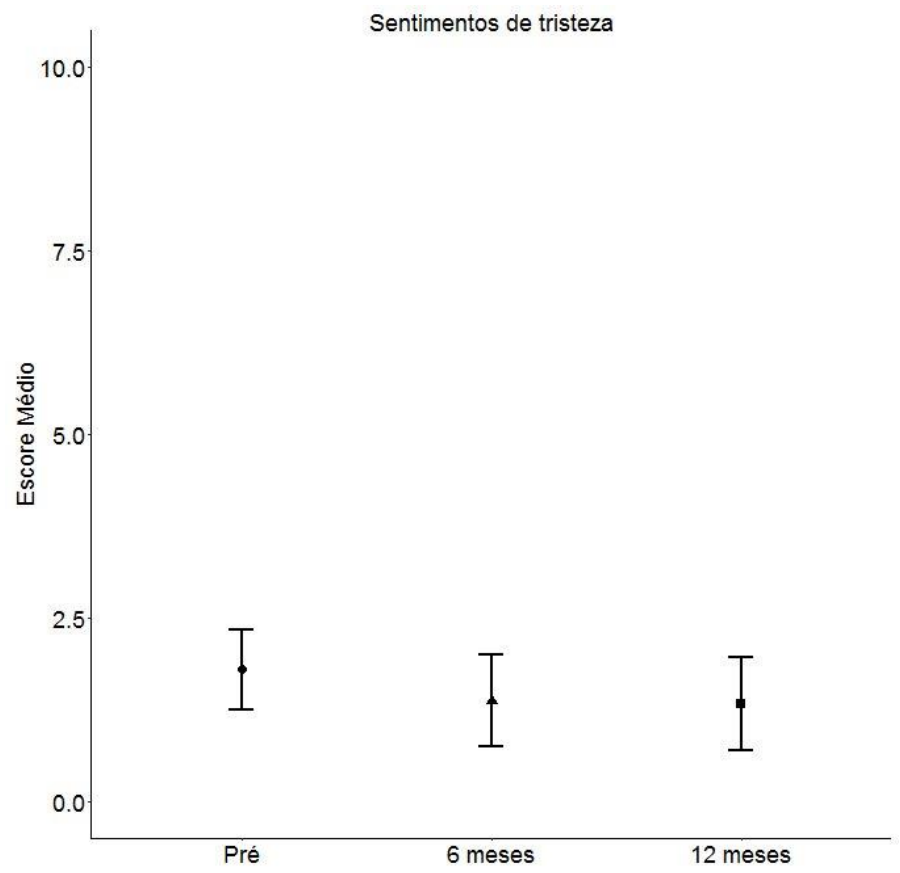

Figura 28 Valores médios e respectivos intervalos de confiança para o escore do sintoma Sentimento de tristeza (MDASI) ao longo das avaliações 


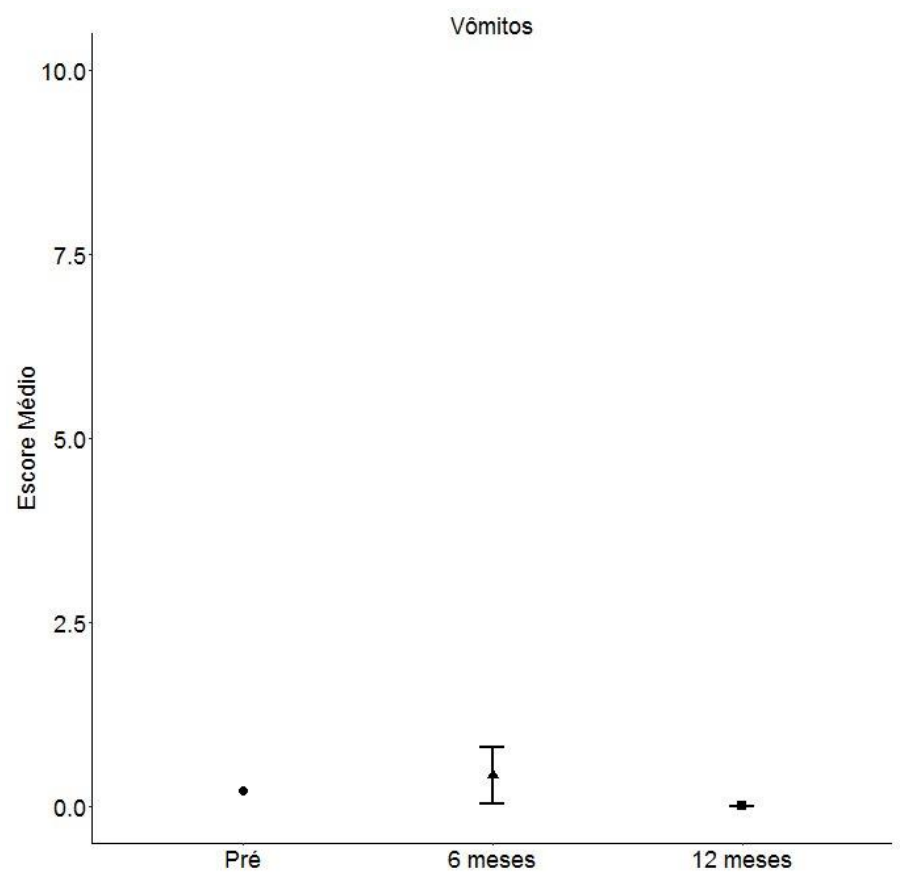

Figura 29 Valores médios e respectivos intervalos de confiança para o escore do sintoma Vômitos (MDASI) ao longo das avaliações

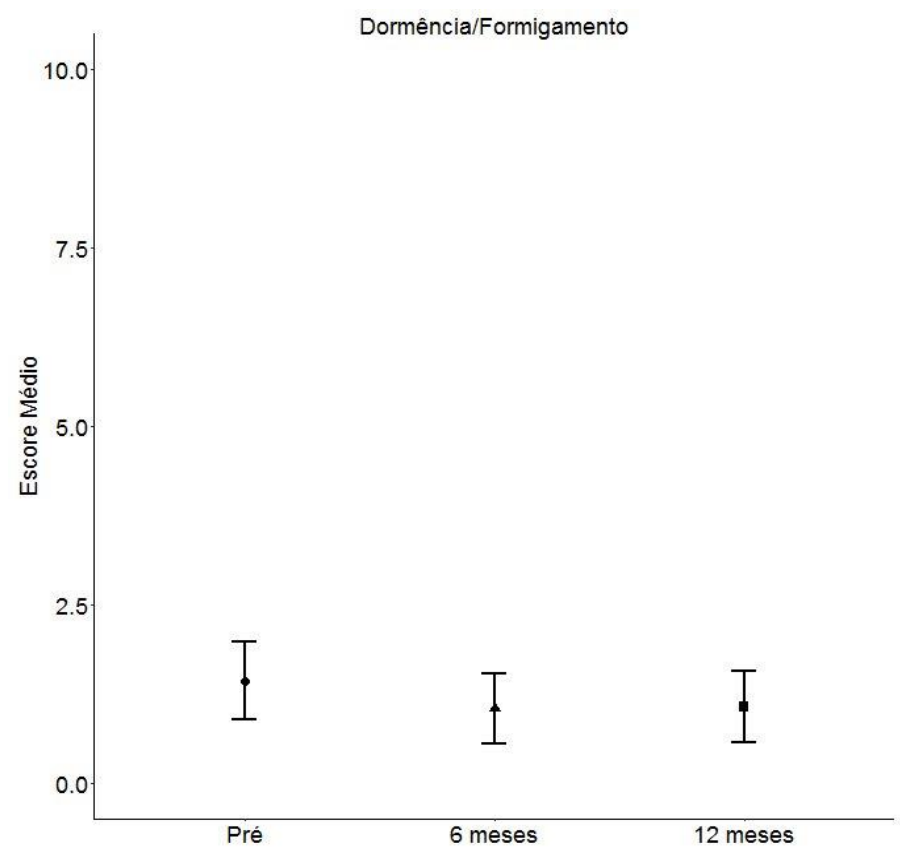

Figura 30 Valores médios e respectivos intervalos de confiança para o escore do sintoma Sensação de dormência/formigamento (MDASI) ao longo das avaliações 


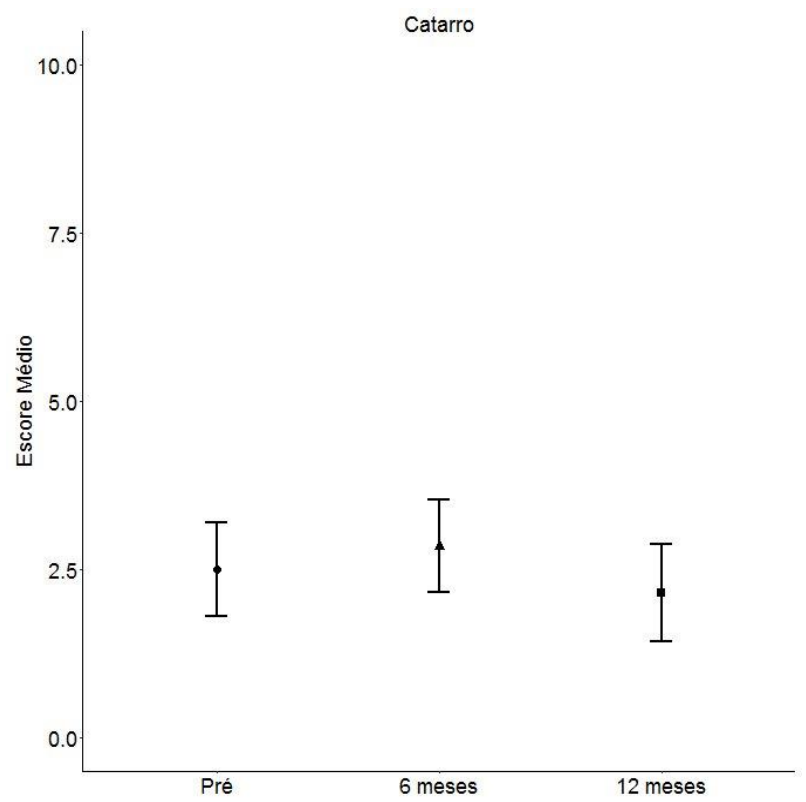

Figura 31 Valores médios e respectivos intervalos de confiança para o escore do sintoma Catarro na boca ou na garganta (MDASI) ao longo das avaliações

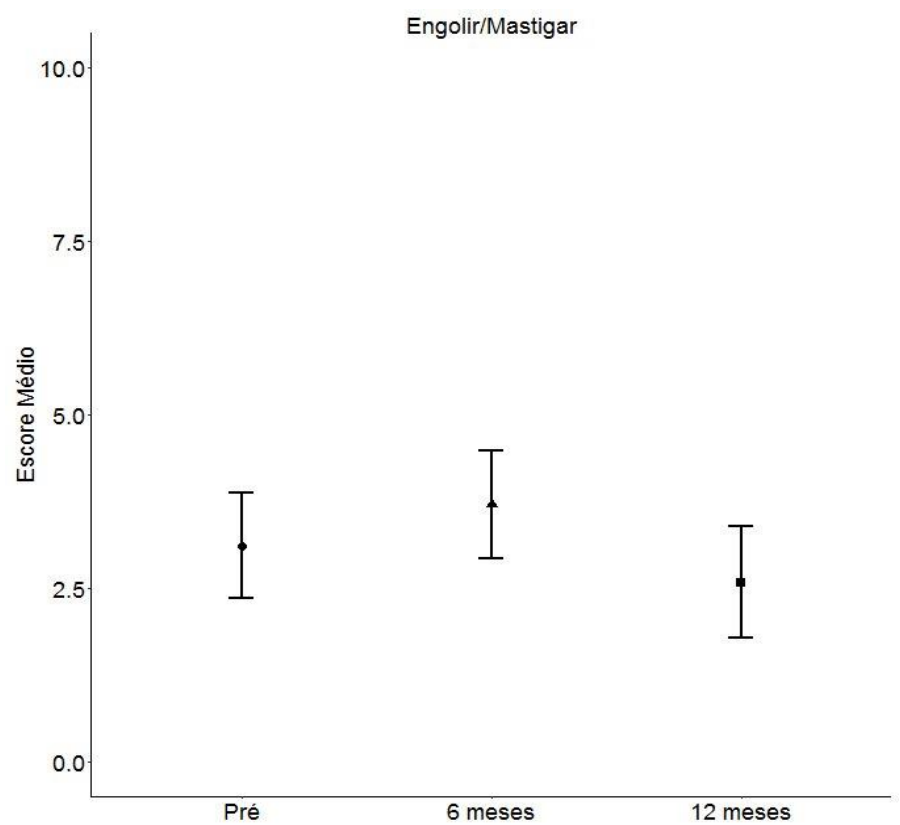

Figura 32 Valores médios e respectivos intervalos de confiança para o escore do sintoma Dificuldade para engolir/mastigar (MDASI) ao longo das avaliações 


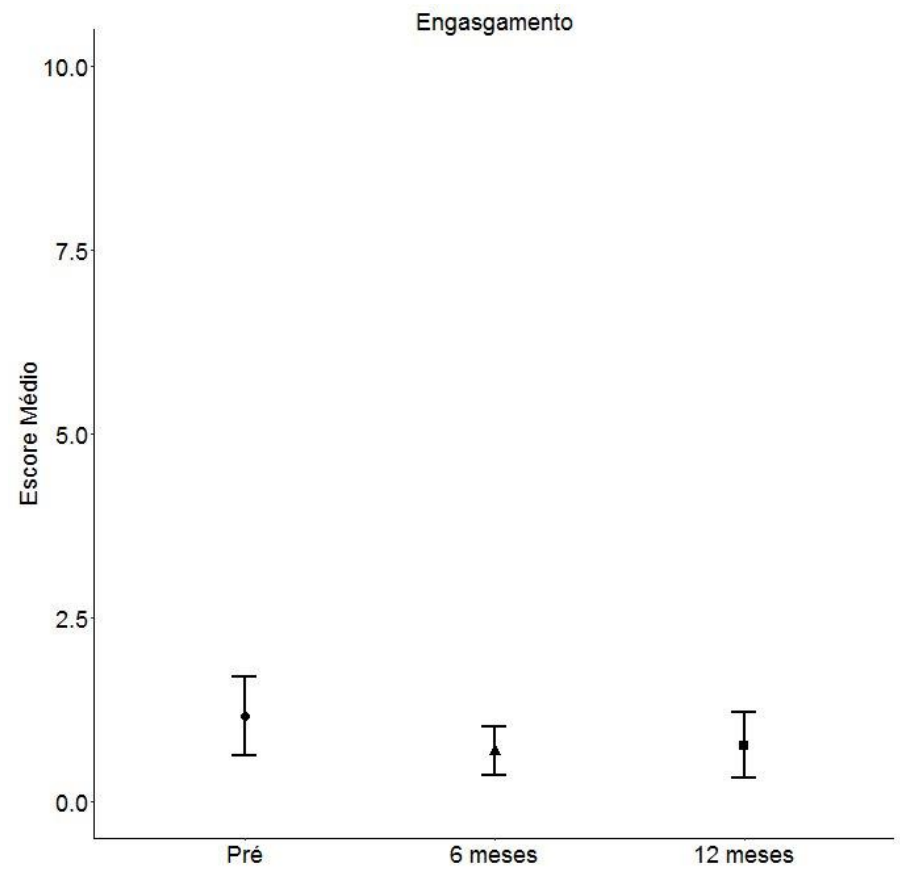

Figura 33 Valores médios e respectivos intervalos de confiança para o escore do sintoma Engasgamento (MDASI) ao longo das avaliações

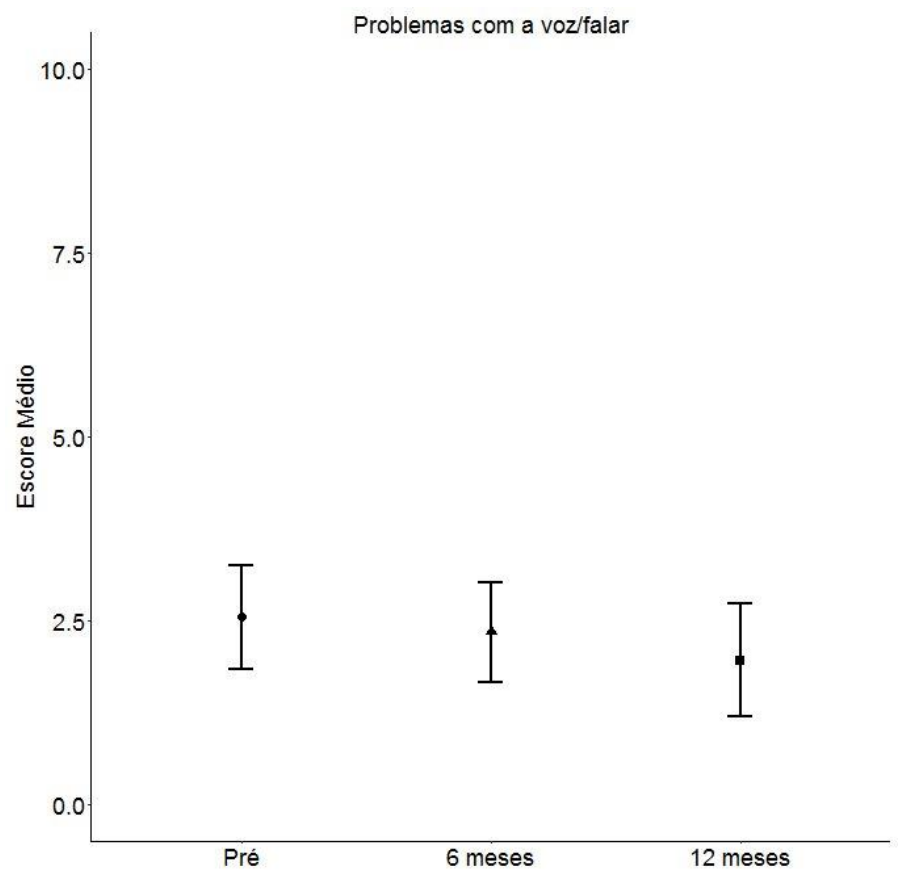

Figura 34 Valores médios e respectivos intervalos de confiança para o escore do sintoma Problemas com a voz/para falar (MDASI) ao longo das avaliações 


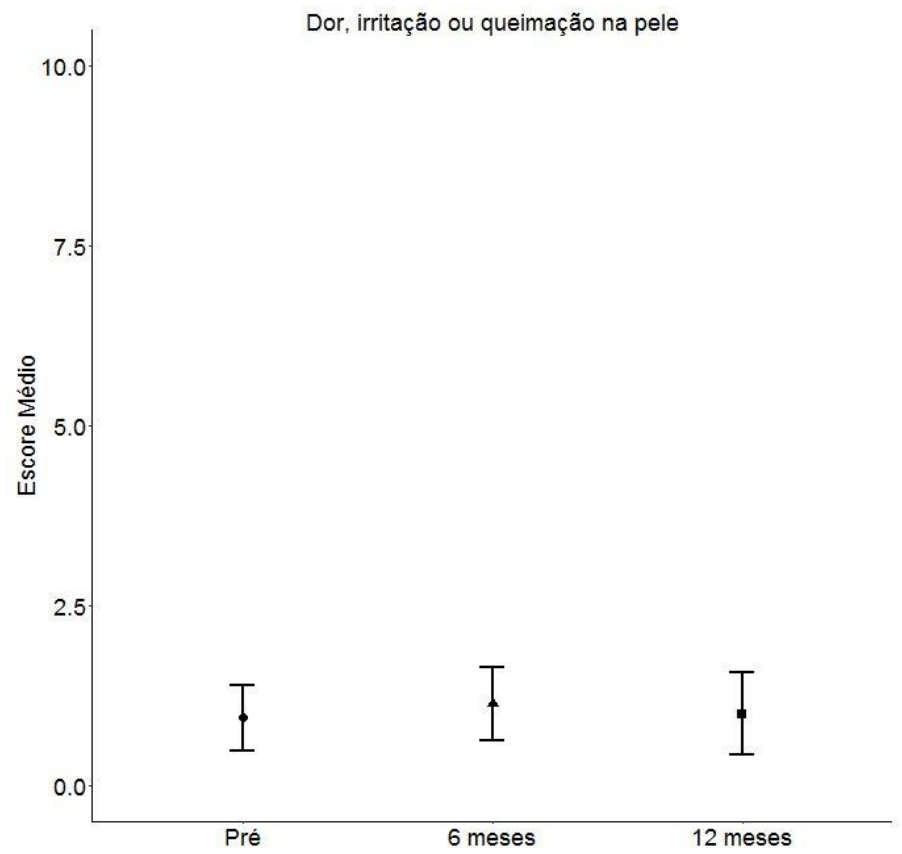

Figura 35 Valores médios e respectivos intervalos de confiança para o escore do sintoma Dor/queimação ou irritação na pele (MDASI) ao longo das avaliações

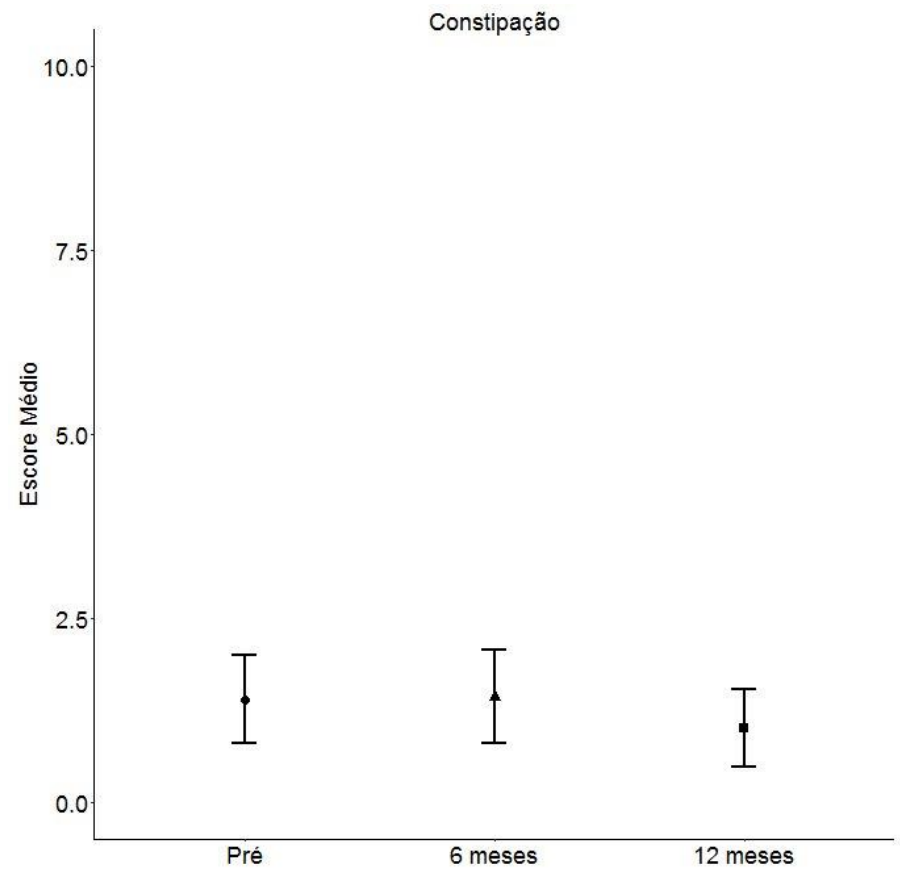

Figura 36 Valores médios e respectivos intervalos de confiança para o escore do sintoma Constipação (MDASI) ao longo das avaliações 


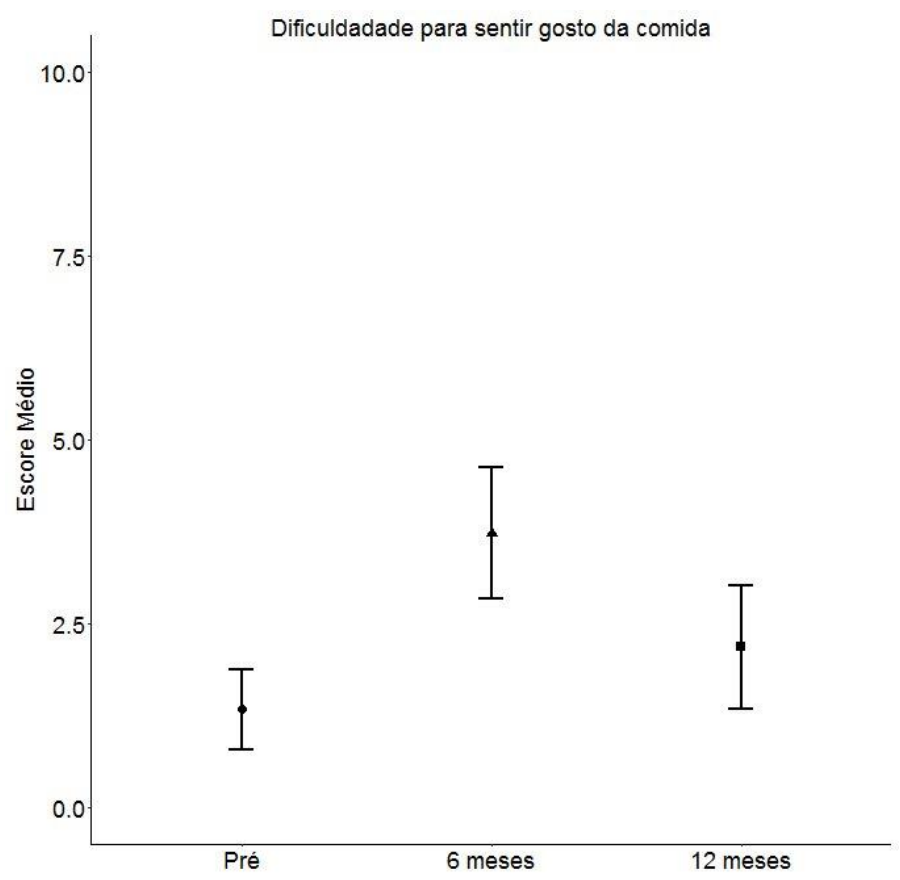

Figura 37 Valores médios e respectivos intervalos de confiança para o escore do sintoma Dificuldade para sentir o gosto da comida (MDASI) ao longo das avaliações

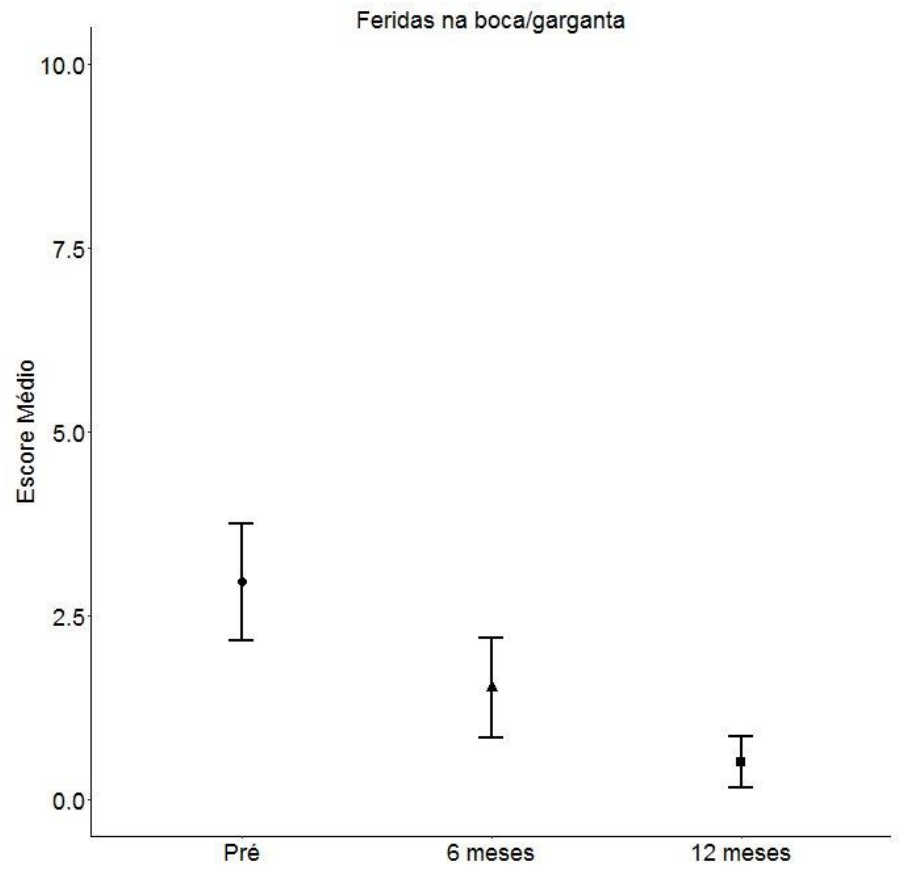

Figura 38 Valores médios e respectivos intervalos de confiança para o escore do sintoma Feridas na boca/garganta (MDASI) ao longo das avaliações 


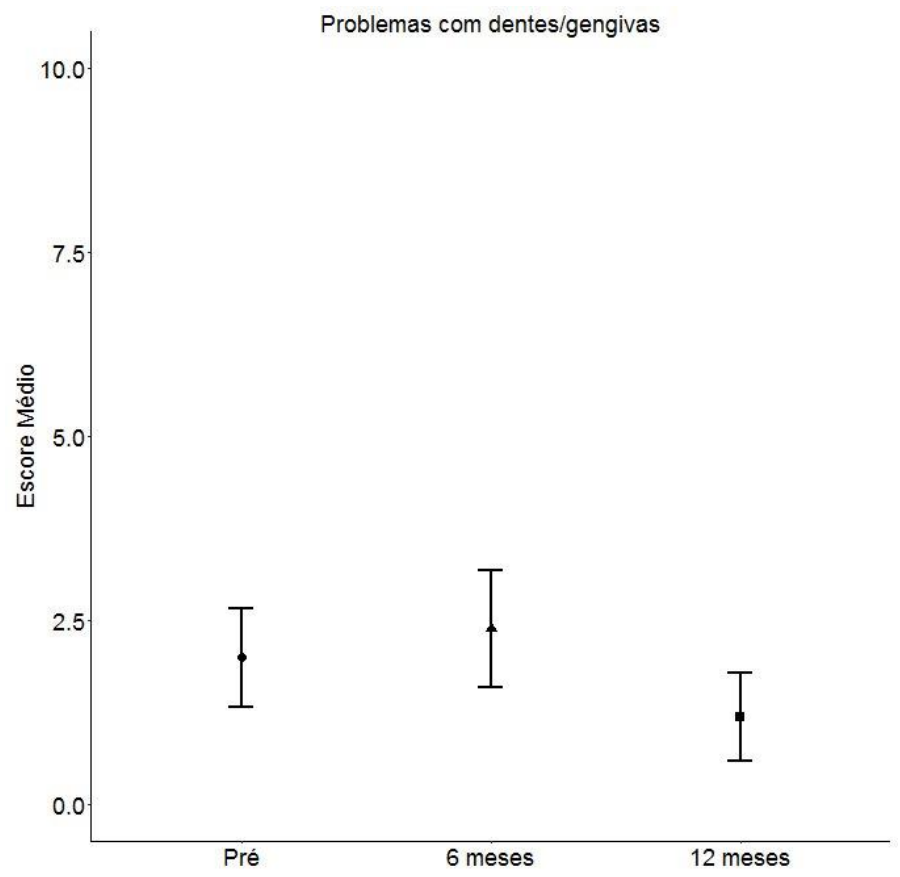

Figura 39 Valores médios e respectivos intervalos de confiança para o escore do sintoma Problemas com dentes/gengivas (MDASI) ao longo das avaliações 


\subsection{NECESSIDADES, PREFERÊNCIAS E ATITUDES FRENTE ÀS INFORMAÇÕES (QIP)}

Nos três momentos do estudo os pacientes assinalaram que queriam receber toda informação geral possível sobre a doença, sendo esta boa ou má (Tabela 11).

Tabela 11 Número e porcentagem de pacientes, nos momentos pré-tratamento $(\mathrm{N}=104), 6$ meses $(\mathrm{N}=80)$ e 12 meses $(\mathrm{N}=62)$ após o diagnóstico, conforme a atitude preferencial no que diz respeito às informações gerais sobre a doença

\begin{tabular}{lccc}
\hline & $\begin{array}{c}\text { Pré } \\
\mathbf{N}=\mathbf{6 0 4})\end{array}$ & $\begin{array}{c}\mathbf{6} \text { meses } \\
\mathbf{( N = 8 0 )}\end{array}$ & $\begin{array}{c}\mathbf{1 2} \text { meses } \\
\mathbf{( N = 6 2 )}\end{array}$ \\
\cline { 2 - 4 } Seção A & $\mathbf{n}(\mathbf{\%})$ & $\mathbf{n ~ ( \% )}$ & $\mathbf{n}(\mathbf{\%})$ \\
\hline Não quero saber detalhes; deixo que o médico decida & $13(12,5)$ & $7(8,8)$ & $6(9,7)$ \\
Quero informações adicionais apenas quando são boas notícias & $5(4,8)$ & $4(5,0)$ & $2(3,2)$ \\
Quero toda informação possível, boa ou má & $86(82,7)$ & $69(86,2)$ & $54(87,1)$ \\
\hline
\end{tabular}

Conforme descrito na Tabela 12, observa-se que a maioria dos pacientes considerava necessário receber informações mais específicas sobre seu diagnóstico, tratamento, progressão da doença, efeitos colaterais do tratamento e prognóstico, em todas as épocas do estudo. 
Tabela 12 Número e porcentagem de pacientes, nos momentos pré-tratamento $(\mathrm{N}=104), 6$ meses $(\mathrm{N}=80)$ e 12 meses $(\mathrm{N}=62)$ após o diagnóstico, conforme a necessidade de informações específicas sobre a doença e o tratamento

\begin{tabular}{|c|c|c|c|c|c|c|c|}
\hline Seção B & $\begin{array}{l}\text { Se é ou não } \\
\text { câncer }\end{array}$ & $\begin{array}{l}\text { Qual o nome } \\
\text { específico da } \\
\text { doença }\end{array}$ & $\begin{array}{c}\text { Quando você está em } \\
\text { tratamento, saber } \\
\text { como está progredindo } \\
\text { semana a semana }\end{array}$ & $\begin{array}{l}\text { Quais são as } \\
\text { chances de } \\
\text { cura }\end{array}$ & $\begin{array}{l}\text { Quais são todos } \\
\text { os tratamento } \\
\text { possíveis }\end{array}$ & $\begin{array}{c}\text { Quais são os } \\
\text { efeitos } \\
\text { colaterais do } \\
\text { tratamento }\end{array}$ & $\begin{array}{c}\text { Como o } \\
\text { tratamento } \\
\text { funciona para } \\
\text { tratar a } \\
\text { doença } \\
\end{array}$ \\
\hline Pré (N=104) & \multicolumn{7}{|c|}{ n (\%) } \\
\hline É necessário saber esta informação de qualquer maneira & $97(93,3)$ & $81(77,8)$ & $99(95,2)$ & $101(97,1)$ & $100(96,1)$ & $95(91,3)$ & $95(91,3)$ \\
\hline Não necessário ter esta informação & $3(2,8)$ & $19(18,3)$ & $3(2,9)$ & $1(1,0)$ & $1(1,0)$ & $5(4,8)$ & $6(5,8)$ \\
\hline É uma informação necessária, mas não gostaria de ter & $4(3,9)$ & $4(3,9)$ & $2(1,9)$ & $2(1,9)$ & $3(2,9)$ & $4(3,9)$ & $3(2,9)$ \\
\hline \multicolumn{8}{|l|}{6 meses $(\mathrm{N}=80)$} \\
\hline É necessário saber esta informação de qualquer maneira & $78(97,5)$ & $65(81,2)$ & $76(95,0)$ & $79(98,7)$ & $76(95,0)$ & $72(90,0)$ & $72(90,0)$ \\
\hline Não necessário ter esta informação & $2(2,5)$ & $14(17,5)$ & $3(3,7)$ & $1(1,3)$ & $3(3,7)$ & $8(10,0)$ & $7(8,7)$ \\
\hline É uma informação necessária, mas não gostaria de ter & 0 & $1(1,3)$ & $1(1,3)$ & 0 & $1(1,3)$ & 0 & $1(1,3)$ \\
\hline É necessário saber esta informação de qualquer maneira & $61(98,4)$ & $54(87,1)$ & $57(91,9)$ & $58(93,5)$ & $61(98,4)$ & $60(96,8)$ & $58(93,5)$ \\
\hline Não necessário ter esta informação & 0 & $8(12,9)$ & $5(8,1)$ & $4(6,5)$ & $1(1,6)$ & $1(1,6)$ & $4(6,5)$ \\
\hline É uma informação necessária, mas não gostaria de ter & $1(1,6)$ & 0 & 0 & 0 & 0 & $1(1,6)$ & 0 \\
\hline
\end{tabular}


Ainda, em todos os momentos do estudo, a maioria dos pacientes preferiu que a primeira informação sobre a doença tivesse sido dada pelo médico especialista do hospital (Tabela 13).

Tabela 13 Número e porcentagem de pacientes, nos momentos pré-tratamento $(\mathrm{N}=104), 6$ meses $(\mathrm{N}=80)$ e 12 meses $(\mathrm{N}=62)$ após o diagnóstico, conforme a preferência quanto à pessoa que o informou sobre a sua doença na primeira vez em que esta lhe foi explicada

\begin{tabular}{lccc}
\hline & $\begin{array}{c}\text { Pré } \\
\mathbf{( N = 1 0 4 )}\end{array}$ & $\begin{array}{c}\mathbf{6} \text { meses } \\
\mathbf{( N = 8 0 )}\end{array}$ & $\begin{array}{c}\mathbf{1 2} \text { meses } \\
\mathbf{( N = 6 2 )}\end{array}$ \\
\cline { 2 - 4 } Seção C & $\mathbf{n ~ ( \% )}$ & $\mathbf{n ~ ( \% )}$ & $\mathbf{n ~ ( \% )}$ \\
\hline Seu clínico geral & $1(1,0)$ & 0 & $1(1,6)$ \\
O médico especialista do hospital & $72(69,2)$ & $64(80,0)$ & $47(75,8)$ \\
Uma enfermerira & 0 & 0 & 0 \\
Sem preferência & $29(27,9)$ & $15(18,7)$ & $14(22,6)$ \\
Um familiar & 0 & 0 & 0 \\
Outros & $2(1,9)^{1}$ & $1(1,3)^{2}$ & 0 \\
\hline
\end{tabular}

1 - Profissional não especificado pelo paciente

2 - Psicólogo 


\subsection{PREOCUPAÇÕES DOS PACIENTES (IPP)}

Dentre os 56 itens presentes na Parte 1 do IPP, as dez preocupações assinaladas com maior frequência pelos pacientes no momento pré-tratamento foram: mastigar/comer $(67,3 \%, n=70)$, tratamento do câncer e fala/voz/ser entendido (ambos $61,5 \%, n=64)$, engolir $(56,7 \%, n=59)$, dor na cabeça e pescoço $(55,8 \%, n=58)$, medo do câncer voltar $(53,9 \%, n=56)$, feridas na boca e sonda para alimentação (ambas $50,0 \%, \mathrm{n}=52)$, apetite $(48,1 \%, \mathrm{n}=50)$ e fadiga/cansaço, juntamente com perda de peso (todos $47,1 \%, \mathrm{n}=49)$.

No item outros (texto livre), foram descritas as seguintes preocupações: ter que realizar tratamentos associados, afastamento do trabalho e saber se/quando será possível retornar ao trabalho.

Os três profissionais mais selecionados pelos pacientes neste momento foram o fonoaudiólogo $(51,9 \%, \quad \mathrm{n}=54), \quad$ nutricionista $(49,0 \%, \quad \mathrm{n}=51)$ e $\quad$ o oncologista/radioterapeuta $(47,1 \%, \mathrm{n}=49)$. $\mathrm{O}$ único profissional sugerido no texto livre foi o profissional de beleza.

Aos 6 meses após o diagnóstico, as dez principais preocupações dos pacientes foram: mastigar/comer e boca seca (ambas 55,0\%, $\mathrm{n}=44$ ), saúde dental/dentes $(52,5 \%, n=42)$, medo do câncer voltar $(51,3 \%, n=41)$, paladar (sentir sabor) e medo de acontecimentos desfavoráveis (ambos 45,0\%, $\mathrm{n}=36$ ), atividade física e catarro/secreção (ambas 42,5\%, n=34), engolir e tratamento do câncer (ambos $41,3 \%, n=33)$.

Já os três profissionais mais selecionados nesta época foram o cirurgião $(46,3 \%, n=37)$, o dentista $(42,5 \%, n=34)$ e o fonoaudiólogo $(32,5 \%, n=26)$. 
Diversas novas preocupações foram citadas pelos pacientes aos 6 meses após o diagnóstico: problemas de visão, dor e queimação no estômago, engasgos assistemáticos (2 vezes), perda da identidade pessoal por causa da mudança na voz, perspectivas futuras em relação à doença e ao tratamento, desafio da retomada da rotina de vida diária, problemas familiares, falecimento do filho, afastamento dos netos, não poder ajudar a família, necessidade de nova internação, perda de emprego, falta de concentração, perda de atenção rapidamente, fraqueza nas pernas (2 vezes), como gerenciar a vida em viagens no que diz respeito à comunicação e alimentação, cirurgia para retirada de tumor (TU) benigno atrás globo ocular esquerdo, saber se conseguirá voltar a beijar na boca e receio de como será a vida sexual por conta da ausência da língua.

Também foram sugeridos novos profissionais para os quais os pacientes gostariam de ser encaminhados: dermatologista, audiologista, pneumologista, urologista, cirurgião vascular e ortopedista.

Aos 12 meses após o diagnóstico, as dez principais preocupações referidas pelos pacientes foram: medo do câncer voltar $(54,8 \%, n=34)$, boca seca $(41,9 \%$, $\mathrm{n}=26)$, tratamento do câncer $(40,3 \%, \mathrm{n}=25)$, mastigar/comer $(38,7 \%, \mathrm{n}=24)$, saúde dental/dentes, níveis de energia e engolir (todos 33,9\%, $\mathrm{n}=21$ ), fadiga/cansaço, audição e catarro/secreção (todos 32,3\%, n=20).

Os profissionais mais selecionados aos 12 meses foram o cirurgião $(53,2 \%$, $\mathrm{n}=33)$, o fonoaudiólogo $(45,2 \%, \mathrm{n}=28)$ e o dentista $(35,5 \%, \mathrm{n}=22)$.

As novas preocupações mencionadas pelos pacientes que completaram a pesquisa aos 12 meses foram: engasgos, cirurgia de reconstrução, problemas na próstata, saber se poderá voltar a beber vinho socialmente, dores na face causada por herpes zoster, perda de motivação profissional, dor de ouvido, tonturas, dores na 
coluna, estenose de esôfago, fibrose no pescoço devido à radioterapia, interações medicamentosas, osteorradionecrose e nova biópsia na laringe.

Os novos profissionais mencionados por estes pacientes foram: médico para controle de dor, proctologista, gastroenterologista, urologista, endocrinologista, ginecologista, dermatologista (2 vezes) e cirurgião plástico.

A comparação entre as frequências das preocupações e dos profissionais assinalados no IPP nos três momentos avaliados está descrita nas Tabelas 14, 15 e 16 e nas Figuras 40 a 44.

As preocupações e os profissionais selecionados no IPP em cada momento do estudo estão descritas nos Anexos U, V, W, X, Y e Z. 
Tabela 14 Frequência das preocupações relacionadas aos itens de Bem-estar Físico e Funcional do Inventário de Preocupações dos Pacientes - IPP, selecionadas pelos pacientes, de acordo com a época do tratamento

\begin{tabular}{|c|c|c|c|c|c|c|c|}
\hline \multicolumn{8}{|l|}{ IPP } \\
\hline & \multirow{2}{*}{ Itens } & \multicolumn{2}{|c|}{ Pré } & \multicolumn{2}{|c|}{6 meses } & \multicolumn{2}{|c|}{12 meses } \\
\hline & & $\mathrm{n}$ & $(\%)$ & $\mathrm{n}$ & $(\%)$ & $\mathrm{n}$ & $(\%)$ \\
\hline & Atividade Física & 35 & 33,7 & 34 & 42,5 & 16 & 25,8 \\
\hline & Apetite & 50 & 48,1 & 27 & 33,8 & 14 & 22,6 \\
\hline & Hábito Intestinal & 25 & 24,0 & 19 & 23,8 & 7 & 11,3 \\
\hline & Respiração & 40 & 38,5 & 17 & 21,3 & 10 & 16,1 \\
\hline & Mastigar/comer & 70 & 67,3 & 44 & 55,0 & 24 & 38,7 \\
\hline & Tosse & 35 & 33,7 & 22 & 27,5 & 15 & 24,2 \\
\hline & Saúde dental/dentes & 46 & 44,2 & 42 & 52,5 & 21 & 33,9 \\
\hline & Boca seca & 37 & 35,6 & 44 & 55,0 & 26 & 41,9 \\
\hline & Níveis de energia & 31 & 29,8 & 31 & 38,8 & 21 & 33,9 \\
\hline & Fadiga/cançaço & 49 & 47,1 & 31 & 38,8 & 20 & 32,3 \\
\hline & Audição & 28 & 26,9 & 22 & 27,5 & 20 & 32,3 \\
\hline & Indisgestão & 14 & 13,5 & 14 & 17,5 & 4 & 6,5 \\
\hline \multirow[t]{17}{*}{ Bem-Estar Físico e Funcional } & Mobilidade & 25 & 24,0 & 13 & 16,3 & 8 & 12,9 \\
\hline & Abertura de boca & 34 & 32,7 & 22 & 27,9 & 17 & 27,4 \\
\hline & Catarro/secreção & 42 & 40,4 & 34 & 42,5 & 20 & 32,3 \\
\hline & Náusea & 24 & 23,1 & 13 & 16,3 & 7 & 11,3 \\
\hline & Dor na cabeça e pescoço & 58 & 55,8 & 20 & 25,0 & 15 & 24,2 \\
\hline & Dor em outro lugar & 27 & 26,0 & 12 & 15,0 & 12 & 19,4 \\
\hline & Regurgitação & 18 & 17,3 & 11 & 13,8 & 4 & 6,5 \\
\hline & Muita salivação & 32 & 30,8 & 10 & 12,5 & 0 & 0,0 \\
\hline & Ombros & 12 & 11,5 & 14 & 17,5 & 10 & 16,1 \\
\hline & Sono & 35 & 33,7 & 20 & 25,0 & 12 & 19,4 \\
\hline & Olfato (sentir cheiro) & 17 & 16,4 & 14 & 17,5 & 6 & 9,7 \\
\hline & Feridas na boca & 52 & 50,0 & 22 & 27,5 & 11 & 17,7 \\
\hline & Engolir & 59 & 56,7 & 33 & 41,3 & 21 & 33,9 \\
\hline & Inchaço & 37 & 35,6 & 15 & 18,8 & 9 & 14,5 \\
\hline & Paladar (sentir sabor) & 39 & 37,5 & 36 & 45,0 & 16 & 25,8 \\
\hline & Vômitos/mal-estar & 20 & 19,2 & 10 & 12,5 & 3 & 4,8 \\
\hline & Perda de peso & 49 & 47,1 & 29 & 36,3 & 16 & 25,8 \\
\hline
\end{tabular}




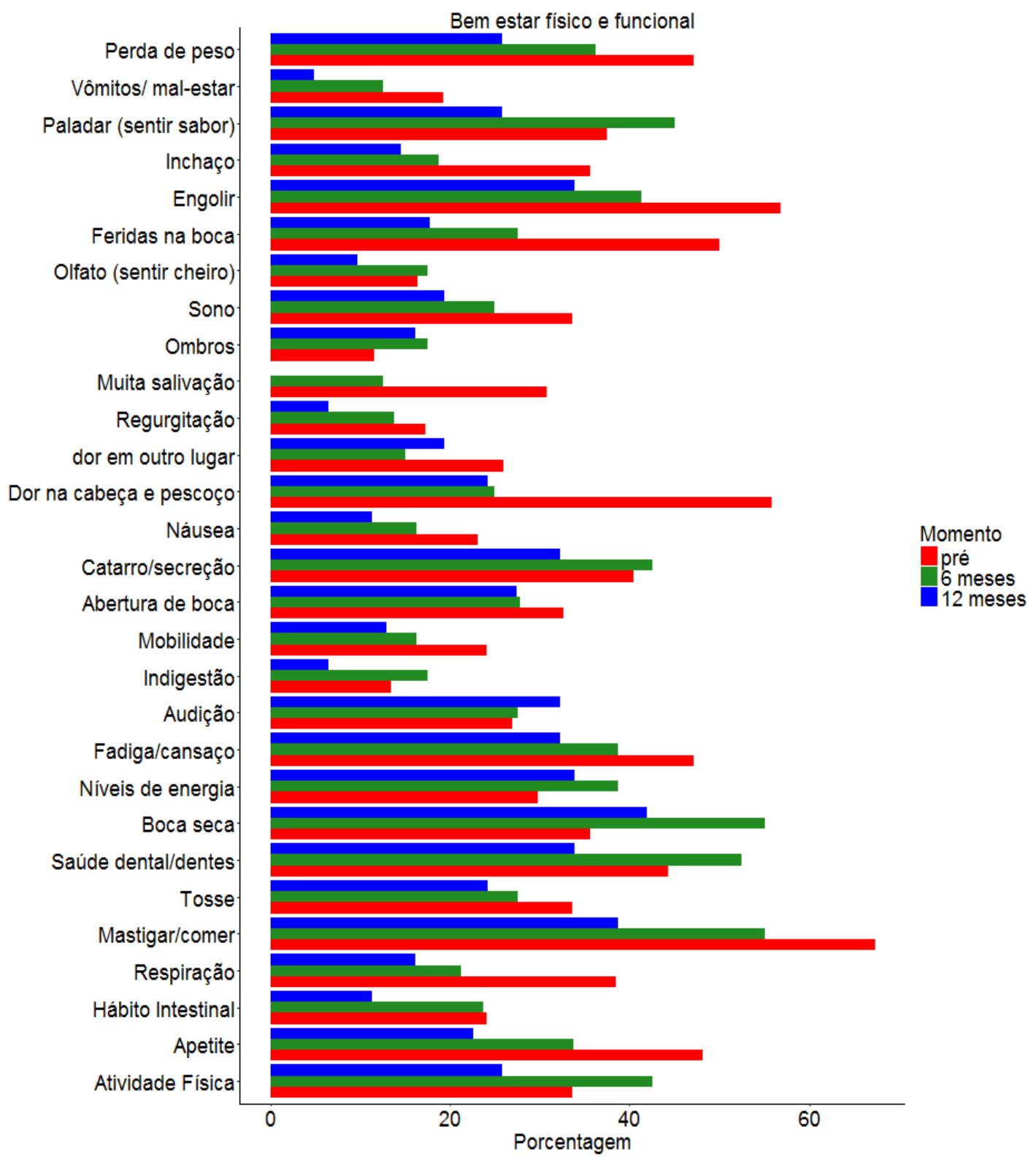

Figura 40 Frequência relativa das preocupações relacionadas aos itens de Bemestar Físico e Funcional do Inventário de Preocupações dos Pacientes IPP, selecionadas pelos pacientes, de acordo com a época do tratamento 
Tabela 15 Frequência das preocupações relacionadas aos itens de Tratamento, Assistência e Bem-estar Social e Bem-estar Psicológico, Emocional e Espiritual do Inventário de Preocupações dos Pacientes - IPP, selecionadas pelos pacientes, de acordo com a época do tratamento

\begin{tabular}{|c|c|c|c|c|c|c|c|}
\hline \multicolumn{8}{|l|}{ IPP } \\
\hline \multirow{6}{*}{ Relacionadas ao tratamento } & \multirow{2}{*}{ Itens } & \multicolumn{2}{|c|}{ Pré } & \multicolumn{2}{|c|}{6 meses } & \multicolumn{2}{|c|}{12 meses } \\
\hline & & $\mathrm{n}$ & (\%) & $\mathrm{n}$ & (\%) & $\mathrm{n}$ & $(\%)$ \\
\hline & Tratamento do câncer & 64 & 61,5 & 33 & 41,3 & 25 & 40,3 \\
\hline & Arrependimento pelo tratamento & 4 & 3,9 & 1 & 1,3 & 0 & 0,0 \\
\hline & Sonda para alimentação & 52 & 50,0 & 24 & 30,0 & 9 & 14,5 \\
\hline & Cicatrização de feridas & 45 & 43,3 & 14 & 17,5 & 5 & 8,1 \\
\hline \multirow{9}{*}{ Assistência e Bem-Estar Social } & Cuidador & 23 & 22,1 & 10 & 12,5 & 3 & 4,8 \\
\hline & Dependentes / crianças & 23 & 22,1 & 12 & 15,0 & 8 & 12,9 \\
\hline & Benefícios financeiros & 32 & 30,8 & 25 & 31,3 & 12 & 19,4 \\
\hline & Atendimento de profissionais à domicílio & 9 & 8,7 & 7 & 8,8 & 1 & 1,6 \\
\hline & Estilo de vida (fumo/álcool) & 16 & 15,4 & 6 & 7,5 & 5 & 8,1 \\
\hline & Recreação & 24 & 23,1 & 15 & 18,8 & 11 & 17,7 \\
\hline & Relacionamentos & 18 & 17,3 & 12 & 15,0 & 7 & 11,3 \\
\hline & Fala/voz/ser entendido & 64 & 61,5 & 33 & 41,3 & 18 & 29,0 \\
\hline & Suporte para minha família & 31 & 29,8 & 25 & 31,3 & 12 & 19,4 \\
\hline \multirow{14}{*}{$\begin{array}{l}\text { Bem-Estar Psicológico, } \\
\text { Emocional e Espiritual }\end{array}$} & Aparência & 43 & 41,4 & 19 & 23,8 & 14 & 22,6 \\
\hline & Raiva & 10 & 9,6 & 7 & 8,8 & 6 & 9,7 \\
\hline & Ansiedade & 43 & 41,4 & 21 & 26,3 & 14 & 22,6 \\
\hline & Estratégias para enfrentar a doença e o tratamento & 34 & 32,7 & 23 & 28,8 & 10 & 16,1 \\
\hline & Depressão & 22 & 21,2 & 10 & 12,5 & 4 & 6,5 \\
\hline & Medo do câncer voltar & 56 & 53,9 & 41 & 51,3 & 34 & 54,8 \\
\hline & Medo de acontecimentos desfavoráveis & 44 & 42,3 & 36 & 45,0 & 20 & 32,3 \\
\hline & Intimidade & 18 & 17,3 & 12 & 15,0 & 5 & 8,1 \\
\hline & Memória & 21 & 20,2 & 17 & 21,3 & 11 & 17,7 \\
\hline & Humor & 27 & 26,0 & 11 & 13,8 & 6 & 9,7 \\
\hline & Auto-estima & 24 & 23,1 & 11 & 13,8 & 10 & 16,1 \\
\hline & Sexualidade & 24 & 23,1 & 14 & 17,5 & 10 & 16,1 \\
\hline & Aspectos espirituais/religiosos & 11 & 10,6 & 7 & 8,8 & 1 & 1,6 \\
\hline & Personalidade e temperamento & 16 & 15,4 & 9 & 11,3 & 4 & 6,5 \\
\hline
\end{tabular}




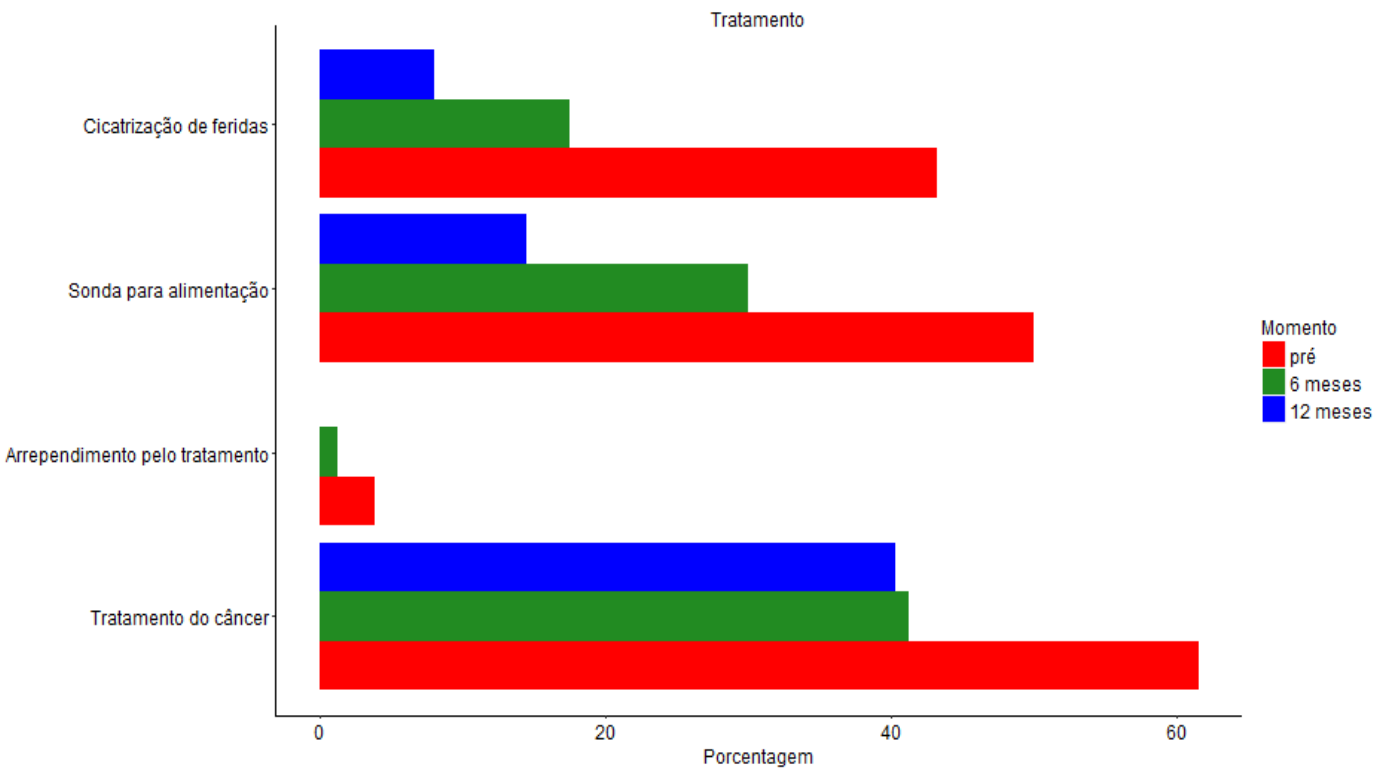

Figura 41 Frequência relativa das preocupações relacionadas aos itens Tratamento do Inventário de Preocupações dos Pacientes-IPP, selecionadas pelos pacientes, de acordo com a época do tratamento

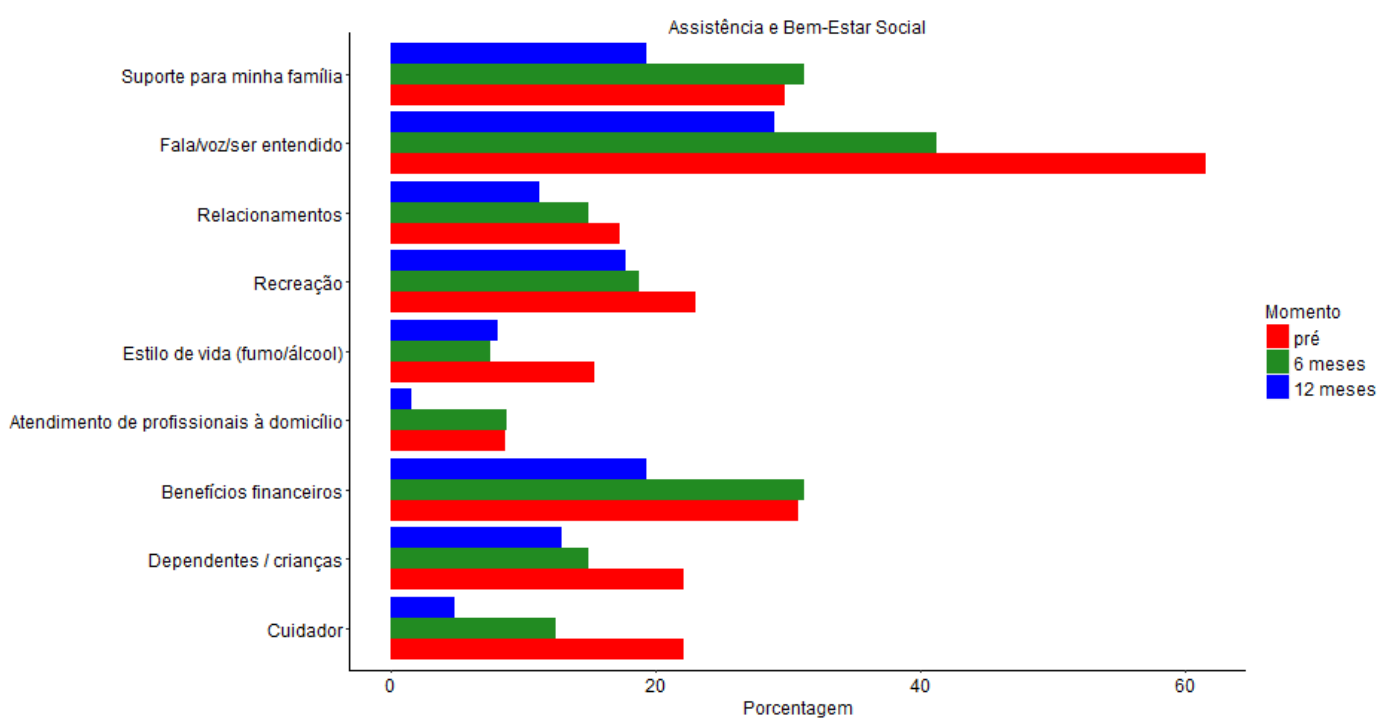

Figura 42 Frequência relativa das preocupações relacionadas aos itens de Assistência e Bem-estar Social do Inventário de Preocupações dos Pacientes-IPP, selecionadas pelos pacientes, de acordo com a época do tratamento 


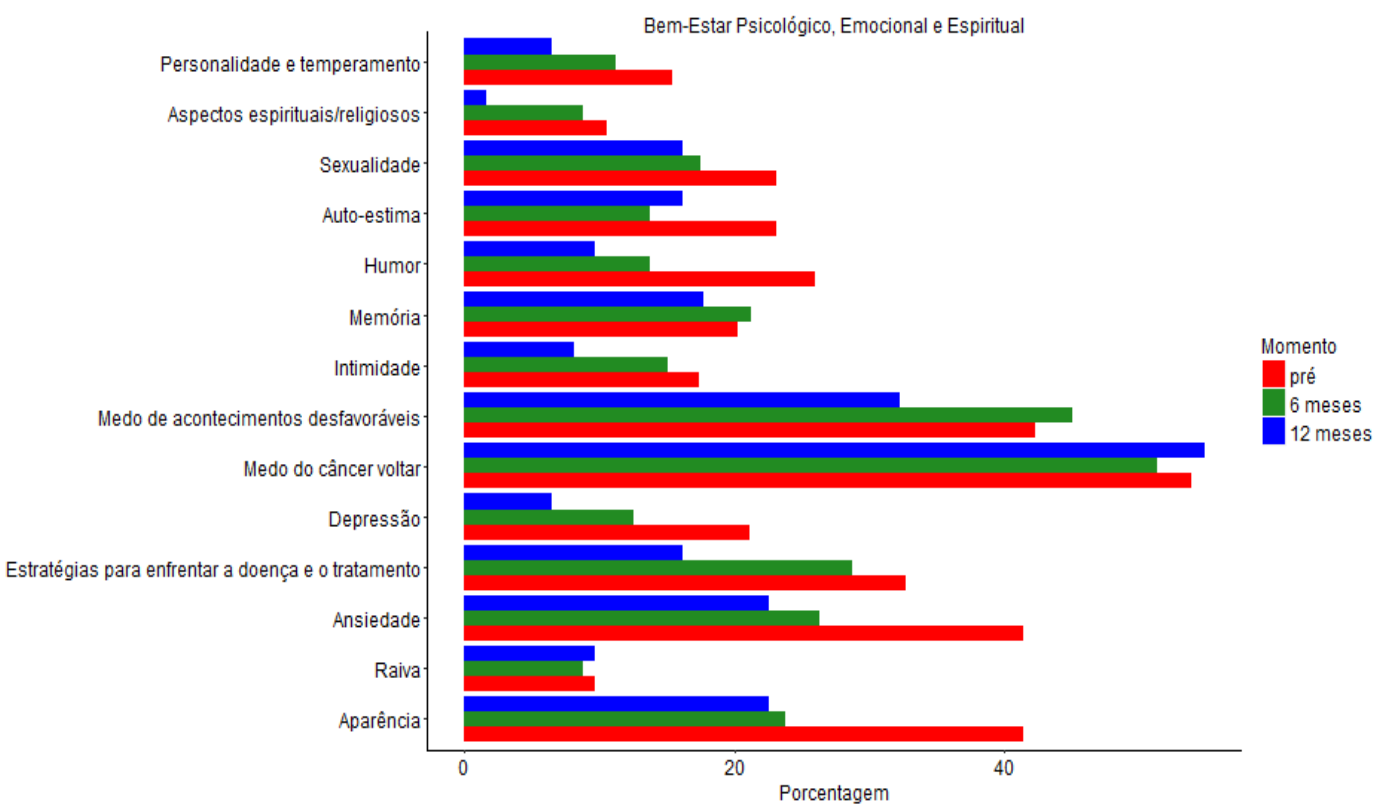

Figura 43 Frequência relativa das preocupações relacionadas aos itens de Bemestar Psicológico, Emocional e Espiritual do Inventário de Preocupações dos Pacientes-IPP, selecionadas pelos pacientes, de acordo com a época do tratamento 
Tabela 16 Frequência dos profissionais selecionados pelos pacientes no Inventário de Preocupações dos Pacientes - IPP, de acordo com a época do tratamento

\begin{tabular}{|c|c|c|c|c|c|c|c|}
\hline \multirow{2}{*}{ IPP } & \multirow{2}{*}{ Itens } & \multicolumn{2}{|c|}{ Pré } & \multicolumn{2}{|c|}{6 meses } & \multicolumn{2}{|c|}{12 meses } \\
\hline & & $\mathbf{n}$ & (\%) & $\mathrm{n}$ & (\%) & $\mathbf{n}$ & $(\%)$ \\
\hline \multirow{16}{*}{ Profissionais } & Dentista & 42 & 40,4 & 34 & 42,5 & 22 & 35,5 \\
\hline & Equipe de reabilitação oral & 33 & 31,7 & 20 & 25,0 & 12 & 19,4 \\
\hline & Nutricionista & 51 & 49,0 & 20 & 25,0 & 16 & 25,8 \\
\hline & Fisioterapeuta & 26 & 25,0 & 15 & 18,8 & 7 & 11,3 \\
\hline & Fonoaudiólogo & 54 & 51,9 & 26 & 32,5 & 28 & 45,2 \\
\hline & Terapeuta ocupacional & 12 & 11,5 & 3 & 3,8 & 2 & 3,2 \\
\hline & Equipe de enfermagem & 23 & 22,1 & 7 & 8,8 & 6 & 9,7 \\
\hline & Cirurgião & 48 & 46,2 & 37 & 46,3 & 33 & 53,2 \\
\hline & Oncologista / Radioterapeuta & 49 & 47,1 & 23 & 28,8 & 20 & 32,3 \\
\hline & Enfermeira clínica especialista & 20 & 19,2 & 9 & 11,3 & 7 & 11,3 \\
\hline & Assistente social & 28 & 26,9 & 13 & 16,3 & 13 & 21,0 \\
\hline & Clínico geral & 21 & 20,2 & 12 & 15,0 & 9 & 14,5 \\
\hline & Assessor financeiro & 9 & 8,7 & 8 & 10,0 & 5 & 8,1 \\
\hline & Autoridade religiosa / Líder da sua religião & 20 & 19,2 & 10 & 12,5 & 4 & 6,5 \\
\hline & Psiquiatra & 17 & 16,4 & 13 & 16,3 & 9 & 14,5 \\
\hline & Psicólogo & 24 & 23,1 & 18 & 22,5 & 9 & 14,5 \\
\hline
\end{tabular}




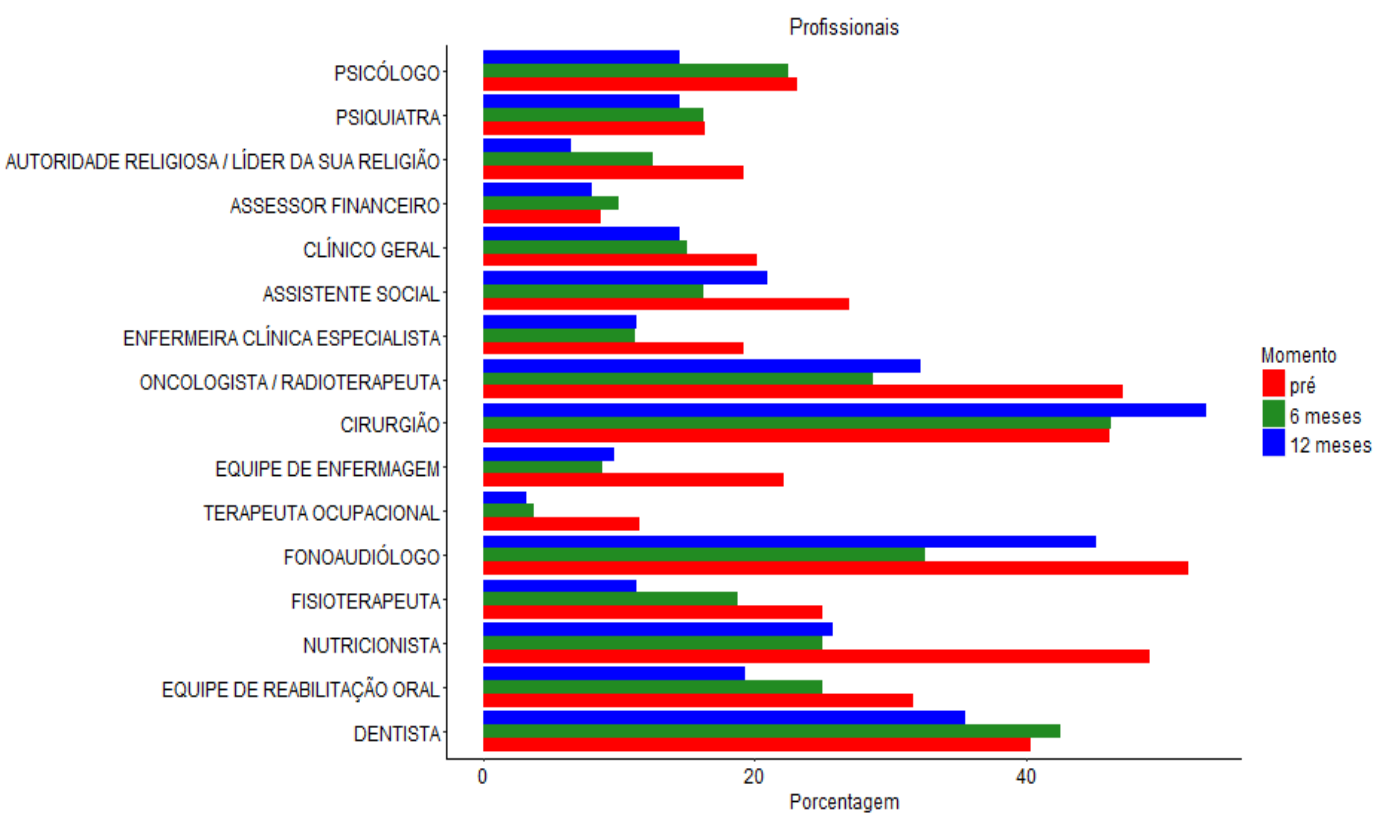

Figura 44 Frequência relativa dos profissionais selecionados pelos pacientes no Inventário de Preocupações dos Pacientes-IPP, de acordo com a época do tratamento 


\subsection{AVALIAÇÃO DAS EXPECTATIVAS NO MOMENTO PRÉ- TRATAMENTO (PAE)}

A maioria dos pacientes possuía boas expectativas para todos os itens relacionados ao bem-estar físico e funcional, sendo que um maior número de pacientes selecionou em maior frequência o item mastigar/comer $(84,6 \%, n=88)$.

Nos itens relacionados ao tratamento, a maioria dos pacientes tinha boas expectativas em relação ao tratamento do câncer $(96,2 \%, n=100)$ e mais da metade dos pacientes consideraram o arrependimento pelo tratamento como item não aplicável $(58,7 \%, \mathrm{n}=61)$.

No âmbito dos itens relacionados à assistência e bem-estar social, as expectativas foram boas, especialmente para os itens fala/voz/ser entendido, estratégias para enfrentar a doença e o tratamento (ambos 83,7\%, n=87), e aparência $(78,9 \%, n=82)$, e em relação às expectativas relacionadas ao bem-estar psicológico, emocional e espiritual em geral.

As Tabelas 17 e 18 descrevem as expectativas dos pacientes e sua frequência, no momento pré-tratamento. 
Tabela 17 Tipo e frequência das expectativas dos pacientes em relação aos itens de Bem-estar Físico e Funcional do Protocolo de Preenchimento das Expectativas - PAE, no momento pré-tratamento $(\mathrm{N}=104)$

\begin{tabular}{|c|c|c|c|c|}
\hline \multirow{2}{*}{\begin{tabular}{l}
\multicolumn{1}{c}{ Itens } \\
Bem-estar Físico e \\
Funcional
\end{tabular}} & \multicolumn{4}{|c|}{ Expectativas } \\
\hline & Não se aplica & Não sei & Ruins & Boas \\
\hline Atividade Física & $21(20,2)$ & $11(10,6)$ & 0 & $72(69,2)$ \\
\hline Apetite & $8(7,7)$ & $11(10,6)$ & $3(2,9)$ & $82(78,9)$ \\
\hline Hábito Intestinal & $24(23,1)$ & $13(12,5)$ & 0 & $67(64,4)$ \\
\hline Respiração & $13(12,5)$ & $12(11,5)$ & $2(1,9)$ & $77(74,0)$ \\
\hline Mastigar/comer & 0 & $7(6,7)$ & $9(8,7)$ & $88(84,6)$ \\
\hline Tosse & $21(20,2)$ & $19(18,3)$ & $4(3,9)$ & $60(57,7)$ \\
\hline Saúde dental $/$ dentes & $15(14,4)$ & $12(11,5)$ & $9(8,7)$ & $68(65,4)$ \\
\hline Boca seca & $24(23,1)$ & $17(16,4)$ & $7(6,7)$ & $56(53,9)$ \\
\hline Níveis de energia & $15(14,4)$ & $15(14,4)$ & $3(2,9)$ & $71(68,3)$ \\
\hline Fadiga/cansaço & $15(14,4)$ & $13(12,5)$ & $4(3,9)$ & $72(69,2)$ \\
\hline Audição & $24(23,1)$ & $14(13,5)$ & $4(3,9)$ & $62(59,6)$ \\
\hline Indigestão & $32(30,8)$ & $21(20,2)$ & 0 & $51(49,0)$ \\
\hline Mobilidade & $23(22,1)$ & $15(14,4)$ & $1(1,0)$ & $65(62,5)$ \\
\hline Abertura de boca & $8(7,7)$ & $12(11,5)$ & $5(4,8)$ & $79(76,0)$ \\
\hline Catarro/secreção & $18(17,3)$ & $13(12,5)$ & $1(1,0)$ & $72(69,2)$ \\
\hline Náusea & $35(33,7)$ & $15(14,4)$ & $1(1,0)$ & $53(51,0)$ \\
\hline Dor na cabeça e pescoço & $14(13,5)$ & $14(13,5)$ & $5(4,8)$ & $71(68,3)$ \\
\hline Dor em outro lugar & $28(26,9)$ & $15(14,4)$ & $3(2,9)$ & $58(55,8)$ \\
\hline Regurgitação & $32(30,8)$ & $17(16,4)$ & $1(1,0)$ & $54(51,9)$ \\
\hline Muita salivação & $22(21,2)$ & $14(13,5)$ & $2(1,9)$ & $66(63,5)$ \\
\hline Ombros & $33(31,7)$ & $17(16,4)$ & $1(1,0)$ & $53(51,0)$ \\
\hline Sono & $17(16,4)$ & $11(10,6)$ & $7(6,7)$ & $69(66,4)$ \\
\hline Olfato (sentir cheiro) & $23(22,1)$ & $14(13,5)$ & $2(1,9)$ & $65(62,5)$ \\
\hline Feridas na boca & $12(11,5)$ & $9(8,7)$ & $11(10,6)$ & $72(69,2)$ \\
\hline Engolir & $4(3,9)$ & $7(6,7)$ & $8(7,7)$ & $85(81,7)$ \\
\hline Inchaço & $22(21,2)$ & $14(13,5)$ & $6(5,8)$ & $62(59,6)$ \\
\hline Paladar (sentir sabor) & $18(17,3)$ & $9(8,7)$ & $9(8,7)$ & $68(65,4)$ \\
\hline Vômitos/mal-estar & $34(32,7)$ & $17(16,4)$ & $3(2,9)$ & $50(48,1)$ \\
\hline Perda de peso & $15(14,4)$ & $13(12,5)$ & $4(3,9)$ & $72(69,2)$ \\
\hline
\end{tabular}


Tabela 18 Tipo e frequência das expectativas dos pacientes em relação aos itens de Tratamento, Assistência e Bem-estar Social e Bem-estar Psicológico, Emocional e Espiritual do Protocolo de Preenchimento das Expectativas - PAE, no momento pré-tratamento $(\mathrm{N}=104)$

\begin{tabular}{|c|c|c|c|c|}
\hline \multirow{2}{*}{$\begin{array}{c}\text { Itens } \\
\text { Relacionados ao Tratamento }\end{array}$} & \multicolumn{4}{|c|}{ Expectativas } \\
\hline & Não se aplica & Não sei & Ruins & Boas \\
\hline Tratamento do câncer & 0 & $1(1,0)$ & $3(2,9)$ & $100(96,2)$ \\
\hline Arrependimento pelo tratamento & $61(58,7)$ & $10(9,6)$ & $1(1,0)$ & $32(30,8)$ \\
\hline Sonda para alimentação & $13(12,5)$ & $14(13,5)$ & $13(12,5)$ & $64(61,5)$ \\
\hline Cicatrização de feridas & $10(9,6)$ & $9(8,7)$ & $6(5,8)$ & $79(76,0)$ \\
\hline \multicolumn{5}{|l|}{ Assistência e Bem-estar Social } \\
\hline Cuidador & $26(25,0)$ & $13(12,5)$ & $2(1,9)$ & $63(60,6)$ \\
\hline Dependentes / crianças & $41(39,4)$ & $10(9,6)$ & $2(1,9)$ & $51(49,0)$ \\
\hline Benefícios financeiros & $26(25,0)$ & $13(12,5)$ & $6(5,8)$ & $59(56,7)$ \\
\hline Atendimento de profissionais à domicílio & $42(40,4)$ & $17(16,4)$ & $1(1,0)$ & $44(42,3)$ \\
\hline Estilo de vida (fumo/álcool) & $46(44,2)$ & $11(10,6)$ & $3(2,9)$ & $44(42,3)$ \\
\hline Recreação & $13(12,5)$ & $8(7,7)$ & $4(3,9)$ & $79(76,0)$ \\
\hline Relacionamentos & $20(19,2)$ & $8(7,7)$ & $5(4,8)$ & $71(68,3)$ \\
\hline Fala / voz / ser entendido & $4(3,9)$ & $6(5,8)$ & $7(6,7)$ & $87(83,7)$ \\
\hline Suporte para minha família & $16(15,4)$ & $13(12,5)$ & $1(1,0)$ & $74(71,2)$ \\
\hline \multicolumn{5}{|l|}{ Bem-estar Psicológico, Emocional e Espiritual } \\
\hline Aparência & $8(7,7)$ & $9(8,7)$ & $5(4,8)$ & $82(78,9)$ \\
\hline Raiva & $48(46,2)$ & $14(13,5)$ & $2(1,9)$ & $40(38,5)$ \\
\hline Ansiedade & $27(26,0)$ & $11(10,6)$ & $6(5,8)$ & $60(57,7)$ \\
\hline Estratégias para enfrentar a doença e o tratamento & $6(5,8)$ & $10(9,6)$ & $1(1,0)$ & $87(83,7)$ \\
\hline Depressão & $36(34,6)$ & $15(14,4)$ & $5(4,8)$ & $48(46,2)$ \\
\hline Medo do câncer voltar & $20(19,2)$ & $17(16,4)$ & $8(7,7)$ & $59(56,7)$ \\
\hline Medo de acontecimentos desfavoráveis & $19(18,3)$ & $20(19,2)$ & $10(9,6)$ & $55(52,9)$ \\
\hline Intimidade & $30(28,9)$ & $14(13,5)$ & $2(1,9)$ & $58(55,8)$ \\
\hline Memória & $24(23,1)$ & $14(13,5)$ & 0 & $66(63,5)$ \\
\hline Humor & $14(13,5)$ & $12(11,5)$ & $3(2,9)$ & $75(72,1)$ \\
\hline Auto-estima & $12(11,5)$ & $13(12,5)$ & $3(2,9)$ & $76(73,1)$ \\
\hline Sexualidade & $25(24,0)$ & $13(12,5)$ & $2(1,9)$ & $64(61,5)$ \\
\hline Aspectos espirituais / religiosos & $19(18,3)$ & $11(10,6)$ & 0 & $74(71,2)$ \\
\hline Personalidade e temperamento & $22(21,2)$ & $13(12,5)$ & $3(2,9)$ & $66(63,5)$ \\
\hline \multicolumn{5}{|l|}{ Outros } \\
\hline \multicolumn{5}{|l|}{ Descobrir um saldo positivo disto / me tornar uma } \\
\hline pessoa melhor & & & & $1(1,0)$ \\
\hline
\end{tabular}




\subsection{PREENCHIMENTO DAS EXPECTATIVAS (PPE)}

\subsubsection{Aos 6 meses}

Dentre os aspectos relacionados ao bem-estar físico e funcional, os resultados indicaram que, aos 6 meses após o diagnóstico, os pacientes consideraram que sua experiência em relação aos itens atividade física, apetite, hábito intestinal, mastigar/comer, saúde dental/dentes, níveis de energia, fadiga/cansaço, catarro/secreção, sono, engolir, paladar (sentir sabor), e perda de peso tinha sido pior ou igual ao que esperavam. Os itens tosse e olfato não se aplicaram na maioria dos casos, tendo sido em seguida considerados como pior ou melhor do que o esperado, em porcentagens próximas.

Os itens indigestão, náusea, regurgitação, dor na cabeça e pescoço e vômitos foram considerados, em geral, como não aplicáveis (para $\leq 50,0 \%$ dos pacientes) e como iguais ou melhores do que o esperado para os que experimentaram estes problemas, assim como a audição.

Problemas com dor em outro lugar, muita salivação, ombros e inchaço eram itens não aplicáveis para $\leq 57,5 \%$ dos pacientes ou tidos como piores ou iguais ao que esperavam, bem como com mobilidade, abertura de boca e feridas na boca.

Em geral, as expectativas dos pacientes em relação aos itens ligados à alimentação - mastigar/comer $(50,0 \%, n=40)$, boca seca $(48,8 \%, n=39)$, engolir $(47,5 \%, n=38)$, paladar (sentir sabor) $(45,0 \%, n=36)$ e perda de peso $(40,0 \%, n=32)$ foram as menos preenchidas aos 6 meses após o diagnóstico.

No âmbito dos itens relacionados ao tratamento, 95,0\% $(n=76)$ dos pacientes entendiam o arrependimento pelo tratamento como item não aplicável. O tratamento do câncer foi sentido por $61,3 \%(n=49)$ e por $25,0 \%(n=20)$ dos pacientes, 
respectivamente, como melhor ou igual do que o esperado. Dentre os 46 pacientes que utilizaram sonda para alimentação, a maior parte considerou a experiência pior do que o esperado $(23,8 \%, n=19)$. Já a cicatrização de feridas preencheu as expectativas dos pacientes, tendo sido melhor $(46,2 \%, n=37)$ ou igual $11,3 \%, n=9)$ do que a esperada.

Os resultados dos aspectos referentes aos itens de assistência e bem-estar social indicaram que a maioria teve suas expectativas preenchidas quanto ao cuidador $(62,5 \%, \mathrm{n}=50)$ e que a maioria não recebeu atendimento de profissionais à domicílio $(86,3 \%, n=6)$. Mais da metade dos pacientes não possuía expectativas em relação a dependentes/crianças $(57,5 \%, n=46)$ e, dentre os $42,5 \%(n=34)$ que as tinham, os resultados foram iguais $(15,0 \%, n=12)$ ou melhores $(22,5 \%, n=18)$ do que o esperado. Benefícios financeiros não se aplicavam à $62,5 \%(n=50)$ e a mesma porcentagem de pacientes considerou este item como pior ou melhor do que o esperado.

A fala/voz/ser entendido $(30,0 \%, n=24)$ e a recreação $(26,2 \%, n=21)$ e foram os aspectos mais frequentemente considerados pelos pacientes como piores do que o esperado. Os itens relacionamentos e suporte para minha família foram os que mais preencheram as expectativas dos pacientes, assim como o estilo de vida (fumo/álcool), para os indivíduos que interromperam o(s) vício(s) após o diagnóstico.

Muitos dos itens do domínio de bem-estar psicológico, emocional e espiritual preencheram de forma igual ou melhor as expectativas dos pacientes: estratégias para enfrentar a doença e o tratamento, medo do câncer voltar, intimidade, humor, autoestima, aspectos espirituais/religiosos e personalidade e temperamento. A raiva e a depressão não se aplicaram à $75,0 \%(n=60)$ dos pacientes. A aparência $(23,8 \%$, 
$\mathrm{n}=19)$, a ansiedade $(17,5 \%, \mathrm{n}=14)$ e a sexualidade $(17,5 \%, \mathrm{n}=14)$ foram os itens que pior preencheram as expectativas dos pacientes.

Ainda, de forma geral, aos 6 meses após o diagnóstico, os pacientes tiveram suas expectativas preenchidas no que diz respeito aos profissionais com o quais conversaram, especialmente com o cirurgião $(95,0 \%, n=76)$, a equipe de enfermagem $(80,0 \%, n=64)$, o oncologista/radioterapeuta $(63,7 \%, n=51)$, enfermeira clínica especialista $(57,5 \%, n=46)$ e o dentista $(53,8 \%, n=43)$. Nesta época, o nutricionista foi o profissional mais citado por ter preenchido pouco $(15,0 \%, \mathrm{n}=12)$ ou razoavelmente $(16,2 \%, \mathrm{n}=13)$ as expectativas dos pacientes.

À esta época, nenhum dos pacientes havia conversado com um terapeuta ocupacional e com um assessor financeiro $(100,0 \%, \mathrm{n}=80)$.

\subsubsection{Aos 12 meses}

Assim como ocorreu aos 6 meses após o diagnóstico, o preenchimento das expectativas dos pacientes quanto aos itens mastigar/comer, saúde dental/dentes, níveis de energia, fadiga/cansaço, catarro/secreção, sono, engolir, paladar (sentir sabor) e perda de peso foi pior ou igual ao esperado. Os itens atividade física, apetite e hábito intestinal passaram a corresponder ou a superar as expectativas dos pacientes, quando comparados à avaliação anterior.

Houve também um maior grau de preenchimento das expectativas no que diz respeito à respiração e tosse. Entretanto, as expectativas quanto à audição foram menos preenchidas, quando comparada aos 6 meses.

A indigestão, náusea, dor na cabeça e pescoço, regurgitação, e vômitos, permaneceram como itens não aplicáveis para uma grande porcentagem dos pacientes (entre $61,2 \%$ a $80,7 \%$ ) ou como iguais ou melhores do que os pacientes 
esperavam. Os problemas com os ombros e inchaço tornaram-se não aplicáveis para uma maior porcentagem de pacientes, entretanto, ainda que em menor frequência do que aos 6 meses, estes permaneceram como pior ou igual ao esperado para os pacientes com estes problemas.

Os pacientes reportaram estar mais satisfeitos em suas expectativas com os itens muita salivação, feridas na boca e mobilidade, do que aos 6 meses.

Aos 12 meses após o diagnóstico, as expectativas em relação à boca seca estavam dentro do esperado para uma porcentagem maior de indivíduos do que aos 6 meses, porém $33,9 \%(\mathrm{n}=21)$ dos pacientes ainda consideravam este problema como pior do que haviam esperado.

Novamente, ainda que em porcentagens menores do que aos 6 meses, os aspectos que corresponderam menos às expectativas dos pacientes aos 12 meses foram àqueles relacionados à alimentação: mastigar/comer $(46,8 \%, n=29)$, boca seca $(33,9 \%, n=21)$, engolir $(27,4 \%, n=17)$, paladar (sentir sabor) $(30,7 \%, n=19)$ e perda de peso $(33,9 \%, n=21)$.

Quanto ao tratamento do câncer, a grande maioria dos pacientes ainda considerava o arrependimento pelo tratamento como item não aplicável. $O$ tratamento do câncer, como um todo, foi de encontro às expectativas de $27,4 \%$ $(\mathrm{n}=17)$ dos pacientes e superou as expectativas de 64,5\% $(\mathrm{n}=40)$ dos indivíduos tratados. O uso de sonda para alimentação ficou dentro do que era esperado para uma maior porcentagem de pacientes $(24,2 \%, n=24)$, assim como a cicatrização de feridas $(17,7 \%, \mathrm{n}=11)$.

No âmbito de assistência e bem-estar social, houve um grande aumento na porcentagem de pacientes que não necessitaram de cuidador $(54,8 \%, \mathrm{n}=34)$. Os 
poucos pacientes que receberam atendimento de profissionais à domicílio, assim como aos 6 meses, tiveram um atendimento igual ou melhor do que o esperado.

A porcentagem de pacientes cujas expectativas em relação à dependentes/crianças não se aplicavam também aumentou $(67,7 \%, \mathrm{n}=42)$ e mantevese próxima aos graus apresentados aos 6 meses para os indivíduos que as consideraram pior ou igual ao esperado.

Os graus de preenchimento das expectativas do ponto de vista dos benefícios financeiros, apresentou mudanças em todos os aspectos, com maior porcentagem de indivíduos recebendo estes benefícios, porém com mais pacientes menos ou igualmente satisfeitos do que aos 6 meses e com um discreto aumento no número de indivíduos mais satisfeitos do que o esperado.

Aos 12 meses, um maior número de pacientes considerou suas expectativas os itens fala/voz/ser entendido e a recreação igualmente ou mais preenchidas do que o esperado, quando comparado aos 6 meses. Mas, estes ainda foram os dois itens com maior frequência e porcentagem de insatisfação neste domínio, respectivamente $21,0 \%(n=13)$ e $16,1 \%(n=10)$.

As expectativas sobre estilo de vida (fumo/álcool) também foram de encontro ao esperado para uma porcentagem maior de pacientes $(11,3 \%, \mathrm{n}=7)$, mas é necessário ressaltar que lidar com este problema foi pior ou melhor do que o esperado para uma mesma porcentagem de indivíduos do que aos 6 meses.

Observou-se um aumento na porcentagem de pacientes que reportaram como sendo não aplicáveis os itens relacionamentos e suporte para minha família, com o grau de insatisfação com os relacionamentos diminuindo em relação aos 6 meses. Apesar de ter correspondido às expectativas de $40,3 \%(n=25)$ dos pacientes e ter 
superado as expectativas de $17,8 \%(n=11)$ de outros, estas porcentagens sofreram uma queda, quando comparadas à avaliação anterior.

No domínio de bem-estar psicológico, emocional e espiritual, os resultados demostraram que houve um aumento em relação aos 6 meses na porcentagem de pacientes que vivenciou como pior do que o que esperavam a depressão, o medo do câncer voltar, o medo de acontecimentos desfavoráveis e o humor (discreto).

Em contrapartida, também houve um aumento na porcentagem de pacientes para os quais as estratégias para enfrentar a doença e o tratamento, o medo do câncer voltar (mais acentuadamente) e o medo de acontecimentos desfavoráveis se igualaram às expectativas.

As expectativas sobre a aparência foram superadas para $27,4 \%(n=17)$ pacientes, mas houve discreta redução em relação aos 6 meses na porcentagem de pacientes para os quais a aparência ficou pior do que o esperado.

O número de pacientes que reportaram como não aplicáveis os itens raiva, ansiedade, intimidade, memória, humor, auto-estima, sexualidade, aspectos espirituais/religiosos e personalidade e temperamento também aumentou.

Houve um discreto aumento na proporção de indivíduos para os quais a intimidade e a sexualidade superou as expectativas que possuíam aos 6 meses.

Aos 12 meses após o diagnóstico, a aparência $(21,0 \%, n=13)$, o medo do câncer voltar $(19,4 \%, \mathrm{n}=12)$, seguidos pela ansiedade, medo de acontecimentos desfavoráveis e sexualidade (todos 14,5\%, $\mathrm{n}=9$ ) foram os aspectos mais frequentemente indicados como pior do que o esperado.

Os pacientes indicaram, em porcentagens mais altas do que aos 6 meses, que suas expectativas tinham sido muito preenchidas pelo cirurgião $(98,4 \%, n=61)$, equipe de enfermagem $(88,7 \%, n=55)$, oncologista $/$ radioterapeuta $(74,2 \%, n=46)$, 
enfermeira clínica especialista $(71,0 \%, \mathrm{n}=44)$, dentista $(58,1 \%, \mathrm{n}=36)$ e fonoaudiólogo $(48,4 \%, \mathrm{n}=30)$. Novamente, o nutricionista foi o mais citado pelo pouco ou razoável preenchimento das expectativas, respectivamente $4,8 \%(n=3)$ e $9,7 \%(n=6)$.

As Tabelas 19, 20 e 21 descrevem o grau de preenchimento das expectativas dos pacientes, de acordo com as diferentes épocas do estudo. 
Tabela 19 Grau de preenchimento das expectativas dos pacientes, em relação aos itens de Bem-estar Físico e Funcional do Protocolo de Preenchimento das Expectativas - PPE, de acordo com as diferentes épocas do tratamento

\begin{tabular}{|c|c|c|c|c|c|c|c|c|}
\hline \multirow{2}{*}{ PPE } & \multicolumn{4}{|c|}{6 meses $(\mathrm{N}=80)$} & \multicolumn{4}{|c|}{12 meses $(\mathrm{N}=62)$} \\
\hline & \multicolumn{8}{|c|}{ Grau de Preenchimento das Expectativas } \\
\hline Bem-estar Físico e & não se aplica & pior & igual & melhor & não se aplica & pior & igual & melhor \\
\hline Atividade Física & $13(16,2)$ & $21(26,3)$ & $35(43,8)$ & $11(13,7)$ & $12(19,4)$ & $11(17,7)$ & $24(38,7)$ & $15(24,2)$ \\
\hline Apetite & $6(7,5)$ & $27(33,7)$ & $32(40,0)$ & $15(18,8)$ & $10(16,1)$ & $10(16,1)$ & $31(50,0)$ & $11(17,8)$ \\
\hline Hábito Intestinal & $11(13,8)$ & $16(20,0)$ & $40(50,0)$ & $13(16,2)$ & $15(24,2)$ & $2(3,2)$ & $38(61,3)$ & $7(11,3)$ \\
\hline Respiração & $17(21,2)$ & $10(12,5)$ & $42(52,5)$ & $11(13,8)$ & $15(24,2)$ & $6(9,7)$ & $30(48,4)$ & $11(17,7)$ \\
\hline Mastigar/comer & $4(5,0)$ & $40(50,0)$ & $24(30,0)$ & $12(15,0)$ & $1(1,6)$ & $29(46,8)$ & $18(29,0)$ & $14(22,6)$ \\
\hline Tosse & $29(36,2)$ & $16(20,0)$ & $19(23,8)$ & $16(20,0)$ & $32(51,6)$ & $4(6,5)$ & $18(29,0)$ & $8(12,9)$ \\
\hline Saúde dental/dentes & $13(16,2)$ & $27(33,8)$ & $28(35,0)$ & $12(15,0)$ & $10(16,1)$ & $18(29,0)$ & $24(38,7)$ & $10(16,2)$ \\
\hline Boca seca & $17(21,2)$ & $39(48,8)$ & $10(12,5)$ & $14(17,5)$ & $18(29,0)$ & $21(33,9)$ & $14(22,6)$ & $9(14,5)$ \\
\hline Níveis de energia & $7(8,7)$ & $27(33,8)$ & $31(38,8)$ & $15(18,7)$ & $14(22,6)$ & $11(17,7)$ & $30(48,4)$ & $7(11,3)$ \\
\hline Fadiga/cansaço & $16(20,0)$ & $28(35,0)$ & $26(32,5)$ & $10(12,5)$ & $24(38,7)$ & $12(19,3)$ & $20(32,3)$ & $6(9,7)$ \\
\hline Audição & $29(36,2)$ & $8(10,0)$ & $33(41,3)$ & $10(12,5)$ & $23(37,1)$ & $9(14,5)$ & $20(32,3)$ & $10(16,1)$ \\
\hline Indigestão & $48(60,0)$ & $5(6,2)$ & $19(23,8)$ & $8(10,0)$ & $44(71,0)$ & $1(1,6)$ & $11(17,7)$ & $6(9,7)$ \\
\hline Mobilidade & $30(37,5)$ & $17(21,2)$ & $23(28,8)$ & $10(12,5)$ & $35(56,5)$ & $7(11,3)$ & $11(17,7)$ & $9(14,5)$ \\
\hline Abertura de boca & $24(30,0)$ & $21(26,2)$ & $20(25,0)$ & $15(18,8)$ & $21(33,9)$ & $14(22,6)$ & $18(29,0)$ & $9(14,5)$ \\
\hline Catarro/secreção & $20(25,0)$ & $22(27,5)$ & $26(32,5)$ & $12(15,0)$ & $23(37,1)$ & $12(19,3)$ & $21(33,9)$ & $6(9,7)$ \\
\hline Náusea & $40(50,0)$ & $12(15,0)$ & $12(15,0)$ & $16(20,0)$ & $39(62,9)$ & $3(4,8)$ & $12(19,4)$ & $8(12,9)$ \\
\hline Dor na cabeça e pescoço & $42(52,5)$ & $10(12,5)$ & $13(16,2)$ & $15(18,8)$ & $38(61,2)$ & $5(8,1)$ & $13(21,0)$ & $6(9,7)$ \\
\hline Dor em outro lugar & $52(65,0)$ & $8(10,0)$ & $13(16,2)$ & $7(8,8)$ & $42(67,7)$ & $6(9,7)$ & $8(12,9)$ & $6(9,7)$ \\
\hline Regurgitação & $57(71,2)$ & $4(5,0)$ & $12(15,0)$ & $7(8,8)$ & $48(77,4)$ & $1(1,6)$ & $7(11,3)$ & $6(9,7)$ \\
\hline Muita salivação & $51(63,7)$ & $12(15,0)$ & $11(13,8)$ & $6(7,5)$ & $50(80,7)$ & $3(4,8)$ & $5(8,1)$ & $4(6,4)$ \\
\hline Ombros & $50(62,5)$ & $9(11,3)$ & $15(18,7)$ & $6(7,5)$ & $46(74,2)$ & $4(6,5)$ & $9(14,5)$ & $3(4,8)$ \\
\hline Sono & $17(21,2)$ & $16(20,0)$ & $34(42,5)$ & $13(16,3)$ & $25(40,3)$ & $10(16,1)$ & $20(32,3)$ & $7(11,3)$ \\
\hline Olfato (sentir cheiro) & $31(38,8)$ & $10(12,5)$ & $29(36,2)$ & $10(12,5)$ & $29(46,8)$ & $6(9,7)$ & $21(33,9)$ & $6(9,6)$ \\
\hline Feridas na boca & $36(45,0)$ & $20(25,0)$ & $14(17,5)$ & $10(12,5)$ & $29(46,8)$ & $7(11,3)$ & $17(27,4)$ & $9(14,5)$ \\
\hline Engolir & $4(5,0)$ & $38(47,5)$ & $27(33,8)$ & $11(13,7)$ & $7(11,3)$ & $17(27,4)$ & $22(35,5)$ & $16(25,8)$ \\
\hline Inchaço & $46(57,5)$ & $13(16,3)$ & $12(15,0)$ & $9(11,2)$ & $41(66,1)$ & $6(9,7)$ & $10(16,1)$ & $5(8,1)$ \\
\hline Paladar (sentir sabor) & $6(7,5)$ & $36(45,0)$ & $28(35,0)$ & $10(12,5)$ & $9(14,5)$ & $19(30,7)$ & $20(32,3)$ & $14(22,5)$ \\
\hline Vômitos/mal-estar & $50(62,5)$ & $7(8,8)$ & $15(18,7)$ & $8(10,0)$ & $48(77,4)$ & $2(3,2)$ & $8(12,9)$ & $4(6,5)$ \\
\hline Perda de peso & $15(18,8)$ & $32(40,0)$ & $18(22,5)$ & $15(18,7)$ & $15(24,2)$ & $21(33,9)$ & $18(29,0)$ & $8(12,9)$ \\
\hline
\end{tabular}


Tabela 20 Grau de preenchimento das expectativas dos pacientes, em relação aos itens de Tratamento, Assistência e Bem-estar Social e Bem- estar Psicológico, Emocional e Espiritual do Protocolo de Preenchimento das Expectativas - PPE, de acordo com as diferentes épocas do tratamento

\begin{tabular}{|c|c|c|c|c|c|c|c|c|}
\hline \multirow{2}{*}{ PPE } & \multicolumn{4}{|c|}{6 meses $(\mathrm{N}=80)$} & \multicolumn{4}{|c|}{12 meses $(N=62)$} \\
\hline & \multicolumn{8}{|c|}{ Grau de Preenchimento das Expectativas } \\
\hline Relacionadas ao Tratamento & não se aplica & pior & igual & melhor & não se aplica & pior & igual & melhor \\
\hline Tratamento do câncer & 0 & $11(13,7)$ & $20(25,0)$ & $49(61,3)$ & 0 & $5(8,1)$ & $17(27,4)$ & $40(64,5)$ \\
\hline Arrependimento pelo tratamento & $76(95,0)$ & 0 & $3(3,8)$ & $1(1,2)$ & $59(95,2)$ & 0 & $3(4,8)$ & 0 \\
\hline Sonda para alimentação & $34(42,5)$ & $19(23,8)$ & $10(12,5)$ & $17(21,2)$ & $28(45,2)$ & $10(16,1)$ & $15(24,2)$ & $9(14,5)$ \\
\hline Cicatrização de feridas & $29(36,2)$ & $5(6,3)$ & $9(11,3)$ & $37(46,2)$ & $24(38,7)$ & $4(6,5)$ & $11(17,7)$ & $23(37,1)$ \\
\hline \multicolumn{9}{|l|}{ Assistência e Bem-estar Social } \\
\hline Cuidador & $20(25,0)$ & $2(2,5)$ & $8(10,0)$ & $50(62,5)$ & $34(54,8)$ & 0 & $6(9,7)$ & $22(35,5)$ \\
\hline Dependentes / crianças & $46(57,5)$ & $4(5,0)$ & $12(15,0)$ & $18(22,5)$ & $42(67,7)$ & $3(4,8)$ & $10(16,1)$ & $7(11,4)$ \\
\hline Atendimento de profissionais à domicílio & $69(86,3)$ & 0 & $5(6,2)$ & $6(7,5)$ & $52(83,9)$ & 0 & $6(9,7)$ & $4(6,4)$ \\
\hline Estilo de vida (fumo/álcool) & $54(67,5)$ & $4(5,0)$ & $5(6,2)$ & $17(21,3)$ & $39(62,9)$ & $3(4,8)$ & $7(11,3)$ & $13(21,0)$ \\
\hline Recreação & $12(15,0)$ & $21(26,2)$ & $34(42,5)$ & $13(16,3)$ & $14(22,6)$ & $10(16,1)$ & $25(40,3)$ & $13(21,0)$ \\
\hline Relacionamentos & $10(12,5)$ & $14(17,5)$ & $38(47,5)$ & $18(22,5)$ & $12(19,4)$ & $8(12,9)$ & $31(50,0)$ & $11(17,7)$ \\
\hline Fala/voz/ser entendido & $4(5,0)$ & $24(30,0)$ & $32(40,0)$ & $20(25,0)$ & $7(11,3)$ & $13(21,0)$ & $25(40,3)$ & $17(27,4)$ \\
\hline Suporte para minha família & $21(26,2)$ & $4(5,0)$ & $38(47,5)$ & $17(21,3)$ & $23(37,1)$ & $3(4,8)$ & $25(40,3)$ & $11(17,8)$ \\
\hline \multicolumn{9}{|l|}{ Bem - estar Psicológico, Emocional e Espiritual } \\
\hline Aparência & $5(6,2)$ & $19(23,8)$ & $39(48,8)$ & $17(21,2)$ & $5(8,1)$ & $13(21,0)$ & $27(43,5)$ & $17(27,4)$ \\
\hline Raiva & $60(75,0)$ & $6(7,5)$ & $11(13,7)$ & $3(3,8)$ & $48(77,4)$ & $2(3,2)$ & $9(14,5)$ & $3(4,9)$ \\
\hline Depressão & $60(75,0)$ & $4(5,0)$ & $9(11,2)$ & $7(8,8)$ & $47(75,8)$ & $6(9,7)$ & $5(8,0)$ & $4(6,5)$ \\
\hline Medo do câncer voltar & $29(36,3)$ & $12(15,0)$ & $23(28,7)$ & $16(20,0)$ & $18(29,0)$ & $12(19,4)$ & $26(41,9)$ & $6(9,7)$ \\
\hline Medo de acontecimentos desfavoráveis & $38(47,5)$ & $9(11,2)$ & $24(30,0)$ & $9(11,3)$ & $26(41,9)$ & $9(14,5)$ & $23(37,1)$ & $4(6,5)$ \\
\hline Intimidade & $22(27,5)$ & $9(11,2)$ & $38(47,5)$ & $11(13,8)$ & $24(38,7)$ & $6(9,7)$ & $23(37,1)$ & $9(14,5)$ \\
\hline Memória & $23(28,8)$ & $8(10,0)$ & $41(51,2)$ & $8(10,0)$ & $23(37,1)$ & $6(9,7)$ & $29(46,8)$ & $4(6,4)$ \\
\hline Humor & $16(20,0)$ & $7(8,7)$ & $44(55,0)$ & $13(16,3)$ & $15(24,2)$ & $6(9,7)$ & $31(50,0)$ & $10(16,1)$ \\
\hline Auto-estima & $13(16,3)$ & $9(11,2)$ & $42(52,5)$ & $16(20,0)$ & $15(24,2)$ & $6(9,7)$ & $31(50,0)$ & $10(16,1)$ \\
\hline Sexualidade & $22(27,5)$ & $14(17,5)$ & $36(45,0)$ & $8(10,0)$ & $19(30,7)$ & $9(14,5)$ & $27(43,6)$ & $7(11,2)$ \\
\hline Aspectos espirituais/religiosos & $20(25,0)$ & $2(2,5)$ & $38(47,5)$ & $20(25,0)$ & $18(29,0)$ & 0 & $32(51,6)$ & $12(19,4)$ \\
\hline Personalidade e temperamento & $15(18,8)$ & $3(3,7)$ & $48(60,0)$ & $14(17,5)$ & $17(27,4)$ & $2(3,2)$ & $30(48,4)$ & $13(21,0)$ \\
\hline Outros & $80(100,0)$ & 0 & 0 & 0 & $62(100,0)$ & 0 & 0 & 0 \\
\hline
\end{tabular}


Tabela 21 Grau de preenchimento das expectativas dos pacientes, em relação à qualidade, quantidade e clareza das informações fornecidas pelos profissionais, de acordo com as diferentes épocas do tratamento

\begin{tabular}{|c|c|c|c|c|c|c|c|c|}
\hline \multirow{2}{*}{ PPE } & \multicolumn{4}{|c|}{6 meses $(\mathrm{N}=80)$} & \multicolumn{4}{|c|}{12 meses $(\mathrm{N}=62)$} \\
\hline & \multicolumn{8}{|c|}{ Grau de Preenchimento das Expectativas } \\
\hline Profissionais & $\begin{array}{c}\text { não } \\
\text { conversei }\end{array}$ & pouco & razoavelmente & muito & $\begin{array}{c}\text { não } \\
\text { conversei }\end{array}$ & pouco & razoavelmente & muito \\
\hline Dentista & $22(27,5)$ & $4(5,0)$ & $11(13,7)$ & $43(53,8)$ & $17(27,4)$ & $3(4,8)$ & $6(9,7)$ & $36(58,1)$ \\
\hline Equipe de reabilitação oral & $55(68,8)$ & $5(6,2)$ & $2(2,5)$ & $18(22,5)$ & $41(66,1)$ & $2(3,2)$ & $3(4,8)$ & $16(25,9)$ \\
\hline Nutricionista & $17(21,3)$ & $12(15,0)$ & $13(16,2)$ & $38(47,5)$ & $19(30,7)$ & $5(8,1)$ & $10(16,1)$ & $28(45,1)$ \\
\hline Fisioterapeuta & $55(68,8)$ & $1(1,2)$ & $6(7,5)$ & $18(22,5)$ & $41(66,1)$ & 0 & $1(1,6)$ & $20(32,3)$ \\
\hline Fonoaudiólogo & $34(42,5)$ & $3(3,7)$ & $6(7,5)$ & $37(46,3)$ & $28(45,2)$ & $1(1,6)$ & $3(4,8)$ & $30(48,4)$ \\
\hline Terapeuta ocupacional & $80(100,0)$ & 0 & 0 & 0 & $61(98,4)$ & 0 & 0 & $1(1,6)$ \\
\hline Equipe de enfermagem & $5(6,2)$ & 0 & $11(13,8)$ & $64(80,0)$ & $5(8,1)$ & $1(1,6)$ & $1(1,6)$ & $55(88,7)$ \\
\hline Cirurgião & 0 & $1(1,2)$ & $3(3,8)$ & $76(95,0)$ & 0 & 0 & $1(1,6)$ & $61(98,4)$ \\
\hline Oncologista / Radioterapeuta & $19(23,7)$ & $5(6,3)$ & $5(6,3)$ & $51(63,7)$ & $13(21,0)$ & 0 & $3(4,8)$ & $46(74,2)$ \\
\hline Enfermeira clínica especialista & $27(33,8)$ & $1(1,2)$ & $6(7,5)$ & $46(57,5)$ & $17(27,4)$ & $1(1,6)$ & 0 & $44(71,0)$ \\
\hline Assistente social & $58(72,5)$ & 0 & $2(2,5)$ & $20(25,0)$ & $42(67,7)$ & $1(1,6)$ & $2(3,2)$ & $17(27,5)$ \\
\hline Clínico geral & $63(78,7)$ & $1(1,3)$ & $1(1,3)$ & $15(18,7)$ & $48(77,4)$ & 0 & $2(3,2)$ & $12(19,4)$ \\
\hline Assessor financeiro & $80(100,0)$ & 0 & 0 & 0 & $62(100,0)$ & 0 & 0 & 0 \\
\hline Autoridade religiosa / Líder da sua religião & $75(93,8)$ & 0 & 0 & $5(6,2)$ & $61(98,4)$ & 0 & 0 & $1(1,6)$ \\
\hline Psiquiatra & $77(96,3)$ & 0 & $1(1,2)$ & $2(2,5)$ & $57(91,9)$ & 0 & $2(3,2)$ & $3(4,9)$ \\
\hline Psicólogo & $70(87,5)$ & $2(2,5)$ & 0 & $8(10,0)$ & $58(93,6)$ & $1(1,6)$ & $1(1,6)$ & $2(3,2)$ \\
\hline
\end{tabular}




\subsection{ASSOCIAÇÕES ENTRE O GRAU DE PREENCHIMENTO DAS EXPECTATIVAS E A QUALIDADE DE VIDA}

\subsubsection{Aos 6 meses}

O grau de preenchimento das expectativas de doze itens apresentou associação significante ( $\mathrm{p}<0,001)$ com a QV global dos pacientes aos 6 meses após o diagnóstico: apetite, hábito intestinal, mastigar/comer, tosse, saúde dental/dentes, boca seca, níveis de energia, fadiga/cansaço, catarro/secreção, paladar, perda de peso (domínio de bem-estar físico e funcional) e aparência (domínio de bem-estar psicológico, emocional e espiritual). No geral, quanto pior foi a expectativa em relação a um determinado item, pior também foi a QV global.

Do mesmo modo, foram encontradas associações significantes $(0,001<\mathrm{p}<$ $0,01)$ entre a QV global referida pelos pacientes com o grau de preenchimento das expectativas de outros oito itens do domínio de bem-estar físico e funcional (indigestão, mobilidade, abertura de boca, dor na cabeça e pescoço, dor em outro lugar, feridas na boca, engolir, vômito/mal-estar), dois itens relacionados ao tratamento (tratamento do câncer e sonda para alimentação), dois itens ligados à assistência e bem-estar social (recreação e relacionamentos) e três itens relativos ao bem-estar psicológico, emocional e espiritual (raiva, sexualidade e personalidade e temperamento). Conforme observado anteriormente, quanto melhor foi a expectativa em relação a um determinado item, melhor também foi a QV global.

Não foram encontradas associações significantes entre a QV global dos pacientes e o grau de preenchimento das expectativas com os profissionais.

As associações significantes entre o grau de preenchimento das expectativas e QV global dos pacientes aos 6 meses após o tratamento estão descritas nas Tabelas 22 e 23. 
Tabela 22 Associações significantes entre o grau de preenchimento das expectativas e qualidade de vida global aos 6 meses após o tratamento $(\mathrm{p}<0,001)$

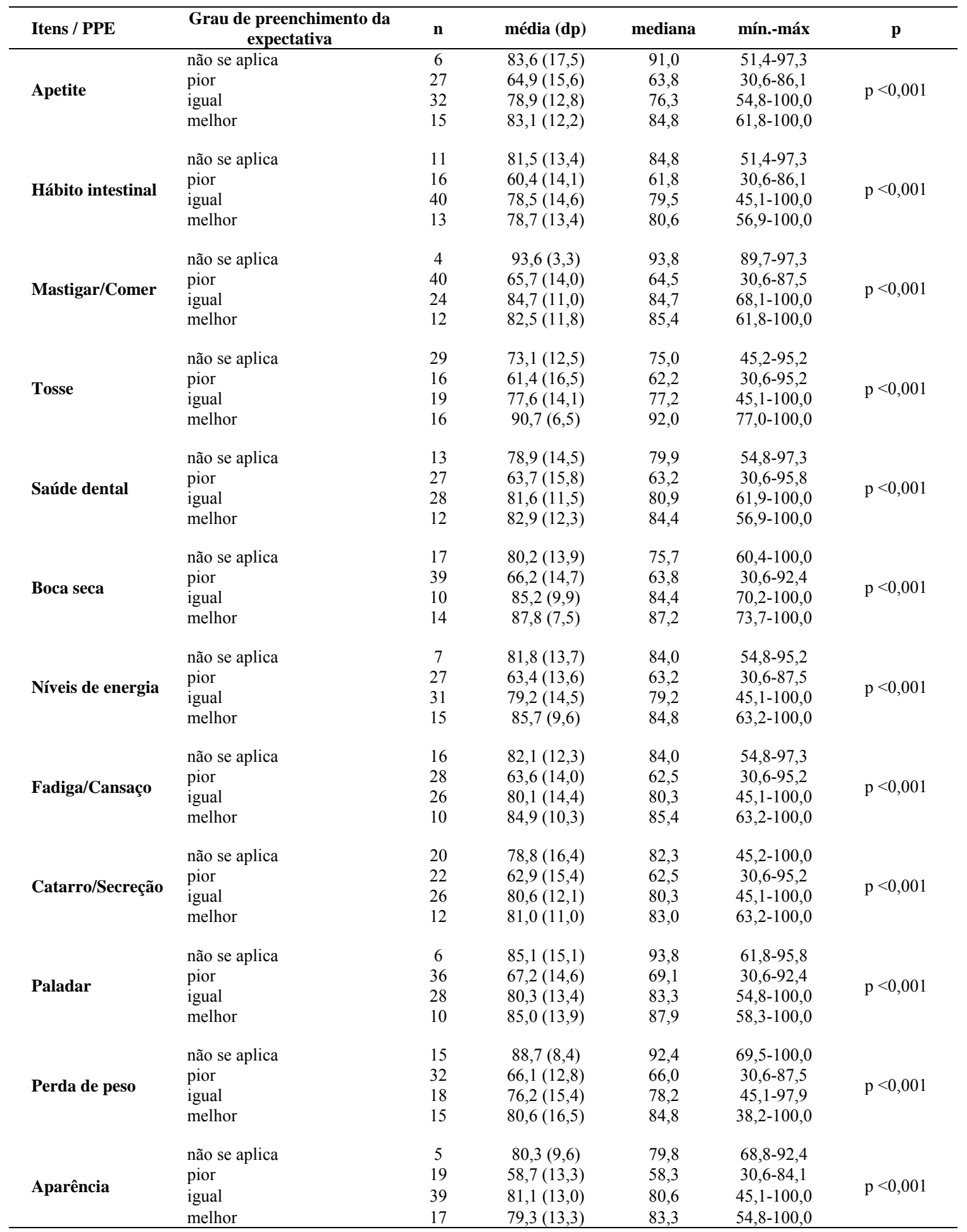

dp: desvio padrão; mín-máx: mínimo-máximo 
Tabela 23 Associações significantes entre o grau de preenchimento das expectativas e qualidade de vida global aos 6 meses após o tratamento $(0,001<$ $\mathrm{p}<0,01)$

\begin{tabular}{|c|c|c|c|c|c|c|}
\hline Itens / PPE & $\begin{array}{c}\text { Grau de preenchimento } \\
\text { da expectativa }\end{array}$ & $\mathbf{n}$ & Média (dp) & mediana & mín. -máx & $\mathbf{p}$ \\
\hline \multirow{4}{*}{ Indigestão } & não se aplica & 48 & $74,8(16,3)$ & 75,7 & $30,6-100,0$ & \multirow{4}{*}{$0,001<\mathrm{p}<0,01$} \\
\hline & pior & 5 & $61,8(12,7)$ & 57,7 & $45,2-75,0$ & \\
\hline & igual & 19 & $74,4(14,6)$ & 77,0 & $45,1-97,9$ & \\
\hline & melhor & 8 & $89,2(6,5)$ & 86,5 & $82,7-100,0$ & \\
\hline \multirow{4}{*}{ Mobilidade } & não se aplica & 30 & $77,3(15,2)$ & 79,5 & $38,2-97,3$ & \multirow{4}{*}{$0,001<\mathrm{p}<0,01$} \\
\hline & pior & 17 & $65,7(12,1)$ & 63,8 & $47,3-87,5$ & \\
\hline & igual & 23 & $75,8(17,1)$ & 77,0 & $30,6-100,0$ & \\
\hline & melhor & 10 & $84,5(14,0)$ & 86,5 & $56,9-100,0$ & \\
\hline \multirow{4}{*}{$\begin{array}{l}\text { Abertura de } \\
\text { boca }\end{array}$} & não se aplica & 24 & $75,0(15,8)$ & 78,1 & $38,2-97,3$ & \multirow{4}{*}{$0,001<\mathrm{p}<0,01$} \\
\hline & pior & 21 & $64,8(16,2)$ & 63,2 & $30,6-92,4$ & \\
\hline & igual & 20 & $81,3(10,9)$ & 79,5 & $68,1-100,0$ & \\
\hline & melhor & 15 & $82,6(13,8)$ & 84,8 & $56,9-100,0$ & \\
\hline \multirow{4}{*}{$\begin{array}{l}\text { Dor na cabeça e } \\
\text { pescoço }\end{array}$} & não se aplica & 42 & $77,8(13,8)$ & 79,5 & $51,4-100,0$ & \multirow{4}{*}{$0,001<\mathrm{p}<0,01$} \\
\hline & pior & 10 & $53,7(15,4)$ & 52,4 & $30,6-82,7$ & \\
\hline & igual & 13 & $79,0(13,7)$ & 77,2 & $47,3-97,9$ & \\
\hline & melhor & 15 & $79,7(12,4)$ & 80,6 & $57,7-100,0$ & \\
\hline \multirow{4}{*}{$\begin{array}{l}\text { Dor em outro } \\
\text { lugar }\end{array}$} & não se aplica & 52 & $76,2(16,2)$ & 79,5 & $30,6-100,0$ & \multirow{4}{*}{$0,001<\mathrm{p}<0,01$} \\
\hline & pior & 8 & $59,5(10,2)$ & 58,3 & $45,2-75,0$ & \\
\hline & igual & 13 & $76,5(14,4)$ & 75,7 & $45,1-97,9$ & \\
\hline & melhor & 7 & $85,2(7,8)$ & 84,8 & $74,4-100,0$ & \\
\hline \multirow{4}{*}{ Feridas Boca } & não se aplica & 36 & $77,3(16,1)$ & 79,9 & $45,2-100,0$ & \multirow{4}{*}{$0,001<\mathrm{p}<0,01$} \\
\hline & pior & 20 & $64,5(15,2)$ & 66,7 & $30,6-84,8$ & \\
\hline & igual & 14 & $79,1(11,2)$ & 78,8 & $61,9-97,9$ & \\
\hline & melhor & 10 & $84,5(11,2)$ & 86,1 & $63,2-100,0$ & \\
\hline \multirow{4}{*}{ Engolir } & não se aplica & 4 & $79,9(14,7)$ & 81,3 & $61,8-95,2$ & \multirow{4}{*}{$0,001<\mathrm{p}<0,01$} \\
\hline & pior & 38 & $68,4(15,7)$ & 69,8 & $30,6-97,3$ & \\
\hline & igual & 27 & $80,2(14,3)$ & 80,6 & $54,8-100,0$ & \\
\hline & melhor & 11 & $85,6(9,7)$ & 86,1 & $63,2-100,0$ & \\
\hline \multirow{4}{*}{$\begin{array}{l}\text { Vômito / Mal- } \\
\text { estar }\end{array}$} & não se aplica & 50 & $76,8(14,9)$ & 79,5 & $45,2-100,0$ & \multirow{4}{*}{$0,001<\mathrm{p}<0,01$} \\
\hline & pior & 7 & $59,7(14,7)$ & 57,7 & $38,2-80,6$ & \\
\hline & igual & 15 & $70,5(16,4)$ & 71,6 & $30,6-97,9$ & \\
\hline & melhor & 8 & $88,6(6,5)$ & 86,5 & $80,6-100,0$ & \\
\hline \multirow{3}{*}{$\begin{array}{l}\text { Tratamento do } \\
\text { câncer }\end{array}$} & pior & 11 & $67.9(15.3)$ & 76,1 & $38.2-84.8$ & \multirow{3}{*}{$0,001<\mathrm{p}<0,01$} \\
\hline & igual & 20 & $68.1(12.3)$ & 68,1 & $45.1-95.2$ & \\
\hline & melhor & 49 & $80.0(15.7)$ & 84,0 & $30.6-100.0$ & \\
\hline \multirow{4}{*}{$\begin{array}{l}\text { Sonda para } \\
\text { alimentação }\end{array}$} & não se aplica & 34 & $81,5(14,0)$ & 83,3 & $51,4-100,0$ & \multirow{4}{*}{$0,001<\mathrm{p}<0,01$} \\
\hline & pior & 19 & $67,2(16,8)$ & 73,7 & $38,2-92,4$ & \\
\hline & igual & 10 & $69,0(9,6)$ & 68,5 & $54,8-92,4$ & \\
\hline & melhor & 17 & $75,7(16,7)$ & 83,3 & $30,6-100,0$ & \\
\hline \multirow{4}{*}{ Recreação } & não se aplica & 12 & $73,3(14,9)$ & 77,1 & $38,2-92,4$ & \multirow{4}{*}{$0,001<\mathrm{p}<0,01$} \\
\hline & pior & 21 & $64,8(13,1)$ & 63,8 & $30,6-87,5$ & \\
\hline & igual & 34 & $80,1(15,3)$ & 81,6 & $45,1-100,0$ & \\
\hline & melhor & 13 & $81,6(14,5)$ & 84,8 & $57,7-100,0$ & \\
\hline & não se aplica & 10 & $73,2(16,9)$ & 75,0 & $38,2-92,4$ & \\
\hline & pior & 14 & $63,8(10,7)$ & 62,9 & $45,2-84,1$ & $0001<n<001$ \\
\hline Relacionamentos & igual & 38 & $77,9(14,4)$ & 78,2 & $45,1-100,0$ & $0,001<\mathrm{p}<0,01$ \\
\hline & melhor & 18 & $80,1(17,9)$ & 84,4 & $30,6-100,0$ & \\
\hline
\end{tabular}




\section{Continuação}

Tabela 23 Associações significantes entre o grau de preenchimento das expectativas e qualidade de vida global aos 6 meses após o tratamento $(0,001<$ $\mathrm{p}<0,01)$

\begin{tabular}{|c|c|c|c|c|c|c|}
\hline Itens / PPE & $\begin{array}{c}\text { Grau de preenchimento } \\
\text { da expectativa }\end{array}$ & $\mathbf{n}$ & Média (dp) & mediana & mín. -máx & $\mathbf{p}$ \\
\hline \multirow{4}{*}{ Raiva } & não se aplica & 60 & $78,0(14,8)$ & 79,9 & $38,2-100,0$ & \multirow{4}{*}{$0,001<\mathrm{p}<0,01$} \\
\hline & pior & 6 & $63,2(14,0)$ & 59,0 & $45,2-84,1$ & \\
\hline & igual & 11 & $64,0(16,5)$ & 70,2 & $30,6-84,0$ & \\
\hline & melhor & 3 & $87,8(4,1)$ & 86,1 & $84,8-92,4$ & \\
\hline \multirow{4}{*}{ Sexualidade } & não se aplica & 22 & $68,0(16,4)$ & 68,8 & $38,2-93,8$ & \multirow{4}{*}{$0,001<\mathrm{p}<0,01$} \\
\hline & pior & 14 & $68,9(16,7)$ & 70,1 & $30,6-95,2$ & \\
\hline & igual & 36 & $79,3(13,4)$ & 78,5 & $54,8-100,0$ & \\
\hline & melhor & 8 & $88,7(7,7)$ & 89,3 & $75,7-100,0$ & \\
\hline \multirow{4}{*}{$\begin{array}{l}\text { Personalidade e } \\
\text { temperamento }\end{array}$} & não se aplica & 15 & $66,7(16,4)$ & 69,5 & $38,2-87,5$ & \multirow{4}{*}{$0,001<\mathrm{p}<0,0$} \\
\hline & pior & 3 & $70,4(11,8)$ & 75,0 & $56,9-79,2$ & \\
\hline & igual & 48 & $75,1(15,4)$ & 75,7 & $30,6-100,0$ & \\
\hline & melhor & 14 & $86,4(11,2)$ & 89,3 & $63,8-100,0$ & \\
\hline
\end{tabular}

dp: desvio padrão; mín-máx: mínimo-máximo

\subsubsection{Aos 12 meses}

Neste momento, foram encontradas associações significantes $(\mathrm{p}<0,001)$ entre a QV global dos pacientes e o grau de preenchimento de suas expectativas para os itens mastigar/comer, fadiga/cansaço, engolir (todos ligados ao bem-estar físico e funcional) e a ansiedade (bem-estar psicológico, emocional e espiritual), e também com o oncologista/radioterapeuta, indicando que quanto pior/melhor foi $\mathrm{o}$ preenchimento da expectativa, pior/melhor também foi a QV.

Ainda, houve associação significante $(0,001<\mathrm{p}<0,01)$ entre a QV global e o grau de preenchimento das expectativas relativas aos itens níveis de energia, dor na cabeça e pescoço, inchaço, paladar, tratamento do câncer, recreação, suporte para minha família, medo do câncer voltar e medo de acontecimentos desfavoráveis. Novamente, quanto pior/melhor foi o preenchimento da expectativa, pior/melhor também foi a QV. 
As associações significantes entre o grau de preenchimento das expectativas e QV global dos pacientes aos 12 meses após o tratamento estão descritas nas Tabelas 24 e 25.

As associações não significantes entre a QV global dos pacientes e as outras variáveis do PPE estão descritas nos Apêndices 1 e 2.

Tabela 24 Associações significantes entre o grau de preenchimento das expectativas e qualidade de vida global aos 12 meses após o tratamento $(\mathrm{p}<0,001)$

\begin{tabular}{|c|c|c|c|c|c|c|}
\hline Itens & $\begin{array}{c}\text { Grau de } \\
\text { preenchimento da } \\
\text { expectativa }\end{array}$ & $\mathbf{n}$ & média (dp) & mediana & mín. -máx & $\mathbf{p}$ \\
\hline \multirow{4}{*}{ Mastigar/Comer } & não se aplica & 1 & 97,3 (NA) & 97,3 & $97,3-97,3$ & \multirow[t]{4}{*}{$\mathrm{p}<0,001$} \\
\hline & pior & 29 & $75,7(11,5)$ & 76,4 & $47,3-94,5$ & \\
\hline & igual & 18 & $85,5(12,7)$ & 91,0 & $52,1-100,0$ & \\
\hline & melhor & 14 & $90,4(11,2)$ & 94,5 & $59,7-100,0$ & \\
\hline \multirow{4}{*}{ Fadiga/Cansaço } & não se aplica & 24 & $82,8(11,8)$ & 83,7 & $55,6-97,9$ & \multirow[t]{4}{*}{$\mathrm{p}<0,001$} \\
\hline & pior & 12 & $69,0(11,8)$ & 71,9 & $47,3-88,9$ & \\
\hline & igual & 20 & $85,7(11,6)$ & 88,3 & $54,9-100,0$ & \\
\hline & melhor & 6 & $94,6(4,3)$ & 95,2 & $87,5-100,0$ & \\
\hline \multirow{4}{*}{ Engolir } & não se aplica & 7 & $92,7(6,8)$ & 93,8 & $82,0-100,0$ & \multirow[t]{4}{*}{$\mathrm{p}<0,001$} \\
\hline & pior & 17 & $71,3(13,6)$ & 73,7 & $47,3-94,5$ & \\
\hline & igual & 22 & $83,5(10,7)$ & 83,0 & $63,3-100,0$ & \\
\hline & melhor & 16 & $87,4(10,9)$ & 91,0 & $59,7-100,0$ & \\
\hline \multirow{4}{*}{ Ansiedade } & não se aplica & 32 & $86,0(10,5)$ & 86,8 & $55,6-100,0$ & \multirow[t]{4}{*}{$\mathrm{p}<0,001$} \\
\hline & pior & 9 & $63,2(10,5)$ & 63,3 & $47,3-76,4$ & \\
\hline & igual & 16 & $86,2(10,2)$ & 88,6 & $72,9-100,0$ & \\
\hline & melhor & 5 & $79,2(13,8)$ & 73,7 & $64,0-95,2$ & \\
\hline \multirow{3}{*}{$\begin{array}{l}\text { Oncologista / } \\
\text { Radioterapeuta }\end{array}$} & não se aplica & 13 & $93,5(5,7)$ & 94,5 & $84,1-100,0$ & \multirow[t]{3}{*}{$\mathrm{p}<0,001$} \\
\hline & igual & 3 & $78,5(16,4)$ & 86,2 & $59,7-89,7$ & \\
\hline & melhor & 46 & $79,3(13,0)$ & 77,8 & $47,3-100,0$ & \\
\hline
\end{tabular}

dp: desvio padrão; mín-máx: mínimo-máximo (NA) Não avaliável 
Tabela 25 Associações significantes entre o grau de preenchimento das expectativas e qualidade de vida global aos 12 meses após o tratamento $(0,001<\mathrm{p}$ $<0,01)$

\begin{tabular}{|c|c|c|c|c|c|c|}
\hline Itens & $\begin{array}{c}\text { Grau de } \\
\text { preenchimento da } \\
\text { expectativa }\end{array}$ & $\mathbf{n}$ & média (dp) & mediana & mín.-máx & $\mathbf{p}$ \\
\hline \multirow{4}{*}{ Níveis de energia } & não se aplica & 14 & $83,5(10,7)$ & 83,7 & $63,2-97,3$ & $0.001<\mathrm{p}<0.01$ \\
\hline & pior & 11 & $71,4(10,2)$ & 73,7 & $52,1-88,9$ & \\
\hline & igual & 30 & $83,1(13,7)$ & 85,5 & $47,3-100,0$ & \\
\hline & melhor & 7 & $93,0(9,2)$ & 95,2 & $72,9-100,0$ & \\
\hline \multirow{4}{*}{$\begin{array}{l}\text { Dor na cabeça e } \\
\text { pescoço }\end{array}$} & não se aplica & 38 & $86,1(9,9)$ & 88,2 & $54,9-100,0$ & $0.001<\mathrm{p}<0.01$ \\
\hline & pior & 5 & $58,6(7,7)$ & 59,7 & $47,3-67,4$ & \\
\hline & igual & 13 & $80,9(14,2)$ & 77,8 & $52,1-100,0$ & \\
\hline & melhor & 6 & $79,8(13,8)$ & 76,1 & $63,3-100,0$ & \\
\hline \multirow{4}{*}{ Inchaço } & não se aplica & 41 & $85,7(10,7)$ & 88,9 & $59,7-100,0$ & $0.001<\mathrm{p}<0.01$ \\
\hline & pior & 6 & $61,0(12,1)$ & 59,4 & $47,3-80,6$ & \\
\hline & igual & 10 & $78,9(12,7)$ & 75,0 & $54,9-100,0$ & \\
\hline & melhor & 5 & $85,9(11,2)$ & 82,7 & $75,8-100,0$ & \\
\hline \multirow{4}{*}{ Paladar } & não se aplica & 9 & $89,4(9,5)$ & 93,1 & $70,8-100,0$ & $0.001<\mathrm{p}<0.01$ \\
\hline & pior & 19 & $73,9(13,1)$ & 76,4 & $47,3-92,4$ & \\
\hline & igual & 20 & $81,0(13,1)$ & 77,2 & $52,1-100,0$ & \\
\hline & melhor & 14 & $90,6(7,7)$ & 92,8 & $73,7-100,0$ & \\
\hline \multirow{3}{*}{$\begin{array}{l}\text { Tratamento do } \\
\text { câncer }\end{array}$} & pior & 5 & $70,0(9,0)$ & 70,8 & $59,7-82,7$ & $0.001<\mathrm{p}<0.01$ \\
\hline & igual & 17 & $77,1(14,0)$ & 76,4 & $52,1-100,0$ & \\
\hline & melhor & 40 & $85,9(11,9)$ & 89,3 & $47,3-100,0$ & \\
\hline \multirow{4}{*}{ Recreação } & não se aplica & 14 & $81,8(13,5)$ & 81,3 & $52,1-100,0$ & $0.001<\mathrm{p}<0.01$ \\
\hline & pior & 10 & $70,5(13,7)$ & 73,3 & $47,3-88,9$ & \\
\hline & igual & 25 & $82,8(12,4)$ & 84,8 & $54,9-100,0$ & \\
\hline & melhor & 13 & $90,6(7,3)$ & 92,4 & $73,7-100,0$ & \\
\hline \multirow{4}{*}{$\begin{array}{l}\text { Suporte para } \\
\text { minha família }\end{array}$} & não se aplica & 23 & $84,0(11,9)$ & 83,4 & $55,6-100,0$ & $0.001<\mathrm{p}<0.01$ \\
\hline & pior & 3 & $59,5(15,1)$ & 54,9 & $47,3-76,4$ & \\
\hline & igual & 25 & $79,6(12,1)$ & 76,5 & $52,1-100,0$ & \\
\hline & melhor & 11 & $90,6(10,1)$ & 94,5 & $70,8-100,0$ & \\
\hline \multirow{4}{*}{$\begin{array}{l}\text { Medo do câncer } \\
\text { voltar }\end{array}$} & não se aplica & 18 & $87,1(11,2)$ & 88,2 & $55,6-100,0$ & $0.001<\mathrm{p}<0.01$ \\
\hline & pior & 12 & $71,0(12,5)$ & 72,6 & $52,1-92,4$ & \\
\hline & igual & 26 & $83,7(12,6)$ & 84,4 & $47,3-100,0$ & \\
\hline & melhor & 6 & $83,5(13,1)$ & 85,5 & $64,0-97,3$ & \\
\hline \multirow{4}{*}{$\begin{array}{l}\text { Medo de } \\
\text { acontecimentos } \\
\text { desfavoráveis }\end{array}$} & não se aplica & 26 & $86,6(11,4)$ & 89,3 & $55,6-100,0$ & $0.001<\mathrm{p}<0.01$ \\
\hline & pior & 9 & $67,0(10,1)$ & 67,4 & $52,1-80,6$ & \\
\hline & igual & 23 & $83,6(12,8)$ & 84,8 & $47,3-100,0$ & \\
\hline & melhor & 4 & $79,8(10,4)$ & 75,1 & $73,7-95,2$ & \\
\hline
\end{tabular}

dp: desvio padrão; mín-máx: mínimo-máximo 


\section{DISCUSSÃO}

\subsection{PARTE I - TRADUÇÃO, ADAPTAÇÃO TRANSCULTURAL E VALIDAÇÃO}

O conceito de qualidade de vida, amplamente discutido na literatura científica há algumas décadas, assumiu, a partir da década de 80 do Século XX, um caráter multidimensional e tornou-se fonte de contribuição para o avanço de pesquisas científicas. Cerca de $70 \%$ do total dos instrumentos desenvolvidos a fim de mensurar a QV foram publicados nesta época (Costa Neto, 2002).

O caráter de subjetividade deste conceito, agregado ao seu aspecto de multidimensionalidade, consolidou-se a partir do início da década de 90, propiciando o surgimento de pesquisas científicas sobre QV, em diferentes áreas de conhecimento (Seidl; Zannon, 2004).

Em 1999, Fleck et al. comentam que "a oncologia foi a especialidade que, por excelência, se viu confrontada com a necessidade de avaliar as condições de vida dos pacientes que tinham sua sobrevida aumentada devido aos tratamentos realizados, já que, muitas vezes, na busca de acrescentar anos à vida, era deixada de lado a necessidade de acrescentar vida aos anos".

Os focos atuais da oncologia em cabeça e pescoço são, além da cura, o aumento do tempo da sobrevida, obtenção de melhores resultados funcionais e a preservação ou restauração da QV dos pacientes (Kowalski et al., 2000c), tornando a 
mensuração dos resultados QV uma ferramenta importante para a avaliação dos resultados alcançados com o tratamento (Llewellyn et al., 2007; Sayed et al., 2009).

Dwivedi et al. (2009) postulam que os estudos de QV colocam o paciente na posição central das intervenções de tratamento, ajudam na prática da rotina clínica e são efetivos para que se conheçam os contextos de sua vida pessoal e social, afirmando também que as características intrínsecas de um indivíduo, incluindo-se suas crenças, expectativas e experiências afetam diretamente sua QV.

A avaliação psicométrica da $\mathrm{QV}$, por meio de medidas genéricas ou específicas e em diversos domínios funcionais, influenciam clara e diretamente o bem-estar e a QV associada de um indivíduo após o tratamento e, além disso, otimizam os cuidados com o paciente, possibilitam uma completa avaliação das alternativas de tratamento e o desenvolvimento da reabilitação informada e de serviços de educação do paciente, identificando e priorizando os seus problemas e suas preferências e facilitando a comunicação com o médico (Kazi 2007b; Morton; Izzard, 2003; Murphy et al., 2007, Sayed et al., 2009).

Deve-se considerar que as prioridades dos clínicos nem sempre são correlatas às prioridades dos pacientes, o que sugere que estes devem ser a primeira fonte de coleta de dados, minimizando a possibilidade de ocorrência de vieses por parte dos clínicos (Gotay; Moore, 1992, Bjordal; Kaasa, 1992, Hassan; Weymuller, 1993, Mohide et al., 1992), e direcionando, também, o tratamento para o foco do paciente e não apenas no paciente.

Neste contexto, e diante das diversas mudanças que o câncer e seu tratamento impõem à vida dos pacientes desde o momento do diagnóstico e em diferentes momentos a partir do mesmo, a aplicação de questionários de QV também pode servir como instrumento de triagem para diversas situações (depressão, alcoolismo, 
incapacidade), possibilitando o direcionamento de medidas de suporte clínico e social mais abrangentes (Taylor et al., 2004; Duffy et al., 2002; Vartanian et al., 2006b).

Para Gliklich et al. (1997), a realização de uma avaliação de QV global (aspectos físicos, funcionais e psicossociais) seria o ideal, levando-se em conta aspectos genéricos e específicos, porém tais avaliações são inviáveis na prática diária, por serem longas e onerosas.

Ainda, a falta de consenso de uma definição consistente para QV e a ausência de um questionário ideal e único que seja considerado "padrão-ouro" para mensurála, dificultam a seleção de um instrumento adequado que possibilite ao clínico identificar e priorizar os problemas mais importantes para os pacientes, seus resultados e objetivos preferenciais, ajudando a monitorar mudanças/respostas ao tratamento (Sayed et al., 2009; Murphy et al., 2007).

Muito embora diferentes tipos de avaliação sejam extremamente necessárias, importantes e abrangentes, há que se considerar o fato de que é praticamente (senão totalmente) impossível estabelecer uma única forma de avaliar a QV de um indivíduo, especialmente quando se trata de mensurar dados subjetivos relacionados à saúde, que podem envolver aspectos de bem-estar físico, emocional, espiritual e social.

Conforme descrito pela International Society for Quality of Life ResearchISOQOL, "a proposta da mensuração da QVRS deve ser a de quantificar o grau em que uma condição médica ou tratamento impacta a vida de um indivíduo, de forma válida e reprodutível", sendo que devem ser mensurados os efeitos positivos e negativos da doença, das consequências de seu tratamento e as mudanças relativas ou 
absolutas nos conceitos de qualidade de vida, sob a perspectiva do paciente. A mesma entidade também preconiza (baseada na literatura) padrões mínimos para o desenvolvimento de uma ferramenta clínica, centrada nos resultados reportados pelos pacientes, tais como: confiabilidade teste-resteste, validade de conteúdo, validade de construto, validade de critério, responsividade, interpretabilidade dos escores e fardo para o respondente.

Tendo em vista que a maioria destes questionários é desenvolvida nos Estados Unidos, os mesmos devem ser submetidos incialmente ao processo de tradução e adaptação transcultural.

Segundo Peters e Passchier (2006), o objetivo do processo de tradução e adaptação transcultural de uma ferramenta clínica é o desenvolvimento de uma nova versão do instrumento em estudo, equivalente ao instrumento original adaptada ao dialeto do país ou região em que será utilizado, ao contexto cultural e estilo de vida da população a que se destina.

Vartanian et al. (2007) afirmam que a validação psicométrica de um instrumento deve garantir sua validade, confiabillidade e reprodutibilidade na nova população, considerando-se que ao final do processo, o questionário não perdeu o objetivo para o qual foi originalmente elaborado.

O Patients Concerns Inventory - PCI- H\&N foi elaborado com os objetivos de, potencialmente, oferecer aos pacientes com $\mathrm{CA} / \mathrm{CP}$ a liberdade de escolher se querem ou não discutir suas preocupações com os membros da equipe multidisciplinar em qualquer momento do tratamento e de suportar a adoção de estratégias e encaminhamentos apropriados, minimizando o impacto da doença e do tratamento nas diferentes áreas da vida do paciente. Diversas vantagens sobre o uso rotineiro do PCI em ambiente ambulatorial estão descritas: é simples e breve, 
possibilita o monitoramento das necessidades do paciente ao longo do tempo (para os clínicos e para o próprio paciente), favorece a identificação de cuidados de suporte necessários e apropriados ao paciente, não afeta o tempo médio de duração da consulta, direciona o foco da consulta e a simplifica, garante o atendimento às necessidades específicas do paciente, melhora a efetividade dos serviços, esclarece o paciente sobre os serviços de suporte disponíveis, facilita e melhora a comunicação entre o paciente e o clínico, empodera o paciente e o ajuda a discutir suas preocupações (Rogers et al., 2009, Ghazali et al., 2011, Kanatas et al., 2013, Ghazali et al., 2013a, Rogers; Lowe, 2014, Brandes et al., 2014).

Ainda, o PCI foi incluído em 2010 no DAHNO ("Data for Head and Neck Oncology“), sistema que apoia o National Head and Neck Cancer Audit (auditoria nacional obrigatória que coleta dados hospitalares de pacientes com CA de laringe e cavidade oral - UK), como um indicador de qualidade de cuidados que refletem a experiência do paciente. Recentemente, o PCI foi adaptado para pacientes com tumores cerebrais (Rooney et al., 2014) e pacientes portadoras de CA de mama (Kanatas et al., 2014), possuindo versões traduzidas para as línguas francesa, chinesa, sérvia, árabe, grega, urdu, mandarina, alemã, espanhola e malaia. Atualmente, encontra-se em desenvolvimento uma versão do $P C I$, especificamente desenhada para uso junto a pacientes com $\mathrm{CA} / \mathrm{CP}$, em fase diagnóstica, denominada H\&N Cancer Pre-treatment PCI (estudo piloto). A mesma vem sendo aplicada apenas em pacientes que serão submetidos a cirurgia, um dia antes do procedimento cirúrgico e em breve também será testada em pacientes que receberão tratamento quimioterápico, associado ou não à cirurgia. 
Ao confrontarmos os objetivos principais do PCI com o aspecto da confiabilidade teste-reteste, e após extensa discussão com o Dr. Simon Rogers, autor do PCI, concluiu-se que ambos são incompatíveis, pois o objetivo da reprodutibilidade de um teste é o de demonstrar sua habilidade em prover escores consistentes ao longo do tempo, em uma população estável, enquanto o PCI é, basicamente, uma lista de checagem de assuntos sobre os quais os pacientes gostariam de conversar em sua consulta clínica, não tendo por objetivo medir o grau desta preocupação "per se". Pacientes podem ter preocupações específicas e ainda assim não querer discuti-las. Assim, não coube realizar a confiabilidade teste-reteste do IPP.

A validade de um instrumento refere-se ao quanto que esta ferramenta efetivamente mede o que está se propondo a mensurar. A validade de conteúdo do IPP é a mais importante de suas propriedades e foi estabelecida através de rigorosa abordagem na concepção do instrumento original pelos seus autores e mantida através de rigoroso processo de tradução e retro-tradução.

Neste estudo, a validade de construto, realizada por meio das correlações entre os resultados do IPP e dos domínios específicos do UW-QOL, encontrou correlações moderadas, negativas, indicando que os pacientes com piores escores em ambos os domínios (físico e sócio-emocional) selecionaram um maior número de preocupações e um maior número de profissionais. No estudo original de concepção de PCI (Rogers et al., 2009), a casuística era formada por 123 pacientes, a maioria do sexo masculino (57,0\%), com média de idade de 63 anos e com diagnóstico de CEC (86,0\%). O sítio tumoral prevalente era a cavidade oral $(72,0 \%)$, seguido de orofaringe $(21,0 \%)$, com poucos casos de doença avançada (estadiamentos T3-T4, $24,0 \%$ ) e com tempo de diagnóstico menor ou igual a 12 meses $(34,0 \%)$. Os 
resultados do estudo também demonstraram correlações negativas fracas a moderadas entre os escores dos domínios físico e sócio-emocional com o número de preocupações e de profissionais selecionados, indicando que pacientes com piores escores compostos selecionaram mais itens em ambas as partes do questionário, o que concorda com os achados deste estudo.

Quanto às correlações entre as características dos pacientes com as preocupações e profissionais específicos selecionados neste estudo, encontraram-se correlações significantes entre a idade do paciente com os itens saúde dental e medo do câncer voltar, especialmente para pacientes mais jovens, enquanto no estudo de Rogers et al., 2009 a idade correlacionou-se com os itens aparência e fonoaudiólogo (ambos 22,0\%, para pacientes com idade $<55$ anos). Pode-se presumir que pacientes mais jovens possuam mais preocupações relacionadas aos aspectos que refletem uma boa aparência (dentes e face), o que seria inerente a idades menos avançadas, e que os mesmos tenham atividades sociais mais intensas, que demandam melhores padrões de comunicação e alimentação, itens estes dominados pelos profissionais da fonoaudiologia.

Os resultados encontrados demonstram um grande número de correlações significantes entre o menor tempo de diagnóstico e preocupações e profissionais selecionados (apetite, tratamento do câncer, sonda para alimentação, cicatrização de feridas, suporte para a família, nutricionista e fonoaudiólogo), enquanto no estudo de Rogers et al., 2009 houve correlação apenas com os itens atividade $(15,0 \%)$ e ansiedade $(27,0 \%)$ para pacientes com tempo $<12$ meses desde o diagnóstico. Os achados deste estudo vão de encontro ao fato de que muitos dos pacientes haviam realizado radioterapia e/ou cirurgia e ainda experimentavam os efeitos colaterais das mesmas (tais como xerostomia, perda ou diminuição do paladar, dificuldades de 
mastigação, deglutição e perda de peso), que podem permanecer mesmo um ano após o tratamento (Vissink et al., 2003; Larsson et al., 2005).

No presente estudo, pacientes submetidos à reconstrução assinalaram com maior frequência o item muita salivação, enquanto no estudo de 2009 estes pacientes assinalaram os itens fala/voz/ser entendido $(30,0 \%)$ e o fonoaudiólogo $(18,0 \%)$. Considerando-se que, se somados, mais da metade da amostra deste estudo era de pacientes com tumores em cavidade oral ou orofaringe (total de 54 casos, $64,2 \%$ ), foi submetida à cirurgia de reconstrução (46 casos, 54,7\%) e possuía tumores mais avançados (T3-T4, 52,3\%, $\mathrm{n}=44)$, pode-se deduzir que os mesmos foram submetidos a cirurgias mais extensas, com remoção de mais estruturas do sistema estomatognático, as quais são importantes para a efetividade da deglutição e para a contenção de saliva na cavidade oral, resultando em muita salivação (Vicente et al., 1997).

Correlações significantes entre o fato do paciente ter realizado radioterapia e os itens sonda para alimentação - (gastrostomia percutânea - PEG - 9,0\%), fala/voz/ser entendido $(34,0 \%)$ e deglutição $(30,0 \%)$ foram encontradas no estudo original, enquanto neste estudo esta característica associou-se apenas com o item boca seca $(34,0 \%)$. Mais uma vez, aqui, o grande número de pacientes que realizaram a radioterapia justifica este resultado, pois a xerostomia é uma sequela dessa modalidade de tratamento, podendo ocorrer durante e após o término do tratamento, permanecendo mesmo em longo prazo (Jaward et al., 2015).

Diferentemente dos resultados aqui reportados, no estudo de Rogers et al. (2009), os pacientes que realizaram cirurgia e radioterapia assinalaram com mais frequência o item fala/voz/ser entendido $(40,0 \%)$, e os que realizaram radioterapia primária assinalaram a preocupação com a deglutição $(38,0 \%)$. 
Foram encontradas correlações significantes entre os resultados dos domínios compostos do UW-QOL e as preocupações e profissionais especificamente selecionados em ambos os estudos, para pacientes com escores mais baixos de QV. Em 2009, os escores do domínio físico foram amplamente preditivos de assuntos específicos relacionados à função oral (mastigar/comer, abertura da boca, gastrostomia percutânea, fala/voz/ser entendido, engolir e paladar), enquanto o domínio sócio-emocional foi largamente preditivo de assuntos relacionados à emoção e atividade social (depressão, humor, níveis de energia, fadiga/cansaço, recreação e suporte para a família). Em contrapartida, neste estudo, ambos os domínios foram preditivos de assuntos especificamente relacionados à função oral.

Metcalfe et al. (2014) avaliaram 1614 pacientes (cavidade oral $n=751$, orofaringe $n=382$, laringe $n=320$, outros sítios $n=161$ ), comparando os resultados funcionais mais importantes para os pacientes, de acordo com a estratégia de tratamento, estadiamento e sítio tumorais, por meio da aplicação do UW-QOL. Os resultados, demonstraram que, para pacientes com tumores em cavidade oral menos avançados, nenhum domínio foi especialmente importante, enquanto para os pacientes com tumores mais avançados neste sítio, os domínios deglutição, mastigação, fala e saliva foram selecionados com maior frequência. Para pacientes com tumores menos avançados de orofaringe, os aspectos mais importantes foram deglutição e saliva e para os com tumores mais avançados, o paladar. Fala e atividade foram importantes para indivíduos com tumores menos avançados de laringe e a deglutição e fala para portadores de tumores mais avançados. Pacientes de todos os sítios tumorais, quando em estadiamento avançado, consideraram a deglutição e a saliva como os domínios mais importantes. 
Os resultados das correlações acima descritos, de forma geral, demonstram coerência quando se avaliam as características clínicas das amostras estudadas. A análise comparativa entre as preocupações e profissionais mais selecionados em ambos os estudos também refletem as características clínicas das populações em questão.

A preocupação mais frequentemente assinalada pelos pacientes foi o medo do câncer voltar, assim como nos resultados previamente reportados quando da criação do PCI, seguida por boca seca e mastigar/comer e pela indicação do fonoaudiólogo e do dentista, o que vai de encontro com as características clínicas e de tratamento predominantes da amostra. É interessante notar que o terceiro profissional mais selecionado nesta pesquisa foi o psicólogo. Kanatas et al. (2012) avaliaram 204 pacientes tratados do $\mathrm{CA} / \mathrm{CP}$ (num total de 454 consultas médicas) entre 8 e 47 meses após o diagnóstico, submetidos à radioterapia e/ou cirurgia, por meio da aplicação do PCI e do UW-QOL, com o intuito de identificar a presença de preocupações relacionadas ao humor, ansiedade e depressão. A amostra era constituída por pacientes com média de idade de 62 anos, a maioria do sexo masculino (57,0\%), com diagnóstico de CEC $(68,0 \%)$, tumores em estadiamentos menos avançados T1-T2 (77,0\%), tumores primários em cavidade oral $(68,0 \%)$, faringe e outros sítios. Em 32,0\% (145/454) das consultas realizadas os pacientes assinalaram no PCI que gostariam de discutir sobre preocupações relativas à ansiedade, humor e/ou depressão e 44,0\% (89/204) dos pacientes reportaram problemas significantes de ansiedade ou humor no UW-QOL.

Isto demonstra que os aspectos emocionais envolvidos na doença e no seu tratamento têm um peso importante na QV destes pacientes e merecem ser considerados com cuidado, mesmo quando se trata de uma população com maior 
tempo de diagnóstico e tratamento, como é o caso da amostra envolvida no processo de validação.

O tamanho das amostras utilizadas no processo de validação de questionários de QV podem variar. Para a validação do UW-QOL e do M.D. Anderson Dysphagia Inventory - (MDADI) para o português - Brasil, Vartanian et al. (2006a) e Guedes et al. (2013) avaliaram, respectivamente, 109 e 72 pacientes.

A casuística da validação contou com 84 pacientes e, apesar de ter sido constituída predominantemente por pacientes com tumores de cavidade oral, laringe e orofaringe, com poucos casos de nasofaringe, hipofaringe, fossas nasais, seios maxilares e outros sítios de $\mathrm{CA} / \mathrm{CP}$, a amostra foi equilibradamente representada pelos diferentes estadiamentos tumorais, modalidades de tratamento e tempo após o diagnóstico, possibilitando a avaliação da efetividade do IPP na prática clínica ambulatorial.

Todos os itens e profissionais presentes no IPP foram assinalados pelos pacientes, exceto o atendimento de profissionais em domicílio e equipe de enfermagem.

Muitas preocupações e alguns profissionais não existentes no instrumento original emergiram durante a realização deste estudo, o que deverá ser considerado em futuros refinamentos do PCI, aspecto este já considerado pelo autor desde a concepção original do mesmo.

Um dos pacientes avaliados solicitou uma cópia do questionário à pesquisadora, a fim de discorrer mais amplamente sobre cada um dos itens nele contidos (Apêndice 3). 
De forma geral, os pacientes responderam com facilidade ao IPP e demonstraram sua satisfação em fazê-lo. Os resultados descritos indicam a viabilidade de sua aplicação em ambiente ambulatorial para pacientes brasileiros.

Além de ser o único instrumento clínico no gênero já disponível para pacientes com $\mathrm{CA} / \mathrm{CP}$ no Brasil, o IPP se apresenta como uma ferramenta clínica ágil, fácil de ser utilizada em qualquer momento do tratamento, holística e que pode ser utilizada sozinha ou em conjunto com outros questionários de QV. Além disso, possibilita ao paciente identificar e dar voz aos assuntos que o preocupam e sobre os quais gostaria de conversar, ajudando pacientes e clínicos a identificar, abordar e a minimizar essas preocupações.

Uma vez validado, é importante que o uso do IPP seja incorporado na rotina clínica ambulatorial, que seus resultados sejam devidamente documentados e que as ações clínicas resultantes de seu uso sejam avaliadas. 


\subsection{PARTE II - AVALIAÇÃO PRÉ-TRATAMENTO E AOS 6 E 12 MESES APÓs O DIAGNÓSTICO}

\subsubsection{Características Demográficas e Clínicas das Amostras Avaliadas}

O perfil demográfico dos pacientes participantes deste estudo, nos três momentos avaliados (pré-tratamento, 6 e 12 meses após o diagnóstico) está de acordo com os dados epidemiológicos encontrados na literatura. Houve prevalência do sexo masculino, com idades entre a $5^{\mathrm{a}}$ e $7^{\mathrm{a}}$ décadas de vida e fatores de risco como tabagismo e etilismo (Saunders et al., 2007). O baixo grau de escolaridade é descrito na literatura como característica de risco e maior vulnerabilidade para o diagnóstico tardio do CA/CP (Noce et al., 2008, Santos et al., 2012, Fernandes et al., 2013). Entretanto, é interessante observar que, ao momento do diagnóstico, cerca de $51,0 \%(\mathrm{n}=53)$ dos pacientes deste estudo tinham nível de instrução $\geq$ ao ensino médio incompleto. Campos et al. (2007) estudaram os fatores que afetavam o atraso no diagnóstico do $\mathrm{CA} / \mathrm{CP}$ e concluíram que estas variáveis eram os exames subsidiários realizados pelos pacientes e o número de outros profissionais a quem o paciente foi encaminhado, afirmando também que o grau de escolaridade (dentre outros aspectos sócio-demográficos) não influenciava o atraso no diagnóstico.

Santos et al. (2010) avaliaram 74 pacientes portadores de CEC de cavidade oral (78,4\% com doença avançada), dos quais $37,8 \%$ eram analfabetos e $40,3 \%$ tinham o ensino fundamental incompleto ou maior grau de escolaridade. Os autores encontraram uma proporção maior de pacientes que procurou inicialmente o médico generalista, ao invés do médico especialista ou o dentista, sugerindo que o desconhecimento e despreparo dos profissionais que não reconhecem os sinais e sintomas do câncer pode levar a um tratamento incorreto e/ou dificultar ou atrasar o 
encaminhamento dos pacientes. Ainda, os autores verificaram que 41,9\% dos pacientes sabiam da lesão, mas só procuraram o serviço de saúde, quando a mesma começou a incomodar, o que pode indicar a desvalorização no auto-cuidado, a recusa ou negação da doença.

A prevalência de pacientes com tumores em estadiamentos mais avançados (T3-T4) no momento do diagnóstico, o tipo histológico (CEC) e a distribuição dos sítios tumorais também estão de acordo com a literatura (Santos et al., 2012; Casati et al., 2012).

Levando-se em conta as características clínicas dos pacientes no momento pré-tratamento, a proporção de pacientes aos 6 meses após o diagnóstico que havia realizado cirurgia e radioquimioterapia combinada como forma de tratamento inicial também está de acordo com a literatura, que preconiza a abordagem cirúrgica, associada ou não a radioterapia e/ou quimioterapia como principal forma de tratamento para tumores avançados (Mesía et al., 2010; Yom et al., 2016). A frequência de pacientes que receberam doses de radioterapia $\geq 60 \mathrm{~Gy}$, (como tratamento exclusivo, concomitante à quimioterapia ou adjuvante) também está de acordo com a literatura (Kelly, 2007).

\subsubsection{Ansiedade e Depressão}

O diagnóstico do câncer pode causar um grande impacto para a maioria dos pacientes, gerando sentimentos de ansiedade e depressão como respostas às grandes mudanças de vida por ele causados, tais como mudanças nos papéis familiar e de trabalho, na imagem corporal, na auto-estima e na auto-confiança, gerando o medo da morte, do sofrimento, da dor, ou do desconhecido, entre outros. Estes sentimentos podem ocorrer em quaisquer momentos após o diagnóstico e até mesmo muitos anos 
após o seu tratamento (American Cancer Society-ACS, 2016).

As taxas da prevalência da depressão em pacientes com câncer situam-se entre $22,0 \%$ e $29,0 \%$ (Raison; Nemeroff, 2000). Muitos fatores psicossociais de estresse são comuns a todos os tipos de câncer, entretanto, outros fatores de estresse são agregados quando do diagnóstico do $\mathrm{CA} / \mathrm{CP}$, tais como dificuldades funcionais relacionadas à mastigação, deglutição, fala/voz, dores crônicas, desfiguramento e estigma (Devins et al., 2010). A literatura científica reporta que a ocorrência de ansiedade e depressão em pacientes portadores de $\mathrm{CA} / \mathrm{CP}$ ocorre em taxas mais altas do que na população geral, em porcentagens que variam entre $14,0 \%$ a 44,0\% (Duffy et al., 2002; Karnell et al., 2006). De acordo com Vartanian et al. (2006c), os estudos que avaliam a situação emocional e a saúde mental dos pacientes portadores de CA/CP são necessários e relevantes, devido à alta prevalência de sintomas depressivos nesta população, os quais são potencialmente tratáveis, tornando imperativa a identificação precoce da depressão nesta população (Bottino et al 2009). Segundo Maguire e Howell (1995), mais de 80,0\% das comorbidades psicológicas e psiquiátricas presentes nos pacientes oncológicos passam despercebidas e não são tratadas.

Neste estudo, optou-se por avaliar os graus de ansiedade e depressão dos pacientes em todos os momentos do estudo, com o objetivo de caracterizar seu estado emocional em momentos pontuais durante a trajetória de enfrentamento da doença ou seja, logo após a confirmação do diagnóstico da neoplasia, quando muitos dos pacientes ainda não tinham a definição da conduta clínica que seria adotada, aos 6 meses após o diagnóstico, quando a grande maioria dos pacientes ainda enfrentava o auge do tratamento (radioterapia, quimioterapia, cirurgia) e suas sequelas agudas (xerostomia, disgeusia, perda de peso, entre outras) e finalmente aos 12 meses após o 
diagnóstico, quando estes pacientes passam a experimentar as sequelas tardias do(s) tratamento(s) a que foram submetidos, além de confrontarem-se com a possibilidade / impossibilidade de retomar aspectos de sua vida, dos quais tiveram que abdicar anteriormente. Ainda, este é um período marcante para o paciente por se tratar de uma época de avaliação dos resultados clínicos alcançados com o tratamento, do prognóstico e de eventual mudança nos intervalos de seguimento ambulatorial.

É necessário esclarecer que, nesta pesquisa, optou-se por apenas caracterizar o estado emocional dos pacientes nos diferentes momentos estudados. Portanto, os achados de ansiedade e depressão não foram correlacionados estatisticamente com as variáveis sócio-demográficas e clínicas dos pacientes e tampouco com os resultados dos outros instrumentos aplicados, o que limita a discussão sobre os fatores associados à ocorrência destes sintomas nos pacientes avaliados. Tais análises serão objeto de estudos futuros.

Os estudos disponíveis, na literatura, que avaliam os níveis de ansiedade e depressão de pacientes com $\mathrm{CA} / \mathrm{CP}$, apresentam resultados bastante diversificados devido à grande variedade de metodologias adotadas. Krebber et al. (2014) conduziram o levantamento de 211 estudos científicos a fim de analisar as diferenças nas prevalências de depressão em pacientes adultos com câncer. A prevalência média agrupada de depressão nestes pacientes variou entre $8,0 \%$ e $24,0 \%$ e diferiu dependendo do tipo de instrumento usado, tipo de câncer e fase do tratamento avaliados.

Os resultados aqui encontrados indicaram que a porcentagem de pacientes que apresentou graus de ansiedade dentro dos limites da normalidade aumentou ao longo do tempo após o diagnóstico. Já para o grau de ansiedade leve, a maior porcentagem de ocorrência foi à época do diagnóstico, diminuindo acentuadamente 
aos seis meses e tornando a aumentar aos 12 meses, porém em níveis menores no que no pré-tratamento. A ansiedade moderada ocorreu em proporções similares no prétratamento e aos 6 meses, decrescendo acentuadamente aos 12 meses. Já para a ansiedade severa, as ocorrências diminuíram aos 6 meses, sem nenhum caso aos 12 meses. O período que sucede ao diagnóstico coloca os pacientes frente a uma situação de desorganização de sua rotina diária, demandando também uma atenção imediata às informações sobre a doença e opções de tratamento, o que pode contribuir para elevar os níveis de ansiedade (Llewellyn et al., 2006a, National Cancer Alliance 2002).

A curva para graus de depressão dentro da normalidade apresentou o mesmo comportamento que a ansiedade, ou seja, a porcentagem de pacientes sem depressão aumentou ao longo do tempo. A ocorrência de depressão leve também diminuiu ao longo do estudo e de forma acentuada aos 12 meses, quando comparada à avaliação anterior. Entretanto, ainda que a frequência de casos de depressão moderada tenha sido baixa nos três momentos avaliados, esta porcentagem aumentou aos 6 meses, com discreta redução na última avaliação. Apenas um caso de depressão severa foi detectado nos momentos pré-tratamento e aos 12 meses após o diagnóstico.

Considerando-se a presença de ansiedade e depressão de forma agrupada nas três épocas do estudo, um total de $30,8 \%$ dos pacientes apresentou algum grau de ansiedade no momento pré-tratamento, $16,8 \%$ aos 6 meses e $14,5 \%$ aos 12 meses.

Em relação à depressão, um total de $21,2 \%$ dos pacientes a apresentaram no momento pré - tratamento, $16,3 \%$ aos 6 meses e $8,1 \%$ aos 12 meses. É interessante notar que a casuística de pacientes que participaram de todas as épocas do estudo era constituída principalmente por pacientes casados, o que está de acordo com estudos prévios que sugerem que ser casado está associado com menores graus de ansiedade 
e depressão em pacientes com câncer (Lloyd- Williams; Friedman, 2001, Parker et al., 2003).

Uma vez que a escala HADS foi aplicada, juntamente com os outros instrumentos, antes do início da consulta clínica, os pacientes desta pesquisa que apresentaram graus de ansiedade e/ou escores de depressão em qualquer grau foram instruídos pela pesquisadora a conversar com o médico sobre estes resultados durante a consulta para eventual encaminhamento ao Núcleo de Psico-Oncologia da instituição, independentemente da fase do estudo.

As curvas decrescentes de ansiedade e depressão entre o momento após o diagnóstico e 12 meses após o tratamento encontradas neste estudo concordam com os resultados descritos por Abdullah et al. (2015), que avaliaram 60 pacientes com CA/CP, com até um ano de diagnóstico (média de idade 49,76, dp= $= \pm 11,56,66,0 \%$ do sexo masculino, 56,0\% com educação secundária, 50,0\% com tumores em estadiamentos T3-T4, sem metástases à distância, dos quais 40,0\% eram novos casos. É relevante notar que um dos critérios de inclusão para este estudo era o de o paciente ser casado ou ter vivido uma relação afetiva por mais de 6 meses à época do diagnóstico.

Em 2010, Neilson et al. utilizaram a escala HADS para avaliar prospectivamente os sintomas de ansiedade e depressão de 75 pacientes recém diagnosticados com $\mathrm{CA} / \mathrm{CP}$, antes do início do tratamento radioterápico (associado ou não à quimioterapia) e três semanas após o término do mesmo. Os escores médios de ansiedade diminuíram significativamente neste intervalo de tempo e a prevalência de sintomas de ansiedade moderados a severos foi de $30,0 \%$ antes do tratamento, decrescendo para 17,0\% após seu término. Os escores médios de depressão aumentaram significativamente e a prevalência de sintomas de depressão moderada a 
severa foi de $15,0 \%$ e $31,0 \%$ antes e após o tratamento, respectivamente. Estas prevalências discordam dos resultados deste estudo, o que pode eventualmente ser explicado pelo fato de que apenas $30,0 \%$ dos pacientes de nossa casuística havia realizado a radioterapia aos 6 meses após o tratamento.

Verdonck-de Leeuw et al. (2009) triaram prospectivamente 55 indivíduos recém diagnosticados com $\mathrm{CA} / \mathrm{CP}$ a fim de identificar os pacientes com altos níveis de sofrimento emocional. Destes, $64,0 \%$ apresentaram baixos níveis de aflição psicológica no pré-tratamento e no seguimento, o que está de acordo com os resultados encontrados. Entretanto, a prevalência de pacientes com alto grau de sofrimento nesta época foi maior no estudo supra-citado $(18,0 \%)$ do que neste estudo $(13,5 \%$ moderada/severa $)$. Em 2016, Wu et al. pesquisaram as morbidades psiquiátricas de 106 pacientes com diagnóstico recente de CA/CP (60,0\% em estadiamento avançado), por meio da aplicação do instrumento SCID (First et al., 1997), antes do tratamento e aos 3 e 6 meses após seu término. Os resultados demonstraram altas taxas de ansiedade no momento pré-tratamento, as quais claramente declinaram ao longo do tempo, respectivamente $27,3 \%, 6,4 \%$ e $3,3 \%$. Já os padrões de depressão variaram de $8,5 \%$ antes do tratamento para $24,5 \%$ aos 3 meses e 14,0\% aos 6 meses. Comparando-se as prevalências agrupadas de ansiedade e de depressão (antes do tratamento e aos 6 meses apenas) encontradas neste estudo com os resultados reportados por $\mathrm{Wu}$ et al. (2016), observa-se o mesmo comportamento para ambas as curvas, nos dois estudos.

Hammerlid et al. (1999) conduziram um estudo com 357 pacientes recém diagnosticados com $\mathrm{CA} / \mathrm{CP}$ com o intuito de determinar os níveis de aflição psicológica antes, durante e após o tratamento. A casuística era composta prevalentemente por homens (72,0\%), com média de idade de 63 anos, sendo 122 
pacientes com tumores em cavidade oral, 89 com tumores em faringe, 86 com tumores em laringe e 60 casos diversos (glândulas salivares, nariz / seios da face e sítio primário desconhecido). Juntamente com outros questionários, os pacientes completaram o instrumento HADS em seis momentos, durante um ano, respectivamente à época do diagnóstico $(\mathrm{n}=357), 1(\mathrm{n}=306), 2(\mathrm{n}=290), 3(\mathrm{n}=261), 6$ $(n=239)$ e $12(n=215)$ meses após o início do tratamento. Como resultado, encontraram uma taxa de ansiedade de 32,0\% na época do diagnóstico, o que está em concordância com os achados da casuística aqui avaliada. Aos 6 e 12 meses após o início do tratamento, as taxas de ansiedade foram de 20,0\%, o que está em desacordo com os resultados aqui encontrados. Talvez essa diferença possa ser explicada pelo maior número de pacientes avaliados no estudo de 1999. Quanto à depressão, o grau aqui encontrado no momento pré-tratamento $(21,2 \%)$ foi maior do que o do referido estudo (17,0\%); aos 6 meses foram encontradas prevalências menores (16,3\%) e acentuadamente menores aos 12 meses $(8,1 \%)$ do que as reportadas no estudo de 1999, respectivamente $20,0 \%$ e $17,0 \%$. Novamente, talvez esta discrepância possa ser explicada pela diferença nos tamanhos das casuísticas avaliadas.

O desenvolvimento de ansiedade e depressão está relacionado a muitas variáveis psicossociais, tais como necessidade de informações sobre a doença, medo da recorrência da doença, qualidade de vida, padrões de auto-cuidado, personalidade, aparência e suporte social (Humphris; Ozakinci, 2006) e o diagnóstico pode ser dificultado ou inibido por sentimentos de tristeza e desespero desses pacientes, pelo tempo limitado para investigação de questões emocionais, custos associados ao tratamento, confusão entre a morbidade de transtornos depressivos maiores e outras fontes de tristeza do paciente (Bottino et al., 2009) ou até mesmo pela postura do médico, que pode considerar que o paciente solicitará sua ajuda se seu problema 
psicológico for "sério o suficiente" (Maguire, 1985).

Assim sendo, uma comunicação efetiva entre médico e paciente e a aplicação de instrumentos validados e curtos para a detecção de transtornos psicológicos, em diversos momentos ao longo do curso da doença, podem ser determinantes na prevenção, instalação e identificação de casos de depressão, que podem comprometer a qualidade de vida de pacientes com $\mathrm{CA} / \mathrm{CP}$ e sua resposta ao tratamento oncológico.

\subsubsection{Qualidade de Vida}

As definições para o conceito de QV disponíveis na literatura são inúmeras e, em geral, reafirmam seu caráter de subjetividade e multidimensionalidade. Diversos fatores, não excludentes entre si, são determinantes quando se pretende mensurar a qualidade de vida de um indivíduo. O resultado desta mensuração será um balanço final que este indivíduo realiza, em um dado momento de sua vida, considerando seu desempenho e satisfação em relação a todos os papéis que o mesmo desempenha em sua vida, agregado aos seus valores espirituais e percepção de bem-estar físico e emocional. Considerando apenas as variáveis saúde e QV, Almeida et al. (2012) citam: "A relação entre saúde e qualidade de vida depende da cultura da sociedade em que está inserido o sujeito, além de ações pessoais (esfera subjetiva) e programas públicos ligados à melhoria da condição de vida da população (esfera objetiva). $\mathrm{O}$ estado de saúde é um indicador das possibilidades de ação do sujeito em seu grupo, se apresentando como um facilitador para a percepção de um bem-estar positivo ou negativo. É influenciado pelo ambiente, pelo estilo de vida, pela biologia humana e pela organização do sistema de atenção à saúde em que o sujeito está inserido". Quando se trata de avaliar a QV de indivíduos afetados pelo câncer, é imprescindível 
considerar que, para cada um dos pacientes, o diagnóstico representou um "divisor de águas", independentemente do caráter de sua resposta emocional e comportamental à situação. $\mathrm{O}$ diagnóstico do $\mathrm{CA} / \mathrm{CP}$ e seu tratamento trazem consigo consequências transitórias ou permanentes que geralmente assolam não somente a percepção que um indivíduo tem sobre seu bem-estar físico, psicológico e social, mas também podem causar efeitos desabilitantes em diversas funções físicas básicas de sua vida (mastigar, deglutir, falar e respirar). A mensuração da QVRS é um importante indicador em pacientes portadores de $\mathrm{CA} / \mathrm{CP}$ pois possibilita uma medida de sua experiência com a doença e é um preditor de sobrevivência à doença (Rogers, 2010). Sendo assim, a avaliação da QVRS destes pacientes deve ter não somente o objetivo de quantificar em que grau a doença impacta todas as áreas de suas vidas ao longo do tempo, mas efetiva e primordialmente reverter em benefícios para estes, ou seja, possibilitar a estruturação e adoção de medidas que promovam a restauração de seu bem-estar físico, funcional, social e espiritual.

Neste estudo, optou-se pela utilização do UW-QOL para mensurar a QV dos pacientes recrutados por se tratar de uma ferramenta clínica específica para pacientes com CA/CP, amplamente utilizada e validada para a língua portuguesa. Em 2007, Rogers et al. realizaram uma revisão da literatura científica sobre os estudos publicados entre 2000 e 2005 sobre a QVRS de pacientes com CA/CP. Foram identificados 165 estudos, dos quais 97 eram longitudinais, 50 reportavam os resultados funcionais e 38 usavam o questionário UW-QOL. Entre os 128 artigos brasileiros publicados em português no período entre 1998 e 2008, identificados por Bertan e Castro (2009), sobre os aspectos psicológicos relacionados à QV de pacientes adultos com diversos tipos de câncer e em qualquer fase do tratamento, apenas 40 avaliavam o conceito de QV de forma multidimensional, dos quais $23,0 \%$ 
referiam-se a pacientes com $\mathrm{CA} / \mathrm{CP}$.

Outrossim, 77,0\% destes estudos foram publicados na região sudeste, 7,0\% na região Sul e muito poucos nas demais regiões. Testoni et al. (2013) realizaram uma revisão integrativa sobre o mesmo tema dos estudos publicados nas bases de dados entre 1992 a 2012, encontrando 25 artigos, sendo que apenas 8,0\% destes tinham como país de origem o Brasil. Diante destes números, a realização deste estudo parece vir a contribuir para suprir, em parte, a carência de pesquisas sobre a QVRS de pacientes brasileiros com $\mathrm{CA} / \mathrm{CP}$, em qualquer época do tratamento.

A aplicação do $U W-Q O L$ nas casuísticas avaliadas neste estudo, nos três momentos, teve por objetivo caracterizar a QV dos pacientes e será objeto de futuros cruzamentos estatísticos com os resultados sócio-demográficos e clínicos dos pacientes e com os resultados dos outros instrumentos aplicados, possibilitando um melhor entendimento e ampliando a discussão teórica e comparada com os resultados disponíveis na literatura sobre o tema.

Em todas as épocas avaliadas neste estudo, os pacientes apresentaram uma média do escore global do UW-QOL pontuadas entre entre 75 e 90 , sendo que a pior média deste escore ocorreu aos 6 meses (média 75,3, dp =15,8, pontuações entre 30,6 a 100), indicando uma queda na QV global em relação ao momento pré-tratamento (média $=81,4, d p=14$, pontuações entre 33,9 a 100). Já aos 12 meses, a média deste escore global sofreu uma elevação (média $=82,2, d p=13,2$, pontuações entre 47,3 a 100) superando discretamente os escores apresentados à época do diagnóstico. Estes resultados concordam com as pesquisas sobre o tema, que reportam um declínio característico nos resultados de $\mathrm{QV}$ como resposta ao tratamento do $\mathrm{CA} / \mathrm{CP}$, mais pronunciadamente nos primeiros meses, seguido por uma melhora geral ao longo do 
primeiro ano (Hammerlid et al., 1998; Graeff et al., 2000; Bjordal et al., 2001; Lin et al., 2003).

Analisando-se individualmente os domínios do $U W-Q O L$, os domínios dor, ansiedade e humor tiveram seus escores médios mais baixos no momento prétratamento, respectivamente $66,1,61,6$ e 76,4 , com um aumento gradativo destas médias ao longo do estudo. A melhora nos escores médios do domínio humor, apesar da deterioração das funções físicas ao longo do tempo, estão de acordo com os achados encontrados por Graeff et al. (2000) e podem ser interpretados como uma adaptação dos pacientes à situação e/ou ao fato de já ter decorrido algum tempo desde o diagnóstico, quando estes sentem suas vidas ameaçadas e iniciam uma jornada rumo ao desconhecido. Horney et al. (2011) hipotetizaram que pacientes com CA/CP que se mostravam ansiosos e/ou deprimidos no período do diagnóstico reportavam pior QV. Os autores avaliaram 103 pacientes $(71,0 \%$ homens, média de idade 63 anos) por meio da aplicação do instrumento de avaliação de QV SF-12v2 (Ware et al., 2002) e da escala HADS. As correlações estatísticas indicaram que cinco domínios de QV - saúde geral, função emocional, vitalidade, função social e dor - estavam significativamente relacionados com a ansiedade. Os autores concluíram que durante o período que antecede o tratamento a maioria dos pacientes lidava bem com o diagnóstico, apresentava baixos níveis de ansiedade e tinha uma QV moderadamente boa, o que concorda com os resultados deste estudo.

Daher (2013) estudaram 99 pacientes (83,8\% homens), com idades entre 20,6 a 83,9 anos, diagnosticados com CEC de CA/CP (boca, orofaringe, hipofaringe e laringe), não submetidos previamente a tratamento oncológico. Quarenta e oito pacientes $(48,5 \%)$ tinham tumores com estadiamentos $\mathrm{T} 1-\mathrm{T} 2$ e 51 pacientes $(51,5 \%)$ tinham tumores avançados (T3-T4). À primeira avaliação, 17,2\% dos pacientes 
apresentaram queixa de dor local. Os questionários $U W-Q O L$, Índice de Desvantagem Vocal - IDV (Rosen et al., 2009; Behlau 2011) e o Questionário de qualidade de vida em disfagia - SWAL-QOL (Mchorney et al., 2000; Portas, 2009) foram aplicados antes do inicio do tratamento oncológico, entre o término imediato do tratamento até 3 meses após, entre o $4^{0}$ e o $6^{0}$, entre o $7^{0}$ e o $12^{0}$ e após 12 meses de término do tratamento. Os resultados desta pesquisa indicaram que para os domínios dor e ansiedade os escores mais baixos apresentaram-se no momento prétratamento, seguido por melhora progressiva das médias ao longo do tempo, concordando com os resultados aqui encontrados. Além disso, ambas as casuísticas são similares quanto à prevalência dos sítios primários do TU (cavidade oral e orofaringe) e prevalência de tumores avançados, o que pode justificar a presença da dor mais intensa nestes pacientes (Isaac et al., 2012) e o consequente impacto na QV.

Considerando-se os resultados individuais dos domínios atividade, recreação, aparência, deglutição, mastigação, fala, paladar e saliva, os menores escores médios apresentaram-se aos 6 meses após o início do tratamento, sendo que o domínio mastigação apresentou a média mais baixa entre todos os domínios citados (média $58,1, \mathrm{dp}=39,3$, pontuado entre 0 e 100), seguido pelos domínios paladar (média $=$ $59,1, \mathrm{dp}=38,7$, pontuado entre 0 e 100 ) e saliva (média $=70,0, \mathrm{dp}=31,3$, pontuado entre 0 e 100). Estes escores refletem o fato de que, aos 6 meses após o diagnóstico, a maioria dos pacientes ainda enfrenta o tratamento do câncer (muitas vezes a adjuvância) propriamente dito ou vivencia suas sequelas agudas, tais como cicatrização das feridas operatórias em caso de cirurgias extensas, xerostomia, mucosite, disgeusia, disfagia, rouquidão, trismo, fadiga, perda de peso, entre outras, as quais impactam especialmente suas funções físicas e sociais. Ainda, nesta época, 60/80 pacientes analisados tinham sido submetidos ao tratamento radioterápico e/ou 
quimioterápico como forma de tratamento inicial ou adjuvante, o que também justifica os escores médios encontrados.

Cardoso et al. (2005) fizeram o acompanhamento odontológico de 12 pacientes com $\mathrm{CA} / \mathrm{CP}$ submetidos a cirurgia e radioterapia ou radioterapia exclusiva antes, durante e até 180 dias após o tratamento e descreveram uma proporção 83,0\% de ausência de alterações do paladar aos 180 dias. O escore médio para o domínio paladar encontrado na casuística avaliada aos 6 meses indicou que as alterações de paladar ainda se faziam sentir mais intensamente nesta época, impactando a QV dos pacientes avaliados. Talvez sua ocorrência neste estudo possa estar associada a presença da xerostomia (Segreto; Segreto, 2000).

Os escores médios dos domínios saliva, aparência e fala em no presente estudo evoluíram com melhora muito discreta (platô) aos 12 meses, em relação aos 6 meses. A xerostomia induzida pela radioterapia é uma das mais comuns complicações para os pacientes com $\mathrm{CA} / \mathrm{CP}$ e pode reduzir sua QV (Cheng et al., 2011; Chen et al., 2015). Por ser uma sequela aguda e tardia do tratamento radioterápico, é comum que estes experimentem uma sensação subjetiva permanente de boca seca, comprometendo seu bem-estar geral, dificultando a mastigação e a deglutição e comprometendo as habilidades de fala (Kaae et al., 2016), o que é coerente com o comportamento dos escores dos domínios saliva e fala aqui descritos quando se analisam as variáveis clínicas e de tratamento dos pacientes aos 6 e 12 meses. Ainda, deve-se considerar também que aos 6 e 12 meses, respectivamente, 13,8\% (n=11) e 17,7\% (n=11) dos pacientes que constituíam as amostras tinham recebido tratamento para tumores laríngeos e eventualmente experimentavam fibrose laríngea e/ou alterações anatômicas 
da fonte glótica resultantes do tratamento, as quais afetam diretamente a deglutição e a fala.

A aparência após o tratamento oncológico também pode impactar negativamente a QV dos pacientes, especialmente para os que são submetidos a ressecções cirúrgicas que causem desfiguração facial (Djan; Penington, 2013) e decorrente reconstrução (Chigurupati et al., 2013). Na amostra avaliada aos 6 meses e 12 meses, respectivamente $60,0 \%(n=48 / 80)$ e $62,9 \%(n=39 / 62)$ dos pacientes tinha sido submetida à cirurgia, dos quais $73,0 \%(\mathrm{n}=35 / 48)$ e $30,8 \%(\mathrm{n}=12 / 39)$ havia realizado a reconstrução. Aliado a estes fatos, os pacientes portadores de $\mathrm{CA} / \mathrm{CP}$, especialmente quando submetidos à radioterapia, necessitam realizar exodontias no momento pré-tratamento, suspender temporariamente o uso de próteses dentárias parciais e totais durante e após o tratamento (Cardoso et al., 2005), o que pode comprometer o bem-estar do paciente em relação à sua aparência, as funções de mastigação, deglutição e fala, limitando não somente o aspecto funcional destes últimos domínios, mas impactando, também, o caráter social e recreativo da alimentação e da comunicação. Segundo Vartanian et al. (2004), o tratamento é a variável que causa maior interferência na QV de vida de pacientes com tumores em cavidade oral e orofaringe, atribuindo também ao tratamento combinado de cirurgia e radioterapia uma associação com piores escores nos domínios aparência, recreação, mastigação, deglutição e fala. Esta análise vai de encontro ao resultado deste estudo, quando se observam as prevalências dos sítios tumorais e de tratamento das casuísticas aqui analisadas.

Specht (2002) e Rogers et al. (2002) consideram, respectivamente, que a função da cabeça e pescoço e a aparência são fatores críticos na auto-imagem e QV dos pacientes com tumores nestes sítios e que as funções orais estão associadas aos 
resultados de QVRS. Em 2009, Angelo et al. utilizaram-se do UW-QOL para avaliar a QV de 41 pacientes com CEC de CA/CP (média de idade 63,5 anos, 73,2\% do sexo masculino, $53,7 \%$ com tumores avançados, sítio tumoral "anterior" $\mathrm{n}=18$ e “posterior” $\mathrm{n}=23)$, dos quais $80,5 \%(\mathrm{n}=33)$ já haviam concluído o tratamento oncológico. Porém, o tempo decorrido após o término do tratamento não está descrito pelos autores, o que limita a verificação de similaridade com os resultados, aqui, apresentados. Entretanto, a pesquisa indicou que o domínio mastigação tinha sido o mais afetado na amostra, seguido de dor, deglutição, saliva e ansiedade, quando relacionados às características dos pacientes e que, apesar das deficiências em domínios específicos, a maioria dos pacientes apresentava uma QV entre boa e muito boa, o que mostra similaridade com os resultados aqui encontrados.

Os domínios atividade e recreação apresentaram médias menores aos 6 meses do que as encontradas antes do tratamento, evoluindo com acentuada melhora aos 12 meses em relação aos 6 meses. Os escores médios apresentados pelos pacientes deste estudo no momento pré tratamento e aos 12 meses diferem dos resultados reportados por Biazevic et al. (2010), que avaliaram por meio do UW-QOL a QV de 25 pacientes com tumores de cavidade oral e orofaringe tratados cirurgicamente, nos momentos pré-operatório e um ano após o tratamento e encontraram uma piora acentuada nestes domínios com o decorrer do tempo, o que é curioso, pois a maioria dos pacientes avaliados possuía tumores com estadiamentos $\mathrm{T} 1-\mathrm{T} 2(\mathrm{n}=18 / 25)$.

Os altos resultados dos escores médios para o domínio ombros indicaram uma boa QV aos 6 e 12 meses, apesar da frequência de pacientes que tinham realizado o esvaziamento cervical nestas épocas (respectivamente 75,0\% e 74,4\%). List e Bilir (2004) afirmam que o esvaziamento cervical tem potencial suficiente para afetar gravemente a função e a qualidade de vida dos pacientes. Os aspectos que 
podem eventualmente explicar os escores para este domínio são as possíveis variações nos esvaziamentos realizados nestes pacientes (unilateral, bilateral, preservação ou denervação do nervo acessório, níveis de esvaziamento) ou a até mesmo uma menor importância atribuída pelos pacientes para essa função, frente às outras possíveis sequelas funcionais do tratamento oncológico.

Independentemente da metodologia adotada, a análise da QV dos pacientes com $\mathrm{CA} / \mathrm{CP}$, em qualquer fase do tratamento deve levar em conta as relações de causa e efeito entre os domínios avaliados e a QVRS global do paciente (Osoba, 2007) e ser aplicadas com os objetivos de entender o real impacto do CA/CP na vida dos indivduos por ele afetados, auxiliando a escolha terapêutica e direcionando programas de reabilitação e suporte psicossocial (Vartanian et al., 2007).

\subsubsection{Prevalência dos Sintomas}

$\mathrm{O} \mathrm{CA} / \mathrm{CP}$ e seu tratamento podem causar morbidades sintomáticas substanciais de ordem local ou sistêmica (Hanna et al., 2015), agudas, sub-agudas ou crônicas (Chera et al., 2014), a depender da modalidade terapêutica adotada. Apesar dos avanços na cirurgia, radioterapia e quimioterapia terem melhorado o controle loco-regional da doença, a sobrevida e a QV dos pacientes (Cognetti et al., 2008) e, ainda que a radioterapia e a quimioterapia tenham diminuído as sequelas debilitantes e desfiguradoras das cirurgias, a toxicidade delas decorrentes são geralmente difíceis de controlar (Mason et al., 2016). Porém, o controle desta sintomatologia é prioritário para os pacientes (List et al., 2000) e deve ser iniciado na fase diagnóstica, mantido no período do tratamento e estender-se durante a chamada "fase de sobrevivência” (Levy et al., 2009). Gunn et al. (2013) ressaltam que estes sintomas podem ter como origem a própria existência do TU e reafirmam a importância de 
uma avaliação e gerenciamento adequado destes sintomas já no período prétratamento, considerando que a não identificação ou a falta de controle de alguns sintomas potencialmente tratáveis podem levar a um atraso no início da terapia curativa, à exacerbação dos sintomas já esperados durante o curso da terapia antineoplásica a uma tolerância mais pobre do paciente à radiação ou quimioradiação, à escolha de um tratamento menos agressivo, que eventualmente seria o mais indicado para o paciente ou à interrupções inesperadas do tratamento que afetam negativamente o controle do TU (Bese et al., 2007). Todos os aspectos citados podem comprometer a capacidade funcional dos pacientes, diminuir sua QV e sua sobrevida e comprometer o prognóstico do tratamento (Dodd, 2001; Graff, 2007; Teunissen et al., 2006; Palmer; Fisch, 2005).

Neste estudo, à época do diagnóstico, os principais sintomas referidos pelos pacientes, em diferentes intensidades foram dor $(62,5 \%, \quad n=65)$, preocupações/aborrecimentos $(57,7 \%, \mathrm{n}=60)$, problemas de sono $(49,0 \%, \mathrm{n}=51)$, dificuldade para engolir/mastigar $(46,1 \%, n=48)$, cansaço-fadiga $(43,3 \%, n=45)$, catarro na boca ou garganta, problemas com a voz/para falar e tristeza (todos 40,4\%, $\mathrm{n}=42$ ). Um dos sintomas mais assinalados, a dor, pode ser causada pelo tumor primário ou suas metástases (Foley; Abernathy, 1998) ou ser o produto da interpretação do aspecto físico-químico do estímulo nocivo e da interação deste com características individuais como o humor, o significado simbólico atribuído ao fenômeno sensitivo e os aspectos culturais e afetivos dos indivíduos (Teixeira, 1988). A existência da dor causa prejuízos a atividade física, ao sono e ao apetite, podendo debilitar ainda mais o paciente, e é geralmente correlacionada na literatura à depressão, fadiga e a outros sintomas geralmente presentes nos pacientes oncológicos (Morete; Minson, 2010). 
A indicação de sintomas relacionados aos problemas engolir, mastigar, voz/falar estão de acordo com o esperado, levando-se em conta os sítios tumorais e estadiamentos prevalentes na casuística, assim como os problemas com catarro/secreção, especialmente para os pacientes com tumores em nasofaringe e fossas nasais/seios maxilares. Os problemas com o sono e cansaço/fadiga referidos nesta fase, e cuja etiologia é multifatorial (bioquímica, fisiopatológica, psicológica e comportamental são reportados na literatura como um dos principais sintomas dos pacientes com câncer, particularmente antes do diagnóstico, durante o tratamento e na doença avançada e sua experiência pode impactar severamente a QV (Glaus, 1993). Os resultados deste estudo estão de acordo com o esperado, uma vez que cerca de $30,0 \%$ a $75,0 \%$ dos pacientes recém-diagnosticados com câncer apresentam distúrbios relacionados ao sono (Ancoli-Israel et al., 2001) e cerca de 50\% a 90\% dos pacientes com câncer experimentam fadiga de forma geral (Curt et al., 2000; Mock et al., 2007).

Em 2013, Gunn et al. utilizaram-se do MDASI para descrever comparativamente o padrão de sintomas experimentados por 270 pacientes diagnosticados com $\mathrm{CA} / \mathrm{CP}(75,6 \%$ homens, média de idade 58,5 anos $\pm 11,9)$, divididos em diferentes subgrupos: 124/280 pacientes sem nenhum tratamento prévio, 67/280 pacientes tratados com quimioterapia exclusiva prévia e 79/280 indivíduos previamente tratados com cirurgia exclusiva ou quimioterapia + cirurgia. O subgrupo de 124 pacientes era constituído por indivíduos com tumores prevalentes em orofaringe $(58,1 \%, n=72)$, laringe $(15,3 \%, n=19)$ e hipofaringe $(5,6 \%, n=7)$, seguidos por nasofaringe $(n=5)$, cavidade oral $(n=4)$, cavidade nasal/seios paranasais $(\mathrm{n}=4)$, glândulas salivares maiores $(\mathrm{n}=1)$ e tireóide $(\mathrm{n}=1)$. Quanto ao estadiamento, $54,8 \%(n=62)$ destes pacientes tinham tumores T1-T2 e 30,6\% (n=38) tinham 
tumores T3-T4. Os resultados indicaram que estes pacientes, ainda não tratados, apontaram em maior proporção queixas em relação aos sintomas dor $(16,9 \%)$, sono $(16,1 \%)$, fadiga $(14,5 \%)$, preocupações $(13,8 \%)$, engolir/mastigar $(12,1 \%)$ e sonolência $(9,7 \%)$ em intensidades moderadas a severas (intensidade $\geq 5$ ). Os sintomas dor $(11,3 \%)$, engolir/mastigar $(9,7 \%)$, sono $(8,9 \%)$, sonolência $(5,6 \%)$, preocupações e catarro (ambos 4,9\%) foram os mais referidos como severos (intensidade $\geq 7$ ) pelos pacientes. Estes resultados estão alinhados aos achados sobre os tipos de sintomas predominates no momento pré-tratamento neste estudo.

Hanna et al. (2015) comentam que os sintomas referidos pelos pacientes que ainda estão por receber o tratamento são provavelmente decorrentes do processo da doença em si e que estes não devem ser confundidos com os efeitos tóxicos do tratamento. Com o intuito de enfatizar a importância crítica da identificação destes sintomas antes do início do tratamento, os autores conduziram um estudo a fim de explorar, dentre outros aspectos, a sintomatologia em vários sub-grupos de pacientes com $\mathrm{CA} / \mathrm{CP}$, nunca antes tratado, de acordo com o sítio primário do tumor. Para tanto, os sítios tumorais foram agrupados em "mucosa" (lábios, cavidade oral, faringe e laringe) e "não mucosa" (glândulas salivares, olhos, pele/subcutâneos, tireóide/endócrinos, sítio primário desconhecido e base de crânio). O inventário de sintomas MDASI foi aplicado em 748 pacientes (média de idade 59 anos, 68,0\% do sexo masculino) dos quais $58,0 \%(\mathrm{n}=434)$ tinham tumores de mucosa (lábios e cavidade oral $n=122$, faringe/laringe $n=312$ ). $O$ estadiamento dos tumores para cada sub-grupo, especificamente, não está descrito pelos autores. A análise parcial do gráfico disponível no referido estudo e sua curta descrição nos resultados possibilitou a identificação da preponderância dos sintomas considerados como moderados a severos pelo sub-grupo de pacientes com tumores em mucosa: sono $(39,0 \%)$, dor 
(34,0\%), cansaço, preocupações, tristeza, sonolência, perda do apetite $(19,0 \%)$, boca seca $(20,0 \%)$, falta de ar (16,0\%), dificuldades para lembrar e formigamento (12,0\%). De forma geral, os autores concluíram que mais de um terço do total de pacientes com TU de CP avaliados apresentaram sintomas moderados a severos antes do início do tratamento (particularmente dor, cansaço, preocupações e sono) e sublinharam a importância de sua identificação e avaliação rotineira, diante da piora esperada para os mesmos após o início do mesmo. Neste estudo, encontramos também a prevalência dos sintomas dor, sono, preocupações, cansaço e tristeza, assim como no estudo de Hanna et al. (2015). Contrariamente, não foi encontrada neste momento a prevalência de perda do apetite, boca seca, falta de ar, dificuldades para lembrar e formigamento. Talvez esta diferença possa ser explicada pela grande diferença entre o número de pacientes avaliados em ambas as casuísticas e pela ausência de informações específicas no estudo de Hanna et al. (2015) sobre as características clínicas e demográficas dos sub-grupos avaliados.

Aos 6 meses após o diagnóstico observou-se neste estudo a exacerbação dos sintomas dificuldade para engolir/mastigar $(65,0 \%, \mathrm{n}=52)$, boca seca $(63,7 \%, \mathrm{n}=$ $51)$, catarro na boca ou garganta $(57,5 \%, n=46)$, dificuldade para sentir o gosto da comida $(56,2 \%, n=45)$, preocupações (aborrecimentos) $(50,0 \%, n=40)$, problemas com a voz/para falar $(48,7 \%, n=39)$, cansaço (fadiga) $(46,2 \%, n=37)$ e problemas com dentes/gengivas $(40,0 \%, \mathrm{n}=32)$. Considerando-se as características clínicas e de tratamento da casuística avaliada aos 6 meses, estes resultados estão alinhados com a literatura disponível sobre os efeitos agudos e tardios do tratamento oncológico, que afetam especialmente os aspectos funcionais da mastigação, deglutição e comunicação (Hammerlid et al., 1998, de Graeff et al., 1999; List et al., 1999, Happ et al., 2003; Boscollo-Rizzo et al., 2008, Lazarus 2009; Feng et al., 2010, van der 
Laan et al., 2015).

Dentre os 80 pacientes avaliados aos 6 meses após o diagnóstico, um total de $75,0 \%(n=60)$ tinha sido submetido à radioterapia em diferentes regimes e 90,0\% destes $(\mathrm{n}=54)$ tinha recebido doses $\geq$ a 60 Gy. Alguns dos pacientes avaliados nesta época tinham recém finalizado a radioterapia adjuvante, o que pode também justificar a presença dos sintomas descritos. A radioterapia provoca alterações nos tecidos moles e duros da boca e áreas adjacentes, associadas à dose aplicada e ao tipo de radiação e seus principais efeitos deletérios (agudos e tardios) relacionados são a dermatite, mucosite, odinofagia, xerostomia, perda do paladar, disfagia, infecções secundárias (ex: candidíase), trismo, cáries, osteorradionecrose, fibrose dos tecidos moles e/ou estenose da hipofaringe, afetando os mecanismos da deglutição (Cardoso et al., 2005; Perkins et al., 2007). Segundo Cardoso et al. (2005), a xerostomia é uma das sequelas que mais incomoda os pacientes na fase tardia de acompanhamento. De acordo com Rolim et al. (2011), o fluxo salivar em pacientes irradiados na cabeça e pescoço pode diminuir em até $90,0 \%$ e nos casos mais acentuados a mucosa oral fica sem qualquer umidificação, prejudicando a fala, causando disfagia, alterando a gustação, podendo incorrer em alteração nutricional e perda de peso. Ainda, a perda da função salivar pode causar maior frequência de intolerância a produtos de higiene bucal, alterações do pH, aumento da sensibilidade dentária e impossibilitar o uso de próteses dentárias, entre outras coisas (Rankin et al., 2008). Novamente, considerando-se as variáveis clínicas e de tratamento dos pacientes, a indicação de problemas relativos aos dentes/gengivas pelos pacientes ocorreu provavelmente em função da presença de sequelas decorrentes de tratamentos cirúrgicos mais extensos, com remoção de mais estruturas da cavidade oral devido ao TU (especialmente quando há envolvimento do palato e/ou mandíbula) e/ou em função da remoção de 
elementos dentários antes do tratamento radioterápico e das sequelas decorrentes da radioterapia, já acima descritas.

O problema com a voz/para falar indicado nesta época também pode ser explicado pela presença de pacientes com tumores de laringe $(13,8 \%, n=11)$ e de hipofaringe $(1,2 \%, n=1)$ na casuística avaliada, que podem ter sido abordados cirurgicamente e/ou ter sido irradiados. Pacientes com tumores nestes sítios, tratados com cirurgia e/ou radioterapia, podem ter alterações vocais (e também de deglutição) dependendo da extensão da ressecção cirúrgica e podem experimentar alterações temporárias ou permanentes na voz, na ressonância, imprecisão articulatória, coordenação oral comprometida e redução da inteligibilidade de fala associada ao edema e irritação da mucosa que caracterizam a mucosite (Perkins et al., 2007).

A referência à presença da fadiga pelos pacientes aqui avaliados também está de acordo com Campos et al. (2011), que efetuaram uma revisão sobre os inúmeros aspectos que envolviam a fadiga relacionada ao câncer, citando 98 estudos relacionados ao tema (patogênese, incidência, abordagem e tratamento). Nesta ampla revisão, a fadiga é tida como um sintoma que estará presente para estes pacientes não só pelo câncer, mas também pelo tratamento, que pode gerá-la ou agravar uma fadiga já manifestada antes, podendo persistir por meses a anos após o tratamento.

Aos 12 meses após o diagnóstico, os sintomas predominantes, reportados em diferentes intensidades, foram boca seca $(66,1 \%, n=41)$, engolir/mastigar $(53,2 \%$, $\mathrm{n}=33)$, preocupações/aborrecimentos $(50,0 \%, \mathrm{n}=31)$, catarro na boca ou garganta $(50,0 \%, n=31)$, problemas com a voz/para falar $(43,5 \%, n=27)$, dificuldade para sentir o gosto da comida $(40,3 \%, n=25)$ e cansaço $(32,3 \%, n=20)$. Observou-se, portanto, que os dois primeiros sintomas mais referidos aos 12 meses são os mesmos que os indicados aos 6 meses, porém com um aumento na proporção dos pacientes 
que se queixaram de secura na boca e diminuição na proporção de queixas quanto aos problemas para mastigar/ engolir. Provavelmente, a mastigação e a deglutição já se encontravam melhor adaptadas nesta fase em virtude da diminuição dos efeitos agudos do tratamento, bem como em decorrência de provável reabilitação fonoaudiológica e odontológica realizadas. A diminuição apenas discreta na proporção de queixas em relação à voz/ para falar, comparando-se à avaliação anterior, pode estar relacionada ao aumento na proporção de casos de pacientes com tumores laríngeos nesta época, os quais estariam vivenciando as sequelas permanentes da cirurgia neste sítio e/ou os efeitos da fibrose nos tecidos da laringe e/ou no arcabouço laríngeo decorrente da radioterapia, o que causa alterações na produção da voz.

A diminuição na proporção de pacientes com queixas relativas à dificuldade para sentir o gosto da comida deveu-se, possivelmente, ao padrão de recuperação gradual da acuidade do paladar entre um a cinco anos após a radioterapia, que, entretanto, dependerá da dose de radiação recebida e da sensação subjetiva de paladar (Tomita; Osaki, 1990). Aos 12 meses houve também discreta diminuição na proporção de pacientes com problemas com catarro na boca ou garganta, porém a metade dos pacientes mantinham esta queixa, provavelmente pelas alterações ocorridas na textura da saliva, mais pegajosa e espessa e/ou aumento na produção de secreção e eventuais dificuldades de expectoração. É interessante notar que a queixa relacionada ao sintoma preocupações/aborrecimentos foi a terceira mais referida aos 12 meses, em proporção igual à encontrada aos 6 meses, indicando que já neste segundo momento os pacientes manifestam os efeitos de um confronto com as incertezas de seu futuro, tanto nos aspectos relacionados aos resultados de seu tratamento, como em relação aos aspectos que envolvem a possibilidade ou não da 
retomada de suas vidas e da volta à normalidade.

Os sintomas encontrados nas casuísticas aqui avaliadas, apesar de descritos, necessitam ser melhor explorados e correlacionados às variáveis clínicas e de tratamento específicas, possibilitando uma melhor compreensão dos resultados obtidos e ampliando os parâmetros para uma análise comparada com a literatura científica disponível.

\subsubsection{Necessidades, Preferências e Atitudes dos Pacientes Frente às Informações}

O diagnóstico do câncer, segundo Sawyer (2000), provoca uma resposta alarmante nos pacientes, mais do que qualquer outra doença. Os pacientes recémdiagnosticados com esta doença, além de se confrontar com uma ameaça às suas vidas, iniciam uma jornada que provoca uma desorganização em sua rotina diária, sendo compelidos a considerar opções de tratamento que possivelmente irão afetar seu bem-estar físico e emocional (Mills; Sullivan, 1999). Diante das possíveis sequelas desfigurantes e dos possíveis prejuízos funcionais decorrentes do tratamento, considera-se que os pacientes diagnosticados com $\mathrm{CA} / \mathrm{CP}$ têm necessidades especiais, mais do que as dos pacientes diagnosticados com outros tipos de câncer, em termos de provimento de informações apropriadas e específicas (Semple, 2001 e 2002). Todavia, as preferências e necessidades dos pacientes frente ao tipo e quantidade de informações sobre a doença, assim como o momento em que a mesma lhes é fornecida podem variar, de acordo com a doença, as características sócio-demográficas, clínicas e culturais do paciente, bem como em função do estilo de enfrentamento que o mesmo tem frente à sua doença (Mossman et al., 1999; Gimenes, 2008).

Em 2011, ter Hoeven et al. investigaram145 pacientes com diferentes tipos de 
câncer para averiguar as possíveis razões pelas quais os pacientes preferiam informações completas ou limitadas sobre sua doença, por meio da aplicação do questionário Considerations Concerning Cancer Information-CCCI, por eles desenvolvido. As dimensões supostas pelos autores como determinantes para o desejo de informações completas foram senso de controle, expectativas dos outros, prevenção da ansiedade e autonomia, e para o desejo de informações limitadas os comportamentos de evitação, otimismo, dificuldade de compreensão das informações e não querer incomodar o médico ou atrasar a consulta de outros pacientes. Em geral, os pacientes endossaram mais razões para querer as informações completas, sendo que a mais mencionada foi senso de controle (“...quero saber o que esperar do meu tratamento"). O principal motivo pelo desejo de informações limitadas foi o otimismo (..."não preciso saber de tudo pois tenho fé no futuro"). Para os autores, o conhecimento destas razões é importante pois possibilita a provisão de informações personalizadas, de acordo com a preferência dos pacientes.

No que diz respeito às informações gerais sobre a doença, a grande maioria dos pacientes aqui avaliados considerou necessário receber toda a informação possível sobre a doença, boa ou má, em todos os momentos ao longo do estudo. Houve também um aumento na proporção dos pacientes com este comportamento aos 6 meses após o diagnóstico, em relação à avaliação inicial, seguido por um aumento mais discreto aos 12 meses. Estes resultados sobre o desejo do paciente de receber informações gerais positivas ou negativas aqui encontrados estão alinhados aos achados dos estudos de Blanchard et al. (1988), Pimentel et al. (1999), Jenkins et al. (2001) e Cox et al. (2006). É interessante notar que, apesar da existência de porcentagens consideráveis de pacientes em todas as épocas deste estudo com baixo grau de escolaridade, (analfabetos $+1^{\circ}$ grau incompleto/completo), respectivamente 
$49,1 \%, 46,4 \%$ e $40,3 \%$, o desejo pelas informações gerais prevaleceu. Isto gera a necessidade de atenção por parte dos clínicos que proveem as informações aos pacientes com níveis socioeconômicos mais baixos, no sentido fornecê-las de forma que as mesmas possam ser entendidas e fazer sentido para o paciente, além de checar e garantir que estas sejam assimiladas por eles (Davis, 2002; Semple et al., 2002). Já a proporção de pacientes que não queria saber detalhes e delegava ao médico as decisões na época do diagnóstico (12,5\%) diminuiu aos 6meses $(8,8 \%)$ e aumentou discretamente aos 12 meses (9,7\%). Algumas das hipóteses que podem explicar esta postura aos 6 meses são a conscientização destes pacientes da inevitabilidade do enfrentamento de sua real situação de saúde, mais familiaridade com a doença em si, maior necessidade de informações para poder lidar com os efeitos deletérios e/ou complicações do tratamento, mudanças nas estratégias de enfrentamento da doença, diminuir a ansiedade, necessidade de se sentir capaz de ter algum controle sobre seu futuro, entre outras. Alguns pacientes podem não se sentir em condições emocionais ou até mesmo físicas para ouvir, absorver, reter e aceitar uma grande quantidade de informações importantes e impactantes (especialmente no momento do diagnóstico). Assim, a quantidade de informações, o momento e o formato (verbal, escrito, áudiovisual) mais adequados para o provimento destas, bem como a necessidade de reiterar as informações previamente dadas devem ser avaliados pelo clínico, a fim de garantir que a informação seja efetivamente benéfica e assimilada pelo paciente.

Em 2004, Newell et al. entrevistaram 29 pacientes com CA/CP submetidos à cirurgia, entre 3 a 6 meses de pós-operatório, com a finalidade de explorar suas percepções sobre as informações que haviam recebido no momento do diagnóstico. Muitos dos pacientes declararam ter tido dificuldades de absorver as informações recebidas devido ao choque do diagnóstico, ao uso problemático de jargões médicos, 
ambiente ruidoso, à simultaneidade de informações sobre o diagnóstico e tratamento, à falta de reforço com informação escrita, presença de outras pessoas na sala (falta de privacidade), problemas de audição e escassez de tempo. Muitos pacientes também afirmaram não se lembrar exatamente das informações que haviam recebido na ocasião. Para Ley (1979), os fatores que contribuem basicamente para o esquecimento da informação pelo paciente são o uso de terminologia médica, o modo da informação (escrita ou falada) e o baixo nível educacional ou expectativas específicas do paciente. Kessels (2003) complementa que a memória para as informações médicas é geralmente pobre e imprecisa, especialmente se o paciente for idoso ou ansioso e que o estresse causado ao paciente pelo recebimento de informações relacionadas à uma ameaça a sua vida pode aumentar ainda mais, quando acompanhado por informações sobre o prognóstico e o tratamento.

Diante deste contexto complexo, o formato da informação, verbal ou escrita, parece ser um aspecto de grande importância, uma vez que ambas têm suas vantagens e limitações. O material escrito possibilita que os pacientes acessem seu conteúdo em diferentes momentos, no seu próprio ritmo, de acordo com suas necessidades e preferências nos diferentes momentos da jornada contra o câncer (Semple et al., 2002). Entretanto, pode se tornar uma ferramenta de difícil entendimento para os pacientes de menor nível de instrução e com menos habilidades de leitura, o que é uma questão relevante em se tratando da realidade de muito dos pacientes brasileiros acometidos pelo câncer e por outras doenças. Já as informações verbais possibilitam uma maior interação entre o paciente e o clínico, mas podem ter um efeito diferente do esperado, a depender da maneira como são transmitidas. Este aspecto foi identificado neste estudo, diante do comentário feito por um familiar de um dos pacientes de nossa casuística: “.... Porque na radioterapia o médico fala que 
se você não fizer o tratamento de radioterapia você vai ter $\mathrm{X} \%$ de recidiva. Por que não falar que se você fizer o tratamento terá $\mathrm{X} \%$ de chance de cura? Acho que este foi um dos motivos para ele não querer fazer a radio..." (Apêndice 4). Também não se pode ignorar o fato de que, atualmente, os pacientes podem ter acesso às informações virtuais sobre o câncer e seu tratamento (fidedignas ou não) através da internet, em qualquer momento ao longo do curso da doença, o que enfatiza ainda mais a importância do domínio das habilidades de comunicação por parte dos clínicos responsáveis.

Em relação à atitude preferencial dos pacientes quanto às informações específicas sobre a doença e o tratamento, observou-se que a maioria dos pacientes desejava receber estes tipos de informação em todos os momentos, mais notadamente no que diz respeito ao diagnóstico (saber se é câncer ou não) e ao nome específico da doença, com um aumento das proporções ao longo do tempo. As porcentagens de pacientes que desejavam saber sobre sua resposta semanal ao tratamento se mantiveram altas e similares no momento pré-tratamento e aos 6 meses, com leve declínio aos 12 meses, o que é coerente com o fato de que os dois primeiros momentos estudados são críticos quanto às expectativas sobre a efetividade do tratamento e avaliações das respostas terapêuticas alcançadas. Inversamente, na época da última avaliação $95,2 \%(n=59 / 62)$ dos pacientes se encontrava apenas em seguimento ambulatorial e fora de tratamento. Isto também pode justificar a diminuição na porcentagem de pacientes que desejava informações sobre as chances de cura na última avaliação. Durante a coleta de dados aos 12 meses, diversos pacientes participantes do estudo verbalizaram estar curados. Comparando-se os resultados do pré-tratamento e os de 12 meses após o diagnóstico, é interessante e importante notar que houve um aumento tardio pelo desejo de informações 
específicas sobre as todas as formas de tratamento disponíveis e mecanismo de funcionamento do tratamento. Isto pode sugerir que, mesmo sentindo-se curados, muitos dos pacientes poderiam estar convivendo com o medo da recaída e necessitavam se sentir seguros e cientes dos tratamentos possíveis e disponíveis nessa situação. O aumento no interesse sobre os efeitos colaterais do tratamento aos 12 meses pode ter sido em decorrência da necessidade de lidar com as sequelas tardias/permanentes do tratamento já realizado, ou pode também referir-se à necessidade de conhecimento de possíveis sequelas que poderiam advir em caso de tratamento de recidiva.

Jenkins et al. (2001) encontraram resultados similares aos deste estudo ao avaliarem as preferências de 2331 pacientes com tumores em diferentes sítios $(2.4 \%$, $\mathrm{n}=57$ com $\mathrm{CA} / \mathrm{CP}$ ) frente às informações gerais e específicas sobre o câncer, por meio da aplicação do questionário QIP (adaptado). A amostra era constituída por pacientes em tratamento curativo $(40,0 \%, n=940)$, paliativo $(36,0 \%, n=841)$, em fase de remissão $(9,0 \%, n=215)$ e intenção de tratamento incerta $(14,0 \%, n=335)$. Os resultados foram conclusivos de que a vasta maioria dos pacientes querem grande quantidade de informações sobre sua doença e tratamento, independentemente de sua situação clínica.

A maioria dos pacientes aqui avaliados, em todas as épocas, também preferiu que as informações sobre a doença tivessem sido fornecidas inicialmente pelo médico especialista do hospital. O aumento desta proporção pacientes aos 6 meses pode ser entendida como o resultado da criação de vínculos de confiança entre o paciente e seu médico responsável e/ou confiança em sua expertise como principal fonte para o provimento de informações. Para Anelli (2002), a tarefa de informar ao paciente sobre seu diagnóstico é uma tarefa que cabe ao médico, não devendo ser 
delegada aos familiares ou outros profissionais que não acompanharão o paciente durante todo o seu tratamento, possibilitando também a formação do elo primordial de confiança na relação médico-paciente.

Tendo em vista que as preferências dos pacientes quanto às informações sobre a doença e tratamento podem ser dinâmicas durante o curso da doença (ter Hoeven et al., 2011), é importante que o clínico responsável pelo seu fornecimento reavalie constantemente as necessidades dos pacientes, a fim de que estas sejam por eles entendidas e utilizadas como uma ferramenta para melhor adaptação, compreensão e enfrentamento da doença, e não como mais um fardo a ser carregado.

\subsubsection{Preocupações dos Pacientes}

Ao longo das últimas décadas, a avaliação da QVRS dos pacientes passou a ter um papel proeminente no campo da oncologia, baseada principalmente nos importantes pressupostos de que os pacientes e seus médicos estão dispostos a discutir uma ampla gama de assuntos relacionados à saúde física e psicossocial, bem como percebem a importância de fazê-lo (Detmar et al., 2000). Para Teutsch (2003), a comunicação é um importante componente dos cuidados à saúde, devendo haver um bom entendimento entre o paciente e seu clínico, o qual deve compreender a perspectiva que o paciente tem sobre sua doença. Segundo Golden e Johnston (1970) e Chaitchik et al. (1992), muitas vezes esta comunicação pode ser prejudicada pela dificuldade do médico em se comunicar bem com seu paciente e/ou pela dificuldade do paciente em verbalizar suas necessidades. Brandes et al. (2015), preconizam que as barreiras que mais influenciam o paciente a não verbalizar suas preocupações durante as consultas são o comportamento do "provedor", (não convidar explicitamente o paciente a verbalizá-las, assumir uma atitude defensiva ou falta de 
empatia), o ambiente onde a consulta transcorre (falta de tempo durante a consulta, presença de residentes ou familiares na sala) e barreiras legítimas do próprio paciente (medo ou vergonha de se expressar, medo de deteriorar a relação com o provedor ou de incomodá-lo). Ainda, diante dos inúmeros aspectos que podem ser afetados na vida do paciente pelo diagnóstico e/ou pelo tratamento do câncer, a identificação destas preocupações pode se tornar difícil, fazendo com que alguns dos assuntos que preocupam o paciente sejam completamente ignorados ou superficialmente abordados (Rogers et al., 2009).

O Patients Concerns Inventory (PCI) é uma ferramenta clínica desenvolvida com o objetivo de possibilitar a identificação das preocupações dos pacientes, facilitando sua discussão com o clínico responsável, bem como identificar seu desejo por cuidados específicos de suporte e agilizar os encaminhamentos. Porém esta ferramenta tem sido utilizada apenas em pacientes em tratamento ou após o seu término. Considerando-se a escassez de literatura empírica sobre as preocupações dos pacientes recém diagnosticados com $\mathrm{CA} / \mathrm{CP}$, optou-se pela aplicação de sua versão validada para o Português (Brasil) - Inventário de Preocupações dos Pacientes - IPP, realizada na Parte I deste estudo, ao longo do período compreendido entre o diagnóstico e 12 meses após o mesmo. De acordo com a literaratura, esta é a primeira vez que esta ferramenta é utilizada exclusivamente em uma coorte de pacientes recém diagnosticados e ainda não submetidos a tratamento oncológico, seguida por avaliação longitudinal.

O IPP, entretanto, é um instrumento que não mensura a intensidade das preocupações e, portanto, é interessante que o mesmo seja eventualmente aplicado junto com outro(s) questionário(s) de QVRS validados para pacientes com $\mathrm{CA} / \mathrm{CP}$, à depender dos objetivos da avaliação. 
As principais preocupações assinaladas no IPP pelos pacientes à época de seu diagnóstico foram mastigar/comer, tratamento do câncer, fala/voz/ser entendido, engolir, dor na cabeça e pescoço, medo do câncer voltar, feridas na boca, sonda para alimentação, apetite, fadiga/cansaço e perda de peso. Estes resultados demonstram que nesta fase houve um maior desejo dos pacientes de discutir com o médico sobre preocupações relacionadas aos itens de bem-estar físico e funcional, coerentes com a sintomatologia inicial dos tumores com sítio primário em cavidade oral, orofaringe e laringe (Cancer.Net 2015), predominantes na casuística, especialmente em caso de doença avançada e coerentes com as dificuldades de ordem funcional decorrentes da presença do tumor. Lango et al. (2014) avaliaram 159 pacientes recém diagnosticados com $\mathrm{CA} / \mathrm{CP}$ antes do início do tratamento e concluíram que a presença de disfagia, dor e a percepção reportada pelos pacientes sobre seu estado de saúde nesta época estavam intimamente relacionadas à perda de peso antes do tratamento e à doença avançada. Seria interessante avaliar mais cuidadosamente em que medida as preocupações de ordem física e funcional foram elicitadas nesse momento pelos pacientes apenas em decorrência da real presença dos sintomas da doença em si ou se eram preocupações antecipatórias, decorrentes das informações recém recebidas sobre o as sequelas do tratamento ao qual seriam submetidos.

A preocupação com o tratamento do câncer provavelmente reflete as incertezas, dúvidas e sentimento de impotência destes pacientes frente à necessidade de lidar com situações e intervenções clínicas por eles desconhecidas, cujo gerenciamento depende de fatores que fogem totalmente de seu alcance. Já a preocupação com o uso de sonda para alimentação pode advir do impacto causado pelas intensas dificuldades de se alimentar e consequente perda de peso experimentadas na época. $\mathrm{O}$ medo do câncer voltar foi indicado por mais da metade 
dos pacientes avaliados, demonstrando que, mesmo antes de terem iniciado qualquer tipo de tratamento, esta já é uma preocupação bastante latente para esta população.

Preocupações relacionadas ao hábito intestinal, respiração, tosse, mobilidade, abertura de boca, náusea, dor em outro lugar, regurgitação, muita salivação, sono inchaço, vômitos/mal-estar, arrependimento pelo tratamento, cicatrização de feridas, cuidador, dependentes/crianças, estilo de vida (fumo/álcool), recreação, relacionamentos, aparência, ansiedade, estratégias para enfrentar a doença e o tratamento, depressão, intimidade, humor, auto-estima, sexualidade, aspectos espirituais/religiosos e personalidade/temperamento tiveram suas maiores porcentagens de indicação à época do diagnóstico. Observa-se, portanto, a existência de um grande número de preocupações relativas aos domínios de assistência e bemestar social e de bem-estar emocional, psicológico e social mais intensas nesta fase do que em qualquer outra época avaliada.

Pacientes com $\mathrm{CA} / \mathrm{CP}$ e/ou médicos podem ter dificuldade em iniciar uma conversa sobre assuntos não relacionados aos aspectos físicos propriamente ditos, fazendo com que as preocupações de ordem pessoal, tais como alterações na intimidade, sexualidade, relacionamentos, aparência, ansiedade e depressão, entre tantas outras, não sejam abordadas durante as consultas. Apesar da inclusão destes temas nos questionários de $\mathrm{QV}$ específicos para pacientes com $\mathrm{CA} / \mathrm{CP}$, há escassez de estudos sobre sua prevalência nesta população e estes dificilmente são reconhecidos em ambiente ambulatorial (Flexen et al., 2012; Moore et al., 2014, Rogers et al., 2015a). Durante a coleta de dados (aplicação do IPP) aos 6 meses, diversos pacientes (primordialmente homens) comentaram com a pesquisadora sobre sua diminuição da libido após o tratamento. Apenas uma paciente, jovem, submetida à glossectomia total, explicitou claramente suas preocupações relativas às limitações 
em sua vida sexual decorrentes da cirurgia e dúvidas sobre suas possíveis chances de estabelecer uma relação afetiva no futuro. Outra paciente manifestou o desejo de perguntar ao médico quando e se poderia voltar a beijar na boca. Embora estes comentários não tenham ocorrido durante a fase do diagnóstico, sugere-se que as preocupações nestes âmbitos sejam detectadas, abordadas verbalmente pelo clínico responsável já na fase que antecede o tratamento, devidamente monitoradas e direcionadas ao longo do tempo, evitando a instalação de fatores estressores que possam comprometer a QVRS dos pacientes.

A indicação mais frequente do fonoaudiólogo e do nutricionista no momento pré-tratamento provavelmente reflete sua vontade imediata de voltar a se alimentar normalmente e recuperar peso, bem como ao entendimento sobre a necessidade que teriam de futuro acompanhamento e reabilitação das sequelas de ordem funcional que decorreriam de seu tratamento e que acarretariam um impacto imediato em sua QV. A literatura científica discorre largamente sobre a frequência e o impacto significante das disfunções de mastigação, deglutição e fala na QV, emoções, autoestima e função social dos pacientes tratados do CA/CP (Chen et al., 2001; Rinkel et al., 2009; Lazarus, 2009; Jacobi et al., 2010; Ghazali et al. 2012).

Já a indicação do oncologista/radioterapeuta deveu-se provavelmente ao número de pacientes encaminhados para o tratamento primário, que incluía a radioterapia e a quimioterapia, em diferentes protocolos.

Aos 6 meses após o diagnóstico, muitas das principais preocupações dos pacientes estavam relacionadas ao bem-estar físico e funcional e eram diretamente vinculadas às sequelas do tratamento: mastigar/comer, boca seca, saúde dental/dentes, paladar (sentir sabor), atividade física, catarro/secreção e engolir. Conforme já discutido anteriormente neste estudo, as sequelas agudas do tratamento 
cirúrgico e/ou radioterápico (disfagia, xerostomia, disgeusia, mucosite) esperadas nesta época são coerentes com as preocupações assinaladas pelos pacientes, justificando sua porcentagem de ocorrência. Provavelmente, também, estes itens foram mais assinalados em virtude da real existência e da intensidade dos sintomas vivenciados no período, não estando diretamente vinculados às informações previamente recebidas na época do diagnóstico. Conforme lembrado por Ringash (2015), quando se consideram as preocupações e necessidades de pacientes com $\mathrm{CA} / \mathrm{CP}$, deve-se lembrar que houve um aumento na intensidade das terapias padrão ao longo das últimas décadas, que ocasionam um aumento de cerca de 500,0\% nas cargas aguda e tardia de toxicidade (Trotti et al., 2007).

É importante ressaltar que a preocupação em relação ao tratamento do câncer tornou-se menos frequente aos 6 meses, o que pode ser explicado pelo tempo já decorrido desde o diagnóstico, possibilitando a vivência e maior entendimento do paciente em relação ao seu protocolo de tratamento. Também é necessário notar que a preocupação com o medo de acontecimentos desfavoráveis, antes a décima quarta mais frequente, tornou-se a sexta preocupação mais indicada. Muito provavelmente, isto deve-se ao fato de que nesta fase os pacientes encontram-se em estrita vigilância, seguimento e avaliação dos resultados alcançados, estando sujeitos a enfrentar diversas intercorrências decorrentes da própria doença e do tratamento, bem como a confrontar-se com o insucesso terapêutico. O medo do câncer voltar sofreu discreta diminuição em relação à avaliação inicial, todavia tornou-se a quarta maior preocupação referida nesta época. Conforme os autores citados por Howren et al. (2013), o medo da recorrência não é um simplesmente um estado afetivo transitório que se manifesta após a conclusão do tratamento, mas sim um construto que envolve 
o medo ou a preocupação associada à possibilidade de enfrentar outro diagnóstico de câncer (Lee-Jones et al., 1997; Simard et al., 2010).

As preocupações sobre benefícios financeiros e suporte para a família foram mais evidentes nesta fase do estudo do que nos outros momentos avaliados. Isto se justifica, uma vez que o tratamento do câncer impacta não somente os aspectos funcionais e psicossociais da vida dos pacientes, mas também a vida financeira pessoal e familiar. A incapacitação para o trabalho e/ou a perda do emprego decorrentes do tratamento provocam uma redução significativa na renda familiar (Vartanian et al., 2006b), agravada por outras despesas (Rogers et al., 2012), tais como o deslocamento frequente para o hospital (tarifas de transporte, combustível, estacionamento) e mudanças na alimentação (dietas por sonda, espessantes, suplementos alimentares). Esta questão tem um peso importante no contexto brasileiro, já que a grande maioria dos pacientes diagnosticados e tratados do $\mathrm{CA} / \mathrm{CP}$ em nosso país pertencem a um nível socioeconômico mais baixo. Além disso, estes pacientes dificilmente dispões de orientação financeira especializada e muitos deles referiram dificuldades de ordem burocrática para agilizar a obtenção dos benefícios financeiros a que tinham direito.

Diversas novas preocupações citadas no texto livre aos 6 meses referem-se, a dificuldades de cunho sócio-emocional, decorrentes da doença e de seu tratamento: perda da identidade pessoal por causa da mudança na voz, desafio da retomada da rotina de vida diária, problemas familiares, afastamento dos netos, não poder ajudar a família, perda de emprego e dúvidas sobre como gerenciar a vida em viagens no que diz respeito à comunicação e alimentação. Também foram referidas preocupações de caráter físico, decorrentes do tratamento: problemas de visão, dor e queimação no estômago, engasgos assistemáticos, fraqueza nas pernas, falta de concentração e 
perda de atenção rapidamente. Ainda, foram levantadas preocupações relativas ao andamento do tratamento/intercorrências (perspectivas futuras em relação à doença e ao tratamento e necessidade de nova internação / cirurgia para retirada de tumor (TU) benigno atrás globo ocular esquerdo).

Neste período o cirurgião foi o profissional mais indicado pelos pacientes como fonte de suporte e cuidados específicos. Esta indicação é coerente com as principais preocupações assinaladas, uma vez que o cirurgião é o profissional que possui a expertise necessária para gerenciar o tratamento, definir condutas terapêuticas, realizar prognósticos e detectar recaídas. Isto também pode indicar que houve sucesso na formação do elo de confiança entre o paciente e seu clínico responsável. Em seguida, foram indicados o dentista e o fonoaudiólogo, o que também vai de encontro às necessidades dos pacientes no sentido buscar suporte de profissionais habilitados a minimizar os efeitos deletérios transitórios ou permanentes do(s) tratamento(s) ainda em andamento ou já realizados e/ou promover a reabilitação funcional. Mahmood et al. (2014) aplicaram os questionários PCI e UW-QOL em 317 pacientes com tumores predominantemente em cavidade oral e faringe em diferentes estadiamentos (média de idade 63 anos, 60,0\% do sexo masculino), submetidos a diversas modalidades de tratamento, entre 4 e 42 meses após o diagnóstico/tratamento primário. Os resultados revelaram que 52,0\% dos pacientes indicaram problemas significantes de mastigação ou o desejo de discutir suas preocupações relacionadas aos dentes/saúde dental. Após uma revisão de literatura sobre a reabilitação dental em pacientes com câncer de cavidade oral, PaceBalzan e Rogers (2012) concluíram que o estado da saúde oral está fortemente associado à QVRS e a dificuldades psicológicas em pacientes com CA/CP.

Aos 12 meses após o diagnóstico, a preocupação mais reportada foi o medo 
do câncer voltar, seguida por preocupações com a boca seca, tratamento do câncer (manutenção e frequência do seguimento ambulatorial), mastigar/comer, saúde dental/dentes, níveis de energia, engolir, fadiga/cansaço (eventualmente também relacionado à hipotireoidismo), audição (decorrente da ototoxicidade de agentes quimioterápicos e/ou efeitos locais da cirurgia) e catarro/secreção. Alguns destes resultados estão alinhados com os achados de Kanatas et al. (2013), que descreveram o medo do câncer voltar, saúde dental/dentes, mastigar/comer, engolir, cansaço/fadiga, entre as principais preocupações de 447 pacientes com tumores em cavidade oral, orofaringe e laringe, em diferentes estadiamentos, entre 12 e 60 meses ou mais (média de 50 meses) após o tratamento primário. No referido estudo, estas preocupações se apresentaram em proporções menores do que as aqui encontradas, mas provavelmente isto se deve à grande diferença de intervalo de tempo após o tratamento entre as casuísticas.

Muitas das principais preocupações dos pacientes aos 12 meses são de caráter físico e funcional, decorrentes das sequelas tardias do tratamento, o que vai de encontro ao esperado, conforme discutido anteriormente. $\mathrm{O}$ mesmo se aplica às novas preocupações que surgiram no texto livre - engasgos, dor de ouvido, tonturas, dores na coluna, estenose de esôfago, fibrose no pescoço devido à radioterapia, interações medicamentosas, osteorradionecrose (mais frequente em pacientes que receberam doses superiores a $60 \mathrm{~Gy}$ ), cirurgia de reconstrução e nova biópsia na laringe (que também agrega o domínio emocional).

Curiosamente, nenhum dos pacientes ao longo de todo este estudo indicou (verbalmente ou no IPP) a preocupação com a morte. 
Em todas as épocas avaliadas, mais de 50,0\% dos pacientes indicaram a preocupação com o medo da recorrência da doença, em proporções muito próximas. Entretanto, esta preocupação atingiu sua maior incidência aos 12 meses após o diagnóstico. O medo do câncer voltar é descrito na literatura como uma das sequelas psicológicas mais angustiantes e mais comumente experimentada por pacientes diagnosticados com câncer, especialmente após o tratamento (Mehnert et al., 2009; Koch et al., 2013), podendo ser exacerbado ou reativado por diversos gatilhos, tais como visitas de seguimento médico, exames e sintomas que mimetizam a doença (Ghazali et al., 2013b). Apesar de ser uma resposta racional e apropriada às reais ameaças impostas pelo câncer e seu tratamento, quando em níveis elevados, o medo da recorrência pode se tornar disfuncional, afetando o bem-estar, a QV e as funções sociais de um indivíduo (Herschbach; Dinkel, 2014).

Em 2013, Crist e Grunfeld conduziram uma revisão sistemática de 43 estudos sobre o medo da recorrência em pacientes com diversos sítios de câncer, e concluíram que a maioria dos estudos analisados sugeria que este medo permanecia bastante estável ao longo do tempo e evidenciava que, se o medo da recorrência era inicialmente alto, provavelmente permaneceria alto mais tardiamente. Estas conclusões concordam com os resultados, aqui descritos. Rogers et al. (2010) avaliaram, por meio da aplicação do PCI, a presença de medo da recorrência em 123 pacientes com tumores de $\mathrm{CA} / \mathrm{CP}$, em diversos sítios e estadiamentos, submetidos à cirurgia e/ou radioterapia, entre menos de 12 meses do término do tratamento até 36 meses ou mais. Destes, 42,0\% (52/123) assinalaram o medo do câncer voltar. Dentre os pacientes tratados entre 12 a 35 meses $(n=34), 41,0 \%$ assinalaram o medo da recorrência. No referido estudo, a amostra era bastante heterogênea quanto ao intervalo de tempo desde o término do tratamento, diferentemente desse estudo, o 
que pode talvez explicar a diferença entre as porcentagens encontradas. Os autores supra-citados também tentaram averiguar, no mesmo estudo, se as características clínicas e demográficas (sexo, estadiamento do TU, modalidade de tratamento e QVRS) influenciavam a presença ou não do desejo de discutir esta preocupação durante a visita clínica de rotina. Os resultados por eles encontrados indicaram que estas variáveis não influenciaram este desejo, porém os pacientes que selecionaram esta preocupação possuíam maiores graus de estresse psicológico.

Ghazali et al. (2013b) avaliaram a presença de preocupação com o medo da recorrência da doença em 189 pacientes com predominância de tumores em cavidade oral $(73,0 \%)$ e faringe $(23,0 \%)$, em estadiamentos menos avançados T1-T2 (80,4\%), submetidos a diversos regimes de tratamento, entre 12 meses $(42,0 \%)$ a 48 meses após o término do tratamento primário e com idade média de 62 anos. Os dados foram coletados, repetidamente, durante 29 meses, durante consultas de seguimento ambulatorial. Os instrumentos utilizados foram o PCI, o $U W-Q O L$ e o questionário FoR (Ozakinci et al. em preparação, indisponível), que mensura a frequência e intensidade do medo da recorrência. Os resultados revelaram uma prevalência estável de $35,0 \%$ deste medo ao longo do tempo, em intensidade significante. Todas as correlações estatísticas realizadas indicaram uma relação inversamente proporcional entre o escores do $U W-Q O L$ e o escore global do FoR. Neste estudo encontramos uma porcentagem maior de ocorrência desta preocupação, o que pode ser supostamente explicado pelas diferenças entre o tamanho das amostras, prevalência dos estadiamentos, pelo intervalo de tempo avaliado e pelas próprias metodologias utilizadas.

Devido à natureza delicada do tema, o medo do câncer voltar dificilmente é abordado espontaneamente pelos clínicos ou pelos pacientes, porém é importante que 
este a sua existência, a intensidade, o grau de interferência desta preocupação na QV do paciente e eventuais comorbidades concorrentes (ansiedade/depressão) sejam reconhecidas, discutidas e, caso necessário, seguidas de encaminhamento do paciente para suporte especializado.

Os profissionais mais selecionados foram o cirurgião, o fonoaudiólogo e o dentista, o que também está de acordo com o caráter físico e funcional das principais preocupações referidas nesta fase, assim como em relação aos novos profissionais sugeridos no texto livre (médico para controle de dor, proctologista, gastroenterologista, urologista, endocrinologista, ginecologista, dermatologista e cirurgião-plástico).

Em geral, a maioria dos pacientes, em todas as fases deste estudo, considerou que o preenchimento do IPP antes de sua consulta era de extrema importância, pois os ajudava a organizar o pensamento, lhes dava liberdade e oportunidade para falar com o médico sobre diversos assuntos e proporcionava a sensação de acolhimento, fazendo-os sentir que todas as suas preocupações eram relevantes (Apêndice 4).

\subsubsection{Avaliação das Expectativas}

O paciente diagnosticado com câncer enfrenta mudanças nos âmbitos físico e emocional de sua vida, provocando no mesmo a necessidade de lidar com uma ampla gama de emoções que podem mudar a cada dia, hora ou mesmo minuto a minuto (ACS, 2014). Segundo Carver et al. (2010), entre esta ampla gama de emoções, geralmente estão incluídos sentimentos positivos e negativos, que variam desde ansiedade, raiva e depressão a entusiasmo, força e superação, e a adoção de uma orientação pessimista ou otimista na vida dependerá fortemente do balanço que o indivíduo faz entre estes sentimentos. A literatura tem atribuído aos conceitos de 
otimismo e pessimismo uma dimensão que vai além da cognitiva, agregando a estes um caráter emocional e motivacional (Woyciekoski et al., 2012). Ainda, a presença do otimismo em níveis mais elevados é citada na literatura como um fator relevante durante o processo de recuperação da doença oncológica e também associado significativamente a menores índices de ansiedade, depressão, desespero, e melhor QV (Applebaum et al., 2014).

Alguns modelos teóricos também têm tentado explicar quais fatores são subjacentes à seleção e à adoção de determinados comportamentos adotados pelos pacientes. O modelo proposto por Leventhal et al. (1998), denominado modelo de auto-regulação -"Self Regulation Model" - SRM, é largamente usado nas pesquisas sobre os aspectos que permeiam a adoção de determinados comportamentos frente à saúde. Este modelo propõe que este comportamento seria o resultado da potencial interação entre os processos cognitivo e afetivo do paciente. As representações cognitivas são conceitualizadas em cinco dimensões centrais: 1- Identidade: crenças sobre as definições da doença e os sintomas que a descrevem, 2- Etiologia: crenças sobre as possíveis causas do aparecimento da doença, 3- "Timeline“: crenças sobre a provável duração da doença e seu curso (agudo, crónico ou cíclico), 4Consequências: crenças sobre a severidade da doença e sobre seu impacto físico, social, emocional e econômico e 5- Controlabilidade/Cura: crenças sobre quais estratégias podem controlar ou curar a doença e sobre a eficácia do tratamento.

Portanto, a somatória de diversos fatores cognitivos e emocionais inerentes ao próprio paciente serão determinantes nas suas percepções sobre o câncer e na elaboração de suas expectativas, positivas ou negativas. Aspectos relacionados aos fatores socioculturais também parecem influir na elaboração destas expectativas e nas respostas emocionais (Morton, 2003). 
Existem diversas definições para expectativas na literatura. Olson et al. (1996) definem expectativas como crenças sobre estados futuros e para Koller et al. (2000), quer sejam reais ou falsas, as expectativas afetam a maneira como os pacientes respondem à sua doença, sendo cruciais para o sucesso da reabilitação (Mondloch et al., 2001). De acordo com Kravitz et al. (1996), as expectativas dividem-se em dois principais tipos: expectativas de probabilidade, que se refere aos julgamentos do paciente sobre as probabilidades de um evento e as expectativas de valores, que seriam as esperanças ou desejos concernentes a um evento. Já Williams et al. (1995) definem expectativas em termos de necessidades, predições, pedidos ou desejos dos pacientes antes de buscar o médico. Para Winterling et al. (2008) existem dois tipos de expectativas, definidas como expectativas de situação-específicas (relacionadas a saúde física, psicológica, sexualidade, situação socioeconômica e pensamentos sobre estilo de vida) ou expectativas disposicionais (relacionadas a uma ampla gama de assuntos).

A elaboração do Protocolo de Expectativas dos Pacientes (PAE), baseado nas preocupações listadas no IPP surgiu da hipótese de que, diferentes assuntos podem ou não ser fontes de preocupação para alguns pacientes e, consequentemente, podem ou não gerar expectativas nos mesmos. Como exemplo hipotético, podemos citar um indivíduo que possui um histórico de má cicatrização e que será submetido a uma extensa cirurgia. Este indivíduo provavelmente, além de preocupado com sua cicatrização, terá expectativas ruins sobre os resultados que pode esperar. A expectativa em relação a um dado assunto também pode não se aplicar, como no caso hipotético de um paciente que já abandonou o fumo e/ou o álcool muito antes de iniciar o tratamento oncológico, ou do paciente que nunca foi tabagista ou etilista e, assim, não se preocupa com o assunto ou com a eventual dificuldade de abandonar o hábito. Outro exemplo hipotético seria o de um paciente que teve definida a 
radioterapia como forma de tratamento primário e, portanto, não necessita se preocupar ou ter expectativas sobre os efeitos colaterais da quimioterapia. Ainda, alguns pacientes podem ter preocupações com determinados assuntos, porém não conseguem se posicionar sobre suas expectativas ou antecipar sua resposta comportamental e, portanto, não sabem o que podem esperar antes de vivenciar o problema.

Também não se encontrou na literatura nenhum questionário ou ferramenta clínica específica, que abrangesse tantos aspectos, para avaliar as expectativas dos pacientes com $\mathrm{CA} / \mathrm{CP}$ antes do início de seu tratamento. Portanto, o PAE foi utilizado neste estudo como um piloto.

A aplicação do PAE limitou-se a avaliar as expectativas dos pacientes frente aos diversos aspectos físicos, funcionais, de tratamento, assistência e bem-estar social, psicológicos, emocionais e espirituais que poderiam ser afetados pelo câncer e/ou seu tratamento, porém não questionou suas expectativas em relação aos diversos profissionais e clínicos responsáveis pelo gerenciamento dos aspectos envolvidos na doença e no seu tratamento. Isto deveu-se ao fato de que, nesta fase, dificilmente o paciente poderia saber exatamente qual seria sua demanda por atendimento de suporte específico.

Em geral, as expectativas dos pacientes no momento pré-tratamento eram positivas, especialmente quanto aos aspectos de bem-estar físico e funcional relacionados às funções orais e aspectos nutricionais: mastigar/comer $(84,8 \%)$, engolir $(81,7 \%)$, apetite $(78,9 \%)$, perda de peso $(69,2 \%)$. Ainda, neste domínio, os pacientes tinham boas expectativas quanto às feridas na boca, fadiga e dor na cabeça e pescoço. Uma maioria expressiva dos pacientes também referiu ter expectativas positivas relacionadas ao tratamento do câncer $(96,2 \%)$, independentemente do grau de estadiamento tumoral ou do tratamento proposto. $\mathrm{O}$ mesmo comportamento 
otimista se observou em relação aos aspectos relativos às funções sociais, predominantemente fala/voz/ser entendido $(83,6 \%)$, recreação $(76,0 \%)$, suporte para minha família $(71,2 \%)$ e relacionamentos $(68,3 \%)$. No âmbito de bem-estar psicológico, emocional e espiritual, observou-se que houve a predominância de um comportamento positivo diante das expectativas quanto às atitudes de enfrentamento da doença e do tratamento $(83,6 \%)$, auto-estima, humor e aparência. As expectativas ruins, quando existentes, variaram entre $1,0 \%$ a $12,5 \%$, considerando-se todos os itens de todos os domínios.

É bastante interessante e importante perceber que as melhores expectativas dos pacientes foram atribuídas justamente a alguns dos aspectos antes identificados no IPP como as maiores fontes de preocupação para os mesmos, na seguinte ordem de prevalência: mastigar/comer, tratamento do câncer, fala/voz/ser entendido, engolir, dor na cabeça e pescoço, feridas na boca, apetite, fadiga/cansaço e perda de peso.

Muito embora a literatura científica, nas diversas áreas de cuidados ao paciente oncológico, seja praticamente unânime ao afirmar que as expectativas positivas têm influência benéfica e aumentam a QV de pacientes com câncer, seria importante averiguar as possíveis causas para esta dicotomia entre respostas encontradas no PAE frente às respostas previamente encontradas no IPP, a fim de determinar se estas expectativas eram realistas ou não. Algumas das hipóteses que podem estar relacionadas a este fato seriam a falta de entendimento dos pacientes sobre as informações previamente recebidas, fornecimento de informações incompletas ou superficiais por parte do clínico responsável, falta de fornecimento da informação propriamente dita, dificuldades de retenção de informações recebidas, comportamento de negação por parte do paciente, criação de falsas expectativas como mecanismo de defesa ou até mesmo uma legítima postura otimista dos 
pacientes.

A importância deste questionamento reside no fato de que a maioria das pesquisas sobre as expectativas dos pacientes antes do tratamento avaliam principalmente suas expectativas em relação aos sintomas específicos decorrentes do tratamento, a potencial ocorrência destes sintomas com a QVRS, a suposta influência destas expectativas na real ocorrência destes sintomas ou papel das informações na elaboração das expectativas (Cassileth et al., 1985; List et al., 2000; Koller et al., 2000; Hickok et al 2001; Hofman et al., 2004; Llewellyn et al., 2005b; Olver et al., 2005; Sohl et al., 2009; Colagiuri et al., 2012; Rogers et al., 2015b).

Em 1999, Staniszewska propôs uma abordagem de avaliação das expectativas de 33 pacientes com problemas cardíacos em fase de investigação clínica ou antes da hospitalização, na qual os pacientes indicavam o grau de importância atribuído às suas expectativas de tratamento: nada importante, um pouco importante, incerta, importante ou muito importante. Esta abordagem, aparentemente simplista, parece ser interessante pois possibilita a avaliação do eventual impacto do não preenchimento de uma expectativa específica para o paciente.

Diante da complexidade de abordagens metodológicas e diferentes conceitos de expectativas que embasam as pesquisas neste tema, são necessários mais estudos que se limitem a avaliar, inicialmente, as associações qualitativas entre as variáveis sócio-demográficas e clínicas dos pacientes no momento do diagnóstico com suas expectativas e o grau de importância atribuída a cada uma delas. De posse destes dados, o delineamento de estudos mais específicos, associando-se as variáveis específicas de tratamento, provavelmente facilitarão a obtenção de resultados mais acurados. 


\subsubsection{Preenchimento das Expectativas}

Além dos cuidados à pessoa, o modelo de cuidados de saúde centrado no paciente pressupõe a identificação pelo médico das ideias e emoções do paciente sobre o adoecer e sua resposta a elas, a identificação de objetivos comuns entre médicos e pacientes sobre a doença e sua abordagem, o compartilhamento de decisões e responsabilidades, bem como a consideração do desejo do paciente por informações e subsequente resposta apropriada a esse desejo (Ribeiro; Amaral, 2008). Este modelo confere ao paciente grande participação nos aspectos que envolvem sua doença, mas também implica na necessidade de reconhecimento por parte dos clínicos, não somente das expectativas dos pacientes decorrentes deste envolvimento e desta abordagem, mas também dos possíveis fatores que podem corroborar para o preenchimento ou não destas expectativas. Segundo Winterling et al. (2008), não é apenas a existência de uma expectativa em relação a um dado assunto que pode influenciar o bem-estar de um indivíduo, mas também o que acontece com esta expectativa, ou seja, se esta é ou não é preenchida. Em 2007, Richardson et al. revisaram as ferramentas disponíveis para a avaliação das expectativas dos pacientes com câncer e concluíram que poucas delas cobriam todas as dimensões envolvidas no assunto.

A importância do preenchimento das expectativas dos pacientes com câncer tem sido reconhecida e estudada na literatura (Brown et al., 1997; Rogers et al., 2011; Morrison et al., 2012; Llewellyn et al. 2005b, 2006b).

Harrison et al. (2009) afirmam que a identificação e o gerenciamento das expectativas não preenchidas é um componente essencial nos cuidados de pessoas com câncer e que a obtenção de dados sobre estas prevalências pode informar o planejamento e a remodelação dos serviços de cuidados à saúde. Estes autores 
avaliaram uma revisão sistemática de 94 estudos disponíveis sobre estas prevalências, em diferentes épocas da jornada dos pacientes com câncer. Destes, 57 quantificavam o predomínio de expectativas não preenchidas. Suas prevalências, tendências e preditores eram muito variáveis em todos os domínios e em todas as épocas. O não preenchimento das expectativas relacionadas aos domínios atividades de vida diária $(1,0 \%-73,0 \%)$, psicológico $(12,0 \%-85,0 \%)$, de informações $(6,0 \%$ - 93,0\%), psicossocial $(1,0 \%-89,0 \%)$ e físico $(7,0 \%-89,0 \%)$ eram os mais referidos. As necessidades relativas aos domínios espiritual $(14,0 \%-51,0 \%)$, de comunicação $(2,0 \%-57,0 \%)$ e sexualidade $(33,0 \%-63,0 \%)$ eram os menos frequentemente investigados. A prevalência de necessidade não preenchidas pareceu ser maior e mais variada durante o tratamento, entretanto um grande número de indivíduos pareceu mais suscetível em expressá-las após o tratamento, em comparação com qualquer outra época. A relação destas prevalências com a especificidade do tumor foi difícil de distinguir. A grande variabilidade nas formas de classificação das expectativas não preenchidas, as diferenças nas descrições dos métodos e a diversidade das amostras de pacientes inibiram a comparação entre os estudos. Algumas ferramentas estão disponíveis para avaliar em que extensão os pacientes têm suas expectativas de cuidados de suporte não preenchidas, nos domínios físico, psicológico e de informação, tais como o Supportive Care Needs Survey (McElduff et al., 2004), o Cancer Survivors Unmet Needs measure (Hodgkinson et al., 2007) e o Cancer Patient Needs Questionnaire (Foot e SansonFisher 1995).

Correntemente, a literatura científica internacional utiliza as expressões "unmet needs" (necessidades não satisfeitas) ou "expectations fulfillment " 
(preenchimento das expectativas) quando o objetivo é avaliar a insatisfação ou satisfação do paciente quanto à resposta de satisfação que o mesmo obteve frente às suas expectativas. Com o intuito de se manter a coerência lógica com a terminologia adotada neste estudo, quando da avaliação das expectativas dos pacientes (PAE), optou-se pela utilização da expressão preenchimento das expectativas no processo de elaboração do Protocolo de Preenchimento das Expectativas - PPE. Sua elaboração seguiu a lógica anteriormente adotada, ou seja, a de que a existência de preocupações pode gerar expectativas, as quais podem ser preenchidas (total ou parcialmente) ou não ao longo do tempo. Parece importante também, que todos os instrumentos utilizados para avaliar as preocupações (IPP), expectativas (PAE) e preenchimento das mesmas (PPE) abrangessem os mesmos assuntos, facilitando o entendimento do paciente e possibilitando o fornecimento de respostas mais acuradas. Ainda, a categorização das respostas do PPE em não se aplica/ pior/igual/melhor possibilita uma avaliação do grau de preenchimento destas expectativas. A satisfação dos pacientes com os profissionais também foi avaliada, uma vez que aos 6 e 12 meses após o diagnóstico os pacientes já teriam tido a oportunidade, necessidade ou interesse de ter contato com os mesmos. O PPE também foi utilizado neste estudo como um piloto.

No domínio das expectativas de bem-estar físico e funcional, os resultados encontrados aos 6 e aos 12 meses após o diagnóstico revelaram que as expectativas dos pacientes quanto a mastigar/comer, engolir e perda de peso foram as menos preenchidas, com respectivamente $50,0 \%(\mathrm{n}=40), 47,5 \%(\mathrm{n}=38)$ e $40,0 \%(\mathrm{n}=32)$ dos pacientes considerando que estes aspectos tinham sido piores do que o esperado aos 6 meses e 46,8\% (n=29), 27,4\% (n=17) e 33,9\% (n=21) aos 12 meses. Curiosamente, estes aspectos estavam entre as preocupações mais prevalentes e possuíam as 
melhores expectativas à época do diagnóstico. O mesmo comportamento se observou em relação ao item fala/voz/ser entendido.

As dificuldades de deglutição (disfagia) sabidamente são sequelas do $\mathrm{CA} / \mathrm{CP}$ e/ou de seu tratamento (Gaziano, 2002), podendo causar mudanças nos padrões de alimentação, na vida social, impactar fortemente a QVRS e até mesmo a sobrevida do paciente (Wilson et al., 2011; McQuestion et al., 2011; Semenov et al., 2012). Entretanto as proporções de pacientes que esperavam uma melhor evolução em sua capacidade de mastigar/comer e engolir aqui encontradas denota que há uma disparidade entre as suas expectativas iniciais e o real comportamento de melhora destes aspectos ao longo do tempo, especialmente no caso de pacientes tratados com radioterapia, o que corresponde à $75,0 \%$ dos casos aqui avaliados, nesta época.

Estes achados se assemelham aos resultados encontrados por Brockbanck et al. (2015). Em seu estudo, os autores avaliaram 24 pacientes tratados do CA/CP (os sítios tumorais não estão descritos), com média de idade de 59 anos, entre 2 a 20 meses após o tratamento radioquimioterápico, com diversos graus de disfagia clinicamente diagnosticados $(54,0 \%$ leve, $25,0 \%$ moderada, $21,0 \%$ severa $)$, com o objetivo de avaliar as visões gerais dos pacientes quanto às informações que tinham recebido antes do tratamento sobre as possíveis mudanças em suas habilidade de comer, beber e engolir após o tratamento. Em geral, os resultados indicaram que os pacientes estavam satisfeitos com as informações recebidas antes do tratamento, entretanto, não esperavam que a disfagia persistisse à longo prazo e também subestimaram a gravidade da disfagia. Muitos dos pacientes avaliados tinham desejado toda a informação relevante, especificamente relacionada aos seus casos antes do tratamento, porém muitos descreveram ter tido dificuldades de absorver e reter as informações prognósticas sobre a deglutição, especialmente em função do 
impacto do diagnóstico. Os pacientes tinham recebido informações sobre disfagia, reiteradamente, de diversos profissionais (oncologistas, enfermeiras especialistas e fonoaudiólogos) e reportaram ter preferido receber estas informações apenas de profissionais com profundos conhecimentos em disfagia, alegando ter havido uma sobrecarga de informações e a existência de muitas pessoas fornecendo tais informações. Embora tenham desejado informações compreensíveis e detalhadas sobre as alterações de deglutição, muitos também reconheceram que estas podem ter aumentado sua ansiedade.

Neste estudo, embora os pacientes possam ter recebido do médico informações sobre as possíveis sequelas na mastigação e na deglutição, e muito provavelmente tenham sido encaminhados ao fonoaudiólogo mediante seu surgimento, há que se considerar a necessidade e possibilidade de encaminhamento destes pacientes ao fonoaudiólogo, antes do início do tratamento, em momento apropriado e subsequente (porém não concomitante) ao diagnóstico, a fim de prover e dosar as informações adequadas e preparar o paciente para a possibilidade da ocorrência desta sequela, tornando suas expectativas mais realistas. Morrison et al. (2012), consideram que as expectativas menos preenchidas e mais salientes devem ser alvo de melhor suporte para os pacientes.

De forma geral, aos 6 e aos 12 meses após o diagnóstico, a maioria das expectativas relacionadas ao tratamento do câncer, à assistência e bem-estar social e bem-estar psicológico, emocional e espiritual foram preenchidas, sendo melhor ou igual do que o esperado pelos pacientes. A faixa etária média dos pacientes e o fato de a maioria ser casada pode eventualmente explicar este fato, no que diz respeito especialmente aos itens dependentes/crianças, cuidador, relacionamentos, intimidade e sexualidade, pois nesta fase da vida, em geral, os filhos já são adultos e não 
demandam cuidados especiais, e a presença de um(a) companheiro(a) durante o processo de tratamento e recuperação parece ser um importante agente benéfico em termos de suporte social (Inverso et al., 2015). Este último aspecto está de acordo com os achados de Henry et al. (2014), que identificaram quais eram as expectativas não preenchidas de pacientes com tumores em cavidade oral $(34,3 \%)$, laringe (20,9\%), faringe $(8,2 \%)$, tireóide $(8,2 \%)$ e outros (glândulas salivares, parótida $8,2 \%$ ), a maioria do sexo masculino $(66,7 \%)$, com média de idade de 61 anos, entre menos de um mês a 3 meses (8,4\%), 3 a 12 meses (42,4\%), 12 a 24 meses $(23,7 \%)$, 24 a 60 meses $(16,9 \%)$ e mais do que 60 meses após o diagnóstico, por meio da aplicação dos questionários SCNS-SF34 (McElduff et al., 2004), HADS (Zigmond; Snaith, 1983), FACT-G (Cella et al., 1993) e o FACT- H\&N (List et al., 1996). As diferentes análises realizadas indicaram que as expectativas menos preenchidas e mais endossadas eram de ordem predominantemente psicológica (medo da recorrência, incerteza sobre o futuro, tristeza, preocupações sobre a família/amigos, sentir-se "para baixo"/depressão), físicas (imagem corporal, falta de energia/cansaço, não se capaz de continuar as atividades de vida diária) e relacionadas à informação (saber se o câncer está em remissão ou controlado). As correlações indicaram que os pacientes com maior número de expectativas não preenchidas eram divorciados ou separados, entre outras características.

A literatura também aponta para o fato de que os pacientes podem ter algumas de suas expectativas não preenchidas mesmo após maiores períodos desde o diagnóstico. Wells et al. (2015) avaliaram as necessidades não preenchidas de 199/280 pacientes tratados do CA/CP prevalentemente em cavidade oral, laringe e orofaringe em diversos estadiamentos, submetidos a tratamentos combinados ou cirurgia exclusiva, por meio da aplicação do PCI. Apenas 9,0\% dos pacientes tinham 
sido diagnosticados há menos de um ano e o restante entre 1a 2 anos (22,0\%), 2 a 3 anos $(19,0 \%), 3$ a 4 anos $(25,0 \%)$ e 4 a 5 anos $(25,0 \%)$. Os principais assuntos reportados foram o medo da recorrência $(n=32)$, boca seca $(n=28)$, fadiga/cansaço $(n=27)$, saúde dental/dentes $(n=27)$ e mastigar/comer $(n=15)$. Estes pacientes indicaram que gostariam de ter tido mais suporte e ajuda nestes aspectos, mesmo em fases mais tardias após o diagnóstico. Alguns pacientes $(n=18)$ comentaram que teriam se beneficiado de mais informações sobre as consequências do tratamento antes de seu início, e mais informações sobre como lidar com os efeitos colaterais do tratamento imediatamente após seu término, especialmente dificuldades de engolir, gerenciamento das secreções, sensibilidade dos dentes, dificuldades para comer, dor e formigamento.

No presente estudo, em geral, os pacientes reportaram que suas expectativas em relação à quantidade, qualidade e clareza das informações recebidas dos diferentes profissionais tinham sido muito ou razoavelmente preenchidas, nas duas épocas avaliadas, especialmente pelos profissionais que atuam diretamente nos aspectos de bem-estar físico e funcional (reabilitação e cuidados) e pelos profissionais diretamente responsáveis pelo tratamento, o que sugere que as expectativas físicas e funcionais anteriormente referidas como menos preenchidas são provavelmente resultantes de mecanismos internos dos pacientes e não decorrem de falhas no processo de provisão das informações.

De acordo com Ringash (2015), atualmente, mais de 60,0\% dos sobreviventes do $\mathrm{CA} / \mathrm{CP}$ tem expectativas não preenchidas, e diante do fato de que o número de sobreviventes está aumentando, os modelos atuais de cuidados se tornarão cada vez mais inadequados para ir de encontro às suas necessidades, o que torna urgentemente necessária a exploração de novas estratégias e modelos de cuidados a fím de prover 
melhor atendimento aos assuntos relacionados à $\mathrm{QV}$ e às expectativas destes sobreviventes.

\subsubsection{Associações entre o Grau de Preenchimento das Expectativas e a Qualidade de Vida}

A discussão sobre o impacto do grau de preenchimento das expectativas na QV de pacientes com $\mathrm{CA} / \mathrm{CP}$ é um tema que demanda uma reflexão mais ampla, englobando todos os assuntos anteriormente discutidos neste estudo. Não se pode apenas ponderar sobre resultados estatísticos de QV, quando muitas das variáveis que determinam estes resultados têm um caráter eminentemente subjetivo, multidimensional e cursam simultaneamente na vida dos indivíduos afetados pela doença. Estas variáveis - estado emocional, vivência dos sintomas, preferências por informações, preocupações, necessidades específicas de cuidados de suporte e expectativas (aqui mensuradas por meio dos instrumentos HADS, MDASI, QIP, IPP e PAE) constituem uma espécie de pano de fundo na experiência do câncer que, juntamente à outras variáveis eminentemente objetivas (tais como modalidades de tratamento, respostas de cura, acesso à saúde) serão determinantes na interpretação final do paciente sobre seu grau de satisfação geral ou específico. Portanto, as variáveis subjetivas e objetivas funcionam como uma espécie engrenagem, cujo funcionamento irá variar de paciente para paciente.

Num estudo reflexivo importante e extenso sobre o papel das expectativas "versus" a experiência na determinação dos resultados de QV, Carr et al. (2001) ponderam que as percepções de saúde e seu significado variam de indivíduo para indivíduo e para um mesmo indivíduo ao longo do tempo, dificultando a mensuração da QVRS. Os autores enumeram diversas limitações que envolvem esta mensuração: 
1) expectativas individuais são altamente específicas, portanto, a avaliação da QV se baseará em um horizonte de possibilidades que cada indivíduo vê para si próprio, as quais são componentes fundamentais para sua identidade. Estes horizontes são determinados por fatores como classe social, idade, sexo, etnia, sexualidade, incapacidades e biografia pessoal; 2) as pessoas avaliam sua QVRS comparando suas expectativas com suas experiências, entretanto, as mensurações de QV não levam em conta o modo como os indivíduos chegaram a estes julgamentos, isto é, as medidas existentes para a QV não levam em conta as expectativas de saúde dos indivíduos uma vez que não incorporam os limites dentro dos quais estes níveis de expectativas e experiências pessoais foram mensurados. Como exemplo, os autores citam que um indivíduo com uma experiência pessoal prévia de saúde ruim, e que tenha baixas expectativas, pode não avaliar uma doença grave como fator de grande impacto em sua QV. Inversamente, alguém que geralmente possui uma saúde boa pode experimentar um impacto significante em sua QV com uma doença relativamente menos grave, pois suas expectativas anteriores de saúde eram altas; 3) a magnitude do impacto dependerá de quando esta mensuração é feita e, já que os indivíduos respondem à doença individualmente e de formas diferentes ao longo da trajetória da doença, não há um intervalo de tempo que possa considerado o padrão adequado para mensurar a QV.

Outro aspecto, levantado por Armes et al. (2009), é o de que as medidas de QV geralmente classificam apenas a presença ou a ausência da severidade de um dado item, não considerando de se o indivíduo respondente considera ou não este item como um problema para o qual ele necessita de ajuda. Fazendo-se uma reflexão, este fato pode resultar na não identificação de um problema em potencial, seguida 
pelo não preenchimento de sua necessidade específica e culminando com uma pior percepção do indivíduo sobre seus resultados de QV.

Reflexões de ordem sociológica, também são pertinentes quando se pretende avaliar o impacto da satisfação do paciente em sua QV. Seidl e Zannon (2004) sustentam que as interpretações de um indivíduo sobre sua doença e estado de saúde não podem ser avaliadas somente sob a perspectiva de apenas uma forma de influência específica (exemplo: alimentação), pois fatores como as ações individuais e as políticas públicas, interligadas de forma contínua, influenciarão estas interpretações.

Almeida et al. (2012) discorrem sobre o fato de que o ambiente físico-social, primeiramente, seguido pelas escolhas do sujeito para sua própria vida é que irão estabelecer o que é necessário para se alcançar uma boa QV e, a partir deste ponto, o que ele conseguirá ou não realizar dependerá das oportunidades e possibilidades disponíveis para satisfazer estas necessidades fundamentais e também de seu esforço frente às oportunidades que sua condição de vida oferece, resultando em sua percepção de QV.

Infelizmente, a literatura científica disponível sobre estudos que avaliam as associações entre o grau de preenchimento das expectativas dos pacientes com $\mathrm{CA} / \mathrm{CP}$ e sua respectiva $\mathrm{QV}$ é extremamente limitada e caracterizada pela notória falta de padronização das metodologias de avaliação, bem como dos parâmetros avaliados. As inúmeras buscas realizadas, com o intuito de encontrar estudos que viabilizassem uma discussão mais aprofundada e comparada com os resultados aqui encontrados, resultaram limitadas ou infrutíferas, recaindo sempre sobre estudos já anteriormente aqui apresentados e discutidos ou sobre estudos que envolviam pacientes oncológicos diversos. Os estudos mais recentes, encontrados durante a 
realização destas buscas, avaliavam em geral, isoladamente e em diferentes momentos, a comunicação com os médicos, o papel das informações, as modalidades de tratamento, a ocorrência de sintomas ou fatores sócio-demográficos e seus respectivos impactos na QV. Estas limitações, aliadas ao aumento crescente no número de indivíduos afetados pelo $\mathrm{CA} / \mathrm{CP}$ e de sobreviventes, denotam a necessidade urgente da realização de outros estudos que a avaliem de forma simultânea todos os aspectos que afetam a QV destes pacientes, bem como a adoção de uma sistematização mínima das metodologias de avaliação.

A análise comparativa entre os resultados do IPP, do PAE e do PPE (anteriormente descritos) e os resultados da associação entre o grau de preenchimento das expectativas e a QV denota que os itens de caráter físico/funcional que impactaram mais negativamente a QV dos pacientes aos 6 e 12 meses estavam entre suas maiores preocupações ao longo de todas as épocas, eram objeto de suas melhores expectativas à época do diagnóstico e também estavam entre as expectativas menos preenchidas aos 6 e 12 meses.

Os resultados das associações entre o grau de preenchimento das expectativas alcançados pelos pacientes com sua QV aos 6 meses após o diagnóstico, encontrados neste estudo, demonstram que o grau de satisfação ou insatisfação com inúmeros fatores parecem ter influenciado positivamente ou negativamente os resultados de QV dos mesmos. Nesta época, o número de pacientes cujas expectativas foram menos preenchidas foram as maiores para os assuntos relacionados especialmente às funções de ordem nutricional/oral - mastigar/comer $(n=40)$, boca seca $(n=39)$, paladar $(n=36)$, perda de peso $(n=32)$, engolir $(n=38)$, abertura de boca $(n=21)$, feridas na boca $(n=20)$ e sonda para alimentação $(n=19)$, assim como a fadiga/cansaço $(\mathrm{n}=28)$, e estavam associados à escores médios mais baixos de QV 
para estes pacientes, ou seja, indicando que estes aspectos ainda impactavam mais fortemente os resultados de sua QV global. Já os itens apetite, hábito intestinal, tosse, saúde dental/ dentes, níveis de energia, catarro/secreção, aparência, mobilidade, tratamento do câncer, recreação, relacionamentos, sexualidade e personalidade/temperamento parecem ter correspondido às expectativas dos pacientes, na maioria dos casos, ou até mesmo superado as expectativas para alguns pacientes, impactando positivamente os resultados médios de QV alcançados. A ocorrência de problemas como indigestão, dor na cabeça e pescoço, dor em outro lugar, vômito/ mal-estar e raiva não se aplicaram para mais da metade dos pacientes ou foram de encontro às suas expectativas, o que também parece ter impactado positivamente sua QV.

Já aos 12 meses após o diagnóstico observou-se uma grande redução no número de variáveis cujo grau de preenchimento das expectativas impactou a QV dos pacientes.

Os números de pacientes insatisfeitos em suas expectativas quanto a mastigar/ comer $(n=29)$ e ao paladar $(n=19)$, apesar de serem os mais altos nesta época, estavam associados à escores médios de QV tidos como bons, e notadamente mais altos do que aos 6 meses, indicando que, ainda que estes aspectos tenham impactado negativamente a QV destes pacientes, houve uma provável adaptação por parte dos mesmos a estes problemas. Os resultados relativos ao grau de preenchimento das expectativas com a fadiga/ cansaço, engolir, níveis de energia, tratamento do câncer, recreação, suporte para minha família, medo do câncer voltar e medo de acontecimentos desfavoráveis denotam que estes aspectos, de forma geral, se comportaram conforme o esperado pelos pacientes, impactando positivamente sua QV. 
Observou-se, ainda, uma mudança interessante na essência principal das variáveis de cunho sócio-emocional, cujo preenchimento estava associado aos resultados de QV nesta fase: anteriormente, aos 6 meses, estas eram vinculadas a situações cujo controle e gerenciamento, teoricamente, estavam mais ao alcance da vontade e das ações do paciente e, portanto, mais passíveis de ser contornadas (ansiedade, recreação, relacionamentos, raiva, sexualidade, personalidade/temperamento); porém, aos 12 meses, as preocupações com o suporte para a família, medo do câncer voltar e medo de acontecimentos desfavoráveis passaram também a influenciar os resultados de QV e, obviamente, o comportamento destas variáveis é totalmente impossível de ser controlado pelas vontades ou ações do próprio paciente, bem como dos clínicos. Problemas com dor na cabeça e pescoço ou inchaço não se aplicaram para mais da metade dos pacientes nesta fase, ou foram de encontro ao que os pacientes esperavam, o que também parece ter afetado de forma positiva a QV por eles reportada.

De forma geral, os escores médios de QV encontrados aos 12 meses após o diagnóstico, foram mais altos do que aos 6 meses, independentemente do grau de preenchimento das expectativas a eles associados, o que concorda com os achados prévios da literatura, que sugerem que os sintomas da doença e do tratamento podem persistir, mesmo que os escores de QV reportados pelos sobreviventes não tenham mudado ou mesmo melhorado (Burkett; Cleeland, 2007) e ainda, que apesar de algumas morbidades relacionadas ao tratamento e a $\mathrm{QV}$ de pacientes com $\mathrm{CA} / \mathrm{CP}$ retornarem a níveis próximos existentes na época do diagnóstico (Murphy et al., 2007), alguns domínios de morbidade relacionados ao tratamento não se recuperam aos 12 meses e necessitam ser regularmente monitorados ao longo do primeiro ano após o início do tratamento (So et al., 2012; Kjaer et al., 2016). No que tange ao 
impacto das alterações relacionadas à disfagia na QV dos pacientes, Murphy et al. (2015) consideram que a concordância entre os clínicos e os pacientes é pobre, devido, em parte, à falha dos clínicos em reconhecer o impacto substancial que as alterações discretas ou moderadas podem causar na QV, nas adaptações à dieta e na experiência de alimentação, sugerindo que os pacientes, mesmo com disfagias discretas, devem passar por avaliações periódicas com fonoaudiólogos e nutricionistas para identificar e tratar os efeitos tardios e prevenir resultados de saúde adversos. Em conclusão, os autores afirmam que os efeitos terapêuticos tardios do CA/CP podem afetar adversamente a saúde e a QV dos pacientes, cabendo aos médicos intervir, quando possível, ou, caso contrário, educar o paciente sobre a impossibilidade de intervenção, diminuindo sua ansiedade e aflição.

\subsubsection{Considerações Finais}

Os aspectos avaliados neste estudo, assim como seus resultados, necessitam ser interpretados à luz de suas limitações. A não realização de diversas análises e cruzamentos estatísticos entre os dados obtidos após a realização dos objetivos específicos, restringiu uma análise mais aprofundada e detalhada das interações entre inúmeras facetas envolvidas na jornada dos pacientes com $\mathrm{CA} / \mathrm{CP}$ em sua luta pela sobrevivência. Assim, estes resultados necessitam ser entrelaçados a fim de se obter respostas mais abrangentes e esclarecedoras. Por outro lado, as discussões aqui conduzidas foram prioritariamente embasadas na literatura recente e restrita ao CA/CP. Os aspectos positivos deste estudo recaem sobre seu desenho longitudinal (o que permite a mensuração de mudanças ao longo do tempo), sobre a homogeneidade das amostras avaliadas nos diferentes momentos e sobre a diversidade das características clínicas e demográficas dos pacientes avaliados. 
Este estudo pode, no sentido figurado, ser entendido como uma espécie de "sobrevoo de reconhecimento sobre todo o terreno movediço onde estes pacientes caminham durante sua jornada". Outros estudos qualitativos, que avaliem integradamente os aspectos emocionais, sintomáticos e comportamentais dos pacientes com $\mathrm{CA} / \mathrm{CP}$ são extremamente necessários e possibilitarão um melhor entendimento sobre o universo destes indivíduos, resultando na prestação de melhores serviços de cuidados à saúde, maior satisfação dos pacientes e melhora em sua QV. 
CONCLUSÕES 


\section{CONCLUSÕES}

Com base neste estudo, podemos concluir que:

1 O Inventário de Preocupações dos Pacientes (IPP) é um instrumento apropriado, bem adaptado e validado psicometricamente para uso em pacientes brasileiros com câncer de cabeça e pescoço.

2 A maioria dos pacientes apresentou escores de ansiedade e de depressão dentro dos limites de normalidade, com tendência à diminuição destas comorbidades ao longo do tempo, porém com exacerbação de ansiedade leve após um ano.

3 A qualidade de vida dos pacientes avaliados pode ser considerada boa, em todos os momentos avaliados, com um declínio aos 6 meses após o diagnóstico e melhora ao longo de um ano.

4 A sintomatologia reportada pelos pacientes à época do diagnóstico caracterizou-se pela predominância de sintomas relacionados à existência do tumor, associada a sentimentos de tristeza e preocupações. Aos 6 meses, houve o aumento e exacerbação de sintomas físicos, relacionada a morbidade do tratamento, associado a sentimentos de preocupação. Aos 12 meses houve uma diminuição na ocorrência dos sintomas físicos, porém ainda associada a sentimentos de preocupação.

5 Em todos os momentos avaliados, a maioria dos pacientes desejou receber toda a informação geral sobre a doença, boa ou má, considerou necessário 
saber informações específicas sobre a doença e o tratamento e preferiu ter sido informada sobre a doença pelo médico especialista.

6 Em todas os momentos avaliados, houve o predomínio de preocupações de natureza física/funcional. Preocupações com mastigar/comer e engolir ocorreram nas três épocas avaliadas. Preocupações com fadiga/cansaço foram mais frequentes nos momentos pré-tratamento e ao final de 12 meses e as preocupações com boca seca, saúde dental/dentes e catarro/ secreção aos 6 e 12 meses após o diagnóstico. Preocupações com o tratamento do câncer e o medo do câncer voltar ocorreram em todos os momentos, sendo esta última a principal preocupação dos pacientes aos 12 meses após o diagnóstico. Os profissionais mais selecionados pelos pacientes foram o fonoaudiólogo (nos três momentos), o nutricionista e o oncologista/radioterapeuta (no prétratamento) e o cirurgião e o dentista (aos 6 e 12 meses após o diagnóstico).

7 Ao diagnóstico, em geral, a maioria dos pacientes possuía boas expectativas para todos os itens relacionados ao bem-estar físico e funcional (especialmente mastigar/comer), ao tratamento, à assistência e bem-estar social e ao bem-estar psicológico, emocional e espiritual.

8 Aos 6 e aos 12 meses após o diagnóstico, as expectativas dos pacientes quanto a mastigar/comer, engolir e perda de peso foram as menos preenchidas, sendo consideradas pior do que o esperado. Em ambas as épocas, em geral, a maioria das expectativas relacionadas ao tratamento do câncer, à assistência e bem-estar social, bem-estar psicológico, emocional e espiritual foram preenchidas, assim como em relação à quantidade, qualidade e clareza das informações recebidas dos profissionais. 
9 Aos 6 meses após o diagnóstico, o menor grau de preenchimento das expectativas dos pacientes quanto aos itens mastigar/comer, boca seca, paladar, perda de peso, engolir, abertura de boca, feridas na boca, sonda para alimentação e fadiga/cansaço associou-se com piores escores médios de qualidade de vida. Aos 12 meses após o diagnóstico, um menor grau de preenchimento das expectativas com os itens mastigar/comer e paladar impactou a qualidade de vida dos pacientes, porém os escores médios foram bons, indicando a adaptação dos pacientes a estes problemas. Em ambas as épocas, as expectativas, quando preenchidas dentro do esperado ou melhor do que o esperado pelos pacientes, associaram-se à melhores escores médios de qualidade de vida. 


\section{ANEXOS}

Anexo A - Carta de aprovação do Comitê de Ética em Pesquisa - FMUSP

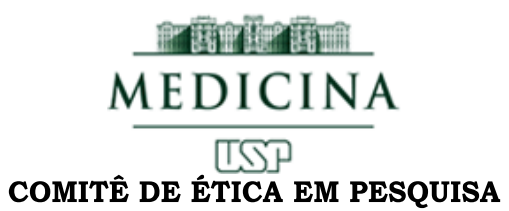

\section{APROVAÇÃo}

O Comitê de Ética em Pesquisa da Faculdade de Medicina da Universidade de São Paulo, em sessão de 17/10/2012, APROVOU o Protocolo de Pesquisa ${ }^{0}$ 331/12 intitulado: "VALIDAÇÃo PARA A LÍNGUA PORTUGUESA BRASILEIRA DO INVENTÁRIO DE PREOCUPAÇÕES DOS PACIENTES (PCI), AVALIAÇÃo das PREOCUPAÇões E EXPECTATIVAS DE PACIENTES TRATADOS DE CÂNCER DE VIAS AERODIGESTIVAS SUPERIORES E SUA RELAÇÃO COM A QUALIDADE DE VIDA" apresentado pelo Departamento de RADIOLOGIA E ONCOLOGIA

Cabe ao pesquisador elaborar e apresentar ao CEP-FMUSP, os relatórios parciais e final sobre a pesquisa (Resolução do Conselho Nacional de Saúde no 196, de 10/10/1996, inciso IX.2, letra "c").

Pesquisador (a) Responsável: Luiz Paulo Kowalski

Pesquisador (a) Executante: Ivy Jungerman

CEP-FMUSP, 18 de Outubro de 2012.

$$
\begin{aligned}
& \text { PLluemun } \\
& \text { Prof. Dr. Roger Chammas } \\
& \text { Coordenador } \\
& \text { Comitê de Ética em Pesquisa }
\end{aligned}
$$


Anexo B - Carta de aprovação do Comitê de Ética em Pesquisa do A.C.Camargo Cancer Center

\section{Hospital A.C.Camargo}

Centro de Tratamento, Énsino e Pesquisa em Câncer

São Paulo, 20 de Dezembro de 2012.

Ao

Dr. Luiz Paulo Kowalski

Aluna: Ivy Jungerman (Doutorado - FMUSP).

Ref.: Projeto de Pesquisa n ${ }^{\circ}$. 1718/12

"Validáção para a Língua Portuguesa - Brasileira do Inventário de Preocupações dos Pacientes (PCI), Avaliação das Preocupaçōes e Expectativas de Pacientes Tratados com' Câncer de Vias Aerodigestivas Superiores e sua Relação com a Qualidade de Vida".

Os membros do Comitê de Ética em Pesquisa em Seres Humanos da Fundação Antonio Prudente - Hospital do Câncer - A.C. Camargo/SP, em sua última reunião de 06/11/2012, aprovaram a realização do protocolo do estudo em referência, o Termo de Consentimento Livre e Esclarecido, o Termo de Consentimento Livre e Esclarecido - PCI, Inventário de Preocupações dos Pacientes (PCI), Escala de Ansiedade e Depressão (HADS), Questionário de Qualidade de Vida da Universidade de Washington (UWQOL), Inventário de Sintomas do M.D. Anderson (MDASI - H\&N), Questionário de Informação do Paciente (QIP) e tomaram conhecimento dos seguintes documentos:

$>$ Folha de Rosto para Pesquisa Envolvendo Seres Humanos

$>$ Termo de Compromisso do Pesquisador com Resoluções do Conselho Nacional de Saúde;

$>$ Declaração sobre o plano de recrutamento dos sujeitos de pesquisa, circunstâncias e responsáveếs pela obtenção do TCLE;

$>$ Declaração Sobre os Dados Coletados, Publicação dos Dados e Propriedade das Informações Geradas;

> Declaração de Infraestrutura e Instalações do Departamento de Cirurgia de Cabeça e Pescoço e Otorrinolaringologia;

$>$ Orçamento Financeiro Detalhado;

Declaração de comprométimento da Instituição co-participante;

D Declaração de Ciência e Comprometimento do Departamento de Cirurgia de - Cabeça e Pescoço e Otorrinolaringologia;

$>$ Cronograma de Pesquisa;

$>$ Carta e parecer consubstanciädo de aprovação do projeto no CEP da USP

>. Identificação dos Currículos na Plataforma Lattes.

Informações a respeito do andamento do referido projeto deverão ser encaminhadas ao CEP dentro de 06 meses.

Atenciosamente,

Dr. Antônio Huge José Frpes Marques Campos $2^{\circ}$ Vice-Coordenador do Comitt de Ética em Pesquisa

Fundacao Antonio Prudente - CNPJ/MF N. 60.961.968/0001-06

Rua Prof Antônio Prudente, 211'- Liberdade - São Paulo, SP - 01509-900

Telefone: (11) 2189-5000

www.accamargo.org.br 


\section{Anexo C - Ficha de Registro do Prontuário}

Nome:

$\mathrm{RGH}$ :

Telefone de Contato:

1. Estadiamento T: (1) T1 (2) $\mathrm{T} 2$ (3) $\mathrm{T} 3$ (4) $\mathrm{T} 4$ (5) $\mathrm{Tx}$

$$
\begin{array}{ll}
\mathrm{N}: & \text { (0) N0 (1) N1 (2) N2 (3) N3 (4) Nx } \\
\mathrm{M}: & \text { (0) M0 (1) M1 (2) Mx }
\end{array}
$$

2. Sítio do tumor primário: (1) Cavidade Oral (2) Orofaringe (3) Hipofaringe (4) Nasofaringe (5) Laringe (6) Fossas Nasais/Seios Maxilares (7) Glândula Salivar (8)Tiróide (9) oculto

3. Histologia: (1) CEC (2) Ca indiferenciado (3) Adenocarcinoma (4) Outro

4. Tratamento :
(0) nenhum
(1) Cirurgia
(2) RxT exclusiva
(3) RxT adjuvante

(4) QT Adjuvante (5) Rxt Neoadjuvante (6) QT Neoadjuvante (7) Rxt + QT

(8) Rxt + QT adjuvantes (9) QT paliativa

5. RT dose Gy (0) não (1) desconhecido

6. Reconstrução: (0) Não (1) Sim

7. Esvaziamento: (0) Não (1) Sim

8. .Estruturas envolvidas na ressecção (parcial/total):

(0) Não (1) Lábios (2) Palato duro (3) Língua Oral (4) Soalho da Boca

(5) Mucosa Jugal (6) Área retromolar (7) Loja amigdaliana (8) Palato mole

(9) Base de língua (10) Maxila (11) Mandíbula (12) Hipofaringe (13) Laringe

(14) Tiróide (15) Nasofaringe (16) Glândulas Salivares (17) Cavidade/ Septo Nasal

9. Sonda NE: (0) Não (1) Sim

10. PEG: (0) Não (1) Sim

11. Traqueostomia: (0) Não (1) Sim

12. Alimentação atual:

(0) VO exclusiva (1) VO mista (2) SNE (3) PEG

13. Terapia Fonoaudiológica: (0) Não (1) Sim

14. Meio de comunicação:
(1) Voz laríngea
(2) VE
(3) VTE
(4) Vibrador Laríngeo
(5) outros

15 .Fisioterapia (0) Não (1) Sim

16. Acompanhamento psicológico / psiquiátrico: (0) Não (1) Sim 
17. Doença em atividade: (0) Não (1) Sim

18. Data do início do tratamento

19. Data da última avaliação

$\frac{1}{1}-1$

20. Situação na última avaliação

(1) Assintomático (2) Vivo com recorrência local (3) Vivo com $2^{\circ} \mathrm{TU}$ primário

(4) óbito por outra causa (5) óbito por CA (6) Perdido de vista

(7) Recidiva sistêmica / Metástase

21. Proposta terapêutica (recorrência)
(0) nenhum
(1) Cirurgia
(2) RxT exclusiva
(3) RxT adjuvante

(4) QT Adjuvante (5) Rxt Neoadjuvante (6) QT exclusiva (7) Rxt + QT

(8) Rxt + QT adjuvantes (9) à definir (10) Cuidados Paliativos 
Anexo D - Ficha de Registro do Paciente

1. Nome:

RGH:

Telefone de Contato

Residência:

2. Sexo: (1) M (2) F

3. Idade:

4. Data de Nascimento:

5. Estado Civil: (1) S (2) C (3) V (4) D

6. Filhos: (0) Não (1) Sim \__ Quantos?

7. Arranjo familiar: (0) mora só (1) mora com alguém

8. Escolaridade: (0) analfabeto (1) Ensino fundamental I incompleto

(2) Ensino fundamental I completo (3) Ensino Fundamental II incompleto

(4) ensino Fundamental II completo (5) Superior incompleto (6) Superior completo

(7) Pós- Graduação

9. Profissão:

10. Religião (0) Ateu (1) Católica (2) Evangélica (3) Protestante (4) Espírita (5) Judaica (6) Budista (7) Islamismo (8) Outras

11. Trabalha atualmente: (0) Não (1) Sim

12. Fumo: (0) nunca (1) parou (2) mantém o vício

13. Álcool: (0) nunca (1) parou (2) mantém o vício 
Anexo E - Termo de Consentimento Livre e Esclarecido I - PCI Validação do Patients Concerns Inventory - PCI

Convidamos você a participar de um estudo que tem por objetivo validar para o português Brasil um inventário que busca identificar as preocupações individuais dos pacientes com câncer de cabeça e pescoço nos diferentes momentos de seu tratamento. Neste inventário são enumerados 57 assuntos, que representam as eventuais preocupações e necessidades dos pacientes e uma lista de 19 profissionais para os quais os pacientes gostariam eventualmente de ser encaminhados. Caso você decida não participar deste estudo, não haverá qualquer prejuízo em relação ao tratamento que você já realiza ou irá realizar. Caso concorde em participar deste estudo solicitaremos inicialmente que você assine um consentimento por escrito, autorizando sua participação. Você completará o inventário proposto $(P C I)$ antes do início de sua consulta ambulatorial e o Questionário de Qualidade de Vida da Universidade de Washington - UW-QOL, um questionário de qualidade de vida doença-específico para pacientes tratados do câncer de cabeça e pescoço. Você ainda receberá um envelope selado com um inventário $(P C I)$ em branco para reteste, que deverá ser enviado via correio em até quinze dias. A duração estimada para a aplicação destes questionários é de aproximadamente 15 minutos.

\section{DESPESAS E COMPENSAÇÕES}

Você não terá despesas pessoais se participar do estudo pois os dados serão coletados antes de sua consulta ambulatorial. Caso seja necessário o agendamento de um horário fora do dia de seu retorno ao ambulatório, a pesquisadora arcará com suas eventuais despesas de transporte. Também não há compensação financeira relacionada à sua participação.

\section{DESCONTINUAÇÃO DO ESTUDO}

Você é livre para desistir de participar do estudo a qualquer momento, sem qualquer tipo de penalização ou prejuízo em seu tratamento ou seguimento Neste caso, você não precisará dizer o motivo pelo qual deseja desligar-se do mesmo e deverá apenas informar sua decisão à pesquisadora responsável. Esclarecemos que este consentimento destina-se somente a sua participação nesta pesquisa, não havendo possibilidade de extensão da mesma autorização para outros projetos.

\section{BENEFÍCIOS E RISCOS POTENCIAIS DO ESTUDO}

Sua participação neste estudo não oferece qualquer risco ou desconforto. Os benefícios potenciais deste estudo incluem a possibilidade de aquisição de informações que contribuirão para um maior conhecimento sobre as preocupações reais dos pacientes oncológicos frente à doença e ao tratamento. Estas informações podem ser valorosas para a melhoria do seu processo de reabilitação, bem como beneficiar futuros pacientes.

\section{REGISTRO DOS PACIENTES}

Se você participar do estudo, seus registros ficarão disponíveis para o pesquisador responsável, as autoridades reguladoras e sanitárias pertinentes ou poderão ser publicados com fins científicos, porém sua identidade permanecerá confidencial. 
ESCLARECIMENTO SOBRE DISPONIBILIDADE PARA COMPENSAÇÃO PELA PARTICIPAÇÃO NA PESQUISA OU PARA DANOS RELACIONADOS À PESQUISA

Item não considerado, pois não há riscos de danos ou desconforto ao paciente.

\section{DÚVIDAS}

Se quaisquer problemas ou pergunta surgirem a respeito do estudo, quanto a seus direitos como participante de uma pesquisa clínica ou a respeito de qualquer outro aspecto relacionado à pesquisa, você deverá entrar em contato com:

Fga Ivy Jungerman. Tel: 98262.0002 ou 3165.6202

Se o pesquisador principal não fornecer informações / esclarecimentos suficientes, por favor, entre em contato com o Comitê de Ética em Pesquisa em Seres Humanos da Fundação Antono Prudente - Hospital do Câncer - A.C. Camargo/SP pelo telefone (11)2189-5000, ramais 2069 ou 5020, de segunda-feira à quinta-feira das 7horas às 18:00 horas e sexta-feira das 7 horas às 16 horas.

\section{POR FAVOR, GUARDE ESTAS INFORMAÇÕES PARA CONSULTA FUTURA.}

\section{FORMULÁRIO DE CONSENTIMENTO DO PACIENTE}

Li e entendi este folheto de informações ao paciente e o formulário de consentimento livre e esclarecido composto de 2 páginas. Concordo voluntariamente em participar do estudo acima. Entendo que, mesmo após a assinatura do formulário de consentimento, posso deixar de participar do estudo a qualquer momento, sem dizer o motivo e sem detrimento ao meu tratamento presente ou futuro pelo médico. Recebi uma cópia deste folheto de informações ao paciente e formulário de consentimento para levar comigo.

Data:

Nome do paciente por extenso:

Assinatura do paciente:

Assinatura do pesquisador: 
Anexo F - Termo de Consentimento Livre e Esclarecido II

Convidamos você a participar de um estudo que tem por objetivo analisar quais são as suas preocupações e expectativas em relação ao tratamento oncológico ao qual você será submetido. Posteriormente, pretendemos avaliar se estas expectativas se modificaram ao longo do tempo e qual o impacto destas eventuais mudanças em sua qualidade de vida. Julgamos ser de grande importância conhecer as preocupações e expectativas que os pacientes com câncer de cabeça e pescoço têm sobre sua doença e tratamento em diferentes épocas após o diagnóstico Sua participação neste estudo é totalmente voluntária. Você terá tempo suficiente para decidir se quer participar ou não. Caso você decida não participar deste estudo, não haverá qualquer prejuízo em relação ao tratamento que você já realiza ou irá realizar. Caso concorde em participar deste estudo solicitaremos inicialmente que você assine um consentimento por escrito, autorizando sua participação. Você completará os questionários propostos em 3 épocas diferentes: antes do tratamento, aos 6 meses e aos 12 meses após o término do tratamento.

\section{DESPESAS E COMPENSAÇÕES}

Não há despesas pessoais para o participante em qualquer fase do estudo pois os dados serão coletados no momento de seu retorno ambulatorial. Caso seja necessário o agendamento de um horário fora do dia de seu retorno ao ambulatório, a pesquisadora arcará com suas eventuais despesas de transporte. Também não há compensação financeira relacionada à sua participação.

\section{DESCONTINUAÇÃO DO ESTUDO}

Você é livre para desistir de participar do estudo a qualquer momento, sem qualquer tipo de penalização ou prejuízo em seu tratamento ou seguimento Neste caso, você não precisará dizer o motivo pelo qual deseja desligar-se do mesmo e deverá apenas informar sua decisão à pesquisadora responsável.. Esclarecemos que este consentimento destina-se somente a sua participação nesta pesquisa, não havendo possibilidade de extensão da mesma autorização para outros projetos.

\section{APLICAÇÃO DOS QUESTIONÁRIOS:}

Logo após o aceite e a assinatura do consentimento pós-informado, você completará 6 questionários:

1. Escala de ansiedade e depressão - HADS

2. Questionário de qualidade de vida da Universidade de Washington- UW-QOL

3. Inventário de Sintomas do M.D. Anderson (MDASI) - Head \& Neck

4. Questionário de Informação do Paciente (QIP)

5. Inventário de Preocupações dos Pacientes (IPP)

6. Protocolo de avaliação das expectativas (PAE) no início de seu tratamento ou o Protocolo de

Preenchimento das Expectativas (PPE), aos 6 e 12 meses após o tratamento.

Os questionários serão aplicados pela pesquisadora responsável ou por uma enfermeira treinada, que estarão à sua disposição para esclarecer qualquer dúvida que você tenha sobre os mesmos. A pesquisadora ou a enfermeira não influenciarão suas respostas. Caso você não seja alfabetizado os questionários serão lidos e suas respostas anotadas. . A duração estimada para a aplicação destes questionários é de aproximadamente 30 minutos. 


\section{BENEFÍCIOS E RISCOS POTENCIAIS DO ESTUDO}

Sua participação neste estudo não oferece qualquer risco ou desconforto. Os benefícios potenciais deste estudo incluem a possibilidade de aquisição de informações que contribuirão para um maior conhecimento sobre as expectativas e percepções reais dos pacientes oncológicos frente à doença e ao tratamento. Estas informações podem ser valorosas para a melhoria do seu processo de reabilitação, bem como beneficiar futuros pacientes.

\section{REGISTRO DOS PACIENTES}

Se você participar do estudo, seus registros ficarão disponíveis para o pesquisador responsável, as autoridades reguladoras e sanitárias pertinentes ou poderão ser publicados com fins científicos, porém sua identidade permanecerá confidencial.

\section{ESCLARECIMENTO SOBRE DISPONIBILIDADE PARA COMPENSAÇÃO PELA PARTICIPAÇÃO NA PESQUISA OU PARA DANOS RELACIONADOS À PESQUISA}

Item não considerado, pois não há riscos de danos ou desconforto ao paciente.

\section{DÚVIDAS}

Se quaisquer problemas ou pergunta surgirem a respeito do estudo, quanto a seus direitos como participante de uma pesquisa clínica ou a respeito de qualquer outro aspecto relacionado à pesquisa, você deverá entrar em contato com:

Fga Ivy Jungerman. Tel: 98262.0002 ou 3165.6202

Se o pesquisador principal não fornecer informações / esclarecimentos suficientes, por favor, entre em contato com o Comitê de Ética em Pesquisa em Seres Humanos da Fundação Antono Prudente - Hospital do Câncer - A.C. Camargo/SP pelo telefone (11)2189-5000, ramais 2069 ou 5020, de segunda-feira à quinta-feira das 7horas às 18:00 horas e sexta-feira das 7 horas às 16 horas.

\section{POR FAVOR, GUARDE ESTAS INFORMAÇÕES PARA CONSULTA FUTURA.}

\section{FORMULÁRIO DE CONSENTIMENTO DO PACIENTE}

Li e entendi este folheto de informações ao paciente e o formulário de consentimento livre e esclarecido composto de 2 páginas. Concordo voluntariamente em participar do estudo acima. Entendo que, mesmo após a assinatura do formulário de consentimento, posso deixar de participar do estudo a qualquer momento, sem dizer o motivo e sem detrimento ao meu tratamento presente ou futuro pelo médico. Recebi uma cópia deste folheto de informações ao paciente e formulário de consentimento para levar comigo.

Data:

Nome do paciente por extenso:

Assinatura do paciente:

Assinatura do pesquisador: 


\section{$[\mathrm{PCl}]$}

Aintree University Hospital WHS NHS Foundation Trust

Where quality matters

\section{Liverpool Head and Neck \\ sheet $1 / 2$ Patient Concerns Inventory $[\mathrm{PCl}]$}

Please choose from the list of issues you would specifically like to talk about in your consultation in clinic today. You can choose more than one option (tick boxes). Professionals you may wish to see.

Physical and functional
well-being:
$\square$ Activity
$\square$ Appetite
$\square$ Bowel habit
$\square$ Breathing
$\square$ Chewing/eating
$\square$ Coughing
$\square$ Dental health/teeth
$\square$ Dry mouth
$\square$ Energy levels
$\square$ Fatigue/tiredness
$\square$ Hearing
$\square$ Indigestion
$\square$ Mobility
$\square$ Mouth opening
$\square$ Mucus
$\square$ Nausea
$\square$ Pain in the head and neck
$\square$ Pain elsewhere
$\square$ Regurgitation
$\square$ Salivation
$\square$ Shoulder
$\square$ Sleeping
$\square$ Smell

Sore mouth

Swallowing

Swelling

$\square$ Taste

$\square$ Vomiting/sickness

$\square$ Weight

Treatment related:

$\square$ Cancer treatment

$\square$ Regret about treatment

$\square$ PEG tube

$\square$ Wound healing

Social care and social well-being:

$\checkmark$ Carer

Dependants/children

Financial benefits

$\square$ Home care/District nurse

$\square$ Lifestyle issues (smoking/ alcohol)

$\square$ Recreation

Relationships

Speech/voice/being understood

$\square$ Support for my family
Psychological, emotional and spriritual well-being:

$\square$ Appearance

$\square$ Angry

$\square$ Anxiety

$\square$ Coping

$\square$ Depression

$\square$ Fear of the cancer coming back

$\square$ Fear of adverse events

$\square$ Intimacy

$\square$ Memory

$\square$ Mood

$\square$ Self-esteem

$\square$ Sexuality

Spiritual/religious aspects

$\square$ Personality and temperament

Others (please state):

\section{NHS number:}

Date: 
Please choose from the list of issues you would specifically like to talk about in your consultation in clinic today. You can choose more than one option (tick boxes).

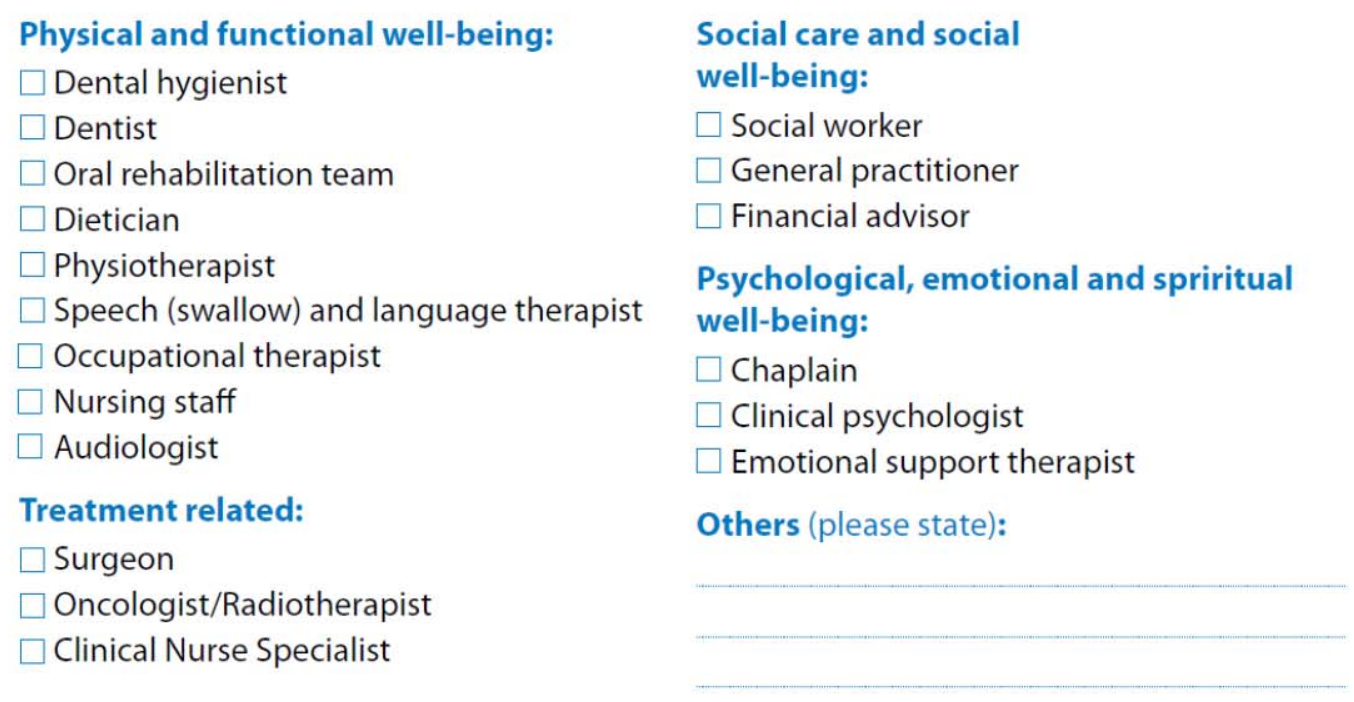

Thank you for your time. All information is confidential. We found PCI has helped patients express issues in their clinic. Rights for the Patient Concerns Inventory.

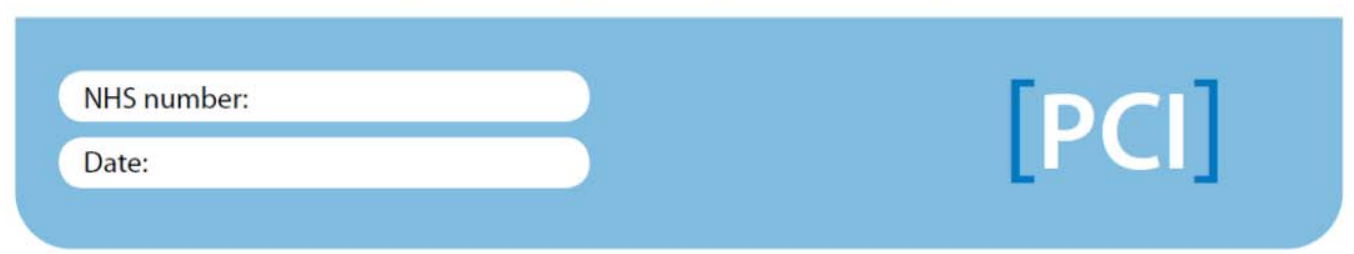


Anexo H - Termo de Autorização - University Hospital Aintree Foundation

WHS

NHS Trust

Professor Simon N Rogers FDS RCS FRCS MD

Consultant

Regional Head and Neck Unit

University Hospital Aintree Foundation Trust

Lower Lane, Liverpool L9 1 AE

Tel 01515295287 Fax 01515295288 Email snrogers@doctors.org.uk

Mrs Ivy Jungerman

Head and Neck Unit

Hospital A. C. Camargo,

São Paulo, Brazil.

$11^{\text {th }}$ May 2012

\section{Patient Concerns Inventory}

Dear Mrs Jungerman

I am delighted that you are able to undertake a clinical outcomes research project using the Patient Concerns Inventory (PCI). I fully support this collaboration. As you realise the copyright and intellectual property for the PCI remains with the University Hospital Aintree and Edge Hill University. However as long as the PCI is properly cited in the study itself, as well as in published papers you have permission to adapt and help validate the PCI in whatever way your research team feels appropriate.

We are currently using a 57-item measure which we are using in Liverpool over the next two to three years. After this time we might consider further changes but wish not to change it too frequently as it complicates assessment of utility. I attach a copy of our current PCI.

Yours sincerely

Simon N Rogers

http://www.patient-concerns-inventory.co.uk/PCI/Home.html

and

http://www.headandneckcancer.co.uk/For+professionals/Quality + of + Life $+\% 28 Q O L \% 29 /$ Pat ient+Concerns+Inventory.aspx 
Anexo I - Questionário de qualidade de vida da Universidade de Washington(UW-QOL v4)

Este questionário pergunta sobre sua saúde e qualidade de vida durante os últimos sete dias. Por favor responda a todas as questões marcando uma alternativa para cada questão.

1. Dor (marque uma alternativa [ ])

100 [ ] Eu não tenho dor

75 [ ] Há dor leve não necessitando de medicação

50 [ ] Eu tenho dor moderada, requerendo uso de medicação regularmente

25 [ ] Eu tenho dor severa controlada somente com medicamentos controlados

0 [ ] Eu tenho dor severa, não controlada por medicação

2. Aparência (marque uma alternativa [ ])

100 [ ] Não há mudança na minha aparência

75 [ ] A mudança na minha aparência é mínima

50 [ ] Minha aparência me incomoda, mas eu permaneço ativo

25 [ ] Eu me sinto desfigurado significativamente e limito minhas atividades devido a minha aparência

0 [ ] Eu não posso estar com outras pessoas devido a minha aparência

3. Atividade (marque uma alternativa [ ])

100 [ ] Eu estou tão ativo quanto sempre estive

75 [ ] Existem vezes em que não posso manter meu ritmo antigo, mas não frequentemente

50 [ ] Eu estou frequentemente cansado e tenho diminuído minhas atividades embora $\mathrm{eu}$ ainda saia de casa

25 [ ] Eu não saio de casa porque eu não tenho força

0 [ ] Eu geralmente fico na cama ou na cadeira e não saio de casa

4. Recreação (marque uma alternativa [ ])

100 [ ] Não há limitações para recreação em casa ou fora de casa

75 [ ] Há poucas coisas que eu não posso fazer, mas eu ainda saio de casa para me divertir

50 [ ] Há muitas vezes que eu gostaria de sair mais de casa, mas eu não estou bem para isso

25 [ ] Há limitação severa para o que eu posso fazer, geralmente eu fico em casa e assisto TV

0 [ ] Eu não posso fazer nada agradável

5.Deglutição (marque uma alternativa [ ])

100 [ ] Eu posso engolir tão bem como sempre

67 [ ] Eu não posso engolir algumas comidas sólidas

33 [ ] Eu posso engolir somente comidas líquidas

0 [ ] Eu não posso engolir porque desce errado e me sufoca 
6.Mastigação (marque uma alternativa [ ])

100 [ ] Eu posso mastigar tão bem como sempre

50 [ ] Eu posso comer alimentos sólidos leves mas não consigo mastigar algumas comidas

0 [ ] Eu não posso mastigar nem mesmo alimentos leves

7.Fala (marque uma alternativa [ ])

100 [ ] Minha fala é a mesma de sempre

67 [ ] Eu tenho dificuldade para dizer algumas palavras mas eu posso ser entendido mesmo ao telefone

33 [ ] Somente minha família e amigos podem me entender

0 [ ] Eu não sou entendido pelos outros

8. Ombro (marque uma alternativa [ ])

100 [ ] Eu não tenho problemas com meu ombro

67 [ ] Meu ombro é endurecido mas isto não afeta minha atividade ou força

33 [ ] Dor ou fraqueza em meu ombro me fizeram mudar meu trabalho

0 [ ] Eu não posso trabalhar devido problemas com meu ombro

9. Paladar (marque uma alternativa [ ])

100 [ ] Eu sinto sabor da comida normalmente

67 [ ] Eu sinto o sabor da maioria das comidas normalmente

33 [ ] Eu posso sentir o sabor de algumas comidas

0 [ ] Eu não sinto o sabor de nenhuma comida

10. Saliva (marque uma alternativa [ ])

100 [ ] Minha saliva é de consistência normal

67 [ ] Eu tenho menos saliva que o normal, mas ainda é o suficiente

33 [ ] Eu tenho muito pouca saliva

0 [ ] Eu não tenho saliva

11. Humor (marque uma alternativa [ ])

100 [ ] Meu humor é excelente e não foi afetado por causa do meu câncer

75 [ ] Meu humor é geralmente bom e é somente afetado por causa do meu câncer ocasionalmente

50 [ ] Eu não estou nem com bom humor nem deprimido por causa do meu câncer

25 [ ] Eu estou um pouco deprimido por causa do meu câncer

0 [ ] Eu estou extremamente deprimido por causa do meu câncer

12. Ansiedade (marque uma alternativa [ ] )

100 [ ] Eu não estou ansioso por causa do meu câncer

67 [ ] Eu estou um pouco ansioso por causa do meu câncer

33 [ ] Eu estou ansioso por causa do meu câncer

0 [ ] Eu estou muito ansioso por causa do meu câncer 
Quais problemas tem sido os mais importantes para você durante os últimos 7 dias? Marque [] em até 3 alternativas
[] Dor
[] Deglutição
[] Paladar
[] Aparência
[] Mastigação
[] Saliva
[] Atividade
[] Fala
[] Humor
[] Recreação
[] Ombro
[] Ansiedade

Questões gerais

Comparado com o mês antes de você desenvolver o câncer, como você classificaria sua qualidade de vida relacionada à saúde (marque uma alternativa: [ ])

[ ] Muito melhor

[ ] Um pouco melhor

[ ] Mais ou menos o mesmo

[ ] Um pouco pior

[ ] Muito pior

Em geral, você poderia dizer que sua qualidade de vida relacionada à saúde nos últimos 7 dias tem sido: (marque uma alternativa [ ])

[ ] Excelente

[ ] Muito boa

[ ] Boa

[ ] Média

[ ] Ruim

[ ] Muito ruim

De um modo geral a qualidade de vida inclui não somente saúde física e mental, mas também muitos outros fatores, tais como família, amigos, espiritualidade, atividades de lazer pessoal que são importantes para sua satisfação com a vida. Considerando tudo em sua vida que contribui para seu bem-estar pessoal, classifique a sua qualidade de vida em geral durante os últimos 7 dias. (marque uma alternativa: [ ])

[ ] Excelente

[ ] Muito boa

[ ] Boa

[ ] Média

[ ] Ruim

[ ] Muito ruim

Por favor descreva quaisquer outros problemas (médicos ou não médicos) que são importantes para sua qualidade de vida e que não tenham sido adequadamente mencionados pelas nossas perguntas (você pode anexar folhas adicionais se necessário). 
Anexo J - Versão final do Inventário de Preocupações dos Pacientes - IPP

Idade: _ـ Sexo: 1.Fem ( ) 2. Masc ( )

\begin{tabular}{|c|c|}
\hline \multicolumn{2}{|r|}{ Bem-estar Físico e Funciona } \\
\hline & ) Atividade Física \\
\hline & ) Apetite \\
\hline & ) Hábito Intestinal \\
\hline & ) Respiração \\
\hline & ) Mastigar/comer \\
\hline & ) Tosse \\
\hline & ) Saúde dental/dentes \\
\hline & ) Boca seca \\
\hline & ) Niveis de energia \\
\hline & ) Fadiga/cansaço \\
\hline & ) Audição \\
\hline & ) Indigestão \\
\hline & ) Mobilidade \\
\hline & ) Abertura de boca \\
\hline & ) Catarro/secreção \\
\hline & ) Náusea \\
\hline & ) Dor na cabeça e pescoço \\
\hline & ) dor em outro lugar \\
\hline & ) Regurgitação \\
\hline & ) Muita salivação \\
\hline & ) Ombros \\
\hline & ) Sono \\
\hline & ) Olfato (sentir cheiro) \\
\hline & ) Feridas na boca \\
\hline & ) Engolir \\
\hline & ) Inchaço \\
\hline & ) Paladar (sentir sabor) \\
\hline & ) Vômitos/mal-estar \\
\hline & ) Perda de peso \\
\hline
\end{tabular}

\section{Relacionadas ao Tratamento}

( ) Tratamento do câncer

( ) Arrependimento pelo tratamento

( ) Sonda para alimentação

( ) Cicatrização de feridas

Assistência e Bem-estar Social

( ) Cuidador

( ) Dependentes / crianças

( ) Benefícios financeiros

( ) Atendimento de profissionais à domicilio

( ) Estilo de vida (fumo/álcool)

( ) Recreação

( ) Relacionamentos

( ) Fala/voz/ser entendido

( ) Suporte para minha família
Bem-Estar Psicológico, Emocional e Espiritual

( ) Aparência

( ) Raiva

( ) Ansiedade

( ) Estratégias para enfrentar a doença e o tratamento

( ) Depressão

( ) Medo do câncer voltar

( ) Medo de acontecimentos desfavoráveis

( ) Intimidade

( ) Memória

( ) Humor

( ) Auto-estima

( ) Sexualidade

( ) Aspectos espirituais/religiosos

( ) Personalidade e temperamento

Outros (por favor, indique) 
Por favor, indique os profissionais com os quais você gostaria de conversar durante seu dia de consulta no hospital ou para os quais você gostaria de ser encaminhado. Você pode indicar mais de uma pessoa.

Marque um X

\section{Bem-estar Físico e Funcional \\ ( ) Dentista \\ ( ) Equipe de reabilitação oral \\ ( ) Nutricionista \\ ( ) Fisioterapeuta \\ ( ) Fonoaudiólogo \\ ( ) Terapeuta Ocupacional \\ ( ) Equipe de enfermagem}

\section{Relacionados ao Tratamento}

（） Cirurgião

( ) Oncologista / Radioterapeuta

( ) Enfermeira clínica especialista

\section{Assistência Social e Bem-estar \\ ( ) Assistente Social \\ ( ) Clínico Geral \\ ( ) Assessor financeiro \\ Bem-estar Psicológico, Emocional e Espiritual \\ ( ) Autoridade religiosa / líder da sua religião \\ ( ) Psiquiatra \\ ( ) Psicólogo}

Outros (por favor, indique): 
Anexo K - Escala de Ansiedade e Depressão - HADS

1. Nome:

2. RGH:

Marque com um $X$ a resposta que melhor corresponder a como você tem se sentindo na última semana. Não é preciso pensar muito, as respostas espontâneas têm mais valor do que aquelas que se pensa muito. Marque apenas uma resposta a cada pergunta.

A1 1. Eu me sinto tenso ou contraído
3 ( ) A maior parte do tempo
2 ( ) Boa parte do tempo
$1 \quad$ ( ) De vez em quando
$0 \quad$ ( ) Nunca

D1 2. Eu ainda sinto gosto pelas mesmas coisas de antes
0 ( ) Sim, do mesmo jeito que antes
1 ( ) Não tanto quanto antes
2 ( ) Só um pouco
3 ( ) Já não sinto mais prazer em nada

A2 3. Eu sinto uma espécie de medo como se alguma coisa ruim fosse acontecer
3 ( ) Sim, de um jeito muito forte
2 ( ) Sim, mas não tão forte
1 ( ) Um pouco, mas isso não me preocupa
$0 \quad$ ( ) Não sinto nada disso

D2 4. Dou risada e me divirto quando vejo coisas engraçadas
0 ( ) Sim, do mesmo jeito que antes
1 ( ) Atualmente um pouco menos
2 ( ) Atualmente bem menos
3 ( ) Não consigo mais

A3 5. Estou com a cabeça cheia de preocupações

$\begin{array}{ll}3 & \text { ( ) A maior parte do tempo } \\ 2 & \text { ( ) Boa parte do tempo } \\ 1 & \text { ( ) De vez em quando } \\ 0 & \text { ( ) Nunca }\end{array}$

D3 6. Eu me sinto alegre
3 ( ) Nunca
2 ( ) Poucas vezes
$1 \quad$ ( ) Muitas vezes
0 ( ) A maior parte do tempo

A4 7. Consigo ficar sentado a vontade e me sentir relaxado

$\begin{array}{ll}0 & \text { ( ) Sim, quase sempre } \\ 1 & \text { ( ) Muitas vezes } \\ 2 & \text { ( ) Poucas vezes } \\ 3 & \text { ( ) Nunca }\end{array}$


D4 8. Eu estou lento para pensar e fazer as coisas

$\begin{array}{ll}3 & \text { ( ) Quase sempre } \\ 2 & \text { ( ) Muitas vezes } \\ 1 & \text { ( ) De vez em quando } \\ 0 & \text { ( ) Nunca }\end{array}$

A5 9. Eu tenho uma sensação ruim de medo com um frio na barriga ou um aperto no estômago

0

$1 \quad$ ( ) De vez em quando

$2 \quad($ ) Muitas vezes

$3 \quad($ ) Quase sempre

D5 10. Eu perdi o interesse em cuidar da minha aparência
3 ( ) Completamente
2 ( ) Não estou mais me cuidando como deveria
1 ( ) Talvez não tanto quando antes
0 ( ) Me cuido do mesmo jeito que antes

A6 11. Eu me sinto inquieto como se eu não pudesse ficar parado em lugar nenhum
3 ( ) Sim, demais
2 ( ) Bastante
$1 \quad$ ( ) Um pouco
0 ( ) Não me sinto assim

D6 12. Fico esperando animado as coisas boas que estão por vir
0 ( ) Do mesmo jeito que antes
1 ( ) Um pouco menos do que antes
2 ( ) Bem menos que antes
$3 \quad($ ) Quase nunca

A7 13. De repente tenho a sensação de entrar em pânico
3 ( ) A quase todo momento
2 ( ) Várias vezes
1 ( ) De vez em quando
$0 \quad$ ( ) Não sinto isso

D7 14. Consigo sentir prazer quando assisto um bom programa de TV, rádio ou quando leio alguma coisa

$\begin{array}{ll}0 & \text { ( ) Quase sempre } \\ 1 & \text { ( ) Várias vezes } \\ 2 & \text { ( ) Poucas vezes } \\ 3 & \text { ( }) \text { Quase nunca }\end{array}$


Anexo L - Inventário de Sintomas do M.D. Anderson (MDASI) - Head \& NeckParte I

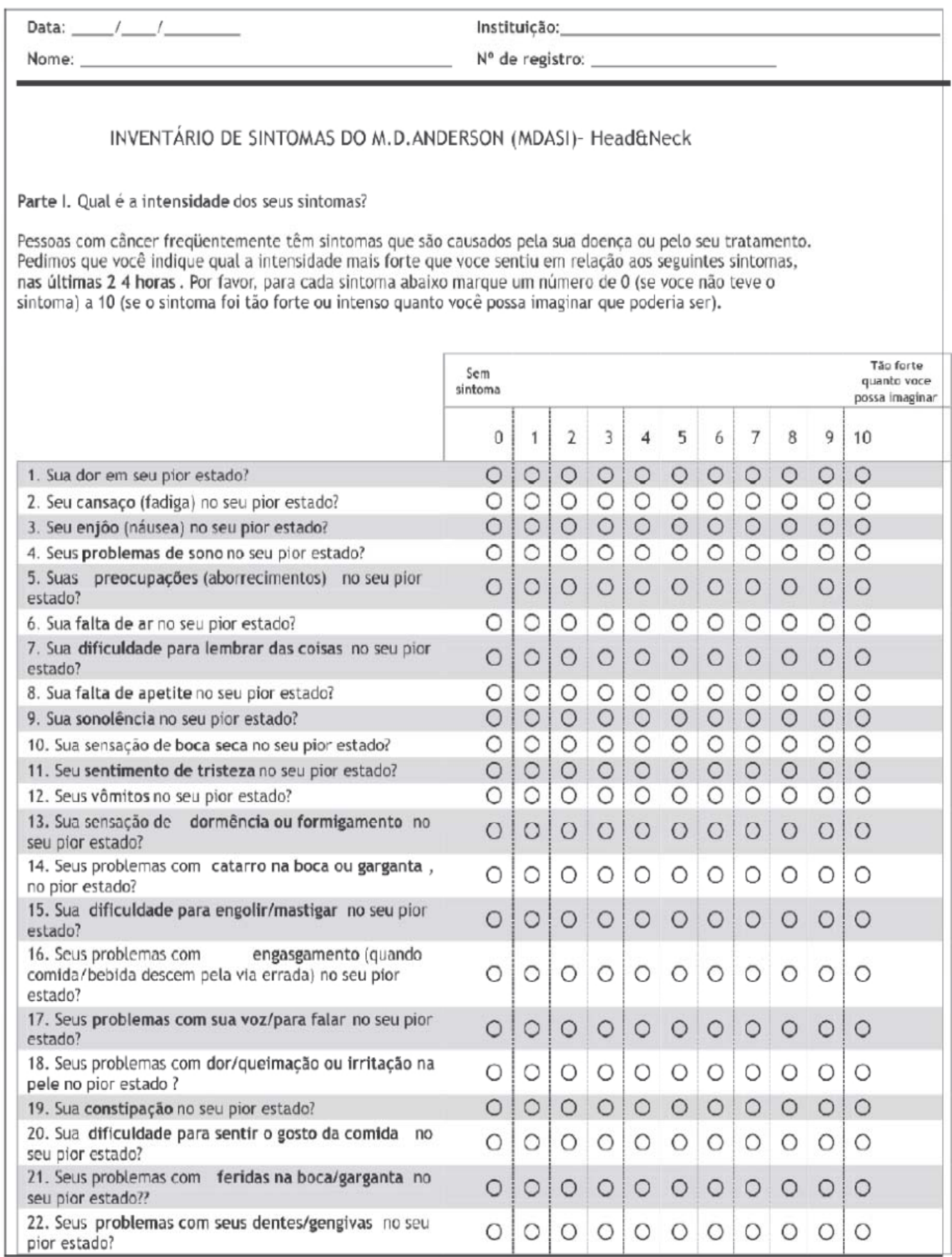


Anexo M - Questionário de Informação do Paciente (QIP)

Nome: Data:

RGH:

As pessoas diferem no que diz respeito a obter detalhar sobre uma doença séria. Estamos tentando compreender melhor este tema para aprimorar as informações que os nossos pacientes recebem.

Seção A:

Qual afirmação descreve melhor a sua atitude no que diz respeito à informação sobre a sua doença? Por favor, escolha apenas uma afirmação:

1. Não quero saber detalhes; deixo que o médico decida ( )

2. Quero informações adicionais apenas quando são boas notícias ( )

3. Quero toda informação possível, boa ou má （ ）

\section{Seção B:}

Esta é uma lista de tipos diferentes e informações sobre doenças e tratamento. Marque apenas um número para cada afirmação.

1. É necessário saber esta informação de qualquer maneira

2. Não é necessário ter esta informação.

3. É uma informação necessária, mas não gostaria de ter.

- Se é ou não câncer

( )

- Qual é o nome médico específico da doença ( )

- Quando você está em tratamento, saber como está progredindo, semana a semana ( )

- Quais são as chances de cura ( )

- Quais são todos os tratamentos possíveis ( )

- Quais são todos os efeitos colaterais do tratamento ( )

- Como o tratamento funciona para tratar a doença ( )

\section{Seção C:}

Gostaríamos de saber se você tem preferência quanto à pessoa que o informou sobre a sua doença na primeira vez que lhe foi explicada. Você gostaria que a informação tivesse sido dada por:

1. Seu clínico geral ( )

2. O médico especialista do hospital ( )

3. Uma enfermeira ( )

4. Sem preferência ( )

5. Um familiar ( )

6. Outros ( ) 
Anexo N - Protocolo de Avaliação das Expectativas (PAE)

Nome: RGH:

Pacientes com câncer geralmente criam expectativas em relação aos diversos aspectos de sua vida que poderão ser afetados pela doença e/ou pelo tratamento. Gostaríamos de saber se suas expectativas sobre os assuntos abaixo são positivas ou negativas Por favor, escolha o número que indica quais são suas expectativas futuras para cada assunto abaixo.

\section{0 - não se aplica \\ 1 - não tenho expectativas \\ 2 - tenho expectativas ruins \\ 3 - tenho boas expectativas}

\section{Bem-estar Físico e Funcional}

( ) Atividade Física

( ) Apetite

( ) Hábito Intestinal

( ) Respiração

( ) Mastigar/comer

( ) Tosse

( ) Saúde dental/dentes

( ) Boca seca

( ) Niveis de energia

( ) Fadiga/cansaço

( ) Audição

( ) Indigestão

( ) Mobilidade

( ) Abertura de boca

( ) Catarro/secreção

( ) Náusea

( ) Dor na cabeça e pescoço

( ) dor em outro lugar

( ) Regurgitação

( ) Muita salivação

( ) Ombros

( ) Sono

( ) Olfato (sentir cheiro)

( ) Feridas na boca

( ) Engolir

( ) Inchaço

( ) Paladar (sentir sabor)

( ) Vômitos/ mal-estar

( ) Perda de peso

\begin{tabular}{|c|c|}
\hline \multicolumn{2}{|r|}{ Relacionadas ao Tratamento } \\
\hline( & ) Tratamento do câncer \\
\hline( & ) Arrependimento pelo tratamento \\
\hline( & ) Sonda para alimentação \\
\hline( & ) Cicatrização de feridas \\
\hline & ssistência e Bem-estar Social \\
\hline( & ) Cuidador \\
\hline( & ) Dependentes / crianças \\
\hline( & ) Benefícios financeiros \\
\hline( & ) Atendimento de profissionais \\
\hline & à domicílio \\
\hline( & ) Estilo de vida (fumo/álcool) \\
\hline( & ) Recreação \\
\hline( & ) Relacionamentos \\
\hline( & ) Fala/voz/ser entendido \\
\hline( & ) Suporte para minha família \\
\hline
\end{tabular}

Bem-Estar Psicológico, Emocional e Espiritual

( ) Aparência

( ) Raiva

( ) Ansiedade

( ) Estratégias para enfrentar a doença e o tratamento

( ) Depressão

( ) Medo do câncer voltar

( ) Medo de acontecimentos desfavoráveis

( ) Intimidade

( ) Memória

( ) Humor

( ) Auto-estima

( ) Sexualidade

( ) Aspectos espirituais/religiosos

() Personalidade e temperamento

Outros (por favor, indique) 
Anexo $\mathrm{O}$ - Protocolo de Preenchimento das Expectativas (PPE)

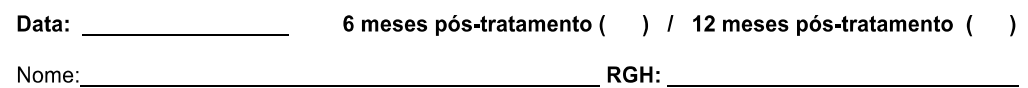

Gostariamos de saber como foi a a experiência que você teve com cada um dos assuntos abaixo (para cada assunto, escolha apenas um número )

\section{0 - não se aplica}

1 - pior do que eu esperava

2 - igual ao que eu esperava

3 - melhor do que eu esperava

\begin{tabular}{|c|c|}
\hline \multicolumn{2}{|c|}{ Bem-estar Físico e Funcional } \\
\hline ( & ) Atividade Física \\
\hline( & ) Apetite \\
\hline( & ) Hábito Intestinal \\
\hline ( & ) Respiração \\
\hline( & ) Mastigar/comer \\
\hline( & ) Tosse \\
\hline( & ) Saúde dental/dentes \\
\hline ( & ) Boca seca \\
\hline( & ) Níveis de energia \\
\hline( & ) Fadiga/cansaço \\
\hline( & ) Audição \\
\hline( & ) Indigestão \\
\hline( & ) Mobilidade \\
\hline( & ) Abertura de boca \\
\hline( & ) Catarro/secreção \\
\hline( & ) Náusea \\
\hline( & ) Dor na cabeça e pescoço \\
\hline ( & ) dor em outro lugar \\
\hline ( & ) Regurgitação \\
\hline( & ) Muita salivação \\
\hline( & ) Ombros \\
\hline( & ) Sono \\
\hline( & ) Olfato (sentir cheiro) \\
\hline( & ) Feridas na boca \\
\hline( & ) Engolir \\
\hline( & ) Inchaço \\
\hline( & ) Paladar (sentir sabor) \\
\hline( & ) Vômitos/ mal-estar \\
\hline( & ) Perda de peso \\
\hline
\end{tabular}

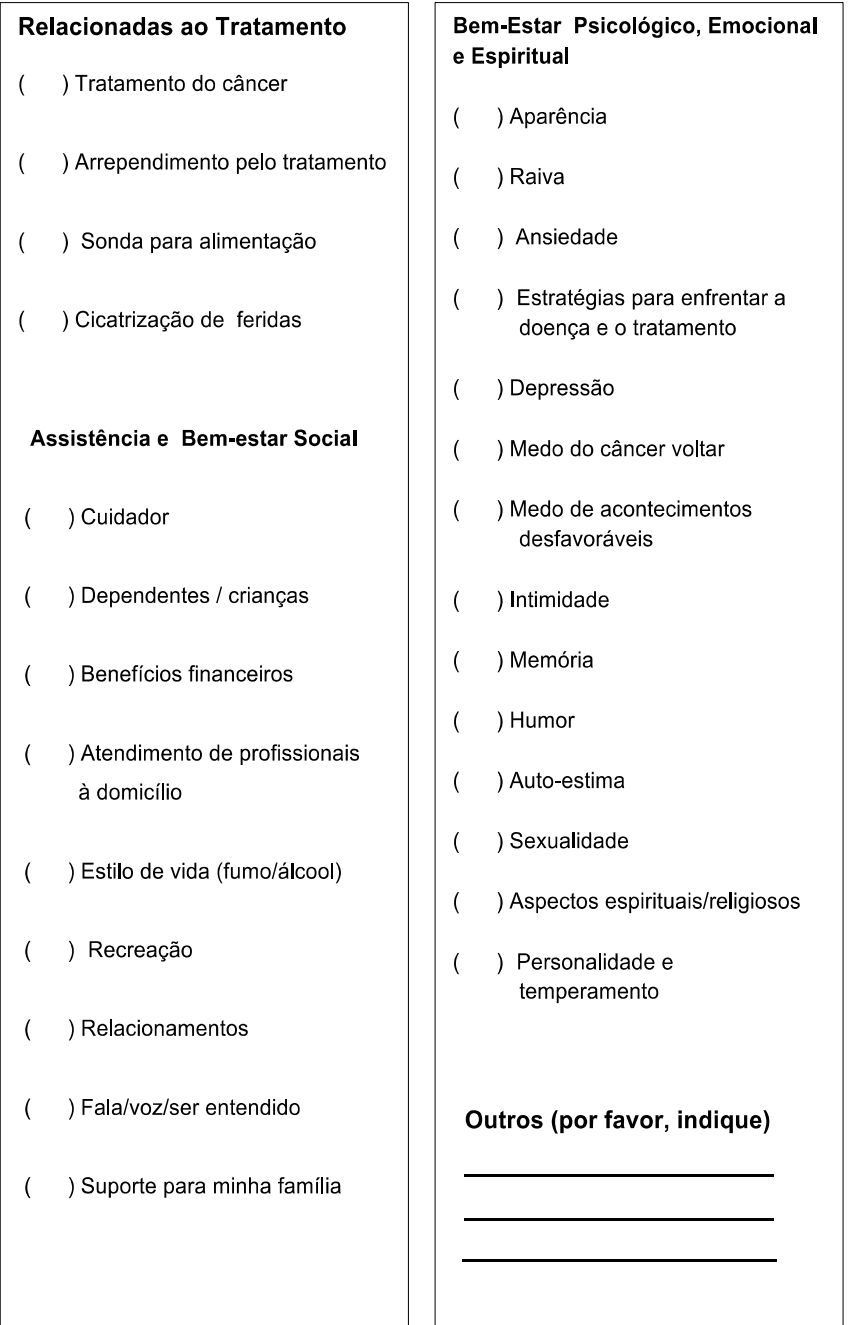


Durante seu tratamento, talvez você tenha conversado com alguns dos profissionais citados abaixo. Gostaríamos de saber se cada um deles preencheu positivamente ou negativamente suas expectativas (em termos de qualidade, quantidade e clareza das informações dadas). Por favor, indique apenas um dos números abaixo para cada profissional:

\section{0- não conversei com este profissional}

1- preencheu pouco minhas expectativas

2- preencheu razoavelmente minha expectativas

3- preencheu muito minhas expectativas

Bem-estar Físico e Funcional
( ) Dentista
( ) Equipe de reabilitação oral
( ) Nutricionista
( ) Fisioterapeuta
( ) Fonoaudiólogo
( ) Terapeuta Ocupacional
( ) Equipe de enfermagem
Relacionados ao Tratamento

Assistência Social e Bem-estar

( ) Assistente Social

( ) Clínico Geral

( ) Assessor financeiro

Bem-estar Psicológico, Emocional e Espiritual

( ) Autoridade Religiosa / líder da sua religião

( ) Psiquiatra

( ) Psicólogo

Outros (por favor, indique):

Enfermeira clínica especialista 
Anexo P - Medidas de tendência central e de variabilidade dos domínios do $U W$ QOL, nos momentos pré-tratamento $(\mathrm{N}=104), 6$ meses $(\mathrm{N}=80)$ e 12 meses $(\mathrm{N}=62)$ após o diagnóstico

\begin{tabular}{|c|c|c|c|c|c|}
\hline Domínios & Momento & $\mathbf{n}$ & média (dp) & mediana & mín- máx \\
\hline \multirow[t]{3}{*}{ Dor } & pré & 104 & $66,1(29,1)$ & 75 & $0-100$ \\
\hline & 6 meses & 80 & $82,5(25,3)$ & 100 & $0-100$ \\
\hline & 12 meses & 62 & $88,7(20,6)$ & 100 & $25-100$ \\
\hline \multirow[t]{3}{*}{ Atividade } & pré & 104 & $82,5(24,1)$ & 100 & $0-100$ \\
\hline & 6 meses & 80 & $74,7(27,1)$ & 75 & $0-100$ \\
\hline & 12 meses & 62 & $85,1(21,5)$ & 100 & $0-100$ \\
\hline \multirow[t]{3}{*}{ Recreação } & pré & 104 & $83,7(24,3)$ & 100 & $25-100$ \\
\hline & 6 meses & 80 & $76,9(25,7)$ & 75 & $25-100$ \\
\hline & 12 meses & 62 & $87,1(22,1)$ & 100 & $25-100$ \\
\hline \multirow[t]{3}{*}{ Ombros } & pré & 104 & $95,5(16,8)$ & 100 & $0-100$ \\
\hline & 6 meses & 80 & $90,4(23,9)$ & 100 & $0-100$ \\
\hline & 12 meses & 62 & $93,6(16,9)$ & 100 & $33-100$ \\
\hline \multirow[t]{3}{*}{ Humor } & pré & 104 & $76,4(30,3)$ & 100 & $0-100$ \\
\hline & 6 meses & 80 & $82,8(25,3)$ & 100 & $25-100$ \\
\hline & 12 meses & 62 & $89,1(20,1)$ & 100 & $25-100$ \\
\hline \multirow[t]{3}{*}{ Ansiedade } & pré & 104 & $61,6(35,1)$ & 67 & $0-100$ \\
\hline & 6 meses & 80 & $70,2(33,7)$ & 67 & $0-100$ \\
\hline & 12 meses & 62 & $77,5(28,1)$ & 83,5 & $0-100$ \\
\hline \multirow[t]{3}{*}{ Aparência } & pré & 104 & $87,7(20,0)$ & 100 & $0-100$ \\
\hline & 6 meses & 80 & $85,3(20,6)$ & 100 & $25-100$ \\
\hline & 12 meses & 62 & $85,5(24,6)$ & 100 & $0-100$ \\
\hline \multirow[t]{3}{*}{ Deglutição } & pré & 104 & $80,1(28,5)$ & 100 & $0-100$ \\
\hline & 6 meses & 80 & $73,0(31,5)$ & 67 & $0-100$ \\
\hline & 12 meses & 62 & $79,7(24,4)$ & 100 & $0-100$ \\
\hline \multirow[t]{3}{*}{ Mastigação } & pré & 104 & $72,1(38,1)$ & 100 & $0-100$ \\
\hline & 6 meses & 80 & $58,1(39,3)$ & 50 & $0-100$ \\
\hline & 12 meses & 62 & $72,6(34,7)$ & 100 & $0-100$ \\
\hline \multirow[t]{3}{*}{ Fala } & pré & 104 & $85,6(24,5)$ & 100 & $0-100$ \\
\hline & 6 meses & 80 & $81,0(21,7)$ & 83,5 & $0-100$ \\
\hline & 12 meses & 62 & $82,4(23,1)$ & 100 & $0-100$ \\
\hline \multirow[t]{3}{*}{ Paladar } & pré & 104 & $87,2(26,8)$ & 100 & $0-100$ \\
\hline & 6 meses & 80 & $59,1(38,7)$ & 67 & $0-100$ \\
\hline & 12 meses & 62 & $74,2(33,3)$ & 100 & $0-100$ \\
\hline \multirow[t]{3}{*}{ Saliva } & pré & 104 & $95,2(15,0)$ & 100 & $33-100$ \\
\hline & 6 meses & 80 & $70,0(31,3)$ & 67 & $0-100$ \\
\hline & 12 meses & 62 & $71,0(33,4)$ & 83,5 & $0-100$ \\
\hline \multirow[t]{3}{*}{ QV Global } & pré & 104 & $81,4(14,5)$ & 84,7 & $33,9-100$ \\
\hline & 6 meses & 80 & $75,3(15,8)$ & 77 & $30,6-100$ \\
\hline & 12 meses & 62 & $82,2(13,2)$ & 83,8 & $47,3-100$ \\
\hline
\end{tabular}

UW-QOL: Questionário de qualidade de vida da Universidade de Washington; dp: desvio padrão; mín-máx: mínimo-máximo; QV: qualidade de vida 
Anexo Q - Frequência e porcentagem de pacientes, de acordo com a intensidade de sintomas, no momento pré-tratamento (N=104)

\begin{tabular}{|c|c|c|c|c|c|c|c|c|c|c|c|}
\hline \multirow[b]{3}{*}{ Sintomas / N(\%) } & \multicolumn{11}{|c|}{ Pré- tratamento } \\
\hline & \multicolumn{11}{|c|}{ Intensidade } \\
\hline & $\mathbf{0}$ & 1 & 2 & 3 & 4 & 5 & 6 & 7 & 8 & 9 & 10 \\
\hline Dor & $39(37,5)$ & $4(3,8)$ & $12(11,5)$ & $3(2,9)$ & $6(5,8)$ & $8(7,7)$ & $15(14,4)$ & $1(1,0)$ & $8(7,7)$ & $6(5,8)$ & $2(1,9)$ \\
\hline Cansaço (fadiga) & $59(56,7)$ & $4(3,8)$ & $3(2,9)$ & $5(4,8)$ & $7(6,7)$ & $8(7,7)$ & $8(7,7)$ & $3(2,9)$ & $3(2,9)$ & $3(2,9)$ & $1(1,0)$ \\
\hline Enjôo (náusea) & $95(91,4)$ & $2(1,9)$ & $1(1,0)$ & $4(3,8)$ & 0 & 0 & $2(1,9)$ & 0 & 0 & 0 & 0 \\
\hline Problemas de sono & $53(51,0)$ & $3(2,9)$ & $9(8,7)$ & $5(4,8)$ & $5(4,8)$ & $8(7,6)$ & $7(6,7)$ & $5(4,8)$ & $3(2,9)$ & $4(3,9)$ & $2(1,9)$ \\
\hline Preocupações (aborrecimentos) & $44(42,3)$ & $5(4,8)$ & $7(6,7)$ & $6(5,8)$ & $7(6,7)$ & $6(5,8)$ & $13(12,5)$ & $4(3,8)$ & $6(5,8)$ & $5(4,8)$ & $1(1,0)$ \\
\hline Falta de ar & $87(83,6)$ & $2(1,9)$ & 0 & $3(2,9)$ & $2(1,9)$ & $3(2,9)$ & $3(2,9)$ & 0 & $1(1,0)$ & $3(2,9)$ & 0 \\
\hline Dificuldade para lembrar das coisas & $76(73,1)$ & $3(2,9)$ & $5(4,8)$ & $3(2,9)$ & $2(1,9)$ & $1(1,0)$ & $11(10,5)$ & $1(1,0)$ & 0 & $2(1,9)$ & 0 \\
\hline Falta de apetite & $76(73,1)$ & 0 & $2(1,9)$ & $7(6,7)$ & $4(3,8)$ & $1(1,0)$ & $7(6,7)$ & $3(2,9)$ & $1(1,0)$ & $2(1,9)$ & $1(1,0)$ \\
\hline Sonolência & $67(64,4)$ & $3(2,8)$ & $5(4,8)$ & $3(2,9)$ & $4(3,9)$ & $4(3,9)$ & $8(7,7)$ & $2(1,9)$ & $3(2,9)$ & $4(3,8)$ & $1(1,0)$ \\
\hline Sensação de boca seca & $69(66,4)$ & $1(1,0)$ & $5(4,8)$ & $1(1,0)$ & $6(5,7)$ & $7(6,7)$ & $10(9,6)$ & 0 & $1(1,0)$ & $3(2,8)$ & $1(1,0)$ \\
\hline Sentimento de tristeza & $62(59,6)$ & $7(6,7)$ & $4(3,9)$ & $7(6,7)$ & $4(3,9)$ & $4(3,9)$ & $8(7,6)$ & $3(2,9)$ & $2(1,9)$ & $2(1,9)$ & $1(1,0)$ \\
\hline Vômitos & $101(97,1)$ & 0 & 0 & 0 & 0 & 0 & $1(1,0)$ & 0 & 0 & $2(1,9)$ & 0 \\
\hline Sensação de dormência/formigamento & $76(73,1)$ & 0 & $5(4,8)$ & $5(4,8)$ & $5(4,8)$ & $3(2,8)$ & $5(4,8)$ & $2(1,9)$ & $1(1,0)$ & $1(1,0)$ & $1(1,0)$ \\
\hline Catarro na boca ou garganta & $62(59,6)$ & $1(1,0)$ & $8(7,7)$ & $5(4,8)$ & $3(2,9)$ & $4(3,9)$ & $7(6,7)$ & $2(1,9)$ & $2(1,9)$ & $8(7,7)$ & $2(1,9)$ \\
\hline Dificuldade para engolir/mastigar & $56(53,9)$ & $2(1,9)$ & $13(12,5)$ & $5(4,8)$ & $1(1,0)$ & 0 & $9(8,7)$ & $5(4,8)$ & $4(3,9)$ & $6(5,7)$ & $3(2,8)$ \\
\hline Engasgamento & $84(80,7)$ & $1(1,0)$ & $4(3,8)$ & $4(3,8)$ & 0 & 0 & $5(4,8)$ & $1(1,0)$ & $1(1,0)$ & $3(2,9)$ & $1(1,0)$ \\
\hline Problemas com a voz/ para falar & $62(59,6)$ & $2(1,9)$ & $10(9,6)$ & $1(1,0)$ & $7(6,7)$ & $2(1,9)$ & $6(5,8)$ & $6(5,8)$ & 0 & $7(6,7)$ & $1(1,0)$ \\
\hline Dor/queimação ou irritação na pele & $85(81,6)$ & $1(1,0)$ & $2(1,9)$ & $5(4,8)$ & $1(1,0)$ & $1(1,0)$ & $4(3,8)$ & $1(1,0)$ & $1(1,0)$ & $1(1,0)$ & $2(1,9)$ \\
\hline Constipação & $84(80,8)$ & 0 & $8(7,7)$ & 0 & $1(1,0)$ & $2(1,9)$ & $6(5,7)$ & $1(1,0)$ & 0 & 0 & $2(1,9)$ \\
\hline Dificuldade para sentir gosto da comida & $81(77,9)$ & $2(1,9)$ & $3(2,9)$ & 0 & $2(1,9)$ & $1(1,0)$ & $7(6,7)$ & $2(1,9)$ & $1(1,0)$ & $3(2,9)$ & $2(1,9)$ \\
\hline Feridas na boca/garganta & $65(62,5)$ & $1(1,0)$ & $14(13,5)$ & 0 & 0 & $1(1,0)$ & $7(6,6)$ & $2(1,9)$ & $3(2,9)$ & $5(4,8)$ & $6(5,8)$ \\
\hline Problemas com dentes/gengivas & $73(70,2)$ & 0 & $9(8,7)$ & $2(1,9)$ & $3(2,9)$ & $2(1,9)$ & $7(6,7)$ & $2(1,9)$ & $1(1,0)$ & $3(2,9)$ & $2(1,9)$ \\
\hline
\end{tabular}


Anexo R - Frequência e porcentagem de pacientes, de acordo com a intensidade de sintomas, aos 6 meses após o diagnóstico (N=80)

\begin{tabular}{|c|c|c|c|c|c|c|c|c|c|c|c|}
\hline \multirow[b]{3}{*}{ Sintomas / N(\%) } & \multicolumn{11}{|c|}{6 meses } \\
\hline & \multicolumn{11}{|c|}{ Intensidade } \\
\hline & 0 & 1 & 2 & 3 & 4 & 5 & 6 & 7 & 8 & 9 & 10 \\
\hline Dor & $59(73,7)$ & $2(2,5)$ & $2(2,5)$ & $3(3,8)$ & $2(2,5)$ & $1(1,3)$ & $7(8,7)$ & $2(2,5)$ & 0 & $2(2,5)$ & 0 \\
\hline Cansaço (fadiga) & $43(53,8)$ & $5(6,2)$ & 0 & $2(2,5)$ & $8(10,0)$ & $7(8,7)$ & $12(15,0)$ & 0 & 0 & $1(1,3)$ & $2(2,5)$ \\
\hline Enjôo (náusea) & $67(83,7)$ & 0 & $1(1,3)$ & $2(2,5)$ & $2(2,5)$ & $2(2,5)$ & $3(3,7)$ & $1(1,3)$ & $1(1,3)$ & $1(1,2)$ & 0 \\
\hline Problemas de sono & $54(67,4)$ & $2(2,5)$ & 0 & $2(2,5)$ & $4(5,0)$ & $4(5,0)$ & $8(10,0)$ & $1(1,3)$ & $2(2,5)$ & $3(3,8)$ & 0 \\
\hline Preocupações (aborrecimentos) & $40(50,0)$ & $4(5,0)$ & $3(3,7)$ & $7(8,7)$ & $3(3,7)$ & $8(10,0)$ & $9(11,3)$ & $3(3,8)$ & 0 & $3(3,8)$ & 0 \\
\hline Falta de ar & $70(87,5)$ & 0 & 0 & $2(2,5)$ & $3(3,8)$ & $2(2,5)$ & $3(3,7)$ & 0 & 0 & 0 & 0 \\
\hline Dificuldade para lembrar das coisas & $60(75,0)$ & $3(3,7)$ & 0 & $3(3,7)$ & $3(3,7)$ & 0 & $5(6,3)$ & $4(5,0)$ & $1(1,3)$ & $1(1,3)$ & 0 \\
\hline Falta de apetite & $53(66,3)$ & $2(2,5)$ & $5(6,2)$ & $5(6,2)$ & $3(3,7)$ & $2(2,5)$ & $3(3,7)$ & 0 & $1(1,3)$ & $5(6,3)$ & $1(1,3)$ \\
\hline Sonolência & $46(57,5)$ & $3(3,8)$ & 0 & $4(5,0)$ & $7(8,7)$ & $4(5,0)$ & $5(6,3)$ & $1(1,2)$ & $2(2,5)$ & $8(10,0)$ & 0 \\
\hline Sensação de boca seca & $29(36,3)$ & $4(5,0)$ & $10(12,5)$ & $2(2,5)$ & $3(3,7)$ & $5(6,3)$ & $14(17,5)$ & $3(3,7)$ & $4(5,0)$ & $4(5,0)$ & $2(2,5)$ \\
\hline Sentimento de tristeza & $56(70,0)$ & $6(7,5)$ & $4(5,0)$ & $4(5,0)$ & $2(2,5)$ & $2(2,5)$ & $2(2,5)$ & 0 & $2(2,5)$ & $1(1,3)$ & $1(1,2)$ \\
\hline Vômitos & $75(93,7)$ & 0 & $1(1,3)$ & 0 & $1(1,3)$ & 0 & $1(1,3)$ & 0 & $1(1,2)$ & $1(1,2)$ & 0 \\
\hline Sensação de dormência/formigamento & $61(76,2)$ & $1(1,2)$ & 0 & $5(6,3)$ & $3(3,8)$ & $2(2,5)$ & $1(1,2)$ & $3(3,8)$ & 0 & $4(5,0)$ & 0 \\
\hline Catarro na boca ou garganta & $34(42,5)$ & $4(5,0)$ & $3(3,7)$ & $5(6,2)$ & $5(6,2)$ & $5(6,2)$ & $10(12,5)$ & $7(8,8)$ & $1(1,3)$ & $5(6,3)$ & $1(1,3)$ \\
\hline Dificuldade para engolir/mastigar & $28(35,0)$ & $3(3,7)$ & $5(6,2)$ & $3(3,7)$ & $4(5,0)$ & $8(10,0)$ & $11(13,7)$ & $5(6,3)$ & $1(1,3)$ & $7(8,8)$ & $5(6,3)$ \\
\hline Engasgamento & $65(81,3)$ & 0 & 0 & $2(2,5)$ & $6(7,5)$ & $3(3,7)$ & $4(5,0)$ & 0 & 0 & 0 & 0 \\
\hline Problemas com a voz/ para falar & $41(51,3)$ & $4(5,0)$ & $2(2,5)$ & $7(8,8)$ & $2(2,5)$ & $4(5,0)$ & $10(12,5)$ & $2(2,5)$ & $2(2,5)$ & $3(3,8)$ & $3(3,6)$ \\
\hline Dor/queimação ou irritação na pele & $60(75,0)$ & 0 & $2(2,5)$ & $5(6,3)$ & $4(5,0)$ & 0 & $7(8,8)$ & $1(1,2)$ & $1(1,2)$ & 0 & 0 \\
\hline Constipação & $61(76,2)$ & 0 & $4(5,0)$ & $1(1,3)$ & $2(2,5)$ & $1(1,3)$ & $7(8,8)$ & $2(2,5)$ & $1(1,2)$ & $1(1,2)$ & 0 \\
\hline Dificuldade para sentir gosto da comida & $35(43,7)$ & $2(2,5)$ & $15(18,7)$ & $3(3,7)$ & $3(3,7)$ & $5(6,2)$ & $7(8,8)$ & $1(1,3)$ & $3(3,8)$ & $5(6,3)$ & $1(1,3)$ \\
\hline Feridas na boca/garganta & $59(73,8)$ & $2(2,5)$ & $5(6,3)$ & $2(2,5)$ & $3(3,7)$ & 0 & $4(5,0)$ & $2(2,5)$ & 0 & $3(3,7)$ & 0 \\
\hline Problemas com dentes/gengivas & $48(60,0)$ & $3(3,7)$ & $8(10,0)$ & $4(5,0)$ & $4(5,0)$ & 0 & $5(6,3)$ & $1(1,3)$ & 0 & $7(8,7)$ & 0 \\
\hline
\end{tabular}


Anexo S - Frequência e porcentagem de pacientes, de acordo com a intensidade de sintomas, aos 12 meses após o diagnóstico (N=62)

\begin{tabular}{|c|c|c|c|c|c|c|c|c|c|c|c|}
\hline \multirow[b]{3}{*}{ Sintomas / N(\%) } & \multicolumn{11}{|c|}{12 meses } \\
\hline & \multicolumn{11}{|c|}{ Intensidade } \\
\hline & $\mathbf{0}$ & 1 & 2 & 3 & 4 & 5 & 6 & 7 & 8 & 9 & 10 \\
\hline Dor & $43(69,4)$ & $6(9,7)$ & 0 & $2(3,2)$ & $2(3,2)$ & $1(1,6)$ & $5(8,1)$ & $2(3,2)$ & 0 & $1(1,6)$ & 0 \\
\hline Cansaço (fadiga) & $42(67,7)$ & $6(9,8)$ & $1(1,6)$ & $3(4,9)$ & $2(3,2)$ & $2(3,2)$ & $2(3,2)$ & $1(1,6)$ & 0 & $1(1,6)$ & $2(3,2)$ \\
\hline Enjôo (náusea) & $57(91,9)$ & $1(1,6)$ & $1(1,6)$ & $2(3,3)$ & 0 & 0 & $1(1,6)$ & 0 & 0 & 0 & 0 \\
\hline Problemas de sono & $44(71,0)$ & $1(1,6)$ & $3(4,8)$ & $3(4,8)$ & $4(6,6)$ & $1(1,6)$ & $2(3,2)$ & $1(1,6)$ & 0 & $3(4,8)$ & 0 \\
\hline Preocupações (aborrecimentos) & $31(50,0)$ & $8(12,9)$ & $3(4,8)$ & $5(8,1)$ & $3(4,8)$ & $1(1,7)$ & $6(9,7)$ & $2(3,2)$ & 0 & $2(3,2)$ & $1(1,6)$ \\
\hline Falta de ar & $54(87,1)$ & $1(1,6)$ & $1(1,6)$ & $1(1,6)$ & $1(1,6)$ & 0 & $2(3,3)$ & $1(1,6)$ & 0 & $1(1,6)$ & 0 \\
\hline Dificuldade para lembrar das coisas & $46(74,2)$ & $2(3,3)$ & 0 & $3(4,8)$ & $3(4,8)$ & $3(4,8)$ & $3(4,8)$ & 0 & 0 & $2(3,3)$ & 0 \\
\hline Falta de apetite & $43(69,4)$ & $5(8,1)$ & 0 & $3(4,8)$ & $1(1,6)$ & $2(3,2)$ & $4(6,5)$ & 0 & $1(1,6)$ & $3(4,8)$ & 0 \\
\hline Sonolência & $43(69,3)$ & $2(3,2)$ & $1(1,6)$ & $4(6,5)$ & $4(6,5)$ & $2(3,2)$ & $4(6,5)$ & $1(1,6)$ & 0 & 0 & $1(1,6)$ \\
\hline Sensação de boca seca & $21(33,9)$ & $4(6,5)$ & $5(8,1)$ & $6(9,7)$ & $5(8,1)$ & $1(1,6)$ & $8(12,9)$ & $7(11,2)$ & 0 & $3(4,8)$ & $2(3,2)$ \\
\hline Sentimento de tristeza & $44(71,0)$ & $3(4,8)$ & $1(1,6)$ & $1(1,6)$ & $3(4,8)$ & $1(1,6)$ & $4(6,6)$ & $2(3,2)$ & $2(3,2)$ & $1(1,6)$ & 0 \\
\hline Vômitos & i2 $(100,0)$ & 0 & 0 & 0 & 0 & 0 & 0 & 0 & 0 & 0 & 0 \\
\hline Sensação de dormência/formigamento & $44(71,0)$ & $1(1,6)$ & 0 & $3(4,8)$ & $7(11,3)$ & $3(4,8)$ & $2(3,3)$ & 0 & 0 & $2(3,2)$ & 0 \\
\hline Catarro na boca ou garganta & $31(50,0)$ & $3(4,8)$ & $2(3,2)$ & $7(11,3)$ & $6(9,7)$ & $2(3,2)$ & $6(9,7)$ & 0 & $1(1,6)$ & $3(4,8)$ & $1(1,7)$ \\
\hline Dificuldade para engolir/mastigar & $29(46,8)$ & $2(3,2)$ & $4(6,5)$ & $5(8,0)$ & $8(12,9)$ & $1(1,6)$ & $5(8,1)$ & $5(8,1)$ & 0 & $2(3,2)$ & $1(1,6)$ \\
\hline Engasgamento & $49(79,0)$ & $1(1,6)$ & 0 & $4(6,5)$ & $3(4,8)$ & $1(1,6)$ & $2(3,2)$ & $1(1,6)$ & 0 & 0 & $1(1,7)$ \\
\hline Problemas com a voz/ para falar & $35(56,5)$ & $5(8,0)$ & $3(4,8)$ & $5(8,1)$ & $4(6,5)$ & $1(1,6)$ & $3(4,8)$ & $1(1,6)$ & $1(1,6)$ & $4(6,5)$ & 0 \\
\hline Dor/queimação ou irritação na pele & $48(77,4)$ & $3(4,9)$ & $1(1,6)$ & $1(1,6)$ & $2(3,2)$ & $1(1,6)$ & $4(6,5)$ & 0 & 0 & $2(3,2)$ & 0 \\
\hline Constipação & $47(75,8)$ & $1(1,6)$ & 0 & $4(6,5)$ & $2(3,2)$ & $1(1,6)$ & $4(6,5)$ & 0 & $1(1,6)$ & $2(3,2)$ & 0 \\
\hline Dificuldade para sentir gosto da comida & $37(59,7)$ & $3(4,8)$ & $4(6,5)$ & $2(3,2)$ & $4(6,5)$ & $2(3,2)$ & $3(4,8)$ & $2(3,2)$ & 0 & $4(6,5)$ & $1(1,6)$ \\
\hline Feridas na boca/garganta & $53(85,5)$ & 0 & 0 & $4(6,5)$ & $2(3,2)$ & 0 & $2(3,2)$ & 0 & $1(1,6)$ & 0 & 0 \\
\hline Problemas com dentes/gengivas & $43(69,4)$ & $4(6,5)$ & $1(1,6)$ & $4(6,5)$ & $3(4,8)$ & $1(1,6)$ & $3(4,8)$ & $1(1,6)$ & 0 & $1(1,6)$ & $1(1,6)$ \\
\hline
\end{tabular}


Anexo T - Frequência e porcentagem de pacientes, de acordo com a intensidade de sintomas nos momentos pré-tratamento $(\mathrm{N}=104), 6$ meses $(\mathrm{N}=80)$ e 12 meses $(\mathrm{N}=62)$ após o diagnóstico

\begin{tabular}{|c|c|c|c|c|c|c|c|c|c|c|c|c|}
\hline \multirow[b]{3}{*}{ Sintomas / N(\%) } & \multicolumn{4}{|c|}{ Pré $(\mathrm{N}=104)$} & \multicolumn{4}{|c|}{6 meses $(\mathrm{N}=80)$} & \multicolumn{4}{|c|}{12 meses $(\mathrm{N}=62)$} \\
\hline & & & & & & Intens & & & & & & \\
\hline & 0 & $1-3$ & 4-6 & $7-10$ & 0 & $1-3$ & $4-6$ & $7-10$ & 0 & $1-3$ & $4-6$ & $7-10$ \\
\hline Dor & $39(37,5)$ & $13(12,5)$ & $24(23,1)$ & $28(26,9)$ & $59(73,7)$ & $7(8,8)$ & $10(12,5)$ & $4(5,0)$ & $43(69,4)$ & $10(16,1)$ & $8(12,9)$ & $1(1,6)$ \\
\hline Cansaço (fadiga) & $59(56,7)$ & $16(15,4)$ & $19(18,3)$ & $10(9,6)$ & $43(53,8)$ & $15(18,7)$ & $19(23,7)$ & $3(3,8)$ & $42(67,7)$ & $11(17,7)$ & $5(8,1)$ & $4(6,5)$ \\
\hline Enjôo (náusea) & $95(91,3)$ & $6(5,8)$ & $2(1,9)$ & $1(1,0)$ & $67(83,7)$ & $4(5,0)$ & $6(7,5)$ & $3(3,8)$ & $57(91,9)$ & $3(4,9)$ & $1(1,6)$ & $1(1,6)$ \\
\hline Problemas de sono & $53(51,0)$ & $13(12,5)$ & $20(19,2)$ & $18(17,3)$ & $54(67,5)$ & $8(10,0)$ & $13(16,2)$ & $5(6,3)$ & $44(71,0)$ & $8(12,9)$ & $4(6,4)$ & $6(9,7)$ \\
\hline Preocupações (aborrecimentos) & $44(42,3)$ & $18(17,3)$ & $23(22,1)$ & $19(18,3)$ & $40(50,0)$ & $14(17,5)$ & $20(25,0)$ & $6(7,5)$ & $31(50,0)$ & $16(25,8)$ & $9(14,5)$ & $6(9,7)$ \\
\hline Falta de ar & $87(83,6)$ & $7(6,7)$ & $6(5,8)$ & $4(3,9)$ & $70(87,4)$ & $5(6,3)$ & $5(6,3)$ & $0(, 0)$ & $54(87,1)$ & $3(4,9)$ & $3(4,8)$ & $2(3,2)$ \\
\hline Dificuldade para lembrar das coisas & $76(73,1)$ & $8(7,7)$ & $13(12,5)$ & $7(6,7)$ & $60(75,0)$ & $9(11,3)$ & $9(11,3)$ & $2(2,4)$ & $46(74,2)$ & $8(12,9)$ & $6(9,7)$ & $2(3,2)$ \\
\hline Falta de apetite & $76(73,0)$ & $11(10,6)$ & $11(10,6)$ & $6(5,8)$ & $53(66,3)$ & $10(12,5)$ & $5(6,2)$ & $12(15,0)$ & $43(69,3)$ & $9(14,5)$ & $6(9,7)$ & $4(6,5)$ \\
\hline Sonolência & $67(64,4)$ & $10(9,6)$ & $14(13,5)$ & $13(12,5)$ & $46(57,5)$ & $14(17,5)$ & $10(12,5)$ & $10(12,5)$ & $43(69,4)$ & $10(16,1)$ & $7(11,3)$ & $2(3,2)$ \\
\hline Sensação de boca seca & $69(66,3)$ & $8(7,7)$ & $17(16,4)$ & $10(9,6)$ & $29(36,2)$ & $9(11,3)$ & $22(27,5)$ & $20(25,0)$ & $21(33,9)$ & $15(24,2)$ & $16(25,8)$ & $10(16,1)$ \\
\hline Sentimento de tristeza & $62(59,6)$ & $18(17,3)$ & $15(14,4)$ & $9(8,7)$ & $56(70,0)$ & $12(15,0)$ & $4(5,0)$ & $8(10,0)$ & $44(70,9)$ & $7(11,3)$ & $7(11,3)$ & $4(6,5)$ \\
\hline Vômitos & $101(97,1)$ & $0(, 0)$ & $1(1,0)$ & $2(1,9)$ & $75(93,7)$ & $1(1,3)$ & $1(1,3)$ & $3(3,7)$ & $62(100,0)$ & $0(, 0)$ & $0(, 0)$ & $0(, 0)$ \\
\hline Sensação de dormência/formigamento & $76(73,1)$ & $10(9,6)$ & $10(9,6)$ & $8(7,7)$ & $61(76,2)$ & $9(11,3)$ & $6(7,5)$ & $4(5,0)$ & $44(71,0)$ & $11(17,7)$ & $5(8,1)$ & $2(3,2)$ \\
\hline Catarro na boca ou garganta & $62(59,6)$ & $9(8,7)$ & $13(12,5)$ & $20(19,2)$ & $34(42,5)$ & $14(17,5)$ & $22(27,5)$ & $10(12,5)$ & $31(50,0)$ & $16(25,8)$ & $8(12,9)$ & $7(11,3)$ \\
\hline Dificuldade para engolir/mastigar & $56(53,8)$ & $8(7,7)$ & $14(13,5)$ & $26(25,0)$ & $28(35,0)$ & $10(12,5)$ & $24(30,0)$ & $18(22,5)$ & $29(46,8)$ & $15(24,2)$ & $11(17,7)$ & $7(11,3)$ \\
\hline Engasgamento & $84(80,7)$ & $5(4,8)$ & $6(5,8)$ & $9(8,7)$ & $65(81,2)$ & $8(10,0)$ & $7(8,8)$ & $0(, 0)$ & $49(79,0)$ & $8(12,9)$ & $4(6,5)$ & $1(1,6)$ \\
\hline Problemas com a voz/ para falar & $62(59,6)$ & $10(9,6)$ & $14(13,5)$ & $18(17,3)$ & $41(51,2)$ & $13(16,3)$ & $16(20,0)$ & $10(12,5)$ & $35(56,4)$ & $14(22,6)$ & $5(8,1)$ & $8(12,9)$ \\
\hline Dor/queimação ou irritação na pele & $85(81,7)$ & $7(6,7)$ & $6(5,8)$ & $6(5,8)$ & $60(75,0)$ & $9(11,2)$ & $8(10,0)$ & $3(3,8)$ & $48(77,4)$ & $6(9,7)$ & $5(8,1)$ & $3(4,8)$ \\
\hline Constipação & $84(80,7)$ & $1(1,0)$ & $9(8,7)$ & $10(9,6)$ & $61(76,3)$ & $3(3,7)$ & $10(12,5)$ & $6(7,5)$ & $47(75,8)$ & $7(11,3)$ & $5(8,1)$ & $3(4,8)$ \\
\hline Dificuldade para sentir gosto da comida & $81(77,8)$ & $4(3,9)$ & $10(9,6)$ & $9(8,7)$ & $35(43,7)$ & $8(10,0)$ & $13(16,3)$ & $24(30,0)$ & $37(59,7)$ & $9(14,5)$ & $7(11,3)$ & $9(14,5)$ \\
\hline Feridas na boca/garganta & $65(62,5)$ & $1(1,0)$ & $10(9,6)$ & $28(26,9)$ & $59(73,7)$ & $7(8,8)$ & $6(7,5)$ & $8(10,0)$ & $53(85,5)$ & $6(9,7)$ & $2(3,2)$ & $1(1,6)$ \\
\hline Problemas com dentes/gengivas & $73(70,2)$ & $5(4,8)$ & $11(10,6)$ & $15(14,4)$ & $48(60,0)$ & $11(13,7)$ & $6(7,5)$ & $15(18,8)$ & $43(69,4)$ & $11(17,7)$ & $5(8,1)$ & $3(4,8)$ \\
\hline
\end{tabular}

NOTA: Intensidade dos sintomas agrupados em graus 0, 1-3, 4-6 e 7-10 
Anexo U - Frequência relativa das preocupações selecionadas pelos pacientes no Inventário de Preocupações dos Pacientes - IPP, no momento pré-tratamento $(\mathrm{N}=104)$

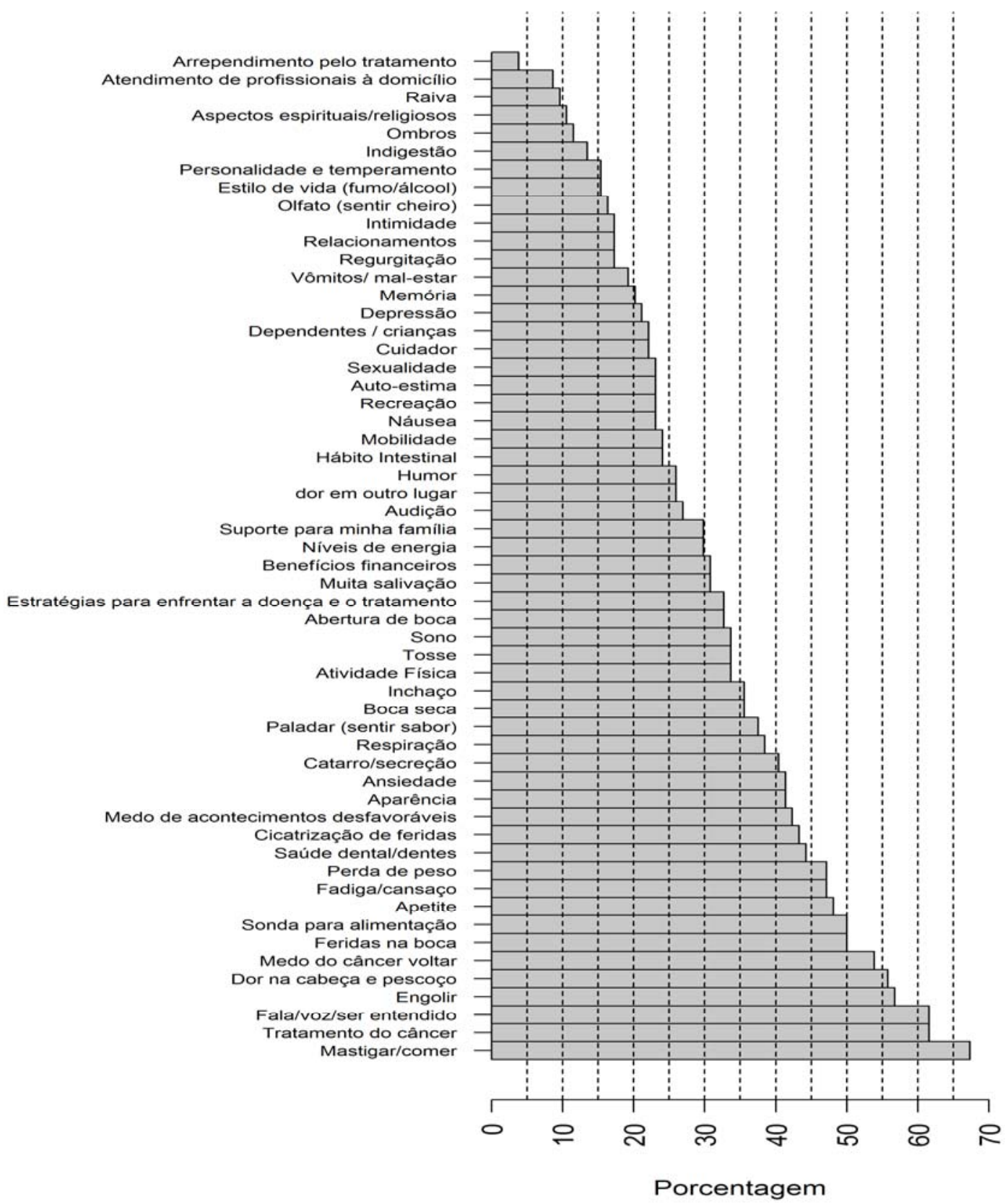


Anexo V - Frequência relativa dos profissionais selecionados pelos pacientes no Inventário de Preocupações dos Pacientes - IPP, no momento pré-tratamento $(\mathrm{N}=104)$

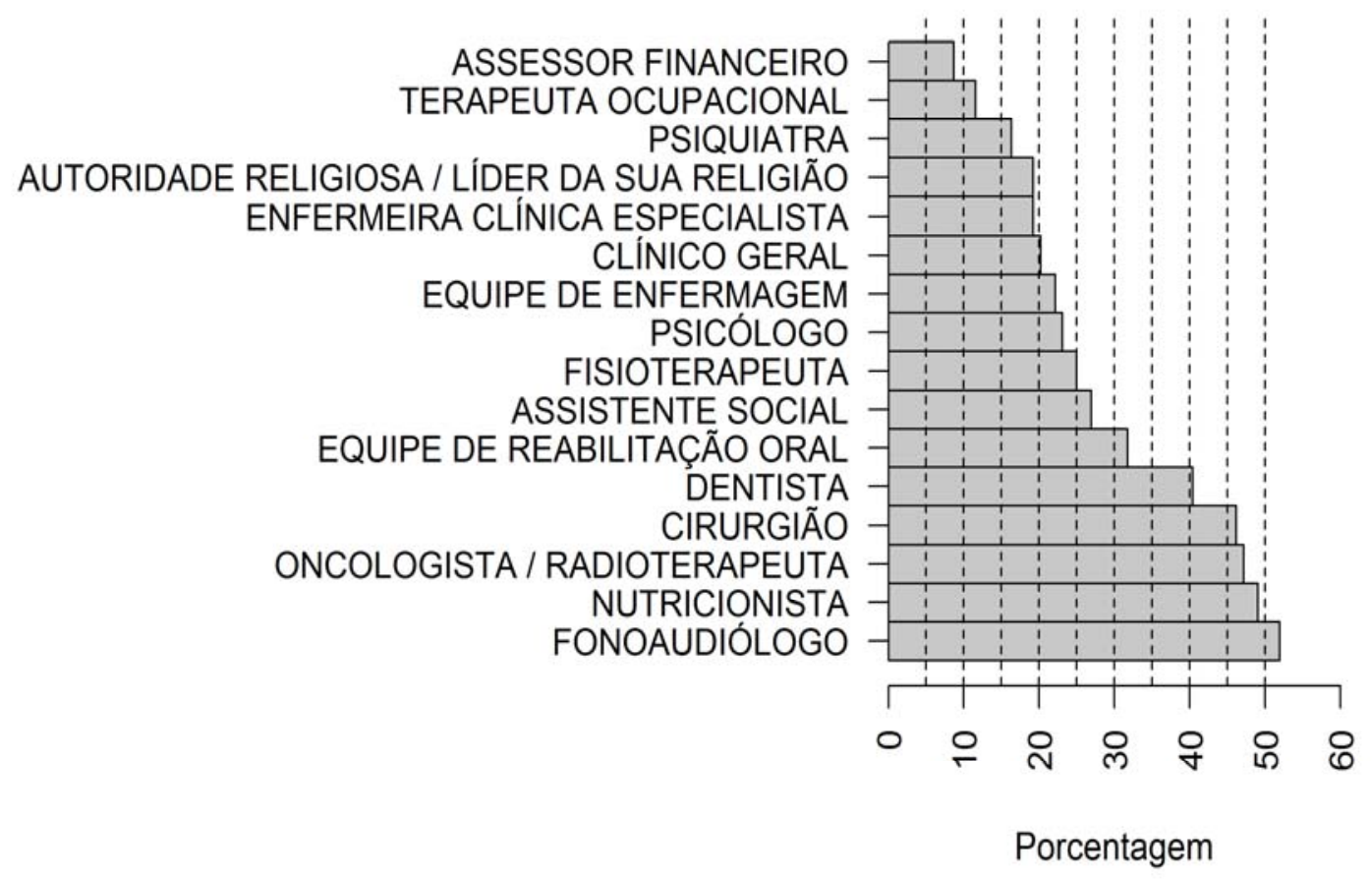


Anexo W - Frequência relativa das preocupações selecionadas pelos pacientes no Inventário de Preocupações dos Pacientes - IPP, aos 6 meses após o diagnóstico $(\mathrm{N}=80)$

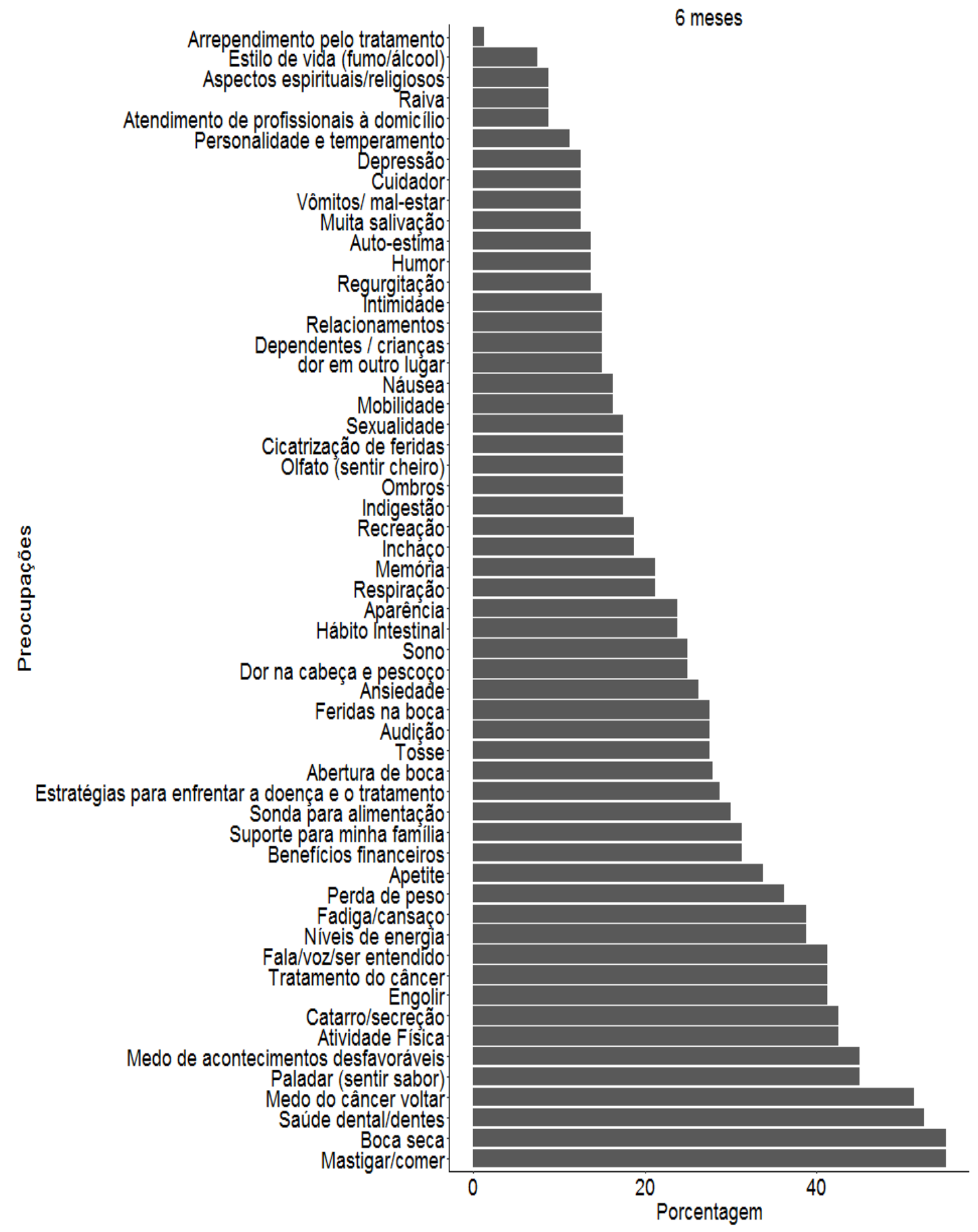


Anexo X - Frequência relativa dos profissionais selecionados pelos pacientes no Inventário de Preocupações dos Pacientes - IPP, aos 6 meses após o diagnóstico $(\mathrm{N}=80)$

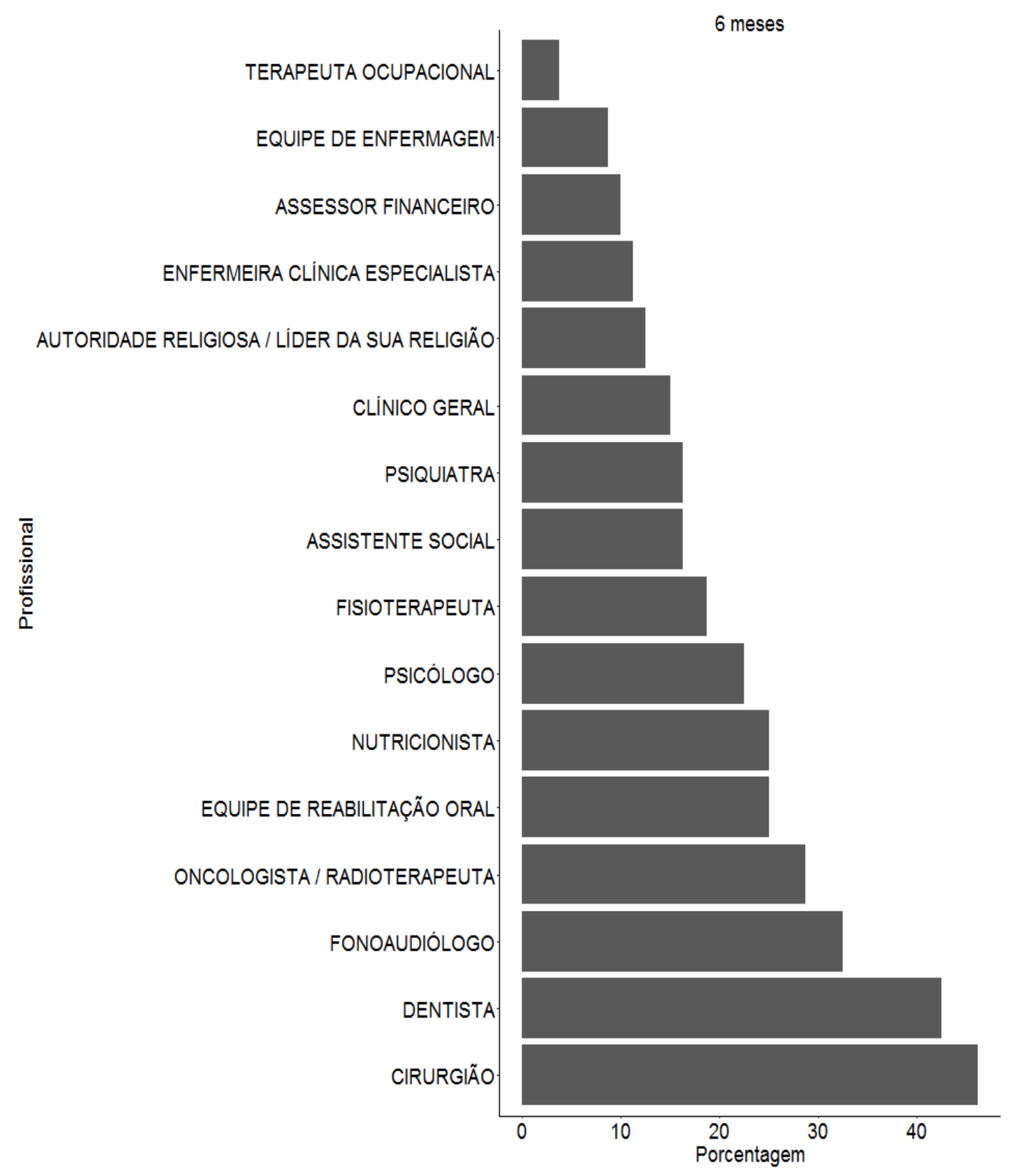


Anexo Y - Frequência relativa das preocupações selecionadas pelos pacientes no Inventário de Preocupações dos Pacientes - IPP, aos 12 meses após o diagnóstico $(\mathrm{N}=62)$

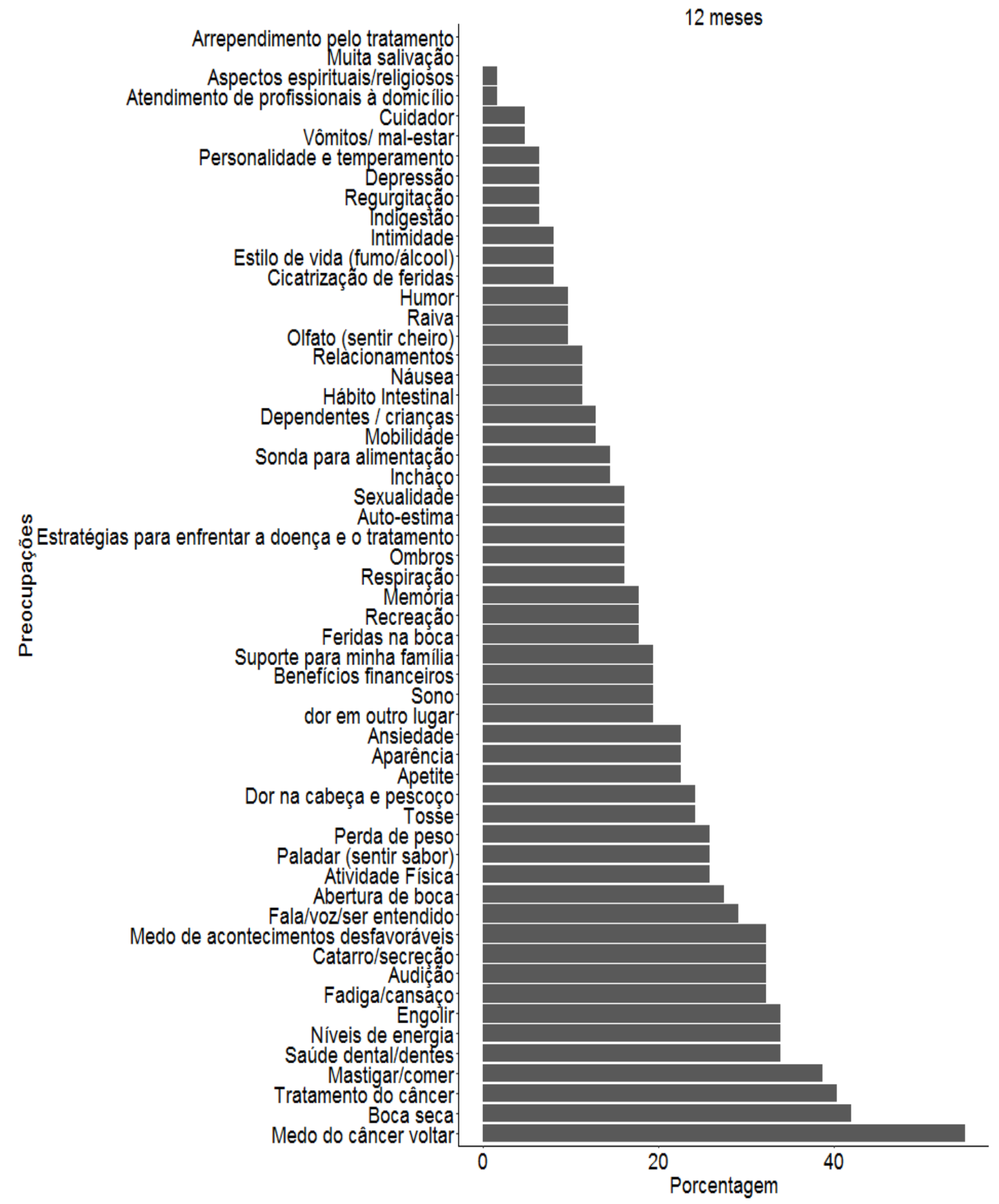


Anexo Z - Frequência relativa dos profissionais selecionados pelos pacientes no Inventário de Preocupações dos Pacientes - IPP, aos 12 meses após o diagnóstico $(\mathrm{N}=62)$

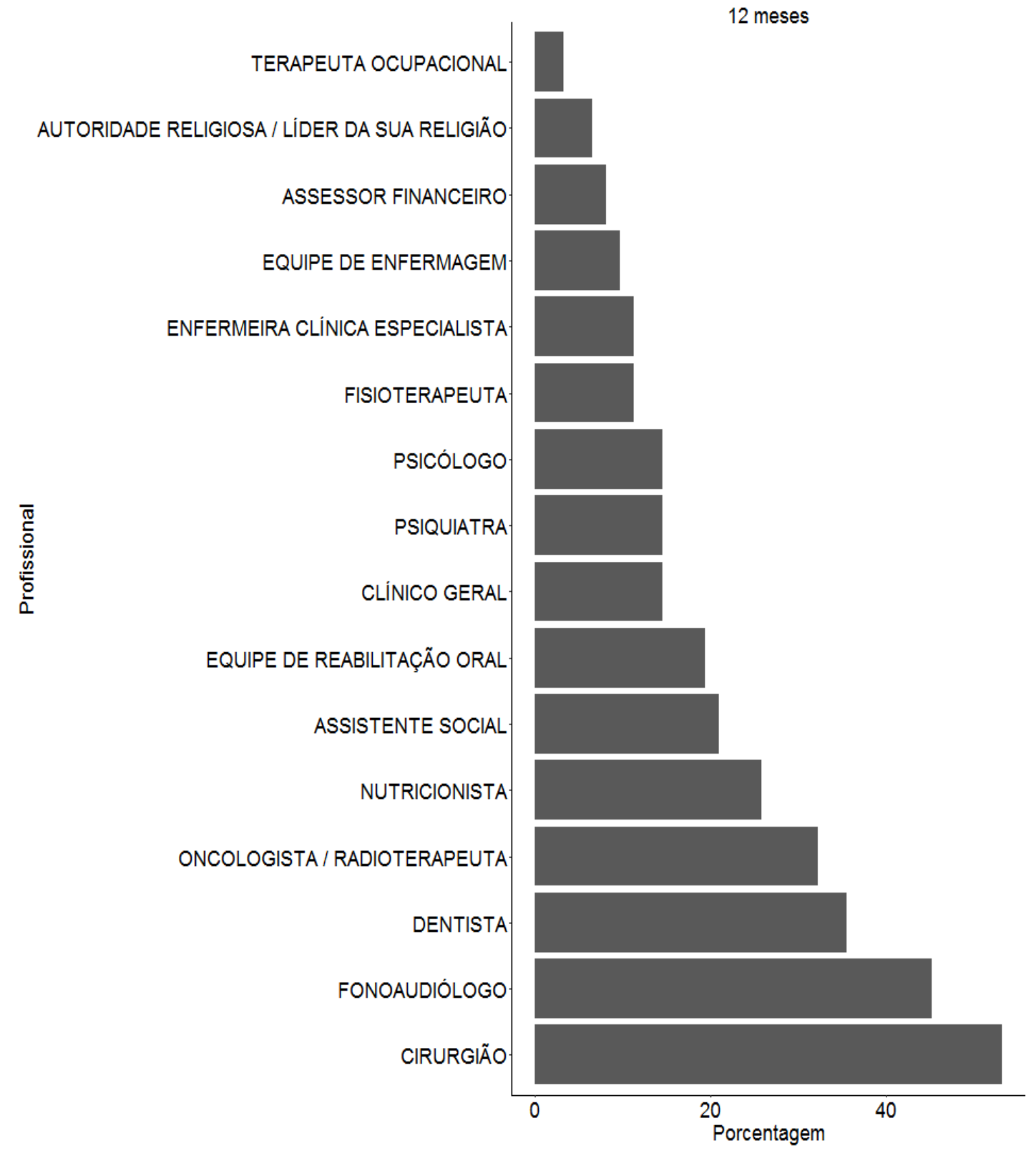




\section{REFERÊNCIAS}

Aaronson NK, Ahmedzai S, Bergman B, Bullinger M, Cull A, Duez NJ, Filiberti A, Flechtner H, Fleishman SB, de Haes JC, Kaasa S, Klee M, Osoba D, Razavi D, Rofe PB, Schraub S, Sneeuw K, Sullivan M, Takeda K. The European Organization for Research and Treatment of Cancer QLQ-C30: a quality-of-life instrument for use in international clinical trials in oncology. J Natl Cancer Inst. 1993;85(5):365-76.

Abdullah MF, Jaafar NR, Zakaria H, Rajandram RK, Mahadevan R, Yunus MR, Shah SA. Posttraumatic growth, depression and anxiety in head and neck cancer patients: examining their patterns and correlations in a prospective study. Psychooncology. 2015;24(8):894-900.

Almeida MAB, Gutierrez GL, Marques R. [on-line]. Qualidade de vida - definição, conceitos e interfaces com outras áreas de pesquisa. São Paulo, Escola de Artes, Ciências e Humanidades-EACH/USP; 2012. Disponível em: http://each.uspnet.usp.br/edicoes-each/qualidade_vida.pdf $>$ Acessado em 20-07-15

Amar A, Rapoport A, Franzi SA, Bisordi C, Lehn CN. Qualidade de vida e prognóstico nos carcinomas epidermóides de cabeça e pescoço. Rev Bras Otorrinolaringol. 2002;68(3):400-3.

American Cancer Society-ACS. Feelings and cancer. Posted: December 2, 2014. Available from: http://www.cancer.gov/about-cancer/coping/feeling.

American Cancer Society-ACS. Anxiety, fear, and depression. Last Revised: 05/24/2016. Available from: http://www.cancer.org/treatment/treatment sandsideeffects/emotionalsideeffects/anxiety-fear-depression-and-cancer.

Ancoli-Israel S, Moore PJ, Jones V. The relationship between fatigue and sleep in cancer patients: a review. Eur J Cancer Care. 2001;10(4):245-55. 
Anelli G. Aspectos éticos no tratamento do paciente oncológico. In: Kowalski LP, Anelli A, Salvajoli JV, Lopes LF, editores. Manual de condutas diagnósticas e terapêuticas em oncologia. São Paulo: Âmbito; 2002. p.33-4.

Angelo AR, Medeiros AC, De Biase RCCG. Quality of life in patients with cancer of the head and neck. Rev Odontol UNESP. 2010;39(1):1-7.

Armes J, Crowe M, Colbourne L, Morgan H, Murrells T, Oakley C, Palmer N, Ream E, Young A, Richardson A. Patients' supportive care needs beyond the end of cancer treatment: a prospective, longitudinal survey. J Clin Oncol. 2009;27(36):6172-9.

Beaton DE, Bombardier C, Guillemin F, Ferraz MB. Guidelines for the proces of cross-cultural adaptation of self-report measures. Spine. 2000;25:3186-91.

Behlau M. Cross-cultural adaptation and validation of the voice handicap índex into Brazilian portugueses. $J$ Voice. 2011;25(3):354-9.

Bertan FC, Castro EK. Qualidade de vida e câncer: revisão sistemática de artigos brasileiros. PSICO Porto Alegre. 2009;40(3):366-72.

Bese NS, Hendry J, Jeremic B. Effects of prolongation of overall treatment time due to unplanned interruptions during radiotherapy of different tumor sites and practical methods for compensation. Int J Radiat Oncol Biol Phys. 2007;68(3):654-61.

Biazevic MGH, Antunes JLF, Togni J, Andrade FP, Carvalho MB, Wünsch-Filho V. Survival and quality of life of patients with oral and oropharyngeal cancer at 1-year follow-up of tumor resection. J Appl Oral Sci. 2010;18(3):279-84.

Bjordal K, Kaasa S, editors. Psychometric validation of the EORTC Core Quality of Life Questionnaire, 30-item version and a diagnosis-specific module for head and neck cancer patients. Acta Oncol. 1992;31(3):311-21. 
Bjordal K, Ahlner-Elmqvist M, Hammerlid E, Boysen M, Evensen JF, Biörklund A, Jannert M, Westin T, Kaasa S. A prospective study of quality of life in head and neck cancer patients. Part II: Longitudinal data. Laryngoscope. 2001;111(8):1440-52.

Blanchard CG, Labrecque MS, Ruckdeschel JC, Blanchard EB. Information and decision-making preferences of hospitalized adult cancer patients. Soc Sci Med. 1988;27(11):1139-45.

Botega NJ, Bio MR, Zomignani MA, Garcia Jr C, Pereira WAB. Mood disorders among medical in-patients: a validation study of the Hospital Anxiety and Depression scale (HAD). Rev Saúde Pública. 1995;29(5):355-63.

Bottino SMB, Fráguas R, Gattaz WF. Depressão e câncer. Rev Psiquiatr Clín (São Paulo). 2009;36(3):109-15.

Boscolo-Rizzo P, Maronato F, Marchiori C. Long-term quality of life after total laryngectomy and postoperative radiotherapy versus concurrent chemoradiotherapy for laryngeal preservation. Laryngoscope. 2008;118(2):300-6.

Brandes K, Linn AJ, Smit EG, van Weert JC. Patients' reports of barriers to expressing concerns during cancer consultations. Patient Educ Couns. 2015;98(3):317-22.

Breitbart W, Holland J. Psychosocial aspects of head and neck cancer. Semin Oncol. 1988;15(1):61-9.

Brockbank S, Miller N, Owen S, Patterson JM. Pretreatment information on dysphagia: exploring the views of head and neck cancer patients. J Pain Symptom Manage. 2015;49(1):89-97.

Brown R, Dunn S, Butow P. Meeting patient expectations in the cancer consultation. Ann Oncol. 1997;8(9):877-82. 
Burkett VS, Cleeland CS. Symptom burden in cancer survivorship. J Cancer Surviv. 2007;1(2):167-75.

Calman KC. Quality of life in cancer patients - an hypothesis. J Med Ethics. 1984;10(3):124-7.

Campos JLG, Chagas JFS, Magna LA. Fatores de atraso no diagnóstico do câncer de cabeça e pescoço e sua relação com sobrevida e qualidade de vida. Rev Bras Cir Cabeça Pescoço. 2007;36(2):65-8.

Campos MPO, Hassan BJ, Riechelmann R, del Giglio A. Fadiga relacionada ao câncer: uma revisão. Rev Assoc Med Bras. 2011;57(2):211-9.

Cardoso MFA, Novikoff S, Tresso A, Segreto RA, Cervantes O. Prevenção e controle das seqüelas bucais em pacientes irradiados por tumores de cabeça e pescoço. Radiol Bras. 2005;38(2):107-15.

Cancer.Net. Head and neck cancer - symptoms and signs. Approved by the Cancer.Net Editorial Board, 05/2015. Available from: http://www.cancer.net/cancertypes/head-and-neck-cancer/symptoms-and-signs.

Carvalho AL, Nishimoto IN, Califano JA, Kowalski LP. Trends in incidence and prognosis for head and neck cancer in the United States: a site-specific analysis of the SEER database. Int J Cancer. 2005;114(5):806-16.

Carver SC, Scheier MF, Segerstrom SC. Optimism. Clin Psychol Rev. 2010;30(7)879-89.

Carr AJ, Gibson B, Robinson PG. Is quality of life determined by expectations or experience? BMJ. 2001;322(7296):1240-3. 
Casati MFM, Vasconcelos JA, Vergnhanini GS, Contreiro PF, da Graça TB, Kanda JL, Akerman M, de Matos LL. Epidemiologia do câncer de cabeça e pescoço no Brasil: estudo transversal de base populacional. Rev Bras Cir Cabeça Pescoço 2012;41(4):186-91.

Cassileth BR, Knuiman MW, Abeloff MD, Falkson G, Ezdini EZ, Mehta CR. Anxiety levels in patients randomized to adjuvant therapy versus observation for early breast cancer. J Clin Oncol. 1986;4(6):972-4.

Cassileth BR, Lusk EJ, Bodenheimer BJ, Farber JM, Jochimsen P, Morrin-Taylor B. Chemotherapeutic toxicity--the relationship between patients' pretreatment expectations and posttreatment results. Am J Clin Oncol. 1985;8(5):419-25.

Cella DF. Quality of life: the concept. J Palliat Care. 1992;8(3):8-13.

Cella DF, Tulsky DS, Gray G, Sarafian B, Linn E, Bonomi A, Silberman M, Yellen SB, Winicour P, Brannon J, Eckberg K, Lloyd S, Purl S, Blendowski C, Goodman M, Barnicle M, Stewart I, McHale M, Bonomi P, Kaplan E, Taylor IV S, Thomas CR Jr, Harris J. The functional assessment of cancer therapy scale: development and validation of the general measure. J Clin Oncol. 1993;11(3):570-9.

Chaitchik S, Kreitler S, Shaked S, Schwartz I, Rosin R. Doctor-patient communication in a cancer ward. J Cancer Educ. 1992;7(1):41-54.

Chen AM, Jennelle RL, Grady V, Tovar A, Bowen K, Simonin P, Tracy J, McCrudden D, Stella JR, Vijayakumar S. Prospective study of psychosocial distress among patients undergoing radiotherapy for head and neck cancer. Int $J$ Radiat Oncol Biol Phys. 2009;73(1):187-93.

Chen J, Liu P, Wang Q, Wu L, Zhang X. Influence of intensity-modulated radiation therapy on the life quality of patients with nasopharyngeal carcinoma. Cell Biochem Biophys. 2015;73(3):731-6. 
Chen AY, Frankowski R, Bishop-Leone J, Hebert T, Leyk S, Lewin J, Goepfert H. The development and validation of a dysphagia-specific quality-of-life questionnaire for patients with head and neck cancer: the MD Anderson dysphagia inventory. Arch Otolaryngol Head \& Neck Surg. 2001;127(7):870-76.

Cheng SC, Wu VW, Kwong DL, Ying MT. Assessment of post-radiotherapy salivary glands. Br J Radiol. 2011;84(1001):393-402.

Chera BS, Eisbruch A, Murphy BA, Ridge JA, Gavin P, Reeve BB, Bruner DW, Movsas B. Recommended patient-reported core set of symptoms to measure in head and neck cancer treatment trials. J Natl Cancer Inst. 2014;106(7). pii: dju127.

Chin D, Boyle GM, Williams RM, Ferguson K, Pandeya N, Pedley J, Campbell CM, Theile DR, Parsons PG, Coman WB. Novel markers for poor prognosis in head and neck cancer. Int J Cancer. 2005;113(5):789-97.

Chigurupati R, Aloor N, Salas R, Schmidt BL. Quality of life after maxillectomy and prosthetic obturator rehabilitation. J Oral Maxillofac Surg. 2013;71(8):1471-8.

Cleeland CS, Mendoza TR, Wang XS, Chou C, Harle MT, Morrissey M, Engstrom MC. Assessing symptom distress in cancer patients: the M.D. Anderson Symptom Inventory. Cancer. 2000;89(7):1634-46.

Cognetti DM, Weber RS, Lai SY. Head and neck cancer: an evolving treatment paradigm. Cancer. 2008;113(7):1911-32.

Colagiuri B, Dhillon H, Butow PN, Jansen J, Cox K, Jacquet J. Does assessing patients' expectancies about chemotherapy side effects influence their occurrence? $J$ Pain Symptom Manage. 2013;46(2):275-81.

Costa Neto SB. Qualidade de vida dos portadores de câncer de cabeça e pescoço [tese]. Brasília: Instituto de Psicologia, Universidade de Brasília; 2002. 
Cox A, Jenkins V, Catt S, Langridge C, Fallowfield L. Information needs and experiences: an audit of UK cancer patients. Eur J Oncol Nurs. 2006;10(4):263-72.

Crist JV, Grunfeld EA. Factors reported to influence fear of recurrence in cancer patients: a systematic review. Psychooncology. 2013;22(5):978-86.

Crozier E, Sumer BD. Head and neck cancer. Med Clin North Am. 2010;94(5):103146.

Curt GA, Breitbart W, Cella D, Groopman JE, Horning SJ, Itri LM, Johnson DH, Miaskowski C, Scherr SL, Portenoy RK, Vogelzang NJ. Impact of cancer-related fatigue on the lives of patients: new findings from the fatigue coalition. Oncologist. 2000;5(5):353-60.

D'Antonio LL, Zimmerman GJ, Cella DF, Long SA. Quality of life and functional status measures in patients with head and neck cancer. Arch Otolaryngol Head Neck Surg. 1996;122(5):482-7.

Daher JL. Análise da qualidade de vida, voz e deglutição no paciente com câncer de cabeça e pescoço pré e pós tratamento oncológico [Dissertação]. Barretos: Hospital de Câncer de Barretos-Fundação Pio XII; 2013.

Davis TC, Williams MV, Marin E, Parker RM, Glass J. Health literacy and cancer communication. CA Cancer J Clin. 2002;52(3):134-49.

De Boer MF, McCormick LK, Pruyn JF, Ryckman RM, van den Borne BW. Physical and psychosocial correlates of head and neck cancer: a review of the literature. Otolaryngol Head Neck Surg. 1999;120(3):427-36.

De Graeff A, de Leeuw JRJ, Ros WJG, Hordijk G-J, Blijham GH, Winnubst J AM. Long-term quality of life of patients with head and neck cancer. Laryngoscope. 2000;110(1):98-106. 
De Graeff A, De Leeuw RJ, Ros WJG. A prospective study on quality of life of laryngeal cancer patients treated with radiotherapy. Head Neck. 1999;21:291-6.

Detmar SB, Aaronson NK, Wever LD, Muller M, Schornagel JH. How are you feeling? Who wants to know? Patients' and oncologists' preferences for discussing health-related quality-of-life issues. J Clin Oncol. 2000;18(18):3295-301.

Devins GM, Otto KJ, Irish JC, Rodin GM. Head and Neck Cancer. In: Holland JC, Breitbart WS, Jacobsen PB, Lederbarg MS, Loscalzo MJ, MccorKle RS, Butow PN, editors. Psycho-Oncology. $2^{\text {nd }}$ ed. New York: Oxford University Press; 2010. p.1359.

Djan R, Penington A. A systematic review of questionnaires to measure the impact of appearance on quality of life for head and neck cancer patients. J Plast Reconstr Aesthet Surg. 2013;66(5):647-59.

Dodd M, Miaskowski C, Paul S. Symptom clusters and their effect on the functional status of patients with cancer. Oncol Nurs Forum. 2001;28(3):465-70.

Duffy SA, Terrell JE, Valenstein M, Ronis DL, Copeland LA, Connors M. Effect of smoking, alcohol, and depression on the quality of life of head and neck cancer patients. Gen Hosp Psychiatry. 2002;24(3):140-7.

Dwivedi RC, Nutting CM, Rhys-Evans P, Harrington KJ, Kazi R. Future perspectives for health related quality of life (HRQOL) studies in head and neck cancer. G Ital Med Lav Ergon. 2009;31(3 Suppl B):B17-20.

Feng FY, Kim HM, Lyden TH, Haxer MJ, Worden FP, Feng M, Moyer JS, Prince ME, Carey TE, Wolf GT, Bradford CR, Chepeha DB, Eisbruch A. Intensitymodulated chemoradiotherapy aiming to reduce dysphagia in patients with oropharyngeal cancer: clinical and functional results. $J$ Clin Oncol. 2010;28(16):2732-8. 
Ferlay J, Soerjomataram I, Ervik M, Dikshit R, Eser S, Mathers C, Rebelo M, Parkin DM, Forman D, Bray F. GLOBOCAN 2012 v1.0, Cancer incidence and mortality Worldwide: IARC Cancer Base $n^{\circ} 11$ [Internet]. Lyon: France: International Agency for Research on Cancer; 2013. Available from: http://globocan.iarc.fr.

Fernandes GM, Bergmann A, de Oliveira JF. Análise epidemiológica de população com câncer de cabeça e pescoço: influência sobre as complicações pós operatórias. Rev Bras Cir Cabeça Pescoço. 2013;42(3):140-9.

Ferreira KASL, William Jr. WN, Mendonza TR, Kimura M, Kowalski LP, Rosenthal DI, Cleeland CS. Tradução para a língua portuguesa do M.D. Anderson Symptom Inventory - head and neck module (MDASI-H\&N). Rev Bras Cir Cabeça Pescoço. 2008;37(2):109-13.

Fisher J, Scott C, Scarantino CW, Leveque FG, White RL, Rotman M, Hodson DI, Meredith RF, Foote R, Bachman DG, Lee N. Phase III quality of life study results: impact on patients' quality of life to reducing xerostomia after radiotherapy for head and neck cancer - RTOG 97-09. Int J Rad Oncol Biol Phys. 2003;56(3):632-6.

First MB, Spitzer RL, Gibbon M, Williams Janet B.W. Structured clinical interview for DSM-IV axis i disorders, clinician version (SCID-CV). Washington, D.C.: American Psychiatric Press, Inc.; 1996.

Fleck MPA, Leal OF, Louzada S, Xavier M, Chachamovich E, Vieira G, dos Santos L, Pinzon V. Desenvolvimento da versão em português do instrumento de avaliação de qualidade de vida da OMS (WHOQOL-100). Rev Bras Psiquiatr. 1999;21(1):21-8.

Flexen J, Ghazali N, Lowe D, Rogers SN. Identifying appearance-related concerns in routine follow-up clinics following treatment for oral and oropharyngeal cancer. $\mathrm{Br} J$ Oral Maxillofacial Surg. 2012; 50(4):314-20. 
Flood AB, Lorence DP, Ding J, McPherson K, Black NA. The role of expectations in patients' reports of post-operative outcomes and improvement following therapy. Med Care. 1993;31(11):1043-56.

Foley KM, Abernathy A. Supportive care and quality of life: management of cancer pain. In: DeVita Jr V, Lawrence TS, Rosenberg AS, editors. DeVita, Hellman, and Rosenberg's cancer: principles \& practice of oncology. $8^{\text {th }}$ ed. Philadelphia: Lippincott Willians \& Wilkins, 2008. p.2757-790.

Foot G, Sanson-Fisher R. Measuring the unmet needs of people living with cancer. Cancer Forum. 1995;19(2):131-5.

Gaziano JE. Evaluation and management of oropharyngeal dysphagia in head and neck cancer. Cancer Control. 2002;9(5):400-9.

Ghazali N, Kanatas A, Langley DJ, Scott B, Lowe D, Rogers SN. Treatment referral before and after the introduction of the Liverpool Patients Concerns Inventory (PCI) into routine head and neck oncology outpatient clinics. Support Care Cancer. 2011;19(11):1879-86.

Ghazali N, Roe B, Lowe D, Rogers SN. Uncovering patients' concerns in routine head and neck oncology follow up clinics: an exploratory study. $\mathrm{Br} J$ Oral Maxillofac Surg. 2013a;51(4):294-300.

Ghazali N, Cadwallader E, Lowe D, Humphris G, Ozakinci G, Rogers SN. Fear of recurrence among head and neck cancer survivors: Longitudinal trends. Psychooncology. 2013b;22(4):807-13.

Ghazali N, Kanatas A, Scott B, Lowe D, Zuydam A, Rogers SN. Use of the patient concerns inventory to identify speech and swallowing concerns following treatment for oral and oropharyngeal cancer. J Laryngol Otol. 2012;126(8):800-8. 
Gimenes VPG. Relação entre as estratégias de enfrentamento e a necessidade de informação sobre o câncer e a prevalência de ansiedade e depressão nos pacientes em tratamento com quimioterapia neoadjuvante, adjuvante ou curativa [Dissertação]. São Paulo; Fundação Antônio Prudente; 2008.

Glaus A. Assessment of fatigue in cancer and non-cancer patients and in healthy individuals. Support Care Cancer. 1993;1(6):305-15.

Gliklich RE, Goldsmith TA, Funk GF. Are head and neck specific quality of life measures necessary? Head Neck. 1997;19(6):474-80.

Golden JS, Johnston GD. Problems of distortion in doctor-patient communications. Psychiatry Med. 1970;1(2):127-49.

Gotay CC, Moore TD. Assessing quality of life in head and neck cancer. Qual Life Res. 1992;1(1):5-17.

Graff P, Lapeyre M, Desandes E, Ortholan C, Bensadoun RJ, Alfonsi M, Maingon P, Giraud P, Bourhis J, Marchesi V, Mège A, Peiffert D. Impact of intensity-modulated radiotherapy on health-related quality of life for head and neck cancer patients: matched-pair comparison with conventional radiotherapy. Int J Radiat Oncol Biol Phys. 2007;67(5):1309-17.

Guedes RL, Angelis EC, Chen AY, Kowalski LP, Vartanian JG. Validation and application of the M.D. Anderson Dysphagia Inventory in patients treated for head and neck cancer in Brazil. Dysphagia. 2013;28(1):24-32.

Guillemin F, Bombardier C, Beaton D. Cross-cultural adaptation of health- related quality of life measures: literature review and proposed guidelines. J Clin Epidemiol. 1993;46(12):1417-32. 
Gunn GB, Mendoza TR, Fuller CD, Gning I, Frank SJ, Beadle BM, Hanna EY, Lu C, Cleeland CS, Rosenthal DI. High symptom burden prior to radiation therapy for head and neck cancer: a patient-reported outcomes study. Head Neck. 2013;35(10):1490-8.

Hammerlid E, Ahlner-Elmqvist M, Bjordal K, Biörklund A, Evensen J, Boysen M, Jannert M, Kaasa S, Sullivan M, Westin T. A prospective multicentre study in Sweden and Norway of mental distress and psychiatric morbidity in head and neck cancer patients. Br J Cancer. 1999;80(5-6):766-74.

Hammerlid E, Mercke C, Sullivan M, Westin T. A prospective quality of life study of patients with laryngeal carcinoma by tumor stage and different radiation therapy schedules. Laryngoscope. 1998;108(5):747-59.

Hanna EY, Mendoza TR, Rosenthal DI, Gunn GB, Sehra P, Yucel E, Cleeland CS. The symptom Burden of treatment-naïve patients with head and neck cancer. Cancer. 2015;121(5):766-73.

Happ MB, Roesch T, Kagan SH. Communication needs, methods, and perceived voice quality following head and neck surgery: a literature review. Cancer Nurs. 2003;26(5):346-54.

Harrison JD, Young JM, Price MA, Butow PN, Solomon MJ. What are the unmet supportive care needs of people with cancer? A systematic review. Support Care Cancer. 2009;17(8):1117-28.

Hassan SJ, Weymuller EA Jr. Assessment of quality of life in head and neck cancer patients. Head Neck. 1993;15(6):485-96.

Henry M, Habib LA, Morrison M, Yang JW, Li XJ, Lin S, Zeitouni A, Payne R, MacDonald C, Mlynarek A, Kost K, Black M, Hier M. Head and neck cancer patients want us to support them psychologically in the posttreatment period: survey results. Palliat Support Care. 2014;12(6):481-93. 
Herschbach P, Dinkel A. Fear of progression. In: Goerling U, editor. Psychooncology, recent results in cancer research. Heilberg: Springer; 2014. p.11-30.

Hickok JT, Roscoe JA, Morrow GR. The role of patients' expectations in the development of anticipatory nausea related to chemotherapy for cancer. J Pain Symptom Manage. 2001;22(4):843-50.

Hodgkinson K, Butow P, Hunt GE, Pendlebury S, Hobbs KM, Lo SK, Wain G. The development and evaluation of a measure to assess cancer survivors' unmet supportive care needs: the CaSUN (Cancer Survivors' Unmet Needs measure). Psychooncology. 2007;16(9):796-804.

Hofman M, Morrow GR, Roscoe JA, Hickok JT, Mustian KM, Moore DF, Wade JL, Fitch TR. Cancer patients' expectations of experiencing treatment-related side effects. Cancer. 2004;101(4):851-7.

Horney DJ, Smith HE, McGurk M, Weinman J, Herold J, Altman K, Llewellyn CD. Associations between quality of life, coping styles, optimism, and anxiety and depression in pretreatment patients with head and neck cancer. Head Neck. 2011;33(1):65-71.

Howren MB, Christensen AJ, Karnell LH, Funk GF. Psychological factors associated with head and neck cancer treatment and survivorship: evidence and opportunities for behavioral medicine. J Consult Clin Psychol. 2013;81(2):299-317.

Humphris GM, Ozakinci G. Psychological responses and support needs of patients following head and neck cancer. Int J Surg. 2006;4(1):37-44.

International Society for Quality of Life Research-ISOQOL. What Is Health-Related Quality of Life Research? Available from: http://www.isoqol.org/about-isoqol/whatis-health-related-quality-of-life-research. 
Inverso G, Mahal BA, Aizer AA, Donoff RB, Chau NG, Haddad RI. Marital status and head and neck cancer outcomes. Cancer. 2015;121(8):1273-8.

Isaac T, Stuver SO, Davis RB, Block S, Weeks JC, Berry DL, Weingart SN. Incidence of severe pain in newly diagnosed ambulatory patients with stage IV cancer. Pain Res Manag. 2012;17(5):347-52.

Jacobi I, van der Molen L, HuiskenscH, Van Rossum MA, Hilgers FJ. Voice and speech outcomes of chemoradiation for advanced head and neck cancer: a systematic review. Eur Arch Oto-Rhino-Laryngol. 2010;267(10):1495-505.

Jawad H, Hodson NA, Nixon PJ. A review of dental treatment of head and neck cancer patients, before, during and after radiotherapy: part 1. Br Dent $J$. 2015;218(2):65-8.

Jenkins V, Fallowfield L, Saul J. Information needs of patients with cancer: results from a large study in UK cancer centres. Br J Cancer. 2001;84(1):48-51.

Jiang R, Ekshyyan O, Moore-Medlin T, Rong X, Nathan S, Gu X, Abreo F, Rosenthal EL, Shi M, Guidry JT, Scott RS, Hutt-Fletcher LM, Nathan CA. Association between HPV/EBV co-infection and oral carcinogenesis. J Oral Pathol Med. 2015;44(1):28-36.

Jones MB, Lund VJ, Howard DJ, Greenberg MP, McCarthy M. Quality of life of patients treated surgically for head and neck cancer. $J$ Laryngol Otol. $1992 ; 106(3): 238-42$.

Kanatas A, Lowe D, Velikova G, Roe B, Horgan K, Shaw RJ, Rogers SN. Issues patients would like to discuss at their review consultation in breast cancer clinics - a cross-sectional survey. Tumori. 2014;100(5):568-79. 
Kanatas A, Ghazali N, Lowe D, Rogers SN. The identification of mood and anxiety concerns using the patients concerns inventory following head and neck cancer. Int $J$ Oral Maxillofac Surg. 2012;41(4):429-36.

Kanatas A, Ghazali N, Lowe D, Udberg M, Heseltine J, O'Mahony E, Rogers SN. Issues patients would like to discuss at their review consultation: variation by early and late stage oral, oropharyngeal and laryngeal subsites. Eur Arch Otorhinolaryngol. 2013;270(3):1067-74.

Kaae JK, Stenfeldt L, Eriksen JG. Xerostomia after radiotherapy for oral and oropharyngeal cancer: increasing salivary flow with Tasteless Sugar-Free Chewing Gum. Front Oncol. 2016;6:111.

Karnell LH, Funk GF, Christensen AJ, Rosenthal EL, Magnuson JS. Persistent posttreatment depressive symptoms in patients with head and neck cancer. Head Neck. 2006;28(5):453-61.

Kazi R. Surgical voice restoration following total laryngectomy. J Can Res Ther. 2007a;3(4):188-9.

Kazi R, De Cordova J, Kanagalingam J, Venkitaraman R, Nutting CM, Clarke P, Rhys-Evans P, Harrington KJ. Quality of life following total laryngectomy: assessment using the UW-QOL scale. ORL $J$ Otorhinolaryngol Relat Spec. 2007b;69(2):100-6.

Kelly LE. Radiation and chemotherapy. In: Ward EC, van-As-Brooks CJ, editors. Head and neck cancer: treatment, rehabilitation, and outcomes. San Diego: Plural Publishing; 2007. p.57-86.

Kessels RP. Patients' memory for medical information. $J$ Soc Med. 2003;96(5):219-22. 
Kjaer T, Johansen C, Andersen E, Karlsen R, Nielsen AL, Frederiksen K, Rørth M, Dalton SO. Do we reach the patients with the most problems? Baseline data from the WebCan study among survivors of head-and-neck cancer, Denmark. J Cancer Surviv. 2016;10(2):251-60.

Koch L, Jansen L, Brenner H, Arndt V. Fear of recurrence and disease progression in long-term ( $\geq 5$ years) cancer survivors-a systematic review of quantitative studies. Psychooncology. 2013;22(1):1-11.

Koller M, Lorenz W, Wagner K, Keil A, Trott D, Engenhart-Cabillic R, Nies C. Expectations and quality of life of cancer patients undergoing radiotherapy. $J R S O C$ Med. 2000;93(12):621-8.

Kowalski LP. Câncer de cabeça e pescoço. In: Carrara-de Angelis E, Furia CLB, Mourão LF, Kowalski LP, editores. A atuação da fonoaudiologia no câncer de cabeça e pescoço. São Paulo: Lovise; 2000a. p.19-25.

Kowalski LP. Bases do Tratamento dos principais tumores de cabeça e pescoço. In: In: Carrara-de Angelis E, Furia CLB, Mourão LF, Kowalski LP, editores. A atuação da fonoaudiologia no câncer de cabeça e pescoço. São Paulo: Lovise; 2000b. p.2731.

Kowalski LP, Carvalho AL, Magrin J. Cirurgia reparadora em câncer de cabeça e pescoço. In: Carrara-de Angelis E, Furia CLB, Mourão LF, Kowalski LP, editores. A atuação da fonoaudiologia no câncer de cabeça e pescoço. São Paulo: Lovise; 2000c. p.127-33.

Kravitz RL, Callahan EJ, Paterniti D, Antonius D, Dunham M, Lewis CE. Prevalence and sources of patients' unmet expectations for care. Ann Intern Med. 1996;125(9):730-7. 
Krebber AMH, Buffart LM, Kleijn G, Riepma IC, de Bree R, Leemans CR, Becker A, Brug J, van Straten A, Cuijpers P, Verdonck-de Leeuw IM. Prevalence of depression in cancer patients: a meta-analysis of diagnostic interviews and self-report instruments. Psychooncology. 2014;23(2):121-30.

Kreitler S, Chaitchik S, Rapoport Y, Kreitler H, Algor R. Life satisfaction and health in cancer patients, orthopedic patients and healthy individuals. Soc Sci Med. 1993;36(4):547-56.

Lang H, France E, Williams B, Humphris G, Wells M. The psychological experience of living with head and neck cancer: a systematic review and meta-synthesis. Psychooncology. 2013;22(12):2648-63.

Lango MN, Egleston B, Fang C, Burtness B, Galloway T, Liu J, Mehra R, Ebersole B, Moran K, Ridge JA. Baseline health perceptions, dysphagia, and survival in patients with head and neck cancer. Cancer. 2014;120(6):840-7.

Larsson MM; Hedelin B; Johansson I; Athlin E. Eating problems and weight loss for patients with head and neck cancer: a chart review from diagnosis until one year after treatment. Cancer Nurs. 2005;28(6):425-35.

Lazarus CL. Effects of chemoradiotherapy on voice and swallowing. Curr Opin Otolaryngol Head Neck Surg. 2009;17(3):172-8.

Lee-Jones C, Humphris G, Dixon R, Hatcher MB. Fear of cancer recurrence-a literature review and proposed cognitive formulation to exacerbation of recurrence fears. Psychooncology. 1997;6(2):95-105.

Leventhal H, Leventhal EA, Contrada RJ. Self-regulation, health and behaviour: a perceptual cognitive approach. Psychol Health. 1998;13(4):717-34. 
Levy MH, Back A, Benedetti C, Billings JA, Block S, Boston B, Bruera E, Dy S, Eberle C, Foley KM, Karver SB, Knight SJ, Misra S, Ritchie CS, Spiegel D, Sutton L, Urba S, Von Roenn JH, Weinstein SM. NCCN clinical practice guidelines in oncology: palliative care. J Natl Compr Canc Netw. 2009;7(4):436-73.

Ley P. Memory for medical information. Br J Soc Clin Psychol. 1979;18(2):245-55.

Lin A, Kim HM, Terrell JE, Dawson LA, Ship JA, Eisbruch A. Quality of life after parotid-sparing IMRT for head-and-neck cancer: a prospective longitudinal study. Int J Radiat Oncol Biol Phys. 2003;57(1):61-70.

List MA, D'Antonio LL, Cella DF, Siston A, Mumby P, Haraf D, Vokes E. The performance status scale for head and neck cancer patients and the functional assessment of cancer therapy-head and neck scale. A study of utility and validity. Cancer. 1996;77(11):2294-301.

List MA, Bilir SP. Functional outcomes in head and neck cancer. Semin Radiat Oncol. 2004;14(2):178-89.

List MA, Stracks J, Colangelo L, Butler P, Ganzenko N, Lundy D, Sullivan P, Haraf D, Kies M, Goodwin W, Vokes EE. How do head and neck cancer patients prioritize treatment outcomes before initiating treatment? J Clin Oncol. 2000;18(4):877-84.

List MA, Siston A, Haraf D. Quality of life and performance in advanced head and neck cancer patients on concomitant chemoradiotherapy: a prospective examination. J Clin Oncol. 1999;17(3):1020-8.

Llewellyn CD, Linklater K, Bell J, Johnson NW, Warnakulasuriya S. An analysis of risk factors for oral cancer in young people: a case-control study. Oral Oncol. 2004;40(3):304-13. 
Llewellyn CD, McGurk M, Weinman J. Are psycho-social and behavioural factors related to health related-quality of life in patients with head and neck cancer? A systematic review. Oral Oncol. 2005a;41(5):440-54.

Llewellyn CD, McGurk M, Weinman J. Striking the right balance: a qualitative pilot study examining the role of information on the development of expectations in patients treated for head and neck cancer. Psych Health Med. 2005b;10(2):180-93.

Llewellyn CD, McGurk M, Weinman J. Illness and treatment beliefs in head and neck cancer: is Leventhal's common sense model a useful framework for determining changes in outcomes over time? J Psychosom Res. 2007;63(1):17-26.

Llewellyn CD, Horne R, McGurk M \& Weinman J. Development and preliminary validation of a new measure to assess satisfaction with information among head and neck cancer patients: the satisfaction with cancer information profile (SCIP). Head Neck, 2006a;28(6):540-8.

Llewellyn CD, McGurk M, Weinman J. How satisfied are head and neck cancer (HNC) patients with the information they receive pre-treatment? Results from the satisfaction with cancer information profile (SCIP). Oral Oncol. 2006b;42(7):726-34.

Lloyd-Williams M, Friedman T. Depression in palliative care patients: a prospective study. Eur J Cancer Care (Engl). 2001;10(4):270-4.

Maguire P, Howell A. Improving the psychological care of cancer patients: Psychiatric aspects of physical disease. J R Coll Physicians Lond. 1995;29(1):41-54.

Maguire P. Improving the detection of psychiatric problems in cancer patients. Soc Sci Med. 1985;20(8):819-23.

Mahmood R, Butterworth C, Lowe D, Rogers SN. Characteristics and referral of head and neck cancer patients who report chewing and dental issues on the Patient Concerns Inventory. Br Dent J. 2014;216(11):E25. 
Mason H, DeRubeis MB, Burke N, Shannon M, Karsies D, Wolf G, Eisbruch A, Worden F. Symptom management during and after treatment with concurrent chemoradiotherapy for oropharyngeal cancer: a review of the literature and areas for future research. World J Clin Oncol. 2016;7(2):220-6.

McElduff P, Boyes A, Zucca A, Girgis A. Supportive care needs survey: a guide to administration, scoring and analysis. Newcastle: Centre for Health Research and Psycho-Oncology; 2004.

McHorney CA, Rosenbek JC, Robbins J, Chignell KA, Logemann JA, Clarke C. The SWAL-QOL outcomes tool for oropharyngeal dysphagia in adults:I: conceptual foundation and item development. Dysphagia. 2000;15(3):115-21.

McHorney, CA. Health status assessment methods for adults: past accomplishments and future challenges. Annu Rev Public Health. 1999;20:309-35.

Macguire P, Selby P. Assessing quality of life in cancer patients. Br J Cancer. 1989;60(3):437-40.

McQuestion M, Fitch M, Howell D. The changed meaning of food: physical, social and emotional loss for patients having received radiation treatment for head and neck cancer. Eur J Oncol Nurs. 2011;15(2):145-51.

Mehanna HM, Morton RP. Patients' views on the utility of quality of life questionnaires in head and neck cancer: a randomised trial. Clin Otolaryngol. 2006;31(4):310-6.

Mehnert A, Berg P, Henrich G, Herschbach P. Fear of cancer progression and cancer-related intrusive cognitions in breast cancer survivors. Psychooncology. 2009;18(12)1273-80. 
Meredith C, Symonds P, Webster L, Lamont D, Pyper E, Gillis CR, Fallowfield L. Information needs of cancer patients in west Scotland: cross sectional survey of patients' views. BMJ. 1996;313(7059):724-6.

Merseyside Regional Head \& Neck Cancer Centre. Quality of Life (QOL). Available from: http//www.headandneckcancer.co.uk/For+professionals /Quality+of+Life $+(\mathrm{QOL}) /$ Patient+Concerns+Inventory.aspx.

Mesía R, Rivera F, Kawecki A, Rottey S, Hitt R, Kienzer H, Cupissol D, De Raucourt D, Benasso M, Koralewski P, Delort JP, Bokemeyer C, Curran D, Gross A, Vermorken JB. Quality of life of patients receiving platinum-based chemotherapy plus cetuximab first line for recurrent and/or metastatic squamous cell carcinoma of the head and neck. Ann Oncol. 2010;21(10):1967-73.

Metcalfe CW, Lowe D, Rogers SN. What patients consider important: temporal variations by early and late stage oral, oropharyngeal and laryngeal subsites. $J$ Craniomaxillofac Surg. 2014;42(5):641-7.

Mills ME, Sullivan K. The importance of information giving for patients newly diagnosed with cancer: a review of the literature. J Clin Nurs. 1999;8(6):631-42.

Ministério da Saúde. Instituto Nacional do Câncer José de Alencar Gomes da Silva. Estimativas 2016 incidência de câncer no Brasil. Disponível em: http://www.inca.gov.br/wcm/dncc/2015/index.asp.

Mock V, Atkinson A, Barsevick AM, Berger AM, Cimprich B, Eisenberger MA, Hinds P, Kaldor P, Otis-Green SA, Piper BF. Cancer-related fatigue. Clinical Practice Guidelines in Oncology. J Natl Compr Cance Netw. 2007;5(10):1054-78.

Mohide EA, Archibald SD, Tew M, Young JE, Haines T. Postlaryngectomy qualityof-life dimensions identified by patients and health care professionals. Am J Surg. 1992;164(6):619-22. 
Molassiotis A, Rogers M. Symptom experience and regaining normality in the first year following a diagnosis of head and neck cancer: a qualitative longitudinal study. Palliat Support Care. 2012;10(3):197-204.

Mondloch MV, Cole DC, Frank JW. Does how you do depend on how you think you'll do? A systematic review of the evidence for a relation between patients' recovery expectations and health outcomes. CMAJ. 2001;165(2):174-9.

Moore K, Ford P, Farah C. Support needs and quality of life in oral cancer: a systematic review. Int J Dent Hyg. 2014;12(1):36-47.

Morton RP. Evolution of quality of life assessment in head and neck cancer. $J$ Laryngol Otol. 1995;109(11):1029-35.

Morton RP, Izzard ME. Quality-of-life outcomes in head and neck cancer patients. World J Surg. 2003;27(3):884-9.

Morton RP. Studies in the quality of life of head and neck cancer patients: results of a two year longitudinal study and a comparative cross sectional cross cultural survey. Laryngoscope. 2003;113(7):1091-103.

Morete MC, Minson FP. Instrumentos para avaliação da dor em pacientes oncológicos. Rev Dor Pesquisa, Clínica e Terapêutica. 2010;11(1):74-80.

Morrison V, Henderson BJ, Zinovieff F, Davies G, Cartmell R, Hall A, Gollins S. Common, important, and unmet needs of cancer outpatients. Eur J Oncol Nurs. 2012;16(2):115-23.

Moss-Morris R, Weinman J, Petrie K, Horne R, Cameron LD, Buick, D. The revised illness perception questionnaire (IPQ-R). Psychol Health. 2002;17(1):1-16.

Mossman J, Boudioni M, Slevin ML. Cancer information: a cost-effective intervention. Eur J Cancer. 1999;35(11):1587-91. 
Murphy BA, Ridner S, Wells N, Dietrich M. Quality of life research in head and neck cancer: a review of the current state of the science. Crit Rev Oncol Hematol. 2007;62(3):251-67.

Murphy BA, Deng J. Advances in supportive care for late effects of head and neck cancer. J Clin Oncol. 2015;33(29):3314-21.

National Cancer Alliance. Head and neck cancer patients' views and experiences. Oxford: The National Cancer Alliance; 2002. Available from: http://www.scan.scot.nhs.uk/Documents/Head\%20and\%20Neck\%20Report\%20Dec $\% 2002$.pdf.

Neilson KA, Pollard AC, Boonzaier AM, Corry J, Castle DJ, Mead KR, Gray MC, Smith DI, Trauer T, Couper JW. Psychological distress (depression and anxiety) in people with head and neck cancers. Med J Aust. 2010;193(5):48-51.

Newell R, Ziegler L, Stafford N, Lewin RJ. The information needs of head and neck cancer patients prior to surgery. Ann R Coll Surg Engl. 2004;86:407-10.

Noce CW, Rebelo MS. Avaliação da relação entre o tamanho do tumor e características sociais em pacientes com carcinoma de células escamosas bucal. Rev Bras Cancerol. 2008;54(2):123-9.

Ojo B, Genden EM, Teng MS, Milbury K, Misiukiewicz KJ, Badr H. A systematic review of head and neck cancer quality of life assessment instruments. Oral Oncol. 2012;48(10):923-37.

Olson JM, Roese NJ, Zanna MP. Expectancies. In: Higgins ET, Kruglanski AW, editors. Social psychology: handbook of basic principles. New York: Guilford; 1996. p.211-38. 
Olver IN, Taylor AE, Whitford HS. Relationships between patients' pre-treatment expectations of toxicities and post chemotherapy experiences. Psychooncology. 2005;14(1):25-33.

Organização Mundial de Saúde-OMS. Divisão de Saúde Mental Grupo WHOQOL. Versão em português dos instrumentos de qualidade de vida desenvolvimento do WHOQOL-OMS (WHOQOL). $1998 . \quad$ Disponível em: http://www.ufrgs.br/psiq/whoqoll.html.

Osoba D. Translating the science of patient-reported outcomes assessment into clinical practice. J Natl Cancer Inst Monogr. 2007;(37):5-11.

Pace-Balzan A, Rogers SN. Dental rehabilitation after surgery for oral cancer. Curr Opin Otolaryngol Head Neck Surg. 2012;20(2):109-13.

Palmer JL, Fisch MJ. Association between symptom distress and survival in outpatients seen in a palliative care cancer center. J Pain Symptom Manage. 2005;29(6):565-71.

Paredes T, Simões MR, Canavarro MC, Serra AV, Pereira M, Quartilho MJ, Rijo D, Gameiro S, Carona C. Impacto da doença crônica na qualidade de vida: comparação entre indivíduos da população geral e doentes com tumor do aparelho locomotor Psicologia, Saúde Doenças, 2008;9(1):73-87.

Parker PA, Baile WF, de Moor Cd, Cohen L. Psychosocial and demographic predictors of quality of life in a large sample of cancer patients. Psychooncology. 2003;12(2):183-93.

Parkin DM. Global cancer statistics in the year 2000. Lancet Oncol. 2001;2(9):53343. 
Pelucchi C, Gallus S, Garavello W, Bosetti C, La Vecchia C. Alcohol and tobacco use, and cancer risk for upper aerodigestive tract and liver. Eur $J$ Cancer Prev. 2008;17(4):340-4.

Perkins K, Hancock KL, Ward EC. Speech and swallowing following laryngeal and hypopharyngeal cancer. In: Ward EC and van-as-Brooks CJ, editors. Head and neck cancer: treatment, rehabilitation, and outcomes. San Diego: Plural Publishing; 2007. p.145-92.

Peters M, Passchier J. Translating instruments for cross-cultural studies in headache research. Headache. 2006;46(1):82-91.

Pimentel FL, Ferreira JS, Vila Real M, Mesquita NF, Maia-Gonçalves JP. Quantity and quality of information desired by Portuguese cancer patients. Support Care Cancer. 1999;7(6):407-12.

Pimentel FL. Qualidade de vida do doente oncológico [tese]. Porto; Faculdade de Medicina da Universidade do Porto; 2003.

Pinto RN. A comunicação do diagnóstico de câncer [dissertação]. São Paulo: Universidade Federal de São Paulo; 2001.

Portas JG. Validação para a língua portuguesa-brasileira dos questionários: qualidade de vida em disfagia (SWAL-QOL) e satisfação do paciente e qualidade do cuidado no tratamento da disfagia (SWAL- CARE) [dissertação]. São Paulo; Fundação Antônio Prudente; 2009.

Pruyn JF, de Jong PC, Bosman LJ, van Poppel JW, van Den Borne HW, Ryckman RM, de Meij K. Psychosocial aspects of head and neck cancer--a review of the literature. Clin Otolaryngol Allied Sci. 1986;11(6):469-74.

Raison CL, Nemeroff CB. Cancer and depression: prevalence, diagnosis and treatment. Home Health Care Consultant. 2000;7(9):34-41. 
Rankin KV, Jones DL, Redding SW. Oral health in cancer therapy: a guide for health care professionals. $3^{\text {rd }}$ ed. 2008. Available from: http://www.exodontia.info/files/Oral_Health_in_Cancer_Therapy_-_A_Guide_for_ Health_Care_Professionals_3rd_edition.pdf.

Reid BC, Alberg AJ, Klassen AC, Koch WM, Samet JM. The American Society of Anesthesiologists' class as a comorbidity index in a cohort of head and neck cancer surgical patients. Head Neck. 2001;23(11):985-94.

Ribeiro MMF, Amaral CFS. Medicina centrada no paciente e ensino médico: a importância do cuidado com a pessoa e o poder médico. Rev Bras Educ Med. 2008;32(1):90-7.

Richardson A, Medina J, Brown V, Sitzia J. Patients' needs assessment in cancer care: a review of assessment tools. Support Care Cancer. 2007;15(10):1125-44.

Ringash J. Survivorship and quality of life in head and neck cancer. J Clin Oncol. 2015;33(29):3322-7.

Rinkel RN, Verdonck-de Leeuw IM, Langendijk JA, van Reij EJ, Aaronson NK, Leemans CR. The psychometric and clinical validity of the SWAL-QOL questionnaire in evaluating swallowing problems experienced by patients with oral and oropharyngeal cancer. Oral Oncol. 2009;45(8):e67-e71.

Rischin D, Ferris RL, Le QT. Overview of advances in head and neck cancer. J Clin Oncol. 2015;33(29):3225-6.

Ritchie J, Spencer L. Qualitative data analysis for applied policy research. In: Bryman A, Burgess R, editors. Analysing qualitative data. London: Routledge; 1994. p.173-94. 
Rogers SN, Laher SH, Overend L, Lowe D. Importance-rating using the University of Washington quality of life questionnaire in patients treated by primary surgery for oral and oro-pharyngeal cancer. J Craniomaxillofac Surg. 2002;30(2):125-32.

Rogers SN, El-Sheikha J, Lowe D. The development of a Patients Concerns Inventory (PCI) to help reveal patients concerns in the head and neck clinic. Oral Oncol. 2009;45(7):555-61.

Rogers SN, Lowe D. An evaluation of the Head and Neck Cancer Patient Concerns Inventory across the Merseyside and Cheshire Network. Br J Oral Maxillofac Surg. 2014;52(7):615-23.

Rogers SN. Quality of life perspectives in patients with oral cancer. Oral Oncol. 2010;46(6):445-7.

Rogers SN, Ahad SA, Murphy AP. A structured review and theme analysis of papers published on 'quality of life' in head and neck cancer: 2000-2005. Oral Oncol. 2007;43(9):843-68.

Rogers SN, Scott B, Lowe D, Ozakinci G, Humphris GM. Fear of recurrence following head and neck cancer in the outpatient clinic. Eur Arch Otorhinolaryngol. 2010;267(12):1943-9.

Rogers SN, Clifford N, Lowe D. Patient and care unmet needs: a survey of the British association of head and neck oncology nurses. Br J Oral Maxillofac Surg. 2011;49(5):343-8.

Rogers SN, Harvey-Woodworth CN, Hare J, Leong P, Lowe D. Patients' perception of the financial impact of head and neck cancer and the relationship to health related quality of life. Br J Oral Maxillofac Surg. 2012;50(5):410-6. 
Rogers SN, Hogg ES, Cheung WK, Lai LK, Jassal P, Lowe D. The use of health related quality of life data to produce information sheets for patients with head and neck cancer. Ann R Coll Surg Engl. 2015b;97(5):359-63.

Rogers SN, Hazeldine P, O'Brien K, Lowe D, Roe B. How often do head and neck cancer patients raise concerns related to intimacy and sexuality in routine follow-up clinics? Eur Arch Oto-Rhino-Laryngol. 2015a;272(1):207-17.

Rolim AEH, Costa LJ, Ramalho LMP. Repercussões da radioterapia na região orofacial e seu tratamento. Raddiol Bras. 2011;44(6):388-95.

Rooney AG, Netten A, McNamara S, Erridge S, Peoples S, Whittle I, Hacking B, Grant R. Assessment of a brain-tumour-specific Patient Concerns Inventory in the neuro-oncology clinic. Support Care Cancer. 2014;22(4):1059-69.

Rosen CA, Lee S, Osborne J, Zullo T, Murry T. Development and validation of the voice handicap index-10. Laryngoscope. 2004;114(9):1549-56.

Rosenthal DI, Mendoza TR, Chambers MS, Asper JA, Gning I, Kies MS, Weber RS, Lewin JS, Garden AS, Ang KK, S Wang X, Cleeland CS. Measuring head and neck cancer symptom burden: the development and validation of the M.D. Anderson symptom inventory, head and neck module. Head Neck. 2007;29(10):923-31

Sahu N, Grandis JR. New advances in molecular approaches to head and neck squamous cell carcinoma. Anticancer Drugs. 2010;22(7):656-64.

Santos RA, Portugal FB, Felix JD, Santos PMO, Siqueira MM. Avaliação epidemiológica de pacientes com câncer no trato aerodigestivo superior: relevância dos fatores de risco álcool e tabaco. Rev Bras Cancerol. 2012;58(1):21-29.

Santos LCO; Batista OM; Maria Cristina Teixeira Cangussu MCT. Caracterização do diagnóstico tardio do câncer de boca no estado de Alagoas. Braz J Otorhinolaryngol. 2010;76(4):416-22. 
Santos RA, Portugal FB, Felix JD, Santos PMO, Siqueira MM. Avaliação epidemiológica de pacientes com câncer no trato aerodigestivo superior: relevância dos fatores de risco álcool e tabaco. Rev Bras Cancerol. 2012;58(1):21-9.

Saunders NA, Coman WB, Guminski AD. Cancer of the head and neck. In: Ward EC, van-As-Brooks CJ, editors. Head and neck cancer: treatment, rehabilitation, and outcomes. San Diego: Plural Publishing; 2007. p.1-27.

Sawyer H. Meeting the information needs of cancer patients. Prof Nurse. 2000;15(4):244-7.

Sayed SI, Elmiyeh B, Rhys-Evans P, Syrigos KN, Nutting CM, Harrington KJ, Kazi R. Quality of life and outcomes research in head and neck cancer: a review of the state of the discipline and likely future directions. Cancer Treat Rev. 2009;35(5):397402.

Scharloo M, Baatenburg de Jong RJ, Langeveld TP, van Velzen-Verkaik E, Doornop den Akker MM, Kaptein AA. Quality of life and illness perceptions in patients with recently diagnosed head and neck cancer. Head Neck. 2005;27(10):857-63.

Scharloo M, Baatenburg de Jong RJ, Langeveld TP, van Velzen-Verkaik E, DoornOp den Akker MM, Kaptein AA. Illness cognitions in head and neck squamous cell carcinoma: predicting quality of life outcome. Support Care Cancer. 2010;18(9):1137-45.

Schlecht NF, Franco EL, Pintos J, Negassa A, Kowalski LP, Oliveira BV, Curado MP. Interaction between tobacco and alcohol consumption and the risk of cancers of the upper aero-digestive tract in Brazil. Am J Epidemiol. 1999; 150(11):1129-37.

Segreto HRC, Segreto RA. Revisão e atualização em radiobiologia: aspectos celulares, moleculares e clínicos. Folha Med. 2000;119(4):9-27. 
Seid EMF, Zannon CMLC. Qualidade de vida e saúde: aspectos conceituais e metodológicos. Cad Saúde Pública. 2004;20(2):580-8.

Semenov YR, Starmer HM, Gourin CG. The effect of pneumonia on short-term outcomes and cost of care after head and neck cancer surgery. Laryngoscope. 2012;122(9):1994-2004.

Semple C. The role of the CNS in head and neck oncology. Nurs Stand. 2001;15(23):39-42.

Semple CJ, McGowan B. Need for appropriate written information for patients, with particular reference to head and neck cancer. Clin Nurs. 2002;11(5):585-93.

Silveira NJ, Varuzza L, Machado-Lima A, Lauretto MS, Pinheiro DG, Rodrigues RV, Severino P, Nobrega FG, Head and Neck Genome Project GENCAPO, Silva WA Jr, de B Pereira CA, Tajara EH. Searching for molecular markers in head and neck squamous cell carcinomas (HNSCC) by statistical and bioinformatic analysis of larynx-derived SAGE libraries. BMC Med Genomics 2008;1:56.

Silveira AP, Gonçalves J, Sequeira T, Ribeiro C, Lopes C, Monteiro E, Pimentel FL. Patient reported outcomes in head and neck cancer: selecting instruments for quality of life integration in clinical protocols. Head Neck Oncol. 2010;2:32.

Simard S, Savard J, Ivers H. Fear of cancer recurrence: Specific profiles and nature of intrusive thoughts. J Cancer Surviv. 2010;4(4):361-71.

So WK, Chan RJ, Chan DN, Hughes BG, Chair SY, Choi KC, Chan CW. Quality-oflife among head and neck cancer survivors at one year after treatment: a systematic review. Eur J Cancer. 2012;48(15):2391-408.

Sohl SJ, Schnur JB, Montgomery GH. A meta-analysis of the relationship between response expectancies and cancer treatment-related side effects. J Pain Symptom Manage. 2009;38(5):775-84. 
Specht L. Oral complications in the head and neck radiation patient. Introduction and scope of the problem. Support Care Cancer. 2002;10(1):36-9.

Staniszewska S. Patient expectations and health-related quality of life. Health Expect. 1999;2(2):93-104.

Taylor JC, Terrell JE, Ronis DL, Fowler KE, Bishop C, Lambert MT, Myers LL, Duffy SA, Bradford CR, Chepeha DB, Hogikyan ND, Prince ME, Teknos TN, Wolf GT; University of Michigan Head and Neck Cancer Team. Disability in patients with head and neck cancer. Arch Otolaryngol Head Neck Surg. 2004;130(6):764-9.

Teixeira MJ. Tratamento neurocirúrgico da dor. In: Raia, A.A.; Zerbini, EJ, editores. Clínica cirúrgica Alípio Correa Neto. $4^{\mathrm{a}}$ ed. São Paulo: Sarvier; 1988. p.541-72.

ter Hoeven CL, Zandbelt LC, Fransen S, de Haes H, Oort F, Geijsen D, Koning C, Smets E. Measuring cancer patients' reasons for their information preference: construction of the Considerations Concerning Cancer Information (CCCI) questionnaire. Psychooncology. 2011;20(11):1228-35.

Testoni RI, Soares VMN, Goncalves, CGO, Kalinke. LP. Qualidade de vida de pacientes com neoplasia de cabeça e pescoço: uma revisão integrativa. Tuiuti: Ciência e Cultura [periódico online]. 2013;4:107-21. Disponível em: http://www.utp.br/tuiuticienciaecultura/ciclo_4/tcc_47_disturbios/pdf_47/art_6.pdf.

Teunissen S, de Graeff A, de Haes H, Voest E. Prognostic significan- ce of symptoms of hospitalised advanced cancer patients. Eur $J$ Cancer. 2006;42(15):2510-6.

Teutsch C. Patient-doctor communication. Med Clin North Am. 2003;87(5):1115-45.

Thomas L, Jones TM, Tandon S, Katre C, Lowe D, Rogers SN. An evaluation of the University of Washington quality of life swallowing domain following oropharyngeal cancer. Eur Arch Otorhinolaryngol. 2008;265 Suppl 1:S29-37. 
Tomita Y, Osaki T. Gustatory impairment and salivary gland pathophysiology in relation to oral cancer treatment. Int J Oral Maxillofac Surg. 1990;19(5):299-304.

Trotti A, Pajak TF, Gwede CK, Paulus R, Cooper J, Forastiere A, Ridge JA, Watkins-Bruner D, Garden AS, Ang KK, Curran W. TAME: development of a new method for summarising adverse events of cancer treatment by the Radiation Therapy Oncology Group. Lancet Oncol. 2007;8(7):613-24.

van der Laan HP, Bijl HP, Steenbakkers RJHM, van der Schaaf A, Chouvalova O, Vemer-van den Hoek JGM, Gawryszuk A, van der Laan BFAM, Oosting SF, Roodenburg JLN, Wopken K, Langendijk JA. Acute symptoms during the course of head and neck radiotherapy or chemoradiation are strong predictors of late dysphagia. Radiother Oncol. 2015;115(1):56-62.

Vartanian JG, Carvalho AL, Yueh B, Priante AV, de Melo RL, Correia LM, Köhler HF, Toyota J, Kowalski IS, Kowalski LP. Long-term quality-of-life evaluation after head and neck cancer treatment in a developing country. Arch Otolaryngol Head Neck Surg. 2004;130(1):1209-13.

Vartanian JG, Carvalho AL, Yueh B, Furia CL, Toyota J, McDowell JA, Weymuller EA Jr, Kowalski LP. Brazilian Portuguese validation of the University of Washington quality of life questionnaire for patients with cancer head and neck. Head Neck. 2006a;28(12):1115-21.

Vartanian JG, Carvalho AL, Toyota J, Kowalski IS, Kowalski LP. Socioeconomic effects of and risk factors for disability in long-term survivors of head and neck cancer. Arch Otolaryngol Head Neck Surg. 2006b;132(1):32-5.

Vartanian J G, Carvalho A L, De Carvalho A Y, Benevides GM, Sanábria A, Toyota J, Kowalski L P. Avaliação de sintomas depressivos em sobreviventes em longo prazo do câncer de cabeça e pescoço. Rev Bras Cir Cabeça Pescoço. 2006c;35(4):226-9. 
Vartanian JG, Carvalho AL, Furia CLB, Castro Junior G, Rocha CN, Igor MLS, Toyota J, Kowalski ISG, Federico MHH, Kowalski LP. Questionários para a avaliação de qualidade de vida em pacientes com câncer de cabeça e pescoço validados no Brasil. Rev Bras Cir Cabeça Pescoço; 2007;36(2):108-15.

Verdonck-de Leeuw IM, de Bree R, Keizer AL, Houffelaar T, Cuijpers P, van der Linden MH, Leemans CR. Computerized prospective screening for high levels of emotional distress in head and neck cancer patients and referral rate to psychosocial care. Oral Oncol. 2009;45(10):129-33.

Vicente CCL, Forte PA, Martins L, Soneghet R. Tumores de cavidade oral e orofaringe: atuação fonoaudiológica. In: Lopes Filho O,editor. Tratado de fonoaudiologia. São Paulo: Roca; 1997. p.1079-102.

Vickery LE, Latchford G, Hewison J, Bellew M, Feber T. The impact of head and neck cancer and facial disfigurement on the quality of life of patients and their partners. Head Neck. 2003;25(4):289-96.

Vissink A, Jansma J, Spijkervet FKL, Burlage FR, Coppes RP. Oral sequelae of head and neck radiotherapy. Crit Rev Oral Biol Med. 2003;14(3):199-212.

Ware JE Jr Kosinski M, Turner-Bowker DM, Gandek B. How to score version 2 of the SF-12 health survey. Lincoln, RI: Quality Metric Incorporated; 2002.

Weinman JA, Petrie KJ. Introduction to the perceptions of health and ilness. In: Petrie KJ, Weinman JA. editors. Perceptions of health and illness: current research and applications. New York: Harwood Academic Publishers; 1998. p.1-18.

Wells M, Cunningham M, Lang H, Swartzman S, Philp J, Taylor L, Thomson J. Distress, concerns and unmet needs in survivors of head and neck cancer: a crosssectional survey. Eur J Cancer Care (Engl). 2015;24(5):748-60.

White CA. Meaning and its measurement in psychosocial oncology. Psychooncology. 2004;13(7):468-81. 
Williams S, Weinman J, Dale J, Newman S. Patient expectations: what do primary care patients want from the GP and how far does meeting expectations affect patient satisfaction? Fam Pract. 1995;12(2):193-201.

Wilson JA, Carding PN, Patterson JM. Dysphagia after nonsurgical head and neck cancer treatment: patients' perspectives. Otolaryngol Head Neck Surg. 2011;145(5):767-71.

Winterling J, Glimelius B, Nordin K. The importance of expectations on the recovery period after cancer treatment. Psychooncology. 2008;17(2):190-8.

Woyciekoski C, Stenert F, Hutz C. Determinantes do bem-estar subjetivo. Psico. 2012;43(3):280-8.

Wu YS, Lin PY, Chien CY, Fang FM, Chiu NM, Hung CF, Lee Y, Chong MY. Anxiety and depression in patients with head and neck cancer: 6-month follow-up study. Neuropsychiatr Dis Treat. 2016;12:1029-36.

Wünsch Filho V. The epidemiology of laryngeal cancer in Brazil. Sao Paulo Med J. 2004;122(5):188-94.

Yan W, Wistuba II, Emmert-Buck MR, Erickson HS. Squamous cell carcinoma: similarities and differences among anatomical sites. Am $J$ Cancer Res. 2011;1(3):275-300.

Yom SS, Ganti AK, Dietz A. What's new in head and neck cancer: key findings in 2015-2016 from ECCO/ESMO, ASTRO, and the multidisciplinary head and neck cancer Symposium. Am Soc Clin Oncol Educ Book. 2016;35:176-83.

Zigmond AS, Snaith RP. The hospital anxiety and depression scale. Acta Psych Scand. 1983;67(6):361-70. 


\section{APÊNDICES}


Apêndice 1 - Associações não significantes entre o grau de preenchimento das expectativas e qualidade de vida global aos 6 meses após o tratamento (Itens/ Profissionais)

\begin{tabular}{|c|c|c|c|c|c|c|}
\hline Itens & Grau de preenchimento & $\mathrm{n}$ & média (dp) & mediana & mín.-máx & $p$ \\
\hline \multirow{4}{*}{ Atividade física } & não se aplica & 13 & $78,4(15,2)$ & 80,6 & $47,9-97,3$ & 0,04 \\
\hline & pior & 21 & $67,7(15,1)$ & 68,1 & $38,2-95,2$ & \\
\hline & igual & 35 & $77,0(16,6)$ & 79,2 & $30,6-100,0$ & \\
\hline & melhor & 11 & $80,8(11,4)$ & 80,6 & $61,8-100,0$ & \\
\hline \multirow{4}{*}{ Respiração } & não se aplica & 17 & $76,7(13,9)$ & 80,6 & $45,2-97,3$ & 0,20 \\
\hline & pior & 10 & $65,7(18,2)$ & 64,6 & $38,2-95,2$ & \\
\hline & igual & 42 & $75,6(15,8)$ & 76,3 & $30,6-100,0$ & \\
\hline & melhor & 11 & $81,0(14,7)$ & 84,8 & $56,9-100,0$ & \\
\hline \multirow{4}{*}{ Audição } & não se aplica & 29 & $75,6(15,1)$ & 77,0 & $38,2-97,3$ & 0,24 \\
\hline & pior & 8 & $63,8(20,9)$ & 61,5 & $30,6-97,9$ & \\
\hline & igual & 33 & $76,3(15,3)$ & 77,0 & $47,3-100,0$ & \\
\hline & melhor & 10 & $80,4(13,2)$ & 84,0 & $54,8-100,0$ & \\
\hline \multirow{4}{*}{ Náusea } & não se aplica & 40 & $79,1(14,6)$ & 82,3 & $47,3-100,0$ & 0,02 \\
\hline & pior & 12 & $62,4(13,8)$ & 62,5 & $38,2-80,6$ & \\
\hline & igual & 12 & $74,0(14,6)$ & 73,0 & $45,1-97,9$ & \\
\hline & melhor & 16 & $76,6(17,1)$ & 79,8 & $30,6-100,0$ & \\
\hline \multirow{4}{*}{ Regurgitação } & não se aplica & 57 & $75,7(15,9)$ & 79,2 & $30,6-100,0$ & 0,06 \\
\hline & pior & 4 & $56,3(13,5)$ & 52,4 & $45,2-75,0$ & \\
\hline & igual & 12 & $74,9(15,3)$ & 70,9 & $45,1-97,9$ & \\
\hline & melhor & 7 & $84,2(8,8)$ & 84,8 & $73,7-100,0$ & \\
\hline \multirow{4}{*}{ Muita salivação } & não se aplica & 51 & $76,2(17,0)$ & 79,8 & $30,6-100,0$ & 0,08 \\
\hline & pior & 12 & $66,5(11,9)$ & 68,1 & $45,1-84,1$ & \\
\hline & igual & 11 & $76,6(12,5)$ & 74,4 & $61,9-97,9$ & \\
\hline & melhor & 6 & $83,6(12,8)$ & 85,4 & $60,4-100,0$ & \\
\hline \multirow{4}{*}{ Ombros } & não se aplica & 50 & $76,6(13,5)$ & 78,2 & $47,9-100,0$ & 0,02 \\
\hline & pior & 9 & $60,0(16,0)$ & 61,8 & $38,2-92,4$ & \\
\hline & igual & 15 & $78,9(15,6)$ & 77,0 & $45,1-100,0$ & \\
\hline & melhor & 6 & $78,6(24,3)$ & 85,4 & $30,6-100,0$ & \\
\hline \multirow{4}{*}{ Sono } & não se aplica & 17 & $78,3(16,1)$ & 82,7 & $38,2-97,3$ & 0,02 \\
\hline & pior & 16 & $64,2(16,0)$ & 64,5 & $30,6-92,4$ & \\
\hline & igual & 34 & $76,7(15,5)$ & 75,7 & $45,1-100,0$ & \\
\hline & melhor & 13 & $81,5(9,7)$ & 80,6 & $63,2-100,0$ & \\
\hline \multirow{4}{*}{ Inchaço } & não se aplica & 46 & $78,0(15,4)$ & 80,6 & $38,2-100,0$ & 0,18 \\
\hline & pior & 13 & $68,0(11,9)$ & 69,5 & $45,2-84,8$ & \\
\hline & igual & 12 & $75,3(15,7)$ & 73,0 & $45,1-100,0$ & \\
\hline & melhor & 9 & $72,1(21,3)$ & 82,7 & $30,6-100,0$ & \\
\hline
\end{tabular}




\begin{tabular}{|c|c|c|c|c|c|c|}
\hline Itens & Grau de preenchimento & $\mathrm{n}$ & média (dp) & mediana & mín-máx & $p$ \\
\hline \multirow{3}{*}{ Arrependimento pelo tratamento } & não & 76 & $75,7(15,8)$ & 77,1 & $30,6-100,0$ & 0,34 \\
\hline & igual & 3 & $63,2(15,9)$ & 70,2 & $45,1-74,4$ & \\
\hline & melhor & 1 & $84,8(\mathrm{NA})$ & 84,8 & $84,8-84,8$ & \\
\hline \multirow{4}{*}{ Cicatrização de feridas } & não se aplica & 29 & $77,3(15,3)$ & 79,2 & $38,2-97,9$ & 0,64 \\
\hline & pior & 5 & $68,1(21,0)$ & 75,0 & $45,1-92,4$ & \\
\hline & igual & 9 & $78,4(9,4)$ & 77,2 & $68,2-93,8$ & \\
\hline & melhor & 37 & $74,0(16,8)$ & 75,7 & $30,6-100,0$ & \\
\hline \multirow{4}{*}{ Cuidador } & não se aplica & 20 & $76,7(17,5)$ & 83,7 & $38,2-100,0$ & 0,52 \\
\hline & pior & 2 & $68,8(16,7)$ & 68,8 & $56,9-80,6$ & \\
\hline & igual & 8 & $69,8(12,4)$ & 73,0 & $45,1-82,7$ & \\
\hline & melhor & 50 & $75,9(15,8)$ & 77,0 & $30,6-100,0$ & \\
\hline \multirow{4}{*}{ Dependentes / Crianças } & não se aplica & 46 & $76,3(16,0)$ & 77,4 & $38,2-100,0$ & 0,15 \\
\hline & pior & 4 & $60,1(9,5)$ & 57,6 & $51,4-73,7$ & \\
\hline & igual & 12 & $74,4(13,3)$ & 73,6 & $45,1-93,8$ & \\
\hline & melhor & 18 & $76,9(17,3)$ & 80,3 & $30,6-100,0$ & \\
\hline \multirow{4}{*}{ Benefícios financeiros } & não se aplica & 50 & $75,6(17,0)$ & 78,1 & $30,6-100,0$ & 0,93 \\
\hline & pior & 9 & $76,3(12,1)$ & 75,0 & $58,3-95,2$ & \\
\hline & igual & 12 & $75,8(13,3)$ & 75,0 & $45,1-100,0$ & \\
\hline & melhor & 9 & $72,1(17,5)$ & 83,3 & $47,3-93,8$ & \\
\hline \multirow{3}{*}{ Atendimento de profissionais em domícilio } & não & 69 & $76,5(15,6)$ & 79,2 & $38,2-100,0$ & 0,23 \\
\hline & igual & 5 & $67,2(7,1)$ & 70,2 & $56,9-74,3$ & \\
\hline & melhor & 6 & $68,8(21,6)$ & 76,4 & $30,6-86,1$ & \\
\hline \multirow{4}{*}{ Estilo de vida } & não se aplica & 54 & $73,7(16,4)$ & 75,3 & $30,6-100,0$ & 0,58 \\
\hline & pior & 4 & $77,6(10,8)$ & 75,7 & $66,7-92,4$ & \\
\hline & igual & 5 & $74,7(20,2)$ & 74,4 & $45,1-100,0$ & \\
\hline & melhor & 17 & $80,0(13,7)$ & 84,1 & $51,4-100,0$ & \\
\hline \multirow{4}{*}{ Fala/voz/ser entendido } & não se aplica & 4 & $72,4(23,1)$ & 82,0 & $38,2-87,5$ & 0,01 \\
\hline & pior & 24 & $66,6(16,5)$ & 67,4 & $30,6-95,2$ & \\
\hline & igual & 32 & $78,0(13,0)$ & 77,1 & $51,4-100,0$ & \\
\hline & melhor & 20 & $82,1(13,9)$ & 85,4 & $56,9-100,0$ & \\
\hline \multirow{4}{*}{ Suporte para minha família } & não se aplica & 21 & $75,3(15,0)$ & 77,0 & $38,2-100,0$ & 0,68 \\
\hline & pior & 4 & $69,1(20,6)$ & 66,7 & $47,9-95,2$ & \\
\hline & igual & 38 & $74,9(14,5)$ & 76,3 & $45,1-100,0$ & \\
\hline & melhor & 17 & $77,8(19,2)$ & 84,8 & $30,6-100,0$ & \\
\hline
\end{tabular}

Continua 


\begin{tabular}{|c|c|c|c|c|c|c|}
\hline Itens & Grau de preenchimento & $\mathrm{n}$ & média (dp) & mediana & mín.-máx & $\mathrm{p}$ \\
\hline \multirow[t]{5}{*}{ Ansiedade } & não se aplica & 32 & $76,4(14,3)$ & 75,7 & $38,2-100,0$ & 0,04 \\
\hline & pior & 14 & $66,1(13,4)$ & 66,0 & $45,2-84,8$ & \\
\hline & igual & 24 & $76,1(18,1)$ & 77,1 & $30,6-100,0$ & \\
\hline & melhor & 10 & $82,9(14,0)$ & 85,8 & $54,8-100,0$ & \\
\hline & não se aplica & 5 & $73,4(21,4)$ & 79,8 & $38,2-93,8$ & 0,54 \\
\hline Estratégias para enfrentar a doença & pior & 7 & $75,1(13,5)$ & 75,0 & $56,9-92,4$ & \\
\hline \multirow[t]{2}{*}{ e 0 tratamento } & igual & 26 & $72,5(14,8)$ & 70,9 & $45,1-100,0$ & \\
\hline & melhor & 42 & $77,3(16,4)$ & 80,6 & $30,6-100,0$ & \\
\hline \multirow[t]{4}{*}{ Depressão } & não se aplica & 60 & $76,2(16,5)$ & 78,2 & $30,6-100,0$ & 0,31 \\
\hline & pior & 4 & $70,1(10,2)$ & 71,5 & $56,9-80,6$ & \\
\hline & igual & 9 & $68,6(16,0)$ & 63,8 & $47,9-95,2$ & \\
\hline & melhor & 7 & $79,6(10,2)$ & 84,0 & $58,3-86,9$ & \\
\hline \multirow[t]{4}{*}{ Medo do câncer voltar } & não se aplica & 29 & $78,1(15,3)$ & 80,6 & $45,1-100,0$ & 0,04 \\
\hline & pior & 12 & $62,7(16,7)$ & 61,1 & $30,6-84,8$ & \\
\hline & igual & 23 & $75,7(14,6)$ & 74,4 & $47,9-97,3$ & \\
\hline & melhor & 16 & $79,3(14,3)$ & 81,6 & $57,7-100,0$ & \\
\hline \multirow[t]{4}{*}{ Medo de acontecimentos desfavoráveis } & não se aplica & 38 & $75,9(16,2)$ & 79,9 & $30,6-100,0$ & 0,06 \\
\hline & pior & 9 & $62,9(14,4)$ & 58,3 & $38,2-84,1$ & \\
\hline & igual & 24 & $76,6(14,7)$ & 75,8 & $47,9-100,0$ & \\
\hline & melhor & 9 & $81,7(14,3)$ & 84,8 & $57,7-100,0$ & \\
\hline \multirow[t]{4}{*}{ Intimidade } & não se aplica & 22 & $69,6(14,9)$ & 69,1 & $38,2-93,8$ & 0,02 \\
\hline & pior & 9 & $67,9(13,5)$ & 65,3 & $45,2-84,1$ & \\
\hline & igual & 38 & $78,1(16,6)$ & 79,5 & $30,6-100,0$ & \\
\hline & melhor & 11 & $83,3(11,2)$ & 84,8 & $58,3-100,0$ & \\
\hline \multirow[t]{4}{*}{ Memória } & não se aplica & 23 & $71,8(14,7)$ & 70,2 & $38,2-93,8$ & 0,05 \\
\hline & pior & 8 & $62,5(19,3)$ & 62,5 & $30,6-91,7$ & \\
\hline & igual & 41 & $79,4(13,9)$ & 79,9 & $51,4-100,0$ & \\
\hline & melhor & 8 & $77,6(18,2)$ & 80,9 & $47,3-100,0$ & \\
\hline \multirow[t]{4}{*}{ Humor } & não se aplica & 16 & $72,5(15,9)$ & 71,9 & $38,2-93,8$ & 0,01 \\
\hline & pior & 7 & $59,1(10,5)$ & 58,3 & $45,2-75,0$ & \\
\hline & igual & 44 & $79,3(15,0)$ & 80,6 & $30,6-100,0$ & \\
\hline & melhor & 13 & $74,0(15,7)$ & 74,4 & $47,3-100,0$ & \\
\hline \multirow[t]{4}{*}{ Auto-estima } & não se aplica & 13 & $67,2(16,4)$ & 69,5 & $38,2-87,5$ & 0,05 \\
\hline & pior & 9 & $67,0(15,4)$ & 61,2 & $47,9-92,4$ & \\
\hline & igual & 42 & $78,4(14,9)$ & 78,2 & $30,6-100,0$ & \\
\hline & melhor & 16 & $78,5(15,3)$ & 83,7 & $47,3-100,0$ & \\
\hline \multirow[t]{4}{*}{ Aspectos espirituais/religiosos } & não se aplica & 20 & $70,9(14,6)$ & 71,9 & $38,2-92,4$ & 0,04 \\
\hline & pior & 2 & $57,6(1,0)$ & 57,6 & $56,9-58,3$ & \\
\hline & igual & 38 & $80,0(13,9)$ & 80,3 & $47,3-100,0$ & \\
\hline & melhor & 20 & $72,8(18,7)$ & 71,9 & $30,6-100,0$ & \\
\hline
\end{tabular}

Continua 


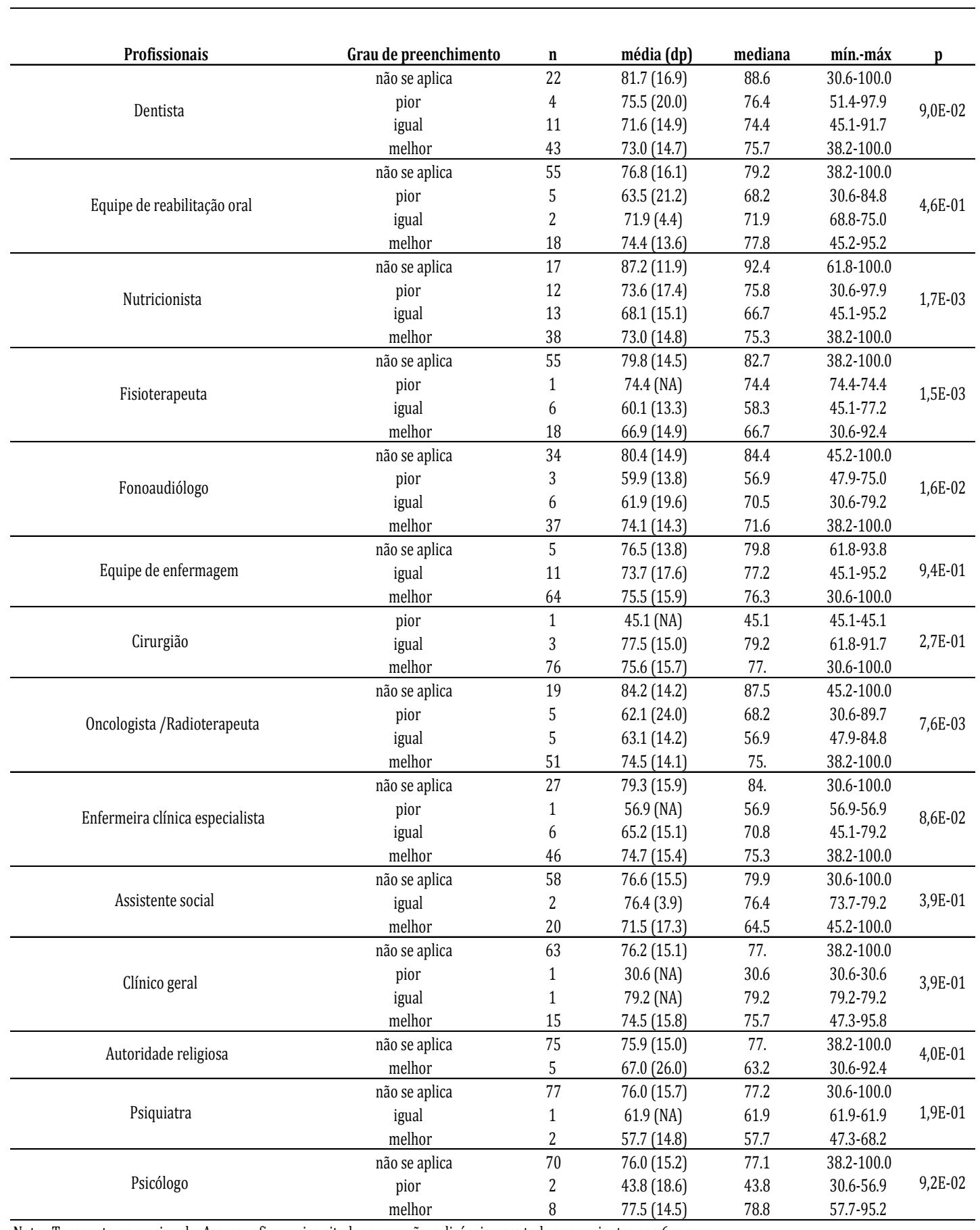

Nota: Terapeuta ocupacional e Assessor financeiro citados como não aplicáveis para todos os pacientes aos 6 meses

Conclusão 
Apêndice 2 - Associações não significantes entre o grau de preenchimento das expectativas e qualidade de vida global aos 12 meses após o tratamento (Itens/Profissionais)

\begin{tabular}{|c|c|c|c|c|c|c|}
\hline Itens & Grau de preenchimento & $\mathbf{n}$ & média (dp) & mediana & mín.-máx & p \\
\hline \multirow{4}{*}{ Atividade física } & não se aplica & 12 & $78,4(13,9)$ & 78,5 & $52,1-97,3$ & 0,06 \\
\hline & pior & 11 & $75,0(12,5)$ & 75,8 & $55,6-94,5$ & \\
\hline & igual & 24 & $85,1(9,7)$ & 84,5 & $67,4-100,0$ & \\
\hline & melhor & 15 & $85,9(16,2)$ & 93,1 & $47,3-100,0$ & \\
\hline \multirow{4}{*}{ Apetite } & não se aplica & 10 & $80,4(12,1)$ & 78,5 & $63,2-97,3$ & 0,04 \\
\hline & pior & 10 & $74,7(12,8)$ & 75,0 & $52,1-92,4$ & \\
\hline & igual & 31 & $82,8(12,8)$ & 84,1 & $47,3-100,0$ & \\
\hline & melhor & 11 & $88,8(13,8)$ & 95,2 & $55,6-100,0$ & \\
\hline \multirow{4}{*}{ Hábito intestinal } & não se aplica & 15 & $81,1(13,4)$ & 80,6 & $54,9-97,3$ & 0,17 \\
\hline & pior & 2 & $60,1(18,1)$ & 60,1 & $47,3-72,9$ & \\
\hline & igual & 38 & $83,1(12,1)$ & 83,8 & $52,1-100,0$ & \\
\hline & melhor & 7 & $86,1(14,8)$ & 87,5 & $59,7-100,0$ & \\
\hline \multirow{4}{*}{ Respiração } & não se aplica & 15 & $83,0(10,6)$ & 84,8 & $63,2-97,3$ & 0,06 \\
\hline & pior & 6 & $67,2(15,5)$ & 69,1 & $47,3-88,9$ & \\
\hline & igual & 30 & $83,2(12,4)$ & 83,8 & $54,9-100,0$ & \\
\hline & melhor & 11 & $86,7(13,5)$ & 95,2 & $59,7-100,0$ & \\
\hline \multirow{4}{*}{ Tosse } & não se aplica & 32 & $81,4(13,6)$ & 84,1 & $47,3-100,0$ & 0,95 \\
\hline & pior & 4 & $80,3(12,9)$ & 77,8 & $67,4-97,9$ & \\
\hline & igual & 18 & $83,2(13,4)$ & 85,1 & $54,9-100,0$ & \\
\hline & melhor & 8 & $84,1(13,8)$ & 86,5 & $63,2-100,0$ & \\
\hline \multirow{4}{*}{ Saúde dental } & não se aplica & 10 & $82,6(14,8)$ & 88,9 & $54,9-97,3$ & 0,02 \\
\hline & pior & 18 & $76,0(12,3)$ & 77,8 & $47,3-93,1$ & \\
\hline & igual & 24 & $82,7(13,2)$ & 83,8 & $52,1-100,0$ & \\
\hline & melhor & 10 & $91,8(7,5)$ & 93,8 & $75,8-100,0$ & \\
\hline \multirow{4}{*}{ Boca seca } & não se aplica & 18 & $87,5(10,0)$ & 87,9 & $64,0-100,0$ & 0,06 \\
\hline & pior & 21 & $76,7(12,6)$ & 75,8 & $47,3-94,5$ & \\
\hline & igual & 14 & $82,9(15,7)$ & 85,1 & $52,1-100,0$ & \\
\hline & melhor & 9 & $83,4(13,4)$ & 83,4 & $59,7-100,0$ & \\
\hline \multirow{4}{*}{ Audição } & não se aplica & 23 & $81,8(13,9)$ & 84,8 & $52,1-100,0$ & 0,16 \\
\hline & pior & 9 & $74,1(12,1)$ & 75,8 & $47,3-91,7$ & \\
\hline & igual & 20 & $86,3(11,0)$ & 89,3 & $63,2-100,0$ & \\
\hline & melhor & 10 & $82,2(14,9)$ & 83,0 & $59,7-100,0$ & \\
\hline \multirow{4}{*}{ Indigestão } & não se aplica & 44 & $83,0(13,3)$ & 84,8 & $47,3-100,0$ & 0,43 \\
\hline & pior & 1 & 73,7 (NA) & 73,7 & $73,7-73,7$ & \\
\hline & igual & 11 & $77,7(14,4)$ & 75,7 & $54,9-100,0$ & \\
\hline & melhor & 6 & $86,0(11,1)$ & 87,2 & $70,8-100,0$ & \\
\hline \multirow{4}{*}{ Mobilidade } & não se aplica & 35 & $85,6(10,8)$ & 86,2 & $63,2-100,0$ & 0,01 \\
\hline & pior & 7 & $67,1(12,6)$ & 67,4 & $52,1-88,9$ & \\
\hline & igual & 11 & $82,7(13,3)$ & 84,1 & $54,9-100,0$ & \\
\hline & melhor & 9 & $80,0(15,6)$ & 82,7 & $47,3-100,0$ & \\
\hline \multirow{4}{*}{ Abertura de boca } & não se aplica & 21 & $86,2(12,5)$ & 91,7 & $55,6-97,9$ & 0,08 \\
\hline & pior & 14 & $75,6(12,1)$ & 75,8 & $47,3-92,4$ & \\
\hline & igual & 18 & $81,7(14,3)$ & 81,3 & $52,1-100,0$ & \\
\hline & melhor & 9 & $84,0(12,2)$ & 84,8 & $63,2-100,0$ & \\
\hline
\end{tabular}

Continua 


\begin{tabular}{|c|c|c|c|c|c|c|}
\hline Itens & Grau de preenchimento & $\mathrm{n}$ & média (dp) & mediana & mín.-máx & $\mathrm{p}$ \\
\hline \multirow{4}{*}{ Catarro/Secreção } & não se aplica & 23 & $85,3(12,6)$ & 89,7 & $47,3-100,0$ & 0,10 \\
\hline & pior & 12 & $73,6(13,3)$ & 75,0 & $52,1-97,9$ & \\
\hline & igual & 21 & $82,8(12,9)$ & 84,1 & $54,9-100,0$ & \\
\hline & melhor & 6 & $85,4(11,9)$ & 87,2 & $70,8-100,0$ & \\
\hline \multirow{4}{*}{ Náusea } & não se aplica & 39 & $85,3(10,7)$ & 87,5 & $55,6-100,0$ & 0,05 \\
\hline & pior & 3 & $62,3(2,3)$ & 63,2 & $59,7-64,0$ & \\
\hline & igual & 12 & $78,3(16,5)$ & 76,8 & $47,3-100,0$ & \\
\hline & melhor & 8 & $80,6(15,0)$ & 77,1 & $54,9-100,0$ & \\
\hline \multirow{4}{*}{ Dor em outro lugar } & não se aplica & 42 & $85,0(10,5)$ & 86,5 & $63,2-100,0$ & 0,02 \\
\hline & pior & 6 & $62,7(15,5)$ & 57,6 & $47,3-88,9$ & \\
\hline & igual & 8 & $82,4(15,1)$ & 81,0 & $54,9-100,0$ & \\
\hline & melhor & 6 & $82,0(12,3)$ & 76,1 & $70,8-100,0$ & \\
\hline \multirow{4}{*}{ Regurgitação } & não se aplica & 48 & $83,4(12,0)$ & 84,8 & $52,1-100,0$ & 0,22 \\
\hline & pior & 1 & $94,5(\mathrm{NA})$ & 94,5 & $94,5-94,5$ & \\
\hline & igual & 7 & $70,8(18,2)$ & 74,3 & $47,3-100,0$ & \\
\hline & melhor & 6 & $84,1(12,3)$ & 82,3 & $70,8-100,0$ & \\
\hline \multirow{4}{*}{ Muita salivação } & não se aplica & 50 & $81,9(13,8)$ & 84,1 & $47,3-100,0$ & 0,85 \\
\hline & pior & 3 & $79,9(6,4)$ & 78,5 & $74,3-86,8$ & \\
\hline & igual & 5 & $84,5(9,8)$ & 84,1 & $75,7-100,0$ & \\
\hline & melhor & 4 & $85,5(16,1)$ & 88,9 & $64,0-100,0$ & \\
\hline \multirow{4}{*}{ Ombros } & não se aplica & 46 & $84,9(10,1)$ & 86,5 & $63,3-100,0$ & 0,05 \\
\hline & pior & 4 & $60,8(13,1)$ & 59,0 & $47,3-77,8$ & \\
\hline & igual & 9 & $77,2(18,5)$ & 75,7 & $52,1-100,0$ & \\
\hline & melhor & 3 & $84,5(14,7)$ & 82,7 & $70,8-100,0$ & \\
\hline \multirow{4}{*}{ Sono } & não se aplica & 25 & $84,9(10,7)$ & 86,8 & $55,6-97,3$ & 0,13 \\
\hline & pior & 10 & $72,8(15,0)$ & 75,0 & $47,3-94,5$ & \\
\hline & igual & 20 & $82,1(13,9)$ & 79,9 & $54,9-100,0$ & \\
\hline & melhor & 7 & $86,2(12,9)$ & 92,4 & $70,8-100,0$ & \\
\hline \multirow{4}{*}{ Olfato } & não se aplica & 29 & $84,8(11,1)$ & 86,2 & $54,9-100,0$ & 0,02 \\
\hline & pior & 6 & $63,9(15,9)$ & 59,4 & $47,3-88,9$ & \\
\hline & igual & 21 & $81,7(12,2)$ & 77,8 & $59,7-100,0$ & \\
\hline & melhor & 6 & $89,6(9,0)$ & 90,7 & $73,7-100,0$ & \\
\hline \multirow{4}{*}{ Feridas na boca } & não se aplica & 29 & $86,9(11,5)$ & 91,7 & $52,1-100,0$ & 0,05 \\
\hline & pior & 7 & $72,8(14,7)$ & 70,8 & $55,6-100,0$ & \\
\hline & igual & 17 & $80,1(11,9)$ & 78,5 & $54,9-100,0$ & \\
\hline & melhor & 9 & $78,3(15,6)$ & 76,5 & $47,3-95,2$ & \\
\hline \multirow{4}{*}{ Vômito/Mal- estar } & não se aplica & 48 & $83,1(13,8)$ & 86,5 & $47,3-100,0$ & 0,49 \\
\hline & pior & 2 & $85,1(12,3)$ & 85,1 & $76,4-93,8$ & \\
\hline & igual & 8 & $77,3(11,9)$ & 75,0 & $63,3-100,0$ & \\
\hline & melhor & 4 & $79,9(10,6)$ & 76,8 & $70,8-95,2$ & \\
\hline \multirow{4}{*}{ Perda de peso } & não se aplica & 15 & $88,0(12,7)$ & 92,4 & $52,1-100,0$ & 0,11 \\
\hline & pior & 21 & $78,8(13,8)$ & 76,4 & $47,3-100,0$ & \\
\hline & igual & 18 & $79,9(12,3)$ & 79,5 & $54,9-100,0$ & \\
\hline & melhor & 8 & $85,4(12,6)$ & 89,3 & $63,2-97,9$ & \\
\hline
\end{tabular}

Continua 


\begin{tabular}{|c|c|c|c|c|c|c|}
\hline Itens & Grau de preenchimento & $\mathrm{n}$ & média (dp) & mediana & mín.-máx & $\mathrm{p}$ \\
\hline \multirow{2}{*}{ Arrependimento pelo tratamento } & não & 59 & $82,1(13,3)$ & 84,1 & $47,3-100,0$ & 1,00 \\
\hline & igual & 3 & $83,3(14,4)$ & 75,7 & $74,3-100,0$ & \\
\hline \multirow{4}{*}{ Sonda para alimentação } & não se aplica & 28 & $86,3(12,9)$ & 92,0 & $52,1-100,0$ & 0,10 \\
\hline & pior & 10 & $75,4(12,9)$ & 76,5 & $54,9-94,5$ & \\
\hline & igual & 15 & $81,4(12,3)$ & 83,4 & $55,6-100,0$ & \\
\hline & melhor & 9 & $78,4(13,6)$ & 79,9 & $47,3-92,4$ & \\
\hline \multirow{4}{*}{ Cicatrização de feridas } & não se aplica & 24 & $79,3(13,8)$ & 76,4 & $52,1-100,0$ & 0,01 \\
\hline & pior & 4 & $65,3(9,4)$ & 66,3 & $54,9-73,7$ & \\
\hline & igual & 11 & $87,7(8,4)$ & 88,9 & $75,7-100,0$ & \\
\hline & melhor & 23 & $85,6(12,3)$ & 87,5 & $47,3-100,0$ & \\
\hline \multirow{3}{*}{ Cuidador } & não se aplica & 34 & $84,1(14,3)$ & 89,3 & $47,3-100,0$ & 0,16 \\
\hline & igual & 6 & $84,9(11,7)$ & 81,7 & $72,9-100,0$ & \\
\hline & melhor & 22 & $78,5(11,5)$ & 79,2 & $55,6-97,9$ & \\
\hline \multirow{4}{*}{ Dependentes/Crianças } & não se aplica & 42 & $83,4(12,9)$ & 85,8 & $52,1-100,0$ & 0,44 \\
\hline & pior & 3 & $72,9(11,9)$ & 76,4 & $59,7-82,7$ & \\
\hline & igual & 10 & $84,1(10,8)$ & 80,3 & $72,9-100,0$ & \\
\hline & melhor & 7 & $76,6(18,1)$ & 74,3 & $47,3-97,9$ & \\
\hline \multirow{4}{*}{ Benefícios financeiros } & não se aplica & 33 & $85,2(11,3)$ & 88,9 & $55,6-100,0$ & 0,24 \\
\hline & pior & 9 & $80,5(18,2)$ & 87,5 & $47,3-97,9$ & \\
\hline & igual & 12 & $76,7(14,9)$ & 74,7 & $52,1-100,0$ & \\
\hline & melhor & 8 & $80,1(10,3)$ & 80,3 & $63,2-97,9$ & \\
\hline \multirow{3}{*}{$\begin{array}{c}\text { Atendimento de profissionais } \\
\text { em domícilio }\end{array}$} & não & 52 & $83,7(12,6)$ & 84,8 & $47,3-100,0$ & 0,10 \\
\hline & igual & 6 & $70,7(16,7)$ & 68,5 & $52,1-100,0$ & \\
\hline & melhor & 4 & $80,4(8,5)$ & 81,0 & $70,8-88,9$ & \\
\hline \multirow{4}{*}{ Estilo de vida } & não se aplica & 39 & $83,0(14,3)$ & 87,5 & $47,3-100,0$ & 0,23 \\
\hline & pior & 3 & $64,3(11,8)$ & 59,7 & $55,6-77,8$ & \\
\hline & igual & 7 & $83,2(10,5)$ & 76,5 & $72,9-100,0$ & \\
\hline & melhor & 13 & $83,3(9,0)$ & 84,1 & $70,8-100,0$ & \\
\hline \multirow{4}{*}{ Relacionamentos } & não se aplica & 12 & $85,3(12,6)$ & 87,9 & $55,6-100,0$ & 0,45 \\
\hline & pior & 8 & $76,8(14,1)$ & 80,3 & $52,1-91,7$ & \\
\hline & igual & 31 & $81,7(12,5)$ & 79,9 & $54,9-100,0$ & \\
\hline & melhor & 11 & $84,2(15,6)$ & 88,9 & $47,3-100,0$ & \\
\hline \multirow{4}{*}{ Fala/voz/ser entendido } & não se aplica & 7 & $88,7(15,6)$ & 93,8 & $55,6-100,0$ & 0,05 \\
\hline & pior & 13 & $73,8(16,0)$ & 76,4 & $47,3-97,9$ & \\
\hline & igual & 25 & $82,4(10,4)$ & 84,1 & $63,2-100,0$ & \\
\hline & melhor & 17 & $85,7(11,4)$ & 88,9 & $59,7-100,0$ & \\
\hline \multirow{4}{*}{ Aparência } & não se aplica & 5 & $89,5(6,0)$ & 88,9 & $83,4-97,3$ & 0,22 \\
\hline & pior & 13 & $75,1(16,3)$ & 80,6 & $47,3-97,9$ & \\
\hline & igual & 27 & $81,8(13,4)$ & 78,5 & $54,9-100,0$ & \\
\hline & melhor & 17 & $86,0(9,7)$ & 87,5 & $70,8-97,9$ & \\
\hline
\end{tabular}




\begin{tabular}{|c|c|c|c|c|c|c|}
\hline Itens & Grau de preenchimento & $\mathrm{n}$ & média (dp) & mediana & mín-máx & $\mathrm{p}$ \\
\hline \multirow{4}{*}{ Raiva } & não se aplica & 48 & $83,7(13,3)$ & 86,5 & $47,3-100,0$ & 0,04 \\
\hline & pior & 2 & $61,5(2,5)$ & 61,5 & $59,7-63,3$ & \\
\hline & igual & 9 & $83,0(10,7)$ & 76,4 & $72,9-100,0$ & \\
\hline & melhor & 3 & $70,2(5,9)$ & 70,8 & $64,0-75,8$ & \\
\hline \multirow{3}{*}{$\begin{array}{l}\text { Estratégias para enfrentar } \\
\text { a doença e o tratamento }\end{array}$} & pior & 3 & $61,8(10,9)$ & 59,7 & $52,1-73,7$ & 0,02 \\
\hline & igual & 28 & $80,2(13,9)$ & 81,0 & $47,3-100,0$ & \\
\hline & melhor & 31 & $86,0(10,6)$ & 88,9 & $63,2-100,0$ & \\
\hline \multirow{4}{*}{ Depressão } & não se aplica & 47 & $84,8(12,0)$ & 86,8 & $47,3-100,0$ & 0,01 \\
\hline & pior & 6 & $66,3(9,6)$ & 68,1 & $52,1-76,4$ & \\
\hline & igual & 5 & $76,0(16,0)$ & 75,7 & $54,9-100,0$ & \\
\hline & melhor & 4 & $83,0(12,5)$ & 83,0 & $70,8-95,2$ & \\
\hline \multirow{4}{*}{ Intimidade } & não se aplica & 24 & $79,3(13,8)$ & 80,3 & $47,3-97,3$ & 0,30 \\
\hline & pior & 6 & $79,8(15,8)$ & 82,0 & $59,7-97,9$ & \\
\hline & igual & 23 & $82,9(13,0)$ & 82,7 & $54,9-100,0$ & \\
\hline & melhor & 9 & $89,8(8,2)$ & 91,7 & $73,7-100,0$ & \\
\hline \multirow{4}{*}{ Memória } & não se aplica & 23 & $81,7(11,1)$ & 82,7 & $55,6-97,3$ & 0,51 \\
\hline & pior & 6 & $78,7(13,2)$ & 76,1 & $59,7-97,9$ & \\
\hline & igual & 29 & $83,0(13,4)$ & 84,8 & $52,1-100,0$ & \\
\hline & melhor & 4 & $85,1(25,3)$ & 96,5 & $47,3-100,0$ & \\
\hline \multirow{4}{*}{ Humor } & não se aplica & 15 & $82,8(10,7)$ & 82,0 & $55,6-97,3$ & 0,13 \\
\hline & pior & 6 & $69,7(13,0)$ & 70,5 & $52,1-88,9$ & \\
\hline & igual & 31 & $83,5(13,3)$ & 84,8 & $47,3-100,0$ & \\
\hline & melhor & 10 & $85,0(14,4)$ & 91,0 & $54,9-100,0$ & \\
\hline \multirow{4}{*}{ Auto-estima } & não se aplica & 15 & $83,2(10,5)$ & 83,4 & $55,6-97,3$ & 0,05 \\
\hline & pior & 6 & $66,9(10,1)$ & 68,5 & $52,1-76,4$ & \\
\hline & igual & 31 & $84,0(12,5)$ & 86,2 & $54,9-100,0$ & \\
\hline & melhor & 10 & $84,2(16,2)$ & 91,0 & $47,3-100,0$ & \\
\hline \multirow{4}{*}{ Sexualidade } & não se aplica & 19 & $77,8(14,2)$ & 80,6 & $47,3-97,3$ & 0,04 \\
\hline & pior & 9 & $77,0(13,3)$ & 76,4 & $59,7-97,9$ & \\
\hline & igual & 27 & $84,2(12,3)$ & 84,8 & $54,9-100,0$ & \\
\hline & melhor & 7 & $92,9(5,7)$ & 92,4 & $82,7-100,0$ & \\
\hline \multirow{3}{*}{ Aspectos espirituais/religiosos } & não se aplica & 18 & $82,3(11,0)$ & 82,7 & $55,6-97,3$ & 0,95 \\
\hline & igual & 32 & $82,7(13,6)$ & 85,5 & $52,1-100,0$ & \\
\hline & melhor & 12 & $80,6(16,1)$ & 79,5 & $47,3-100,0$ & \\
\hline \multirow{4}{*}{ Personalidade e Temperamento } & não se aplica & 17 & $81,5(10,8)$ & 82,0 & $55,6-97,3$ & 0,14 \\
\hline & pior & 2 & $55,9(5,4)$ & 55,9 & $52,1-59,7$ & \\
\hline & igual & 30 & $84,4(12,2)$ & 86,5 & $54,9-100,0$ & \\
\hline & melhor & 13 & $82,0(15,6)$ & 82,7 & $47,3-100,0$ & \\
\hline
\end{tabular}

Continua 


\begin{tabular}{|c|c|c|c|c|c|c|}
\hline Profissionais & Grau de preenchimento & $\mathbf{n}$ & média (dp) & mediana & mín.-máx & $\mathbf{p}$ \\
\hline \multirow{4}{*}{ Dentista } & não se aplica & 17 & $88.5(12.3)$ & 92.4 & $52.1-100.0$ & \multirow{4}{*}{$6,7 \mathrm{E}-02$} \\
\hline & pior & 3 & $86.9(2.5)$ & 86.2 & $84.8-89.7$ & \\
\hline & igual & 6 & $77.9(15.6)$ & 76.1 & $59.7-100.0$ & \\
\hline & melhor & 36 & $79.6(13.0)$ & 77.8 & $47.3-100.0$ & \\
\hline \multirow{4}{*}{ Equipe de reabilitação oral } & não se aplica & 41 & $84.7(13.6)$ & 89.7 & $47.3-100.0$ & \multirow{4}{*}{$1,6 \mathrm{E}-01$} \\
\hline & pior & 2 & $69.9(21.2)$ & 69.9 & $54.9-84.8$ & \\
\hline & igual & 3 & $74.8(13.6)$ & 78.5 & $59.7-86.2$ & \\
\hline & melhor & 16 & $78.9(10.3)$ & 79.2 & $55.6-97.3$ & \\
\hline \multirow{4}{*}{ Nutricionista } & não se aplica & 19 & $87.6(13.6)$ & 93.1 & $52.1-100.0$ & \multirow{4}{*}{$3,3 \mathrm{E}-02$} \\
\hline & pior & 5 & $75.6(11.3)$ & 75.8 & $59.7-91.7$ & \\
\hline & igual & 10 & $85.6(10.0)$ & 87.9 & $70.8-100.0$ & \\
\hline & melhor & 28 & $78.5(13.2)$ & 79.2 & 47.3-97.3 & \\
\hline \multirow{3}{*}{ Fisioterapeuta } & não se aplica & 41 & $85.3(12.1)$ & 88.9 & $52.1-100.0$ & \multirow{3}{*}{$2,0 \mathrm{E}-02$} \\
\hline & igual & 1 & $70.8(\mathrm{NA})$ & 70.8 & $70.8-70.8$ & \\
\hline & melhor & 20 & $76.3(13.7)$ & 76.8 & $47.3-97.3$ & \\
\hline \multirow{4}{*}{ Fonoaudiólogo } & não se aplica & 28 & $86.4(12.7)$ & 91. & $52.1-100.0$ & \multirow{4}{*}{$7,4 \mathrm{E}-02$} \\
\hline & pior & 1 & $59.7(\mathrm{NA})$ & 59.7 & $59.7-59.7$ & \\
\hline & igual & 3 & $80.2(18.3)$ & 76.5 & $64.0-100.0$ & \\
\hline & melhor & 30 & $79.3(12.3)$ & 79.2 & $47.3-97.9$ & \\
\hline \multirow{2}{*}{ Terapeuta 0cupacional } & não se aplica & 61 & $82.0(13.3)$ & 83.4 & $47.3-100.0$ & \multirow{2}{*}{$5,6 \mathrm{E}-01$} \\
\hline & melhor & 1 & $91.7(\mathrm{NA})$ & 91.7 & $91.7-91.7$ & \\
\hline \multirow{4}{*}{ Equipe de enfermagem } & não se aplica & 5 & $74.7(12.8)$ & 75.7 & $55.6-91.7$ & \multirow{4}{*}{$1,2 \mathrm{E}-01$} \\
\hline & pior & 1 & $59.7(\mathrm{NA})$ & 59.7 & $59.7-59.7$ & \\
\hline & igual & 1 & $97.3(\mathrm{NA})$ & 97.3 & $97.3-97.3$ & \\
\hline & melhor & 55 & $83.0(12.9)$ & 84.8 & $47.3-100.0$ & \\
\hline \multirow{2}{*}{ Cirurgião } & igual & 1 & $97.3(\mathrm{NA})$ & 97.3 & $97.3-97.3$ & \multirow{2}{*}{$2,1 \mathrm{E}-01$} \\
\hline & melhor & 61 & $82.0(13.2)$ & 83.4 & $47.3-100.0$ & \\
\hline \multirow{3}{*}{ Enfermeira clínica especialista } & não se aplica & 17 & $87.6(9.3)$ & 88.9 & $73.7-100.0$ & \multirow{3}{*}{$7,5 \mathrm{E}-02$} \\
\hline & pior & 1 & $59.7(\mathrm{NA})$ & 59.7 & $59.7-59.7$ & \\
\hline & melhor & 44 & $80.6(13.8)$ & 81.3 & $47.3-100.0$ & \\
\hline \multirow{4}{*}{ Assistente social } & não se aplica & 42 & $84.8(11.9)$ & 86.8 & $52.1-100.0$ & \multirow{4}{*}{$1,8 \mathrm{E}-01$} \\
\hline & pior & 1 & 82.7 (NA) & 82.7 & $82.7-82.7$ & \\
\hline & igual & 2 & 77.1 (13.7) & 77.1 & $67.4-86.8$ & \\
\hline & melhor & 17 & $76.3(15.2)$ & 75.7 & $47.3-100.0$ & \\
\hline \multirow{3}{*}{ Clínico geral } & não se aplica & 48 & $83.7(12.9)$ & 84.8 & $47.3-100.0$ & \multirow{3}{*}{$1,6 \mathrm{E}-01$} \\
\hline & igual & 2 & 72.9 (18.7) & 72.9 & $59.7-86.2$ & \\
\hline & melhor & 12 & $77.6(13.1)$ & 74.3 & $54.9-95.2$ & \\
\hline Autoridade religiosa & não se aplica & 61 & $81.9(13.2)$ & 83.4 & $47.3-100.0$ & $15 \mathrm{E}-01$ \\
\hline Autoridade religiosa & melhor & 1 & $97.9(\mathrm{NA})$ & 97.9 & 97.9-97.9 & $1,5 \mathrm{E}-01$ \\
\hline & não se aplica & 57 & $82.8(13.1)$ & 84.8 & $47.3-100.0$ & \\
\hline Psquiatra & igual & 2 & $62.9(11.3)$ & 62.9 & $54.9-70.8$ & $1,4 \mathrm{E}-01$ \\
\hline & melhor & 3 & $83.6(9.8)$ & 80.6 & $75.7-94.5$ & \\
\hline & não se aplica & 58 & 83.1 (12.8) & 84.4 & $47.3-100.0$ & \\
\hline Psicóloon & pior & 1 & $59.7(\mathrm{NA})$ & 59.7 & $59.7-59.7$ & $16 \mathrm{E}-01$ \\
\hline PSICOIOg0 & igual & 1 & $54.9(\mathrm{NA})$ & 54.9 & $54.9-54.9$ & $1,6 \mathrm{E}-01$ \\
\hline & melhor & 2 & $79.9(8.8)$ & 79.9 & $73.7-86.2$ & \\
\hline
\end{tabular}

Nota: Assessor financeiro citado como não aplicável para todos os pacientes aos 12 meses

Conclusão 
Apêndice 3 - Carta-comentário de paciente sobre itens do IPP.

\author{
$\mathrm{A} / \mathrm{C}$
}

Sra. Ivy Jungerman

Quero agradecer-lhe pela oportunidade de participar desse trabalho que com certeza contribuirá no atendimento aos pacientes do A.C.Camargo, ainda,

queria agregar mais dados ao seu trabalho

Segue breve retrospecto do meu histórico para criar perfil do paciente.

2004 - Cirurgia de carcinoma adenoide cístico

2005 - Radioterapia da coadjuvante à cirurgia;

2011 - Cirurgia de recidiva do carcinoma adenoide cístico de

2012 - Radioterapia da coadjuvante à cirurgia. Submetido também a sessões de radioterapia na

para conter o avanço de metástase

2012 - Biópsia guiada por tomografia da $\square$ para diagnosticar metástase do carcinoma na

$2012-$ Cirurgia p

2012- Cirurgia para retirar nódulos metastáticos de carcinoma no

2013 - Radioablação no para combater metástase de carcinoma.

Restam nódulos no que estão sendo acompanhados por imagem de modo à tomada de decisão se-necessário. Da mesma forma o tumor na $\square$ esquerda está sendo acompanhado.

Com relação ao inventário faço retrospectiva de cada item conforme nos falamos no hospital.

\title{
BEM-ESTAR FÍSICO FUNCIONAL
}

Atividade física - pedalo por 30 minutos em bicicleta ergométrica na minha residência às segunda-feira, quarta feira e sexta-feira, de forma a melhor a capacidade cardiorrespiratória e expandir os pulmões

Apetite - continua o mesmo apesar de não ter olfato e paladar perdidos pós-radioterapia, ainda, pela dificuldade em alimentar-me sem Apesar de tudo ganhei peso.

Hábito intestinal - normal.

Respiração - tenho minhas limitações devido a retirada de boa parte $\square$ e intervenção no

Mastigar/comer - vide apetite, acrescido da esperança de no futuro, curado da doença, poder ser submetido a reabilitação oral de forma a comer os alimentos que tenho vontade/saudades e participar plenamente da vida social.

Tosse - não tenho

Saúde dental/dentes - devido ao histórico acima tenho dedicado especial atenção à higiene dos dentes (maxilar inferior), pois auxiliam na fragmentação dos alimentos em conjunto com a língua, sem eles, minha alimentação teria que ser totalmente pastosa. Ficaram desalinhados pela perda de referência da removida.

Boca seca - apesar das diversas sessões de radioterapia, graças a De us, a boca não ficou seca. Níveis de energia - estou afastado das minhas atividades profissionais, no entanto no lar auxilio nas atividades. Só não lavo roupa e nem tiro pó, respectivamente por questões de inabilidade e respiratória. Gosto de cozinhar e fico executando as receitas para degustação dos filhos.

Fadiga/cansaço - por causa das intervenções tenho limitaçãode esforço, porémcaminho normalmente. 
Audição - sou acompanhamento pelo Dr.

otorrino da Cabeça e Pescoço do AC Camargo. Os exames de audiometria apresentam discreta perda de audição, sequela das cirurgias mencionadas.

Indigestão - não tenho.

Mobilidade - graças a Deus, apesar de dois episódios de trombose nos membros inferiores e cirurgia caminho e dirijo meu carro com autonomia.

Abertura da boca- devido às cirurgias tenho restrição.

Catarro/secreção - devidos às cirurgias e radioterapias acumulo certa quantidade de crosta que atrapalham a respiração. Para auxiliar na ventilação nasal faço uso diário de soro físiológico e em casos mais extremos a lavagem nasal ocorre com o uso da mangueira do chuveirinho quando estou no banho.

Náusea - não tenho.

Dor na cabeça•e pescoço - por vezes tenho pinçamento do pescoço, porém tenho realizado alongamento para diminuir as ocorrências. Dores de cabeça ocorrem, sobretudo quando estou resfriado.

Dor em outro lugar - por vezes tenho desconforto no tórax e na região lombar pelas ·condições apresentadas.

Regurgitação - não tenho.

Muita salivação - não tenho.

Ombros - nenhum desconforto.

Sono - normal, se tomado todos os cuidados prévios com a limpeza das cavidades nasais. A fé também contribui para não ter pensamentos negativos que podem tirar o sono.

Olfato (sentir/cheiro) - conforme mencionado, após a radioterapia não tenho mais olfato.

Feridas na boca- não tenho.

Engolir - sem dificuldades.

Inchaço - não tenho.

Paladar (sentir sabor) - conforme mencionado, após a radioterapia não ·tenho mais paladar. Consigo distinguir doce e salgado, porém não sinto o sabor dos alimentos.

Vômitos/mal estar- não tenho.

Perda de peso - apesar do cenário, ganhei peso.

\section{RELACIONADAS AO TRATAMENTO}

Tratamento do câncer- tenho todas as informações com relação ao meu quadro e possíveis sequelas caso tenha que ser submetido a cirurgias'nos locais onde tem metástases.

Arrependimento pelo tratamento - jamais, temos que ter fé em Deus, mas também temos que nos submeter à ciência dos homens e pedir que o Pai ilumine e guie nossos médicos.

Sonda para alimentação - já utilizei e graças a Deus no momento não faço uso.

Cicatrização de feridas - graças a Deus, minhas cicatrizações ocorreram rapidamente e ficaram perfeitas conforme constatado pelos profissionais do A.C.Camargo.

\section{ASSISTÊNCIA E BEM ESTAR SOCIAL}

Cuidador - graças a Deus não tenho essa demanda.

Dependência/crianças - graças a Deus não tenho essa demanda e os filhos tem idade (15, 18 e 21 anos) e discernimento para entender meu estado de saúde.

Benefícios financeiros - sei da possibilidade de saque do FGTS e já o realizei por duas vezes. Não necessitei buscar por outros benefícios mas na internet é possível identificar quais são eles.

Atendimento de profissionais domicilio - meu plano de saúde contempla o "home care" mas graças a Deus não necessito.

Estilo de·vida (fumo/álcool) - meu único vício é amar a família e querer que eles estejam sempre próximos. 
Recreação - gosto de pescar com meu filho. Já com a família reunida: cinema, shopping, restaurante, campo e praia.

Relacionamentos - a balança está desequilibrada, algumas pessoas se afastaram e muitas outras se aproximaram. Percebo que os afastados têm dificuldades para saber como se relacionar comigo por medo de não saber o que dizer, já os que se aproximaram em sua grande maioria tem a religiosidade como base de suas vidas, não que isso as deixem insensíveis, mas fazem uso da fé para manifestar apoio e fraternidade.

Fala/voz/ser entendido - se fossemos traçar um gráfico de linha para esse critério, teríamos aclives e declives de-acordo com fatores físicos e de ambiente, explico: se o clima está muito seco o nariz resseca e tenho dificuldades para falar, quando a umidade do ar está alta tenho menos dificuldade para falar, porém resfriado, não' importa as condições do tempo, tenho dificuldades para falar.

Suporte para minha família - graças a Deus todos se apegaram a religiosidade como alicerce para se apoiarem.

\section{BEM STAR PSICOLÓGICO, EMOCIONAL E ESPIRITUAL}

Aparência - logo após a primeira cirurgia de 2004 eu ficava incomodado com os olhares das pessoas, hoje não/me importo e até gosto de falar sobre minha história de fé e do poder de Deus sobre mim.

Raiva - jamais senti raiva, porém me perguntava "Por que comigo?" Hoje eu mesmo respondo: "Porque não comigo!"

Ansiedade- sou um pouco ansioso, menos do que já fui.

Estratégias para enfrentar a doença e o tratamento - a única estratégia, a meu ver, é confiar em Deus e ter a certeza que as coisas se resolverão no tempo Dele e da forma que Ele achar que é melhor para minha alma.

Depressão - graças a Deus a alegria de viver aumentou.

Medo do câncer voltar - eu tinha medo, mas quem está com Deus tem que apenas confiar.

Medo de acontecimentos desfavoráveis - no fundo tem um pontinho de receio, mas quem está com Deus tem que apenas confiar.

Intimidade - percebi que esfriei Não me sinto atraente pelas transformações físicas que sofri e pelas dificuldades para comandar os lábios e beijar.

Memória - procuro realizar atividades que exercitem o cérebro, não saio de casa sem o "Sudoku" e até no celular tenho o jogo, ajuda a passar o tempo e exercitar a concentração e raciocínio.

Humor- brinco e faço piadas da mesma forma.

Auto-estima - baixou.

Sexualidade - diminuiu.

Aspectos espirituais/religiosos - este aspecto aumentou bastante e graças a Deus estou aqui.

Personalidade e temperamento - graças a aproximação com Deus estou mais: sereno, humilde e amoroso com o próximo.

\section{BEM-ESTAR FÍSICO E FUNCIONAL}

Dentista - no momento não há o que ser feito pois não tenho estrutura física para usar prótese dentária.

Equipe de reabilitação oral - conforme a depois da doença ser erradicada do meu organismo é que poderá ser iniciada a reabilitação.

Nutricionista- o peso está controlado e a alimentação adequada a minha condição. 
Fisioterapeuta - não há necessidade.

Fonoaudiólogo - não há necessidade conforme constatado pelos profissionais dessa área quando visitado no leito após cirurgia no A.C.Camargo.

Terapeuta ocupacional - não há necessidade.

Equipe de enfermagem - no momento já passo no ambulatório da cabeça e pescoço do A.C.Camargo para trocar curativos.

\section{RELACIONADOS AO TRATAMENTO}

Cirurgião - já sou acompanhado pelos Doutores:

, respectivamente Cabeça e Pescoço,

Oncologista/radioterapeuta - não há necessidade.

Enfermeira clínica especialista - não há necessidade.

\section{ASSISTÊNCIA SOCIAL E BEM ESTAR}

Assistente social - não há necessidade.

Clínico geral - não há necessidade.

Assessor financeiro - não há necessidade.

\section{BEM ESTAR PSICOLÓGICO, EMOCIONAL E ESPIRITUAL}

Autoridade religiosa/Iíder da sua religião - não há necessidade. Encontrei o caminho graças a anjos que cruzaram a minha vida.

Psiquiatria - não há necessidade

Psicólogo - não há necessidade (já faço consulta diária e a todo o momento a Deus).

Enfim, espero estar contribuindo com a pesquisa e peço perdão se fui muito prolixo, mas na tabulação acredito que os resultados serão extremados devido as variáveis de cada paciente: tempo da doença, espiritualidade, condições físicas e psicológicas entre outros critérios que afetam cada pessoa com mais ou menos intensidade.

Grande abraço,

P.S. Se houver necessidade de mais esclarecimentos coloco-me a disposição. 
Apêndice 4 - Comentários dos pacientes ao longo do estudo

\section{Comentários sobre o IPP}

1- “...Tudo o que eu sinto está escrito aí...! ”

2- "Este questionário foi muito importante para mim, isto podia gerar um folder explicativo..."

3- "A partir de preocupações comuns e casos comuns, poderiam se criar grupos de encontro para o paciente e a família."

4- "Este questionário é um diálogo antecipado com o paciente"!

5- "Em 6 anos ininterruptos de tratamento no A.C. Camargo, esta é a primeira vez que eu fui oficialmente consultado sobre assuntos relacionados ao tratamento. Penso que, com isso, eu poderia contribuir muito mais com minhas experiências para poder aprimorar os serviços do hospital."

6- "Esta foi a primeira vez que alguém me escutou e perguntou como eu me sinto, o que eu sinto. Eu já tomei esta iniciativa em relação ao hospital, mas é a primeira vez que alguém do hospital toma esta iniciativa em relação à mim."

7- "É gratificante saber que têm pessoas preocupadas com seu próximo. Obrigada por este questionário!“

8- "Este questionário é um termômetro importante para o médico."

9- "O questionário faz o médico dar as informações e tirar as dúvidas de acordo com o perfil do paciente"

10- "O questionário me incentivou, aprendi muita coisa." 
11- "O questionário de preocupações é bastante elucidativo, abrangente e permite uma visão ao profissional do que o paciente sente e pensa."

12- "A dor em outro lugar que eu sinto por causa do câncer é no meu bolso."

13- "Pacientes bem-sucedidos no tratamento não estão diariamente no hospital para dividir seu sucesso com os que ainda estão se tratando. Assim, só se encontra aqui quem está na pior, por isso, a partir de dúvidas comuns, talvez fosse proveitoso formar grupos de palestras de pacientes curados para falar com os que ainda estão em tratamento."

14- Paciente de 33 anos, submetida à glossectomia total, sobre a problemática em relação à vida sexual diante da ausência da língua:

"Com este tipo de questionário, eu me sinto à vontade para perguntar para o cirurgião sobre coisas que de outra forma eu não saberia como e para qual profissional perguntar para tirar este tipo de dúvida e expor este problema tipo de problema!"

\section{Comentários sobre o QIP:}

1-“Às vezes o médico não se dispõe a falar, não sei se por tempo ou para não deixar o paciente preocupado. Muitos médicos querem preservar o paciente."

2-"No início eu não queria saber nada, agora quero saber tudo, quero fazer um projeto para o futuro."

\section{Comentários sobre o PAE:}

"Quando um paciente procura um profissional para se tratar, ele tem que ter fé e boa cabeça de que vai ser tratado por especialistas"...

\section{Comentários sobre o PPE:}

1- "Acho que deve acrescentar o termo "péssimo" aí, pois a nutricionista me deu a informação errada!" 
2- "A abordagem foi como se eu fosse fazer uma sessão de quimioterapia, e na verdade era só uma medicação! Acho que às vezes o paciente recebe Informações não compatíveis com o tipo de tratamento a ser realizado! ”

3- Tem muita demora para encaixe de exames, isso- preencheu pouco minha expectativa." 4-“Falta integração entre os departamentos, o tratamento tem que ser mais holístico."

\section{Comentários sobre abordagem da Radioterapia (feitos pela filha de um paciente idoso):}

“...Não há abordagem voltada para o idoso, não há estudos, dados, sobre os resultados pós radioterapia nos idosos, sobre seu prognóstico e recuperação.”

“....Porque na radioterapia o médico fala que se você não fizer o tratamento de radioterapia você vai ter $\mathrm{X} \%$ de recidiva. Por que não falar que se você fizer o tratamento terá $\mathrm{X} \%$ de chance de cura? Acho que este foi um dos motivos para ele não querer fazer a radio..."

\section{Comentário sobre a participação na pesquisa, aos 6 meses / 12 meses:}

1- "Esta avaliação após 6 meses faz com que eu não me sinta abandonado, "este questionário tem que ir para as mãos do médico!! “

\section{Comentário sobre a participação na pesquisa, aos 12 meses:}

1 - Comentário de paciente sem doença em atividade, com quadro de depressão:

"Essa pesquisa favorece o meu pensamento no sentido de organizar num único momento tudo o que está acontecendo e o que já aconteceu na minha vida nos últimos 12 meses, como se fosse um balanço de tudo e com isso pude enxergar o quanto estou sensibilizada e qual foi o resultado deste processo"-

2- "Esta pesquisa (todas as etapas/ épocas) me ajudaram no sentido de balizar a doença com os aspectos sociais. Na maioria dos tratamentos ficamos sem ou não temos a percepção de fatores importantes como família, auto-estima, motivação. Essas questões nos dão alinhamento, nos ajudam na melhor condução social e familiar." 
3- Paciente de 62 anos, com ensino fundamental incompleto:

"Para mim foi muito bom participar da pesquisa, por exemplo, me fez pensar sobre o que eu queria saber...Faz o paciente pensar sobre coisas que podem acontecer durante o tratamento, que ele não sabe... Acho que todo o paciente deveria ter o PRIVILÉGIO de responder os questionários. "

4- - "Achei muito válido responder estes questionários." 